\title{
CSIC VNIVERSIDAD DSALAMANCA
}

CENTRO DE INVESTIGACIÓN DEL CÁNCER / INSTITUTO DE BIOLOGÍA MOLECULAR Y CELULAR DEL CÁNCER (CSIC-USAL)

\section{RASTREO CELÓMICO MEDIANTE GENOTECAS DE EXPRESIÓN DE REGULADORES DE LA GTPasa Rac1}

TESIS DOCTORAL

ANTONIO CASTRO CASTRO

Salamanca, 2010 


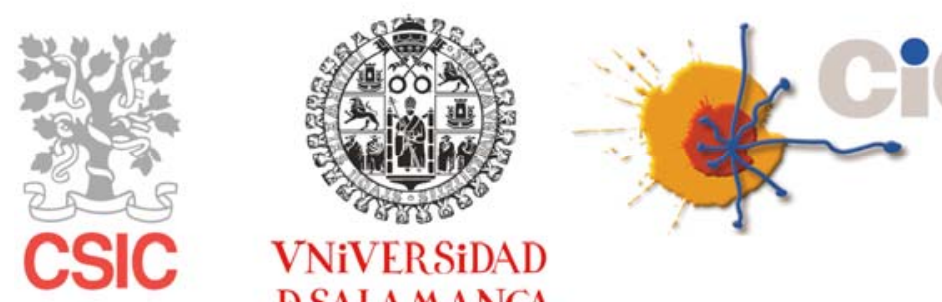

VNiVERSIDAD

DSALAMANCA

EI Dr. XOSÉ RAMÓN GARCía BUSTELO, Profesor de Investigación del Consejo Superior de Investigaciones Científicas en el Instituto de Biología Molecular y Celular del Cáncer de Salamanca,

\section{CERTIFICA:}

Que el licenciado ANTONIO CASTRO CASTRO ha realizado en nuestro Centro y bajo mi dirección el trabajo de doctorado titulado "Rastreo celómico mediante genotecas de expresión de reguladores de la GTPasa Rac1" para optar al grado de Doctor en "Biología Clínica del Cáncer" por la Universidad de Salamanca.

Y para que conste a los efectos oportunos, expido y firmo el presente certificado en Salamanca, a 3 de Junio de 2010.

Fdo. Dr. Xosé Ramón García Bustelo 

A ti, "Loli", a tu coraje, a tu amor incondicional, a tu fuerza de voluntad, a tu capacidad de autosuperación, a todo aquello que fuiste, que eres y que serás... esto ES y VA por ti, mamá.

"El miedo no es un perro, no te acompaña, te atormenta y no te deja vivir... el miedo es tu peor enemigo, el miedo te ata a sus cadenas y no te permite andar... el miedo llena los cementerios de cobardes... el miedo nunca será signo de inteligencia... el miedo... Quien dijo miedo?" 

Este proyecto de tesis ha sido financiado por:

- Una beca FPU del Ministerio de Educación (2005-2009)

- El Ministerio de Ciencia e Innovación (SAF2009-07172 y RD06/0020/0001)

- Acción Especial de Genómica y Proteómica del Ministerio de Ciencia e Innovación (GENZ003-20239-C06-01)

- $\quad$ La Junta de Castilla y León (GR97)

- $\quad 7^{\circ}$ Programa Marco de la Unión Europea (FP7-HEALTH-2007-A-201862)

- El Instituto Nacional de la Salud de los Estados Unidos de América (5R01-CA73735-13) 



\section{ÍNDICE}

INTRODUCCIÓN

1. ANTECEDENTES 3

2. FUNCIONES DE Rac1 6

2.1. Funciones biológicas de las GTPasas Rac $\quad 6$

2.1.1. Regulación de la polimerización del citoesqueleto de actina 6

2.1.2. Regulación de la transcripción 11

2.1.3. Otras funciones 12

2.1.4. Análisis de la función de las GTPasas Rac in vivo mediante la generación de animales genéticamente modificados $\quad 12$

2.2. Patologías causadas por alteraciones de las GTPasas Rac 16

3. REGULACIÓN DE LA ACTIVIDAD DE LAS PROTEÍNAS Rac 18

3.1. Regulación transcripcional y/o mediante degradación diferencial $\quad \mathbf{1 8}$

3.2. Regulación del intercambio de nucleótidos $\quad 19$

3.3. Regulación de la localización subcelular

3.3.1. Modificaciones posttraduccionales y secuencia aminoacídica del extremo C-terminal de las GTPasas Rac $\quad \mathbf{2 4}$

3.3.2. Regulación de la translocación citosol-membrana por moléculas secuestradoras $\quad 24$

OBJETIVOS

MATERIALES Y MÉTODOS 35

RESULTADOS

CAPITULO 1. RASTREO CELÓMICO DE GENOTECAS DE EXPRESIÓN DE ADNc 53

1.1. Generación de una línea celular reportera EGFP-Rac1 HEK293T 53

1.2. Sistema de identificación funcional y clonaje por expresión $\quad 54$

1.3. Corroboración, validación y selección de los clones aislados $\mathbf{5 6}$

CAPITULO 2. CARACTERIZACIÓN DE LA INTERACCIÓN FUNCIONAL ENTRE Coronina-1A Y Rac1

2.1. Papel de Coronina-1A en el mecanismo de translocación y activación de Rac1 63

2.1.1. Coronina-1A solamente transloca GTPasas de la subfamilia Rac

2.1.2. Coronina-1A necesita unirse a F-actina para translocar a la GTPasa

Rac1 a la membrana plasmática

65

2.1.3. Coronina-1A es importante para la correcta translocación y activación de la GTPasa Rac1 in vivo 
2.2. Caracterización de la ruta de señalización que media la translocación y activación

de Rac1 por Coronina-1A

2.2.1. La translocación de Rac1 mediada por Coronina-1A es dependiente de balsas lipídicas, citoesqueleto de actina y actividad Pak

2.2.2. La translocación de Rac1 mediada por Coronina-1A requiere actividad basal de Rac1

2.2.3. Papel de Pak1 en la translocación de Rac1 inducida por Coronina-1A

2.2.4. Coronina-1A favorece la formación de complejos Pak1/RhoGDI in vivo

2.2.5. La formación de complejos Coronina-1A/Pak1/RhoGDI requiere ArhGEF7

2.2.6. ArhGEF7 es esencial para la translocación y activación de Rac1 mediada por Coronina-1A

\section{CAPÍTULO 3. MECANISMOS DE REGULACIÓN DE LA TRANSLOCACIÓN DE Rac1} INDUCIDA POR OTROS CLONES AISLADOS EN EL RASTREO CELÓMICO

3.1. Especificidad de las proteínas translocadoras en la regulación de la localización subcelular de las GTPasas de la familia Rho/Rac

3.2. El efecto de las proteínas translocadoras sobre Rac1 depende de la correcta funcionalidad de las balsas lipídicas y del citoesqueleto de F-actina

3.3. Dependencia diferencial de Rac1 de las proteínas translocadoras

3.4. WDR26, pero no Basigina y TMEM8A, requiere de actividad quinasa de Pak1 para promover la translocación de Rac1 a la membrana

3.5. La translocación de Rac1 inducida por las proteínas transmembrana y las citoesqueléticas está mediada por dos rutas funcionales independientes

3.6. La translocación de Rac1 mediada por Basigina es consecuencia de la estabilización de balsas lipídicas en la superficie celular

DISCUSIÓN 



\section{ANTECEDENTES}

La familia de GTPasas Rho/Rac constituye un subgrupo de la superfamilia de proteínas Ras. Estas GTPasas se encuentran presentes en todos los eucariotas y controlan una amplia variedad de procesos celulares, ya que conectan la activación de receptores de membrana con múltiples rutas intracelulares de señalización. Como la mayoría de los miembros de la superfamilia Ras, las GTPasas Rho/Rac funcionan habitualmente como "interruptores moleculares", ciclando entre un estado inactivo, cuando están unidas a GDP, y un estado activo, cuando están unidas a GTP. Aunque en principio estas GTPasas se relacionaron con el control de la polimerización del citoesqueleto de actina en respuesta a diversos estímulos extracelulares, actualmente se sabe que la familia Rho/Rac participa en la regulación de funciones celulares muy diversas: establecimiento de la polaridad celular, procesos endocíticos y de tráfico vesicular, avance a través del ciclo celular, diferenciación, oncogénesis, transcripción génica y regulación de algunas actividades enzimáticas (Bustelo et al., 2007; Etienne-Manneville and Hall, 2002; Van Aelst and D'Souza-Schorey, 1997).

La pertenencia a la familia Rho/Rac está definida por la presencia de un dominio GTPasa de tipo Rho (Valencia et al., 1991). Este dominio, que es el responsable de la unión a nucleótidos de guanosina y de su hidrólisis, presenta una estructura secundaria común a todas las familias de GTPasas, conteniendo seis láminas $\beta$ y cinco hélices a (Figura 1A pág. siguiente). El intercambio de nucleótidos que origina la activación o desactivación de las proteínas Rho/Rac lleva aparejado un cambio conformacional en dos regiones llamadas switch I y switch II (Figura 1B, azul claro). Estos dominios son los responsables principales de la interacción con moléculas reguladoras y con efectores, por lo que se conocen como "regiones efectoras" de las GTPasas (Vetter and Wittinghofer, 2001). Recientemente se ha demostrado la importancia de regiones adicionales en la interacción con ambos tipos de proteínas (Gao et al., 2001; Li et al., 1997; Li and Zheng, 1997). Las GTPasas Rho/Rac presentan una característica estructural que las diferencia de otros grupos de la superfamilia Ras: poseen una "región inserto" con estructura de hélice $\alpha$ situada entre la quinta lámina $\beta$ y la cuarta hélice $\alpha$ del dominio GTPasa (Valencia et al., 1991) (Figura 1B, hélice morada). Las proteínas Rho/Rac (excepto las pertenecientes a las familias RhoBTB y Miro) son de pequeño tamaño (190-250 aminoácidos) y comprenden únicamente el dominio GTPasa flanqueado en sus extremos $\mathrm{N}-\mathrm{y}$ C-terminales por secuencias cortas de aminoácidos. Dentro del dominio GTPasa, la homología es del 40 al 95\% dentro de la familia Rho/Rac y de aproximadamente un 30\% con las proteínas Ras (Wennerberg and Der, 2004). La mayoría de las proteínas Rho/Rac experimentan modificaciones posttraduccionales en su extremo C-terminal, consistentes en la adición de lípidos isoprenoides, proteolisis y metilaciones. Dichas modificaciones, junto con secuencias específicas situadas en la misma zona de la molécula, determinan su localización subcelular y la asociación con membranas específicas, ambas esenciales para la funcionalidad de las GTPasas (Wennerberg and Der, 2004). 
A

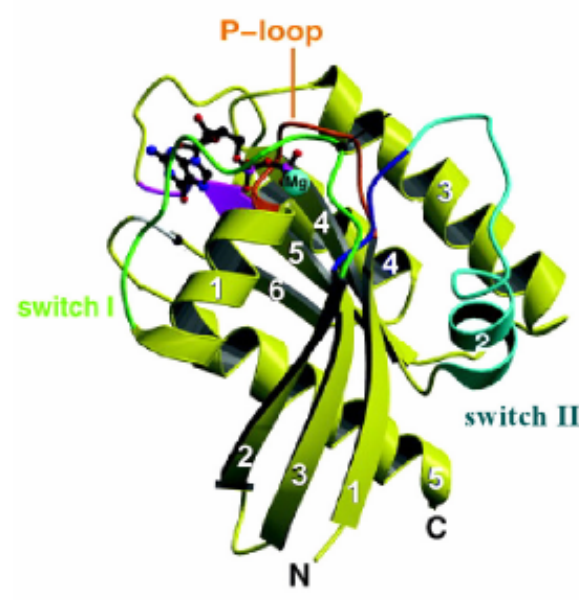

B

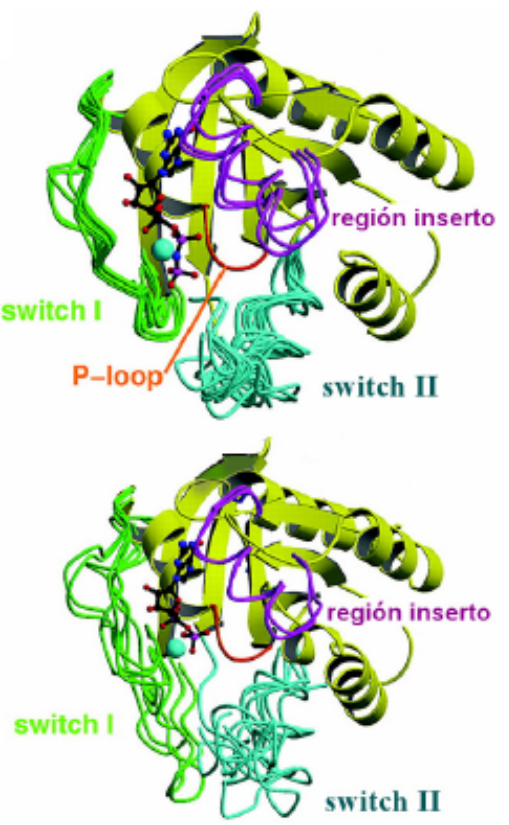

Figura 1. Estructura terciaria de las GTPasas de la superfamilia Ras. (A) Estructura general de las proteínas Ras. Todas las proteínas de esta familia presentan una estructura común caracterizada por poseer seis láminas $\beta$ y cinco hélices $\alpha$, que se presentan numeradas en la figura comenzando por el extremo N-terminal de la molécula. Las zonas principales de interacción con efectores (switch I y switch II) se indican en verde lima y en azul claro, respectivamente. La región denominada "P-loop" participa en la interacción con nucleótidos de guanina (que se representan en la figura como un diagrama de barras y bolas) y con el ión $\mathrm{Mg}^{2+}$ (representado como una bola), un cofactor que, en el caso de las GTPasas Rho/Rac, regula la cinética de intercambio de nucleótidos (Zhang et al., 2000). (B) Estructura de las GTPasas Rho/Rac en su estado activo (panel superior) e inactivo (panel inferior). Las regiones que presentan mayores diferencias conformacionales entre ambos estados de activación son el switch I y el switch II, que se representan como una superposición de estas regiones pertenecientes a distintas proteínas Rho/Rac. La "región inserto", que es una característica estructural exclusiva de la familia Rho/Rac, se muestra en morado (adaptado de Vetter y Wittinghofer, 2001).

Los miembros de la familia Rho/Rac se encuentran codificados en humanos por 23 genes, que pueden dar lugar a 26 proteínas. De acuerdo con su homología en la secuencia primaria de aminoácidos, motivos estructurales y función biológica, las proteínas de esta familia pueden ser clasificadas en seis subfamilias (Figura 2, pág. siguiente), cuyos miembros poseen propiedades biológicas relacionadas, pero no idénticas:

-Subfamilia Rho: RhoA, RhoB, RhoC.

-Subfamilia Rac: Rac1, Rac1b (originada por procesamiento alternativo del gen RAC1 en células tumorales de mama y colon) (Jordan et al., 1999; Schnelzer et al., 2000), Rac2, Rac3 y RhoG.

-Subfamilia Cdc42: Cdc42 y su variante originada por procesamiento alternativo en cerebro G25K, TC10, TCL, Chp/Wrch-2 y Wrch-1.

-Subfamilia Rnd: Rnd1, Rnd2 y RhoE/Rnd3 
-RhoD, Rif y TTF/RhoH constituyen un grupo heterogéneo que no puede ser clasificado dentro de ninguna de las subfamilias anteriores. RhoD y Rif están relacionadas estructuralmente (48\% de identidad) y poseen secuencias adicionales en el extremo amino-terminal (Wennerberg and Der, 2004). RhoH/TTF se identificó inicialmente como un transcrito quimérico debido a una translocación $t(3 ; 4)(q 27 ; p 11-13$ ) (Dallery et al., 1995), y el gen que la codifica se ha encontrado reordenado en linfoma no-Hodking y en mieloma múltiple (Preudhomme et al., 2000). Su expresión es exclusiva de tejidos hematopoyéticos (Li et al., 2002b). Esta GTPasa posee una región inserto más corta y se encuentra siempre unida a GTP. Por este motivo, la regulación de su actividad no se produce mediante el intercambio de nucleótidos sino a nivel transcripcional y por medio de su unión a las proteínas reguladoras RhoGDIs, que determinan su localización subcelular (Li et al., 2002b). RhoD y Rif producen modificaciones en el citoesqueleto de actina (Aspenstrom et al., 2004; Ellis and Mellor, 2000; Murphy et al., 1996), mientras que RhoH/TTF carece de esta actividad (Aspenstrom et al., 2004; Li et al., 2002b).

-Subfamilia RhoBTB (RhoBTB-1, RhoBTB-2 y RhoBTB-3) (Rivero et al., 2001) y la subfamilia Miro (Miro-1 y Miro-2) (Fransson et al., 2003) . Ambas familias se han denominado "GTPasas Rho atípicas", ya que presentan diferencias notables con respecto a las proteínas Rho/Rac clásicas: poseen un peso molecular mucho mayor (contienen alrededor de 700 aminoácidos), el dominio GTPasa está mucho menos conservado, contienen dominios adicionales bien definidos y no experimentan modificaciones posttraduccionales. Aunque RhoBTB-1 y RhoBTB-2 poseen el dominio "inserto" que distingue a la familia Rho/Rac de otras GTPasas de la superfamilia Ras, RhoBTB-3 y las dos proteínas Miro carecen de dicho dominio. Este hecho, junto con la gran divergencia de secuencia observada con respecto a las GTPasas típicas, han dado lugar a que se postule que estas proteínas quizá no deberían ser considerados miembros de la familia Rho/Rac, sino nuevos grupos dentro de la superfamilia Ras (Wennerberg and Der, 2004).

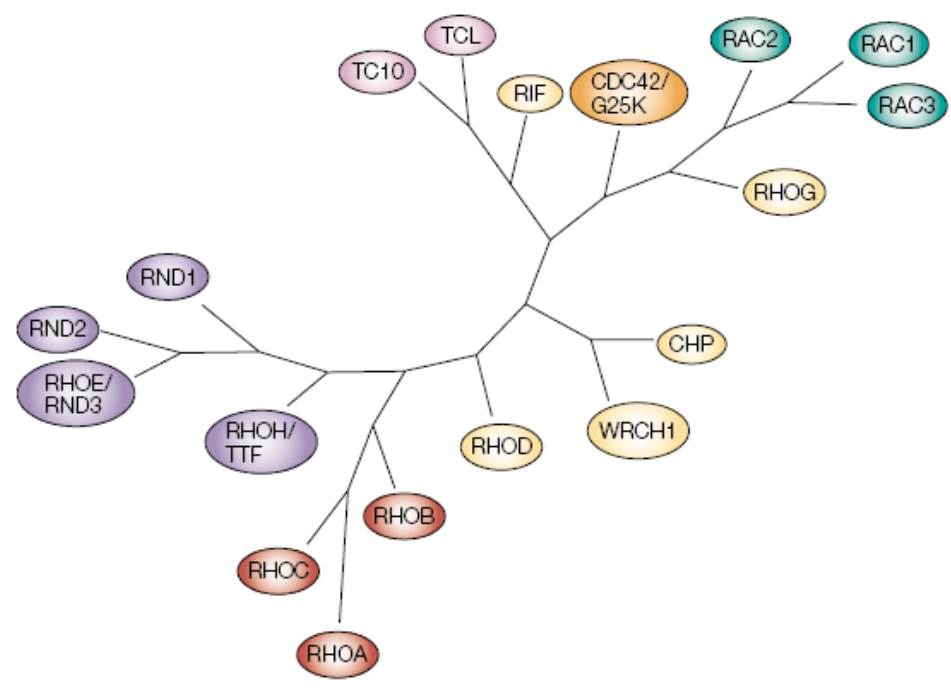

Figura 2. La familia de proteínas Rho/Rac. Las proteínas de la familia Rho/Rac pueden ser clasificadas en base de su funcionalidad, características bioquímicas y estructura primaria. Este árbol filogenético ha sido modificado teniendo en cuenta los estudios funcionales y bioquímicos realizados en los últimos tiempos. Adaptado de Sahai et al., 2002. 
En este trabajo de tesis doctoral nos hemos centrado en la búsqueda, aislamiento y caracterización de nuevos reguladores de la GTPasa Rac1 a través de un rastreo celómico de genotecas de expresión. La GTPasa Rac1, el miembro de la subfamilia de GTPasas Rac más ampliamente estudiado, fue descubierto en 1989 como una nueva proteína de la superfamilia Ras sustrato de la toxina botulínica C3 (Didsbury et al., 1989). Posteriormente se ha demostrado que esta GTPasa juega un papel fundamental en una amplia variedad de procesos celulares tales como la reorganización del citoesqueleto de actina, transformación celular, regulación de transcripción génica, producción de superóxido, morfogénesis en determinados tipos celulares y migración. Actualmente, aún se siguen descubriendo nuevas funciones de Rac1, particularmente en condiciones fisiológicas gracias a la generación de animales transgénicos inducibles y al desarrollo de cultivos celulares primarios (Bustelo et al., 2007).

\section{FUNCIONES DE Rac1}

Rac1 y miembros de su subfamilia (Rac2, Rac3, RhoG) están al cargo del ensamblaje de múltiples respuestas celulares de carácter general como son la modulación de cambios citoesqueléticos, la activación de cascadas de quinasas de lípidos y proteínas, estimulación de cambios transcripcionales, progresión del ciclo celular, morfogénesis y diferenciación. Además, también se encargan de la regulación de respuestas biológicas específicas para algunos tipos celulares como son la producción de radicales libres de oxígeno por los neutrófilos, la fagocitosis de macrófagos, axogénesis en neuronas o la formación de la sinapsis inmune en linfocitos T (Bustelo et al., 2007). Junto a estudios en líneas celulares, la generación reciente de modelos animales de pérdida y ganancia de función para estas GTPasas nos ha permitido obtener una visión más precisa de su importancia in vivo (Bustelo et al., 2007). A lo largo de estos años también se ha descubierto que estas GTPasas partipan en procesos patológicos diversos, lo que ha acentudado todavía más el estudio de su función y regulación. Resumimos a continuación las funciones principales de estas proteínas y su implicación en procesos patológicos.

\subsection{Funciones biológicas de las GTPasas Rac}

\subsubsection{Regulación de la polimerización del citoesqueleto de actina}

Los efectos de Rac1 sobre el citoesqueleto de actina fueron inicialmente descritos usando fibroblastos quiescentes Swiss3T3, una línea celular que en ausencia de suero no muestra estructuras organizadas de F-actina. Factores de crecimiento, como PDGF o EGF, inducen la formación de lamelipodios ricos en F-actina y ondulaciones de membrana (también conocidos como membrane ruffles) que son totalmente inhibidos por la expresión de la forma dominante negativa Rac1 ${ }^{\top 17 \mathrm{~N}}$ (Ridley et al., 1992). No es sorprendente, por tanto, que las GTPasas de la familia Rac jueguen un papel importante en una amplia variedad de procesos que son 
dependientes del citoesqueleto de actina tales como fagocitosis (Caron and Hall, 1998; Cox et al., 1997), pinocitosis (Ridley et al., 1992), morfogénesis (Hakeda-Suzuki et al., 2002; Luo, 2000; Ng et al., 2002; Ozdinler and Erzurumlu, 2001) y migración celular (Keely et al., 1997; Nobes and Hall, 1999).

La internalización de partículas mediante fagocitosis también requiere la activación de las GTPasas Rac y los subsiguientes cambios citoesqueléticos promovidos por éstas (Qualmann and Mellor, 2003). En la fagocitosis de tipo I, la activación localizada de Cdc42 da lugar a la formación de filopodios alrededor de la partícula a fagocitar, y la activación subsiguiente de Rac1 promueve la internalización de la misma (Massol et al., 1998; Nakaya et al., 2008). A continuación, la partícula "se hunde" dentro de la célula sin que se generen protrusiones en la membrana plasmática (Caron and Hall, 1998; May et al., 2000). Las GTPasas Rac también participan en otros mecanismos endocíticos, como la macropinocitosis. Rac1 estimula la formación de vesículas macropinocíticas (Ridley et al., 1992) de forma dependiente del citoesqueleto de actina y del reclutamiento y activación de la quinasa Pak1 (Dharmawardhane and Bokoch, 1997; Dharmawardhane et al., 1997; Dharmawardhane et al., 2000).

Las GTPasas de la subfamilia Rac juegan papeles fundamentales en la morfogénesis de algunos tipos celulares como ocurre con la formación y estabilización de la estructura de ciertos fotorreceptores en Drosophila (Chang and Ready, 2000) o con la diferenciación de determinados precursores celulares a células cardíacas especializadas (Puceat et al., 2003). La formación de axones y dendritas en neuronas, que está dirigida en gran medida por la presencia de señales medioambientales, también está regulada por las GTPasas de esta subfamilia a través de su efecto sobre la polimerización del citoesqueleto de actina (HakedaSuzuki et al., 2002; Luo, 2000).

Las GTPasas Rac también son fundamentales para la migración celular, ya que proporcionan la fuerza motriz necesaria para este proceso a través de la regulación de la polimerización del citoesqueleto de actina. La migración celular se inicia con el establecimiento de un lamelipodio en el frente de avance de la célula, junto con la aparición de nuevas adhesiones al sustrato extracelular. Rac1 es la responsable de la formación del lamelipodio a través de un doble efecto regulador sobre el citoesqueleto de actina: por una parte, estimula la polimerización de la actina a través de la activación del complejo Arp2/3 (Miki et al., 2000; Tolias et al., 2000) y del uncapping de los filamentos de actina situados en las proximidades de la membrana plasmática (Tolias et al., 2000); por otro lado, reduce la tasa de despolimerización de la actina a través de la activación de la ruta Pak1/LIMK, que inactiva a la proteína despolimerizadora cofilina (Stanyon and Bernard, 1999). Sin embargo, cofilina también parece estar implicada en la extensión del lamelipodio, puesto que libera monómeros de actina que 
pueden ser incorporados en los filamentos generados de novo (Chan et al., 2000; Zebda et al., 2000) (Figura 3, pág. siguiente). Mediante la técnica de microscopía denominada FRET (del inglés, Fluorescence resonance energy transfer) se ha observado la aparición de un gradiente de la forma activa de Rac en fibroblastos en proceso de migración. Así, los mayores niveles de Rac activada se encuentran precisamente en el frente de avance de la célula (Kraynov et al., 2000). Además, Rac1 promueve la formación de complejos de adhesión de integrinas en el frente de avance, lo que favorece la acumulación de la forma activada de Rac1 en esta región (Kiosses et al., 2001). Este fenómeno da lugar a un mecanismo de retroalimentación positiva que permite a las células seguir migrando aun cuando se esté produciendo un atenuamiento de la señalización a través de receptores de membrana (Allen et al., 1998b; Bailly et al., 2000).

Entre los efectores a través de los cuales Rac1 promueve estas funciones celulares dependientes del citoesqueleto de actina encontramos proteínas adaptadoras sin actividad catalítica conocida como POR1 o $140^{\mathrm{Sra}-1}$. POR1 es una proteína citosólica necesaria para que se produzca la polimerización de filamentos de actina en la periferia celular mediada por las GTPasas Rac1 y Arf6 (D'Souza-Schorey et al., 1997; Van Aelst et al., 1996). Un ejemplo parecido lo encontramos en el caso de la proteína con capacidad de unión a F-actina denominada $\mathbf{p} 140^{\text {Sra-1 }}$. Esta proteína conecta a Rac1 con el macrocomplejo polimerizador de actina WAVE2-Abi1-Nap1-PIR121 en el frente de avance de células en migración y en las ondulaciones de membrana o membrane ruffles (Innocenti et al., 2004; Kitamura et al., 1997; Steffen et al., 2004). Poco más se conoce de estas dos proteínas con función adaptadora entre Rac1 y el citoesqueleto de actina. Un efector mejor caracterizado de Rac1 es la proteína quinasa de lípidos PI-4-P5K, que cataliza la fosforilación de fosfatidilinositol fosfato (PIP) en la membrana para producir fosfatidilinositol-3,4-bifosfato $\left(\mathrm{PIP}_{2}\right)$. Rac1 interacciona de una forma independiente de su unión a GTP o GDP con PI-4-P5K (Tolias and Carpenter, 2000; Tolias et al., 1998). Estudios realizados en plaquetas han demostrado que la polimerización del citoesqueleto de F-actina inducido por trombina requiere el uncapping de los filamentos de actina, que es absolutamente dependiente de un aumento en los niveles de $\mathrm{PIP}_{2}$. Este aumento en los niveles de $\mathrm{PIP}_{2}$ es mediado por la activación de PI-4-P5K inducida por Rac1 (Hartwig et al., 1995; Tolias et al., 2000). Interesantemente, WAVE, una proteína que se acumula en los membrane ruffles inducidos por PDGF o la forma activada de Rac1, coinmunoprecipita con Rac1, aunque no contiene en su estructura el típico dominio de unión a GTPasas o dominio CRIB (del inglés, Cdc42/Rac interacting binding domain). Esta observación sugiere que esta proteína no es un efector directo de Rac1 (Miki et al., 1998). Posteriormente, diversos estudios han identificado a IRSp53 como el candidato que media la interacción entre WAVE y Rac1 en la polimerización de actina necesaria para la formación de membrane ruffles. Esta proteína con función adaptadora media la unión entre Rac1, a través de su dominio CRIB, y WAVE2, a 


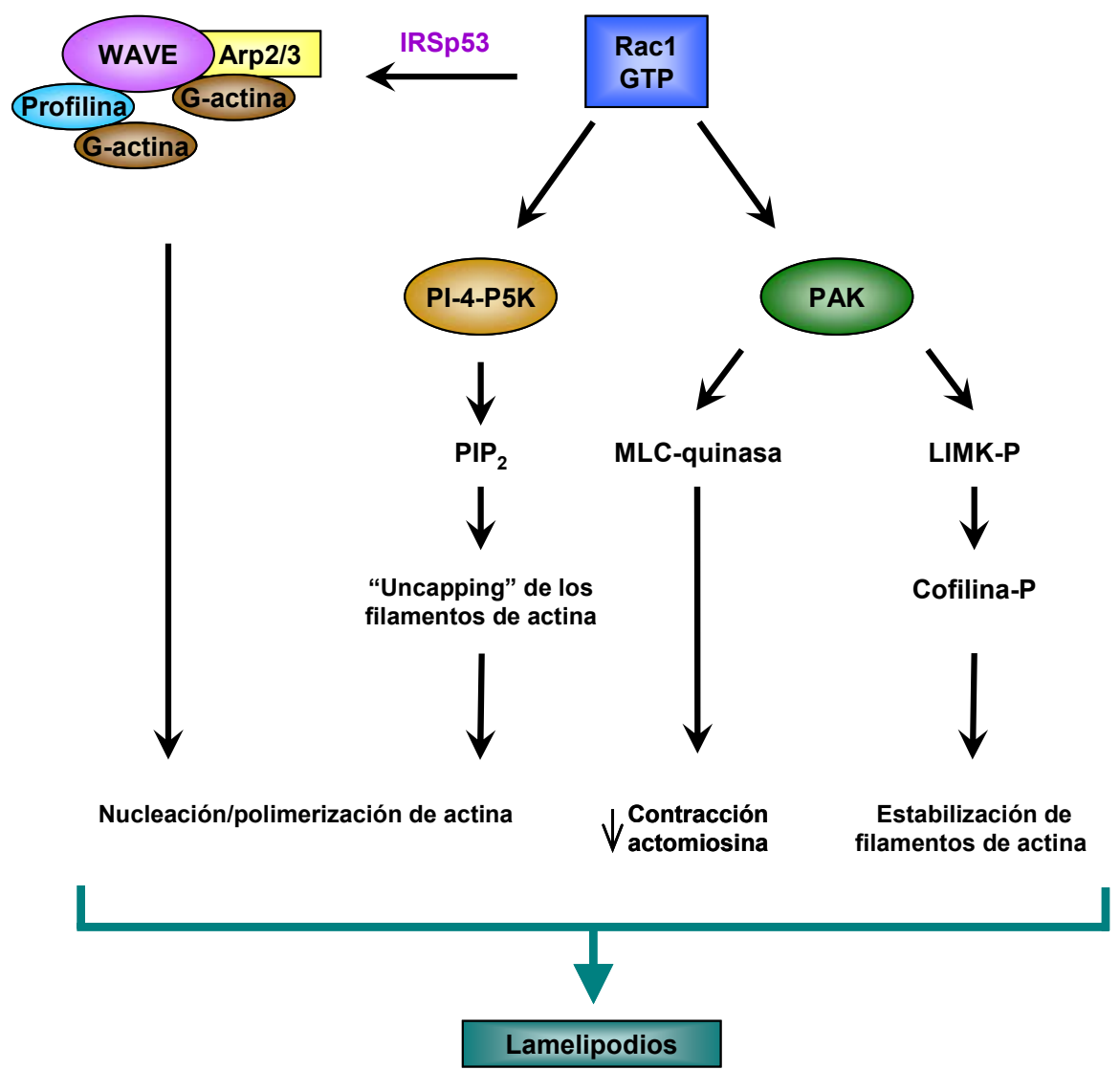

Figura 3. Efectores implicados en las reorganizaciones del citoesqueleto de actina inducidas Rac1. Adaptado de Bishop y Hall, 2000.

través de su dominio SH3 (del inglés, Src homology domain type 3), favoreciendo procesos de polimerización de actina mediado por Arp2/3 en la membrana plasmática (Abou-Kheir et al., 2008; Machesky and Insall, 1998; Machesky et al., 1999; Miki et al., 2000) (Figura 3,).

Además también encontramos otras proteínas efectoras, comunes para las GTPasas Rac1 y Cdc42, implicadas en la reorganización del citoesqueleto de actina como es el caso de la familia de serín-treonín quinasas Paks (Pak1, Pak2, Pak3) o el grupo de IQGAPs (IQGAP1, IQGAP2, IQGAP3). Pak1 es quizás el efector mejor caracterizado estructural y funcionalmente de la GTPasa Rac1 (Bokoch, 2003; Kumar et al., 2006). Sin embargo, el mecanismo por el cual los miembros de la familia Pak llevan a cabo la regulación del citoesqueleto de actina parece controvertido y bastante complejo. Ha sido demostrado que mutantes activos de Pak1 inducen la formación de filopodios y ondulaciones de membrane en fibroblastos Swiss3T3 y causan el crecimiento de la neurita axonal en células PC12, de un modo similar a las formas activadas de Cdc42 y Rac1 (Daniels et al., 1998; Sells et al., 1997). Además, las reorganizaciones citoesqueléticas inducidas por Pak son parcialmente independientes de su actividad quinasa, pero precisan de su localización en la membrana plasmática (Daniels et al., 1998; Lu et al., 
1997; Sells et al., 1997). Estas observaciones podrían ser explicadas teniendo en cuenta que Pak1 se une a través de su región central rica en prolinas a proteínas con dominios SH3 como ArhGEF7, que además posee un dominio Rac-GEF (del inglés, Rac-Guanine nucleotide exchange factor), aunque la funcionalidad de este dominio en la regulación de Rac1 permanece aún sin esclarecerse (Manser et al., 1998; Rosenberger and Kutsche, 2006; ten Klooster et al., 2006b; Webb et al., 2005). Además, numerosas proteínas, implicadas directa o indirectamente en la dinámica del citoesqueleto de F-actina, son sustratos de esta familia de serín-treonín quinasas como es el caso componentes del citoesqueleto de acto-miosina, filamentos intermedios, microtúbulos, integrinas y una variedad de proteínas asociadas con las anteriores (Figura 4).

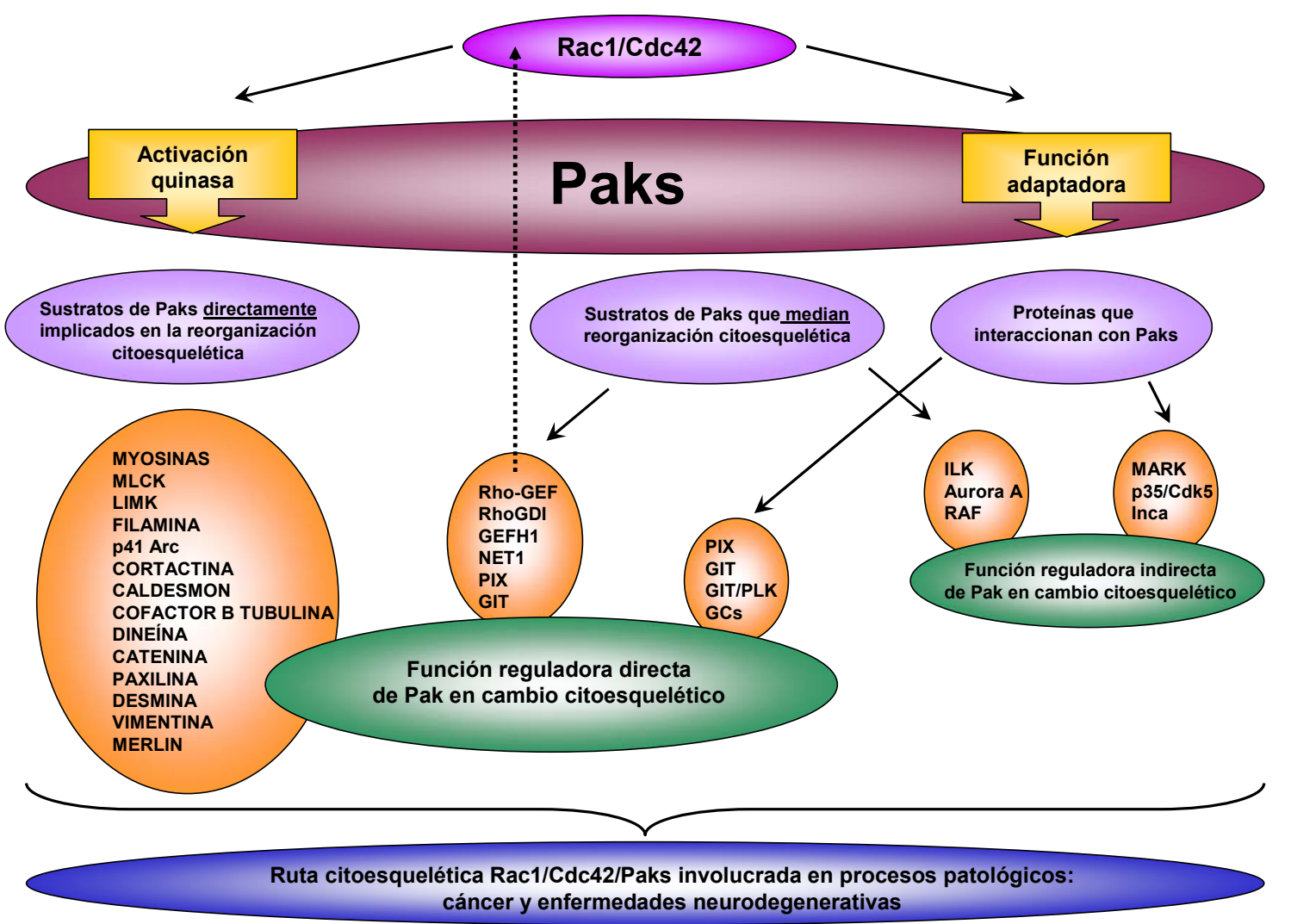

Figura 4. Participación de la ruta Rac1/Cdc42/Paks en las reorganizaciones del citoesqueleto. Sustratos de Paks y otras proteínas que interaccionan con Pak relacionadas directa o indirectamente con las reorganizaciones citoesqueléticas promovidas por el eje Rac1/Cdc42/Pak. Adaptado de Szczepanowska, 2009.

IQGAP1 fue inicialmente caracterizado como una proteína efectora de Rac1 y Cdc42 puesto que era capaz de interaccionar tanto in vitro como in vivo con las formas activadas de ambas GTPasas (Kuroda et al., 1996). IQGAP1 en mamíferos es una proteína que estimula la polimerización de actina in vitro (Bashour et al., 1997; Erickson et al., 1997; Fukata et al., 2002) y se localiza en los lamelipodios ricos en F-actina de células en movimiento (Hart et al., 1996), 
sugiriendo que esta proteína juega un papel importante en la reorganización y dinámica del citoesqueleto de actina. Además de su interacción directa con F-actina a través de su dominio CH (del inglés, Calponin homology domain) (Erickson et al., 1997; Ho et al., 1999; Mateer et al., 2002), IQGAP1 puede modular el citoesqueleto de actina a través de las GTPasas Rac1 y Cdc42. IQGAP1 también se une a E-cadherina y $\beta$-catenina, y estas tres proteínas colocalizan en los sitios de contacto célula-célula (Kuroda et al., 1998; Li et al., 1999). Interesantemente, la sobreexpresión de IQGAP1 (Kuroda et al., 1998) y la translocación de IQGAP1 endógeno a estas uniones intercelulares coincide con un inhibición de la adhesión mediada por E-cadherina (Li et al., 1999). Análisis más detallados han demostrado que IQGAP1 reduce la interacción entre cadherinas y el sistema de filamentos citoplasmáticos que forman parte del citoesqueleto celular, por tanto debilitando la unión célula-célula (Kuroda et al., 1998). Poco se conoce de los otros dos miembros de esta familia de proteínas, IQGAP2 e IQGAP3. Sin embargo parece que estas dos proteínas también influyen en la reorganización del citoesqueleto de actina en determinados tipos celulares específicos, como es el caso de plaquetas (IQGAP2) (Schmidt et al., 2003) o del sistema nervioso central (IQGAP3) (Wang et al., 2007). También parecen tener un papel importante en la activación de la ruta de MAPKs (Kunimoto et al., 2009; Nojima et al., 2008).

\subsubsection{Regulación de la transcripción}

Otra función desempeñada por las GTPasas Rac es la regulación de la expresión génica. La sobreexpresión de las formas activadas de Rac1 da lugar a la activación de la cascada de quinasas que conduce a la activación de JNK (del inglés, c-Jun N-terminal kinase), regulando la actividad del factor transcripcional c-Jun de forma específica en función del tipo celular analizado (Coso et al., 1995; Minden et al., 1995; Teramoto et al., 1996). Rac1 puede incrementar los niveles de ARNm de la ciclina D1, mediado por NF-KB (Joyce et al., 1999), favoreciendo el tránsito a través de la fase G1. En células endoteliales, esta función de Rac1 es crítica para determinar su respuesta frente a determinadas proteínas de la matriz extracelular. Sobre fibronectina, Rac1 es activado y las células entran en ciclo celular, mientras que sobre laminina Rac1 no se activa y las células permanecen quiescentes. Estas diferencias son atribuidas a la activación de diferentes receptores en la superficie celular ya que fibronectina activa a integrinas $\alpha 5 \beta 1$ mientras que laminina actúa sobre integrinas $\alpha 2 \beta 1$ (Mettouchi et al., 2001). Por otro lado, estudios más recientes asignan a Rac1 un papel regulador negativo de la expresión de algunos genes controlados por el factor de transcripción BCL-6 en células de cáncer colorrectal (Barros et al., 2009). Rac1 y RhoG también poseen funciones asociadas a la actividad de algunos factores de transcripción. En células $T$, el factor nuclear de células $T$ activadas NFAT (del inglés, Nuclear factor of activated $T$ cells) regula positivamente la transcripción de la interleuquina-2 y de otras citoquinas, como el interferón- $\gamma$. Rac1 y RhoG promueven la estimulación de NFAT tras la activación del TCR a través de la actividad de la familia de factores transcripcionales AP-1 (Kaminuma et al., 2001; Vigorito et al., 2003). La 
activación de NFAT depende del efecto de RhoG sobre el citoesqueleto de actina, pero no de la activación de Rac1, que a su vez controla la transcripción dependiente de NFAT mediante una ruta de señalización diferente a la activada por RhoG (Vigorito et al., 2003).

Los patrones globales de expresión génica inducidos por las formas activadas de la GTPasa Rac1 han sido analizados mediante el uso de microarrays (Teramoto et al., 2003). Estos estudios han mostrado que la forma mutante constitutivamente activada de Rac1 (Rac1 ${ }^{\text {Q61L }}$ ) regula positivamente la transcripción de genes que codifican para proteínas de adhesión celular y componentes de la matriz extracelular. Los cambios inducidos en el transcriptoma por la expresión de esta GTPasa probablemente tengan significación biológica, puesto que presentan una buena correlación con las funciones descritas previamente para esta proteína. La expresión de la forma constitutivamente activada de Rac1 en células COS-7 protege frente a la apoptosis inducida por irradiación con ultravioleta, puesto que la activación de la ruta de supervivencia de Akt por medio de la interacción de Rac1 con PI3K (del inglés, Phosphatidylinositol-3-kinase) prevalece sobre las señales apoptóticas desencadenadas por la activación de la ruta de JNK en esta línea celular (Murga et al., 2002).

\subsubsection{Otras funciones}

Además de su papel en los procesos anteriores, las proteínas Rac poseen funciones reguladoras específicas. Ciertos miembros de la familia Rac, como es el caso de Rac1, activan al complejo de la NADPH oxidasa (del inglés, Nicotinamide adenine dinucleotide phosphate-oxidase complex) en células fagocíticas, promoviendo la generación de radicales libres de oxígeno que actúan como mecanismo de defensa frente a microorganismos (Abo et al., 1991; Bokoch and Diebold, 2002; Knaus et al., 1991; Werner, 2004). Recientemente se ha descrito que Rac1 también posee esta función en células no fagocíticas. Así, la regulación de las isoformas vasculares de la NADPH oxidasa por Rac1 se ha relacionado con múltiples procesos como hipertrofia cardiaca y vascular, hipertensión, migración leucocitaria y arteriosclerosis (Bokoch and Knaus, 2003; Gregg et al., 2003; Lassegue and Clempus, 2003). Numerosos estudios apuntan que diversas GTPasas Rac pueden regular el tráfico de vesículas (Ellis and Mellor, 2000; Qualmann and Mellor, 2003; Symons and Rusk, 2003). Este es el caso de la GTPasa Rac1 que regula negativamente el tráfico endocítico del receptor de EGF mediado por la ruta de clatrina (Lamaze et al., 1996). Por otro lado, RhoG controla la endocitosis mediada por la ruta de caveolas (Prieto-Sanchez et al., 2006).

\subsubsection{Análisis de la función de las GTPasas Rac in vivo mediante la generación} de animales genéticamente modificados

El estudio de la funcionalidad biológica de las GTPasas Rac in vivo se ha visto dificultado por el hecho de que los ratones deficientes en alguna de estas proteínas generalmente mueren 
durante el periodo embrionario. Este hecho no es sorprendente, dado que estudios previos realizados en Drosophila melanogaster habían demostrado que la señalización mediada por las proteínas Rac es imprescindible para que se produzca correctamente el desarrollo del embrión (Settleman, 2001). Los ratones $\operatorname{Rac1}^{-/}$mueren en etapas tempranas de la embriogénesis debido a que la actividad de Rac1 es esencial para que se formen las tres capas germinales durante el proceso de gastrulación (Sugihara et al., 1998). Por el contrario, la inactivación de otros miembros de la subfamilia Rac da lugar a defectos más limitados, los cuales se encuentran normalmente en los tejidos donde estas GTPasas se expresan predominantemente. Así, los ratones $\boldsymbol{R a C 2}^{-/}$son viables a pesar de sufrir alteraciones importantes en la función de los neutrófilos (Roberts et al., 1999). Los ratones Rac3 ${ }^{-/}$ presentan problemas leves de coordinación motora y habilidades de aprendizaje aumentadas (Corbetta et al., 2005). Por último, los ratones $\mathbf{R h o G}^{-{ }^{-}}$muestran hiperactivación de células T en respuesta a antígenos y defectos menores en la ruta del superóxido de los neutrófilos, responsables de procesos inflamatorios (Condliffe et al., 2006; Vigorito et al., 2004).

Para evitar el problema de la letalidad embrionaria, se han generado ratones transgénicos inducibles con el fin de eliminar la expresión de las GTPasas en tejidos específicos o durante etapas concretas del desarrollo embrionario. La generación de ratones inducibles $\operatorname{Rac1}^{-/}$en tejidos específicos y su comparación con ratones $\operatorname{Rac2}^{-/}$y dobles mutantes Rac1 $^{-/}$; Rac2 $^{-/}$ha permitido un entendimiento global de las funciones fisiológicas de estas dos GTPasas y el grado de solapamiento/especificidad que presentan. En el caso de células troncales hematopoyéticas (del inglés, hematopoietic stem cells, HSCs), el papel de Rac1 y Rac2 ha sido averiguado usando experimentos de reconstitución de animales irradiados subletalmente e inmunocomprometidos y aproximaciones de inactivación génica. Estos estudios han revelado las importantes diferencias funcionales que existen entre estas dos GTPasas. Así, se ha demostrado que Rac1 es importante para la óptima reconstitución del sistema hematopoyético, poseyendo funciones tanto en la colonización como la retención de HSCs en la médula ósea. Sin embargo, las HSCs Rac2 ${ }^{-/}$muestran un comportamiento normal en todos esos procesos. Rac1 y Rac2 también se diferencian en el tipo de respuesta intracelular que regulan en HSCs. Así, Rac1 es esencial para la entrada en ciclo de las HSCs después de estimulación extracelular así como para el progreso durante las fases $S$ y G2/M mientras que Rac2 es importante para respuestas citoesqueléticas, adhesión, extensión celular (del inglés, cell spreading) y supervivencia dependiente de Akt en HSCs (Cancelas et al., 2005; Gu et al., 2003). En el caso de células T, los ratones $\operatorname{Rac}^{-/-}$no muestran problemas aparentes en la diferenciación de esas células en el timo. Por el contrario, las células T maduras $\operatorname{Rac}^{-/}$ muestran defectos en la activación del receptor de células $\mathrm{T}$, polimerización de actina, generación de flujos de $\mathrm{Ca}^{2+}$ y activación de la ruta Ras/Erk tras la estimulación del receptor (Yu et al., 2001). Estos defectos son marginales probablemente debido a la redundancia funcional consecuencia de los altos niveles de Rac1 endógenos presentes en estas HSCs. 
Rac2 también es importante para la diferenciación de las células $T$ auxiliares subtipo $T_{H} 1$ porque regula la inducción de interferón- $\gamma$ dependiente de p38 y NFKB (Li et al., 2000). Los defectos causados por la deficiencia en Rac1 no han sido aún investigados en detalle en células T. Sin embargo, y basándonos en los datos obtenidos con algunos GEFs para Rac1 (Turner and Billadeau, 2002), podemos predecir que esta GTPasa tendrá un papel importante en la diferenciación de células $T$, selección positiva y negativa, estimulación de las rutas de Ras/Erk y PI3K/Akt y una respuesta exacerbada frente antígenos.

En el caso de las células B, los ratones Rac2 $^{-/}$muestran defectos en el compartimento de células $B$, mostrando un reducido número de células $B$ periféricas, células $B$ peritoneales $y$ células plasmáticas secretoras de $\operatorname{lgM}$. Las células maduras $\operatorname{Rac}^{-/}$responden escasamente a la estimulación del receptor de células $\mathrm{B}$, mostrando reducidos niveles de flujos de $\mathrm{Ca}^{2+}$ y proliferación celular (Croker et al., 2002). De acuerdo con esto, la eliminación simultánea de Rac1 y Rac2 induce el agravamiento del fenotipo Rac2 ${ }^{-/}$, que lleva al bloqueo del desarrollo de células B en estadíos muy tempranos (Croker et al., 2002). Esto es causado por las bajas tasas de supervivencia derivadas de la deficiente activación de la ruta de Akt y la ineficiente expresión de dos moléculas antiapoptóticas, Bcl2L1 (más comúnmente conocida como Bcl- $\mathrm{x}_{\mathrm{L}}$ ) y el receptor BAFF (Croker et al., 2002). Sin embargo, los ratones Rac1 ${ }^{-/}$no poseen problemas detectables en esta línea linfoide (Croker et al., 2002). A diferencia de las células B, Rac1 y Rac2 no tienen funciones redundantes en la línea de neutrófilos. Los neutrófilos Rac2 ${ }^{-/}$ muestran un grave daño en motilidad, adhesión, quimiotaxis y fagocitosis así como una drástica reducción de la actividad oxidasa de la NADPH, el complejo enzimático responsable de la generación de moléculas superóxido antibacterianas (Kim and Dinauer, 2001; Li et al., 2002a). La actividad residual de la NADPH oxidasa en estas células es debida a la acción de RhoG, y en menor grado, de Rac1 (Condliffe et al., 2006; Glogauer et al., 2003). Los neutrófilos Rac1 ${ }^{-1}$ poseen problemas más suaves con defectos detectables únicamente en respuestas dependientes de quimioquinas (Glogauer et al., 2003; Sun et al., 2004). A diferencia de los neutrófilos $\operatorname{Rac}^{-{ }^{-}}$, esas células no muestran problemas significativos en el citoesqueleto en ausencia de quimioquinas a excepción de defectos en la retracción del urópodo dependiente de RhoA durante migración aleatoria (Glogauer et al., 2003; Pestonjamasp et al., 2006).

El descubrimiento de las funciones controladas por los miembros de la subfamilia Rac en macrófagos acaba de comenzar. Estudios recientes indican que Rac2 es importante para la producción de superóxido y fagocitosis frente a determinados estímulos (como es el caso de la estimulación del receptor del complemento FcyR) (Yamauchi et al., 2004). Además, también es importante para los procesos de migración de estas células debido a la falta de acumulación de macrófagos exudados durante procesos inflamatorios del peritoneo en los ratones Rac2 $^{-/}$ (Yamauchi et al., 2004). A diferencia de Rac2, la GTPasa Rac1 parece ser importante en la regulación de la morfología celular de los macrófagos y la correcta formación del lamelipodio 
(Wells et al., 2004). Sin embargo, ello no induce un defecto significativo en la migración o quimiotaxis de este tipo celular (Wells et al., 2004).

De acuerdo con los altos niveles de expresión en plaquetas, Rac1 parece ser el miembro de la subfamilia Rac más importante en este tipo celular. Sus funciones incluyen la generación de lamelipodios tras la estimulación de las plaquetas con adenosín difosfato, la inducción de la correcta extensión celular y agregación de las plaquetas y la formación del trombo in vivo. Estos defectos no son muy severos porque los animales deficientes para Rac1 no presentan hemorragias (McCarty et al., 2005). Más recientemente, el desarrollo de ratones inducibles $\operatorname{Rac1}^{-/}$en tejidos específicos ha comenzado a aportar luz sobre la función de esta GTPasa en tejidos no hematopoyéticos. Así, se ha demostrado que Rac1 es importante para la formación de las vainas de mielina en el sistema nervioso central (Thurnherr et al., 2006). En el caso de la piel, Rac1 es importante para la integridad de los folículos pilosos y, como consecuencia, los ratones con la inactivación de locus Rac1 específica en queratinocitos desarrollan un fenotipo sin pelo (Chrostek et al., 2006). Finalmente, se ha demostrado que las proteínas Rac1 y Rac2 tienen importantes funciones en las células dendríticas encargadas de presentar el antígeno a las células T (Benvenuti et al., 2004). Debido a esto, las células dendríticas deficientes para Rac1 y Rac2 muestran defectos en cambios citoesqueléticos, migración y presentación de antígenos que, como resultado, se impide el adecuado contacto celular con células T (Benvenuti et al., 2004). El desarrollo de este defecto requiere la inactivación génica tanto de Rac1 como de Rac2, indicando que estas dos proteínas ejecutan funciones similares y aditivas en células dendríticas (Benvenuti et al., 2004).

Las funciones desempeñadas in vivo por las GTPasas Rac también han sido analizadas mediante la generación de ratones transgénicos expresando formas constitutivamente activadas de estas proteínas. La expresión de Rac1 ${ }^{061 \mathrm{~L}}$ en el timo ha demostrado que esta GTPasa regula la diferenciación y proliferación de los linfocitos T inmaduros a nivel de la transición DN3 a DN4 del estadío pre-T (Gomez et al., 2000). El mutante Rac1 ${ }^{\mathrm{Y} 40 \mathrm{C}+\mathrm{Q} 61 \mathrm{~L}}$, que no promueve la activación de JNK, Pak ni p38 ${ }^{\mathrm{MAPK}}$, pero sí induce la remodelación del citoesqueleto de actina, es capaz de ejercer el mismo efecto que la versión constitutivamente activada de la GTPasa (Gomez et al., 2000). Los datos obtenidos a partir del estudio de estos ratones indican que Rac1 y Rac2 juegan un papel importante en el desarrollo de células linfoides y que, pese a que sus rutas pueden solaparse en algunos casos, en general ejercen sus funciones reguladoras a niveles diferentes. Sin embargo, estos resultados deben ser considerados con precaución, ya que, tanto la ausencia de un ciclo normal de activación y desactivación como la posible estimulación de rutas mediadas por GTPasas relacionadas con la estudiada, pueden dar lugar a artefactos que dificulten la interpretación correcta de los datos obtenidos. 


\subsection{Patologías causadas por alteraciones de las GTPasas Rac}

El amplio espectro de funciones biológicas reguladas por las proteínas Rac explica que la aparición de mutaciones activadoras o inactivadoras en los genes codificantes para estas GTPasas, así como en sus reguladores y efectores, origine la aparición de diversas patologías. Dado el importante papel que juegan en el desarrollo neuronal, se han descrito diversas enfermedades neurológicas causadas por alteraciones de la funcionalidad de las GTPasas Rac o de proteínas relacionadas (Luo, 2000). En el caso del retraso mental no sindrómico asociado al cromosoma $\mathbf{X}$, se han descrito mutaciones en tres loci que codifican proteínas relacionadas con las GTPasas Rac: oligofrenina-1, que es un GAP para Rac1 (aunque también posee actividad hacia RhoA y Cdc42 in vitro) (Billuart et al., 1998); Pak3, quinasa efectora de Rac1, Rac2 y Rac3 (Allen et al., 1998a), y ARHGEF6, un factor de intercambio para Rac1 y Cdc42 (Bagrodia et al., 1998; Kutsche et al., 2000; Manser et al., 1998). Asimismo, se han descrito mutaciones de proteínas relacionadas con las GTPasas Rac en otro tipo de patologías, como la enfermedad de Tangier, donde se ha observado un incremento en los niveles de expresión de Rac1 y RhoG (Boettner and Van Aelst, 2002). La aparición de una mutación inactivadora con efecto dominante negativo en Rac2 (Asp57Asn) se ha relacionado con una inmunodeficiencia neutrofílica que presenta un fenotipo similar al de los ratones Rac2 ${ }^{-/}$ (Williams et al., 2000). Muchos GEFs de la familia Dbl, como Vav (Katzav et al., 1989), fueron aislados inicialmente como oncogenes en ensayos de transformación de fibroblastos murinos con ADN derivado de tumores humanos. Posteriormente se ha comprobado que las formas constitutivamente activadas de Rac1 así como algunos de los efectores de esta GTPasa (IQGAP1) también están implicados en fenómenos de transformación celular (Appledorn et al., ; Jadeski et al., 2008; Jaffe and Hall, 2002). Al contrario que en el caso de Ras, no se ha descrito la presencia de formas constitutivamente activadas de las GTPasas Rac en tumores, aunque algunas de ellas se han encontrado sobreexpresadas en distintos tipos de cánceres. En algunos casos, la sobreexpresión se correlaciona con la evolución clínica de los pacientes, por lo que existe la posibilidad de que estas proteínas puedan ser utilizadas como marcadores pronósticos (Sahai and Marshall, 2002). Un ejemplo de este tipo es RAC1B, que se genera por procesamiento alternativo del gen RAC1 y se encuentra sobreexpresada en tumores de colon y de mama (Matos et al., 2003). El hecho de que no se encuentren formas constitutivamente activadas de las GTPasas Rac en tumores podría deberse a que estas proteínas necesitan ciclar entre su estados inactivo y activo para llevar a cabo correctamente las funciones biológicas en las que están implicadas (Symons and Settleman, 2000). Experimentos realizados en Drosophila melanogaster avalan esta hipótesis, puesto que en este sistema biológico la expresión tanto de la forma constitutivamente activa de Rac1 como de la forma dominante negativa produce el mismo efecto fenotípico (Luo, 2000; Luo et al., 1994).

Como se ha mencionado anteriormente, sí se han clasificado como oncoproteínas los GEFs de la familia Dbl, aunque sólo se han encontrado mutaciones que implican ganancia de 
función en tumores humanos en el gen TIAM (Engers et al., 2000; Kourlas et al., 2000). Bcr es otro regulador de la subfamilia Rac (contiene un dominio RhoGAP para Rac1) que se encuentra frecuentemente reordenado en leucemia mieloide crónica, dando lugar a una proteína de fusión con la tirosín-quinasa Abl (Kharas and Fruman, 2005). No obstante, no parece que la alteración de sus funciones reguladoras sobre Rac1 sea la causa de la enfermedad (Arlinghaus, 2002). Por otra parte, los RhoGAPs podrían actuar como supresores tumorales al ejercer un efecto inhibitorio sobre las GTPasas Rac. Este efecto se ha sugerido para la familia de las quimerinas (Kazanietz, 2000; Yang and Kazanietz, 2003). La expresión de la isoforma quimerina- $\beta 2$ en células de carcinoma mamario de ratón reduce su capacidad metastática, probablemente a través de la inactivación de Rac1 (Menna et al., 2003). Además, los niveles de expresión de la misma isoforma son muy bajos en gliomas malignos en comparación con astrocitomas de bajo grado, sugiriendo que la reducción de la expresión de la quimerina- $\beta 2$ podría ser un indicador de progresión maligna del tumor (Yuan et al., 1995).

Algunas bacterias patógenas han desarrollado factores de virulencia que mimetizan la función de proteínas de las células a las que infectan, y que emplean para manipular la fisiología y las funciones celulares del huésped en su propio beneficio. Varios de estos factores de virulencia tienen como función modificar el ciclo de activación y desactivación de las GTPasas Rac para facilitar el proceso infectivo (Friebel et al., 2001; Stebbins and Galan, 2001). La enterobacteria Salmonella spp libera en la célula huésped dos proteínas estructuralmente muy relacionadas (SopE y SopE2), que se comportan como GEFs para Rac1 y Cdc42. La activación de estas GTPasas origina cambios en el citoesqueleto de actina que facilitan la internalización de la bacteria en las células epiteliales del intestino (Criss et al., 2001; Stebbins and Galan, 2001). Una vez en el interior de la célula huésped, Salmonella contribuye a la vuelta al estado basal del citoesqueleto liberando otra proteína, SptP. Esta proteína es una GAP para Rac1, por lo que da lugar a la desactivación de la GTPasa y, en consecuencia, a que cese la señalización inducida por ésta. De esta manera, el patógeno evita los daños potenciales que podría producir a su célula huésped una señalización exacerbada mediada por dicha GTPasa (Kubori and Galan, 2003; Stebbins and Galan, 2001). De forma análoga, Yersinia spp. y Pseudomonas aeruginosa también poseen proteínas que actúan como GAPs para Rac1 (YopE y ExoS, respectivamente) (Lerm et al., 2000; Stebbins and Galan, 2001).

Otras bacterias patógenas han desarrollado toxinas capaces de modificar a las GTPasas Rac mediante su unión covalente a distintos grupos, activándolas o inactivándolas de forma permanente (Lerm et al., 2000). Toxinas producidas por Clostridium spp dan lugar a la glucosilación de residuos situados en el switch I de la GTPasa Rac1 (Sehr et al., 1998). Esta modificación impide la interacción de la GTPasa con sus efectores, bloquea la actividad GTPasa tanto intrínseca como inducida por GAPs, e inhibe el intercambio de nucleótidos producido por los GEFs (Sehr et al., 1998). 
Las GTPasas de la familia Rho/Rac también son utilizadas por el virus de la inmunodeficiencia humana durante el proceso infectivo. La proteína Nef de este virus es esencial para mantener niveles altos de viremia y para la progresión de la enfermedad en la célula huésped (Deacon et al., 1995; Kirchhoff et al., 1995). Esta proteína interacciona con diversos elementos pertenecientes a la ruta de señalización de las GTPasas Rac. En primer lugar, se une y activa al factor intercambiador Vav, que a su vez induce la activación de Rac1 (Fackler et al., 2000). Por otra parte, Nef es capaz de activar a Rac1 mediante su unión al complejo intercambiador DOCK2-ELMO1 en ausencia de estimulación antigénica del TCR (Janardhan et al., 2004). Además, Nef interacciona directamente con Pak1 (Fackler et al., 2000) a través de su reclutamiento a las balsas lipídicas de la membrana plasmática (Krautkramer et al., 2004). La activación de Pak1 da lugar a cambios citoesqueléticos y al ensamblaje de la cascada de JNK, lo que incrementa tanto la producción como la infectividad del virus (Fackler et al., 2000).

\section{REGULACIÓN DE LA ACTIVIDAD DE LAS PROTEÍNAS Rac}

Con el fin de dar lugar a respuestas celulares controladas, la actividad biológica de las GTPasas de la subfamilia Rac, al igual que la mayoría de las proteínas pequeñas de unión a GTP de la superfamilia Ras, está sometida a diversos controles. Estos incluyen:

\subsection{Regulación transcripcional y/o mediante degradación diferencial}

3.2. Regulación del intercambio de nucleótidos

3.3. Regulación de la localización subcelular

A continuación resumiremos cada uno de estos pasos aunque, dado la temática de esta tesis doctoral, dedicaremos especial atención a la regulación de la localización subcelular de la GTPasa Rac1.

\subsection{Regulación transcripcional y/o mediante degradación diferencial}

Algunas GTPasas Rac están reguladas a nivel transcripcional. Por ejemplo, algunas de ellas presentan una expresión restringida a determinados tejidos, lo que indica que llevan a cabo funciones especializadas (como la generación de radicales de oxígeno mediada por Rac2 en células hematopoyéticas o la diferenciación, desarrollo y sinaptogénesis de las células de Purkinje en ratón mediada por Rac3) (Bolis et al., 2003; Roberts et al., 1999). Otro ejemplo es RhoG, cuyo ARN mensajero se acumula de forma rápida y transitoria tras la estimulación con factores de crecimiento, lo cual indica que esta GTPasa juega algún papel en proliferación celular (Vincent et al., 1992). La actividad de algunas proteínas Rac es también controlada mediante degradación. Así, la región polibásica de Rac1 posee una secuencia de localización 
nuclear que además media la degradación proteolítica de esta GTPasa (Lanning et al., 2004) y no de otros miembros de la subfamilia, como Rac2 y Rac3, que difieren en la secuencia de aminoácidos de dicha región polibásica (Pop et al., 2004). Estudios recientes apuntan que este diferente comportamiento entre Rac1, Rac2 y Rac3 en cuanto a su transporte al interior del núcleo celular reside en la capacidad de Rac1 de interaccionar con la importina conocida como carioferina alfa 2 (Sandrock et al.). Estos resultados apoyan que la GTPasa Rac1 posee funciones específicas en este compartimento celular en el control de la transcripción génica y progresión de ciclo celular (Joyce et al., 1999; Mettouchi et al., 2001).

\subsection{Regulación del intercambio de nucleótidos}

Tanto si las GTPasas de la subfamilia Rac tienen expresión constitutiva o regulada a nivel transcripcional o posttranscripcional, todas ellas tienen como punto de regulación común y principal la transición entre las formas unidas a GDP y las formas unidas a GTP. Este paso está controlado bidireccionalmente a través del uso de dos tipos de proteínas reguladoras: los GEFs (del inglés, Guanine nucleotide exchange factors) y GAPs (del inglés, GTPase activating proteins) (Figura 5, pág. siguiente). Los GEFs estimulan la débil actividad intercambiadora intrínseca de las GTPasas para promover el intercambio de GDP por GTP, dando lugar a la activación de estas proteínas. El mecanismo por el cual actúan los GEFs es doble: por un lado, se unen a la forma inactiva de la GTPasa, desestabilizando su interacción con el GDP y provocando su salida del complejo. La GTPasa se encuentra ahora en un estado de transición libre de nucleótidos que es estabilizado por la presencia del GEF. Puesto que el GTP es mucho más abundante en el citoplasma que el GDP, su entrada en el complejo está muy favorecida. La incorporación de GTP provoca la disociación del GEF de la GTPasa, pemitiendo su activación (Cherfils and Chardin, 1999; Schmidt and Hall, 2002).

El primer GEF aislado fue Dbl (Eva and Aaronson, 1985), que contiene un dominio necesario para la actividad intercambiadora de nucleótidos denominado dominio $\mathrm{DH}$ o de homología con $\mathrm{Dbl}$ (del inglés, $\mathrm{Dbl}$ homology). Este dominio contiene alrededor de 200 aminoácidos y está presente en todos los miembros de la familia de GEFs de tipo Dbl. El dominio DH posee actividad catalítica e interacciona físicamente con la GTPasa, de forma que la introducción de mutaciones en residuos altamente conservados inhibe la actividad intercambiadora (Aghazadeh et al., 1998; Rossman et al., 2005). Además, los GEFs de este tipo contienen en posición inmediatamente distal al dominio $\mathrm{DH}$ un dominio $\mathrm{PH}$ o de homología con pleckstrina (del inglés, Pleckstrin homology). Estos dos dominios aparecen juntos en la gran mayoría de factores de intercambio de la familia Dbl (Rossman et al., 2005). Aunque tradicionalmente la función de los dominios PH se asocia a la unión a fosfolípidos (Lemmon et al., 1996), el dominio $\mathrm{PH}$ del tándem $\mathrm{DH}-\mathrm{PH}$, habitualmente encontrado entre los diferentes Rac-GEFs, no posee la secuencia consenso para la unión específica a fosfoinosítidos. Funcionalmente, este tipo de dominios $\mathrm{PH}$ difiere de aquellos que sí unen fosfoinosítidos, como 
es el caso del dominio PH de Akt y Dapp1, en un aspecto importante: la unión de fosfoinosítiodos al dominio PH del tándem DH-PH no es suficiente para localizar a estos RacGEFs en la membrana plasmática.

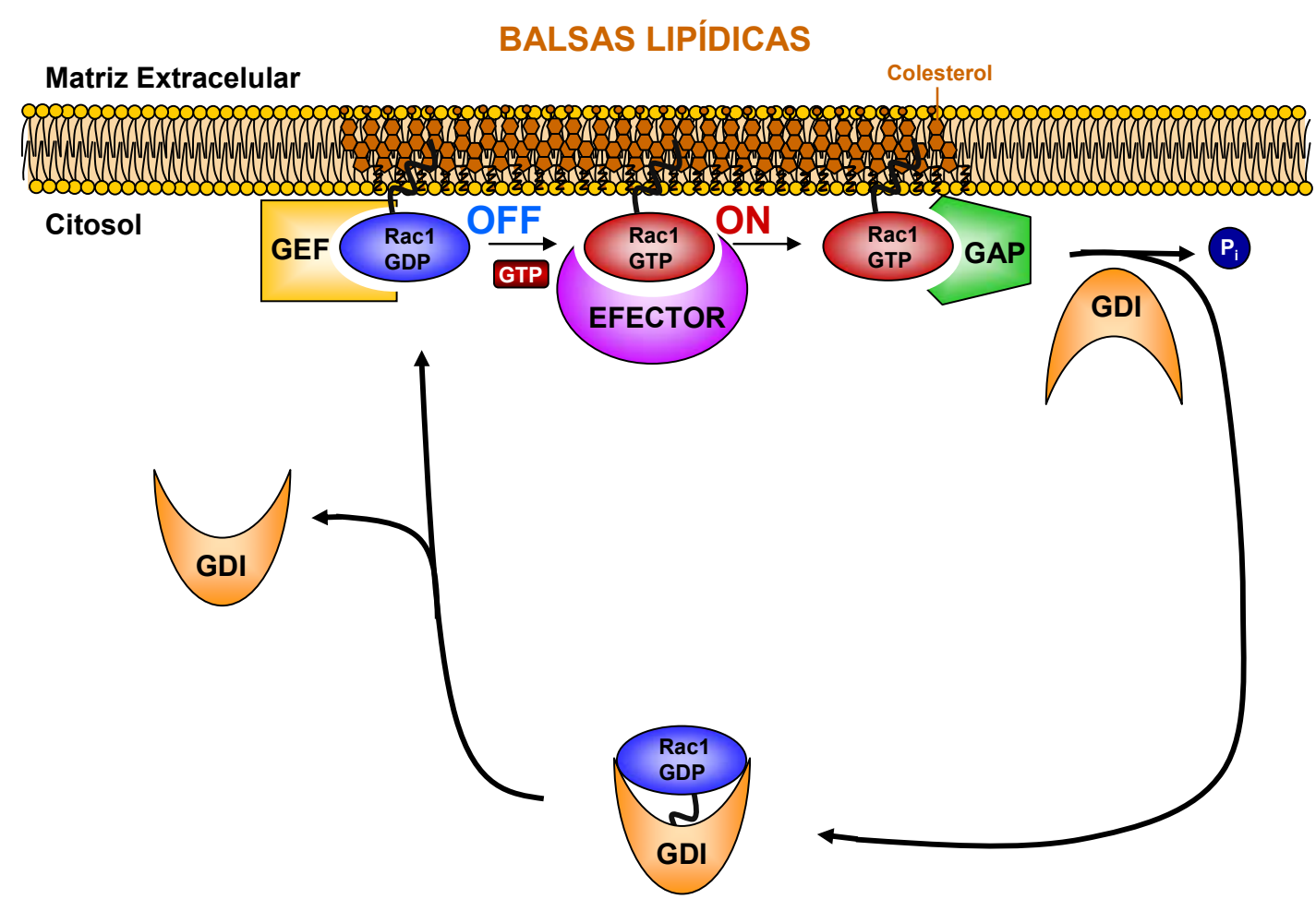

Figura 5. Mecanismo de activación/desactivación de las GTPasas Rho/Rac. Las proteínas Rho/Rac se comportan como interruptores moleculares, ciclando continuamente entre un estado inactivo (unidas a GDP) y un estado activo (unidas a GTP). La regulación de este proceso se lleva a cabo por medio de proteínas activadoras (GEFs) e inhibidoras (GAPs). Además, esta familia de GTPasas posee un mecanismo específico de regulación a nivel de localización subcelular, función que es llevada a cabo por las proteínas denominadas RhoGDls.

De este modo, mientas que la localización en membrana de los GEFs es un prerrequisito generalmente aceptado para la activación de Rac1, ésta se consigue a través de otros dominios diferentes al dominio $\mathrm{PH}$ del tándem $\mathrm{DH}-\mathrm{PH}$, aunque quizás pueda cooperar con otros mecanismos de anclaje a la membrana. En los casos de Sos1 y Vav1, se cree que la unión del dominio $\mathrm{PH}$ a fosfatidilinositol-3,4,5-trifosfato $\left(\mathrm{PIP}_{3}\right)$ libera una inhibición intramolecular que permite la correcta activación del GEF (Das et al., 2000; Nimnual et al., 1998). Sin embargo, las funciones específicas del dominio PH en los diferentes Rac-GEFs claramente necesitan ser estudiadas a fondo. Además del módulo $\mathrm{DH}-\mathrm{PH}$, la mayoría de los GEFs de este tipo contienen otros dominios (SH2, SH3, RasGEF, DEP, PDZ o dominios PH adicionales) implicados en la interacción con receptores o con proteínas de señalización, o bien en funciones adicionales de los GEFs (Figura 6, pág. siguiente). Actualmente se han identificado más de una docena de Rac-GEFs, algunos de los cuales son específicos para la Rac1 (como es el caso de Tiam1) mientras que otros poseen una actividad intercambiadora un tanto más promiscua (como es el caso de Vav que puede regular la actividad de otras GTPasas 
como RhoA). Entre ellos, algunos miembros de las familias Sos, Tiam, ArhGEF6 o aPIX (del inglés Pak1-interacting exchange factor alpha), SWAP-70 y P-Rex son regulados por la actividad de $\mathrm{PI} 3 \mathrm{~K}$ in vivo. Estudios in vitro han demostrado que el producto de esta enzima, $\mathrm{PIP}_{3}$, activa de una manera directa y fuerte la actividad Rac-GEF de P-Rex1 y SWAP-70 (Shinohara et al., 2002; Welch et al., 2002), algo más débilmente la actividad de Sos1 y posiblemente Tiam1 (aunque este último es controvertido) (Das et al., 2000; Fleming et al., 2000; Innocenti et al., 2003), pero probablemente no la de aPIX (Yoshii et al., 1999).

A diferencia de otros GEFs, donde la interacción GEF-GTPasa es transitoria y mediada únicamente por el dominio DH del factor estimulador de intercambio (Vetter and Wittinghofer, 2001), cabe destacar que algunas de estas proteínas GEF además pueden funcionar como proteínas adaptadoras para la correcta translocación y anclaje a la membrana de Rac1 (ten Klooster et al., 2006b). Tal es el caso de AhrGEF7, también conocido como $\beta$ PIX (del inglés, Pak1-interacting exchange factor beta), un GEF específico para Rac1 y Cdc42 que puede interaccionar físicamente y de forma estable con Rac1 a través de diferentes dominios. Así se ha descrito en este caso particular que la interacción GEF-GTPasa, además de a través del dominio DH del propio GEF (Shin et al., 2004), también puede interaccionar con otros dominios estructurales y/o funcionales como su dominio $\mathrm{SH} 3$ a través del cual puede interaccionar con la región rica en prolinas del extremo carboxilo terminal de Rac1 (ten Klooster et al., 2006b). Esta interacción física sería la responsable de la correcta translocación de Rac1 a la membrana plasmática a través de un nuevo mecanismo de interacción proteína-proteína. Además, también se ha demostrado que la interacción física entre Rac1 y ArhGEF7 puede producirse mediante su dominio GBD o dominio de unión a GIT (del inglés, GIT1 binding domain) (Bagrodia et al., 1999), a través del cual ArhGEF7 interacciona tanto con Rac1 como con SmgGDS (Shin et al., 2006), otro GEF con múltiples sustratos, entre ellos Rac1 (Mizuno et al., 1991). La formación del GEF bipartito constituido por ArhGEF7 y SmgGDS podría explicar la activación de Rac1 sostenida en el tiempo que es necesaria para desencadenar procesos de morfogénesis como el crecimiento de neuritas en células PC12 (Shin et al., 2006). Existen además diversos estudios que relacionan a ArhGEF7 con la estimulación de procesos dependientes de Rac1. Así, la expresión ectópica de ArhGEF7 en fibroblastos 3T3 murinos induce la formación de lamelipodios de actina y la activación de la ruta de p38 ${ }^{\mathrm{MAPK}}$ (Koh et al., 2001; Lee et al., 2001). Por el contrario, mutaciones que inactivan al dominio DH de ArhGEF7 bloquean la formación de lamelipodios en mioblastos de ratón (Matsuda et al., 2008). Además, algunos estudios apuntan a que la actividad de ArhGEF7 para estimular la activación de Rac1 depende también de su capacidad de oligomerización y correcta localización en regiones yuxtamembranarias (Chahdi and Sorokin, 2008; Koh et al., 2001). No obstante, sigue sin determinarse con precisión si el dominio DH de ArhGEF7 posee actividad catalítica hacia Rac1 de un modo directo o si los efectos que ArhGEF7 tiene sobre la actividad de Rac1 se deben a otros intermediarios que interaccionen con su dominio $\mathrm{DH}$. 


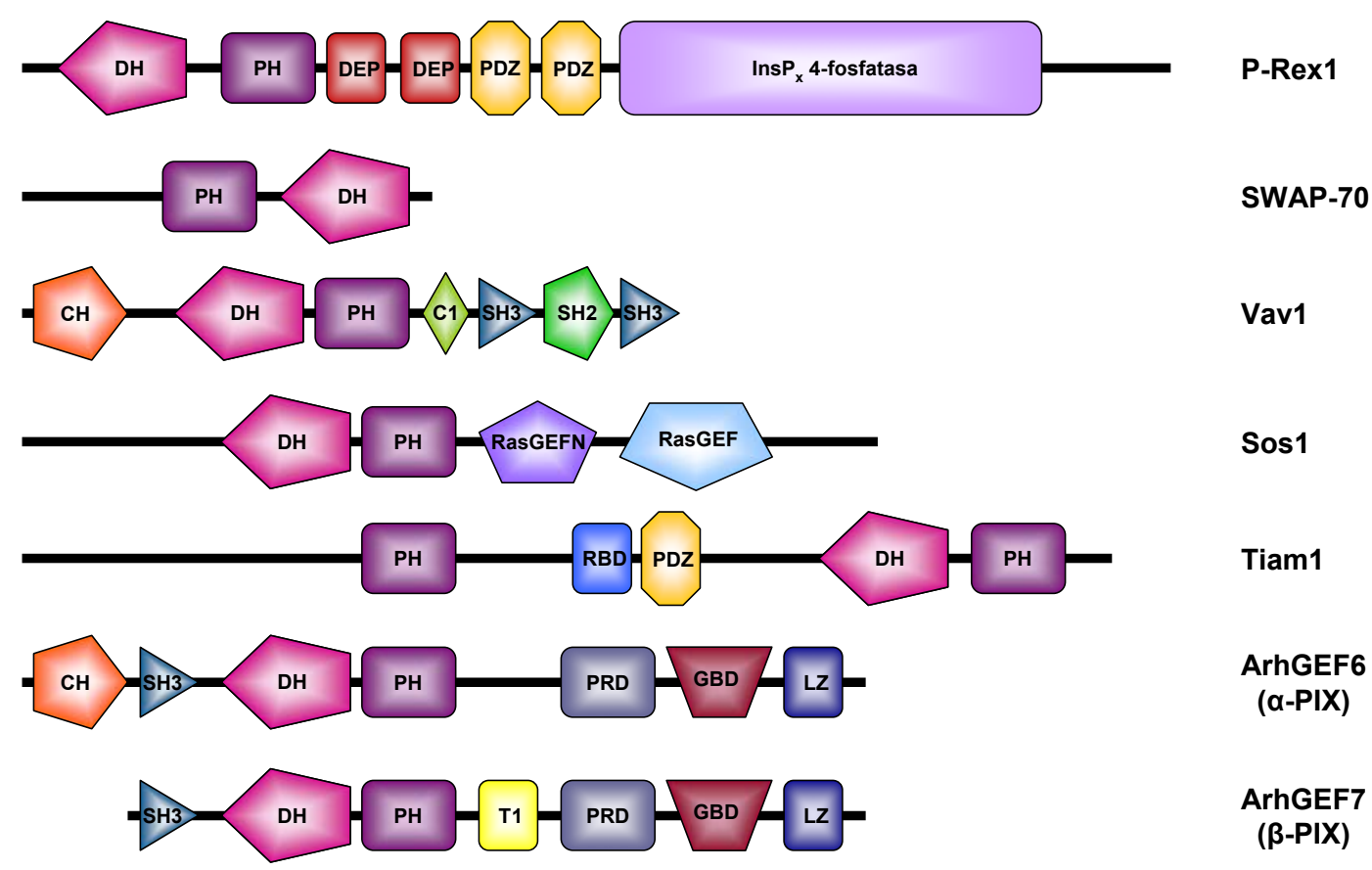

Figura 6. Estructura por dominios de las principales familias de proteínas GEF para Rac1. La predicción de los dominios fue realizada usando la base de datos SMART (htttp://smart.emblheidelberg.de).El dominio de homología a inositol fosfato 4-fosfatasa de P-Rex1 y el dominio $\mathrm{DH}$ de SWAP-70 fueron añadidos manualmente, ya que sus homologías son muy débiles para ser reconocidas por SMART. Las abreviaturas utilizadas son: $\mathbf{C H}$, dominio de homología a calponina; DH, dominio de homología a Dbl; PH, dominio de homología con pleckstrina; DEP, dominio de homología a Discheveled/EGL-10/pleckstrina; PDZ, dominio de interacción con proteínas homólogo a PSD95/DlgA/ZZO1; InsPx 4-fosfatasa, dominio de homología a inositol 4-fosfatasa; $\mathbf{C H}$, dominio de homología a calponina; C1, dominio rico en cisteínas; SH3, dominio de homología a Src tipo 3; SH2, dominio de homología a Src tipo 2; RBD, dominio de unión a Ras; RasGEF, dominio con actividad GEF para Ras; RasGEFN, región aminoterminal del dominio con actividad GEF para Ras; PRD, dominio rico en prolinas; GBD, dominio de unión a GIT; LZ, dominio de cremallera de leucinas; T1, dominio de 18 aminoácidos esencial para la regulación de Pak1 por ArhGEF7 in vivo. Figura adaptada de Welch et al., 2003.

Por otro lado, las proteínas GAP estimulan la actividad GTPasa intrínseca de las proteínas Rac (que es muy baja de por sí), facilitando su vuelta al estado inactivo. Como ocurre en el caso de los GEFs, la especificidad de sustrato de las GAPs varía ampliamente, de forma que algunas de ellos regulan a un único tipo de GTPasa. Tal es el caso de las quimerinas que regulan exclusivamente la actividad de Rac1. Lógicamente, la actividad de las proteínas GAPs, al igual que la de los GEFs, debe estar estrechamente regulada de forma temporal y espacial para impedir que la GTPasa se encuentre permanentemente en su forma inactiva. El tipo de regulación es específico para cada GAP. Por ejemplo, la familia de las quimerinas contiene un dominio rico en cisteínas que actúa como un sitio de unión para diacilglicerol/ésteres de forbol (Caloca et al., 1997; Caloca et al., 1999; Caloca et al., 2001) y que, además de alterar la actividad catalítica del dominio GAP, provoca la translocación de las quimerinas desde el citosol hasta la región perinuclear y Golgi (Caloca et al., 1999; Caloca et al., 2001). Además del 
dominio GAP, estas proteínas contienen otros módulos funcionales, como dominios catalíticos adicionales (RhoGEF y ArfGAP), regiones de interacción con lípidos (dominios $\mathrm{PH}$ ) o proteínas (SH2, SH3). Estos dominios, aparte de modular la actividad GAP, implican a esta familia de proteínas en otro tipo de funciones (GEFs para proteínas Rho/Rac, GAPs para la familia de GTPasas Arf, etc.) (Moon and Zheng, 2003).

La importancia de la regulación del ciclo de activación/desactivación de las GTPasas Rac por medio de GEFs y GAPs se ha puesto de manifiesto por el descubrimiento de mutaciones puntuales que generan formas constitutivamente activas 0 inactivas de estas proteínas. Aunque las mutaciones reseñadas a continuación se refieren a la numeración de la secuencia de Rac1, estos residuos se encuentran altamente conservados entre todas las GTPasas Rho de mamíferos. La sustitución de la Gly12 por Val o de la Gln61 por Leu da lugar a una forma constitutivamente activada de la GTPasa (Paterson et al., 1990; Ridley and Hall, 1992; Ridley et al., 1992), ya que ambas mutaciones bloquean la capacidad de hidrolizar el GTP, tanto intrínseca como inducida por GAPs (Diekmann et al., 1995; Garrett et al., 1989). La sustitución de la Phe28 por Leu da lugar a proteínas denominadas "de ciclaje rápido", ya que incrementa considerablemente la tasa de intercambio de nucleótidos con respecto a las correspondientes formas salvajes sin afectar a la capacidad GTP-hidrolasa. El hecho de que en el citosol celular la relación GTP/GDP sea muy elevada permite que estos mutantes se unan espontáneamente a GTP y, al mantener intacta la actividad GTPasa, ciclen rápidamente entre los dos estados de activación, comportándose como proteínas constitutivamente activas (Lin et al., 1997). La sustitución de la Thr17 por Asn da lugar a un incremento de la afinidad de la GTPasa por GDP, generando una forma inactiva incapaz de interaccionar con efectores. Además esta mutación ocasiona que la proteína se comporte como un dominante negativo, puesto que bloquea la activación de las GTPasas endógenas al competir con ellas por los GEFs, a los que "secuestra" formando complejos inactivos (Feig, 1999; Ridley et al., 1992). Recientemente se ha descrito que la sustitución del residuo Asp57 por Asn en Rac2 es equivalente a la mutación Thr17Asn (Williams et al., 2000). El fenotipo dominante negativo generado por ambas mutaciones puede atribuirse a que tanto el residuo 17 como el 57 se encuentran coordinados con el ión $\mathrm{Mg}^{2+}$, un cofactor que regula la cinética de intercambio de nucleótidos en las GTPasas Rac (Zhang et al., 2000).

\subsection{Regulación de la localización subcelular}

La correcta localización subcelular es esencial para la conexión de las formas activadas de las GTPasas Rac con sus efectores $y$, en algunos casos, para la especificidad funcional de cada uno de los miembros de la subfamilia Rac. Dada la importancia de este proceso, éste se encuentra regulado a través de varios pasos que no son necesariamente excluyentes entre sí. Resumimos a continuación los principales. 


\subsubsection{Modificaciones posttraduccionales y secuencia aminoacídica del extremo} C-terminal de las GTPasas Rac

Las GTPasas Rac sufren, al igual que el resto de proteínas de superfamilia Ras, modificaciones posttraduccionales que son esenciales para su anclaje a membranas (Bustelo et al., 2007). Estas modificaciones consisten en la adición de lípidos isoprenoides a una secuencia denominada "caja CAAX", que se encuentra situada en el extremo C-terminal de estas GTPasas. En la secuencia CAAX, "C" representa un residuo de Cys, "A" se refiere a cualquier aminoácido alifático y "X" corresponde a Met, Ser, Ala o Gln. La modificación lipídica consiste en primer lugar en la adición al residuo Cys de un grupo geranil-geranilo (que contiene 20 átomos de carbono y es altamente hidrofóbico, dando lugar a una asociación de gran afinidad con membranas). Tras la adición del grupo isoprenoide se produce el procesamiento proteolítico de los residuos -AAX y la carboximetilación de la cisteína situada ahora en posición C-terminal. Sin embargo, la isoprenilación per se no es suficiente para originar la inserción de Rac1 en membranas, sino que se requiere una segunda señal. En el caso de las proteínas Rac existen secuencias polibásicas ricas en lisina $\mathbf{y}$ arginina adyacentes a la caja CAAX (Wennerberg and Der, 2004). Diferencias en la región contigua a la caja CAAX entre GTPasas altamente homólogas pueden determinar el comportamiento de estas proteínas in vivo. Así, Rac1 y Rac2, que difieren en la presencia de una secuencia polibásica situada inmediatamente antes de la caja CAAX, presentan localizaciones subcelulares diferentes (Rac1 en la membrana plasmática y Rac2 en endosomas) y cada una de ellas ejerce funciones específicas en neutrófilos in vivo (Filippi et al., 2004). Además la presencia de esta región polibásica puede mediar la asociación de estas GTPasas con determinados lípidos que forman parte de la membrana plasmática (Heo et al., 2006; Yeung et al., 2008). De este modo, la secuencia rica en lisinas (con una elevada carga electrostática positiva) favorece la unión de Rac1 a fosfolípidos cargados negativamente en la membrana plasmática como por ejemplo, fosfatidilinositol-3-fosfato (PI-3-P) fosfatidilinositol-4-fosfato (PI-4-P), fosfatidilinositol-5-fosfato (PI-5-P), fosfatidilinositol-3,4,5-trifosfato (PIP 3 ), y ácido fosfatídico (PA) (Ueyama et al., 2005).

\subsubsection{Regulación de la translocación citosol-membrana por moléculas secuestradoras}

Otro mecanismo de regulación de la localización subcelular, que además es específico para la mayoría de los miembros de la familia Rho/Rac, es la interacción con proteínas inhibitorias denominadas RhoGDIs (del inglés Rho GDP dissociation inhibitors). Estas proteínas ejercen su función inhibidora a dos niveles: por un lado, la interacción del GDI con las GTPasas se produce a través de la región efectora, impidiendo la unión tanto de GEFs y GAPs como de efectores, lo cual mantiene a estas proteínas en su estado inactivo (Del Pozo et al., 2002; Hoffman et al., 2000; Scheffzek et al., 2000). La interacción GDI-GTPasa está mediada por puentes de hidrógeno que se establecen entre determinados residuos clave tanto en la 
estructura de RhoGDI como en la de Rac1. Así, estudios estructurales implican a los aminoácidos Thr35, Tyr64, Arg66, His103 e His104 de Rac1 en la formación de esos puentes de hidrógeno con las moléculas GDIs. La interacción entre Thr35 de Rac1 y Asp45 de RhoGDI es particularmente importante para la inhibición del intercambio GDP/GTP ya que este residuo Thr35 coordina el ión $\mathrm{Mg}^{2+}$, que es un cofactor necesario para la estimulación de la actividad de esta GTPasa. Cabe destacar que la fuerte interacción que se produce entre Rac1 y RhoGDI se produce principalmente mediante puentes de hidrógeno entre la Arg66 de Rac1 con los grupos carbonilo de Pro30 y Ala31 y los átomos de oxígeno de Glu121 and Asp185 del RhoGDI (Grizot et al., 2001). Por otra parte, los GDls extraen a las GTPasas inactivas de las membranas a través de la unión al extremo C-terminal isoprenilado, manteniendo esta región hidrofóbica protegida del solvente acuoso que constituye el citosol celular (Olofsson, 1999). Así, los complejos RhoGDI-GTPasa constituyen una reserva citosólica de proteínas Rho inactivas. La disociación del GDI es un requisito necesario para que se produzca la asociación con membranas y la activación de las GTPasas por los GEFs (Olofsson, 1999).

En contraste con el elevado número de GEFs y GAPs, solamente se han descrito tres RhoGDIs: RhoGDI-1 ( $\alpha$ ), RhoGDI-2 (D4/LyGDI/ $\beta$ ) y RhoGDI-3 ( $($ ) (Olofsson, 1999). Cada uno de ellos es específico en cuanto a distribución y especificidad por el sustrato: RhoGDI-1 se expresa ubícuamente y forma complejos citosólicos de estequiometría 1:1 con Rac1 y Rac2, así como con RhoA, RhoB y Cdc42 in vivo. RhoGDI-2 se expresa específicamente en células hematopoyéticas, principalmente en linfocitos $B$ y $T$. Las proteínas Rho/Rac reguladas por este GDI in vivo aún son desconocidas. RhoGDI-3 se expresa preferentemente en cerebro, aunque también se encuentra en riñón, pulmón y testículos. Aunque interacciona con RhoB y RhoG in vitro, in vivo sólo se une a RhoG (Brunet et al., 2002). Su característica más llamativa es que se encuentra asociado al aparato de Golgi (Brunet et al., 2002), mientras que RhoGDI-1 y RhoGDI-2 son citosólicos (Olofsson, 1999; Zalcman et al., 1996).

La existencia de estos complejos Rac/RhoGDI crea nuevas necesidades reguladoras, puesto que es necesario acoplar la disociación de este complejo con procesos de estimulación celular y activación de los GEFs para asegurar una cinética de activación de las GTPasas Rac1 óptima durante procesos de señalización. Aunque no se tiene todavía una visión completa de cómo se produce este paso regulador, durante los últimos años se han descubierto varios mecanismos que pueden facilitar este proceso. Gracias a estos estudios, ahora sabemos que la estabilidad de la interacción Rac1/RhoGDI está regulada negativamente a través de múltiples señales.

En primer lugar, la translocación de los complejos Rac1/RhoGDI a la membrana plasmática está favorecida por la atracción electrostática entre dichos complejos y la cara interna de la bicapa lipídica. Gracias a los datos estructurales sobre los complejos 
Rac1/RhoGDI, se ha demostrado que el extremo carboxiterminal de la GTPasa, el cual está cargado positivamente, y el extremo aminoterminal de RhoGDI, que está cargado negativamente, están bastante próximos en el complejo (Grizot et al., 2001; Scheffzek et al., 2000). De este modo, la competición entre las cargas negativas de determinados lípidos de la cara interna de la membrana plasmática y el extremo aminoterminal de RhoGDI puede ayudar a la liberación de la GTPasa de su secuestrador (Chuang et al., 1993; Faure et al., 1999; Kreck et al., 1994; Ugolev et al., 2008; Ugolev et al., 2006). De hecho, algunas enzimas relacionadas con el metabolismo de fosfolípidos como $\mathrm{PIP}_{2} \mathrm{O}$ ácido fosfatídico pueden cooperar en el mecanismo de disociación de Rac1 desde los complejos Rac1/RhoGDI y su posterior translocación y/o activación en la membrana (Abramovici et al., 2009; Chae et al., 2008; Tolias et al., 1998). Además, las proteínas RhoGDls poseen cargas positivas en el extremo de su dominio carboxiterminal, lo cual podría definir la correcta orientación del complejo Rac1/RhoGDI hacia la membrana (Figura 7, pág. siguiente).

Otro mecanismo que provoca la desestabilización de los complejos GTPasa/RhoGDI está basado en la inactivación de RhoGDI mediante procesos de fosforilación. De hecho, la activación de RhoA dependiente de PKCa en células endoteliales coincide con la fosforilación de RhoGDI, mientras que ensayos quinasa in vitro han demostrado que RhoGDI puede ser un sustrato para esta proteína quinasa (Mehta et al., 2001). Asimismo, la activación de Rac1 y la posterior formación de lamelipodios parece provocar la fosforilación de RhoGDI por PKC de una forma dependiente de calcio (Price et al., 2003). Es por tanto probable que PKCa fosforile a RhoGDI, induciendo un mecanismo de disociación de la GTPasa que conduciría a la activación de la misma a través de un mecanismo aún desconocido. Un ejemplo parecido es el caso de la proteína quinasa Src que fosforila a RhoGDI en la Tyr156, lo cual se traduce en un descenso dramático de la afinidad de esta proteína secuestradora por Rac1, RhoA y Cdc42 (DerMardirossian et al., 2006). La expresión ectópica de un mutante fosfomimético de RhoGDI en esta tirosina (RhoGDI ${ }^{\mathrm{Y} 156 \mathrm{E}}$ ) provoca además la aparición de ondulaciones en la membrana tipo membrane ruffles y la localización de Rac1 endógeno en estas estructuras ricas en Factina. Estos estudios apuntan a que la fosforilación de la Tyr156 de RhoGDI serviría para:

1. Prevenir la interacción y re-unión de las GTPasas asociadas a la membrana con RhoGDI, por tanto prolongando el período de activación de la GTPasa

2. Interrumpir el estado permanente de la función recicladora de RhoGDI, y por tanto "retrasando" la localización transitoria de RhoGDI en la membrana y revelando que estos pasos transitorios son los factores limitantes en este proceso 


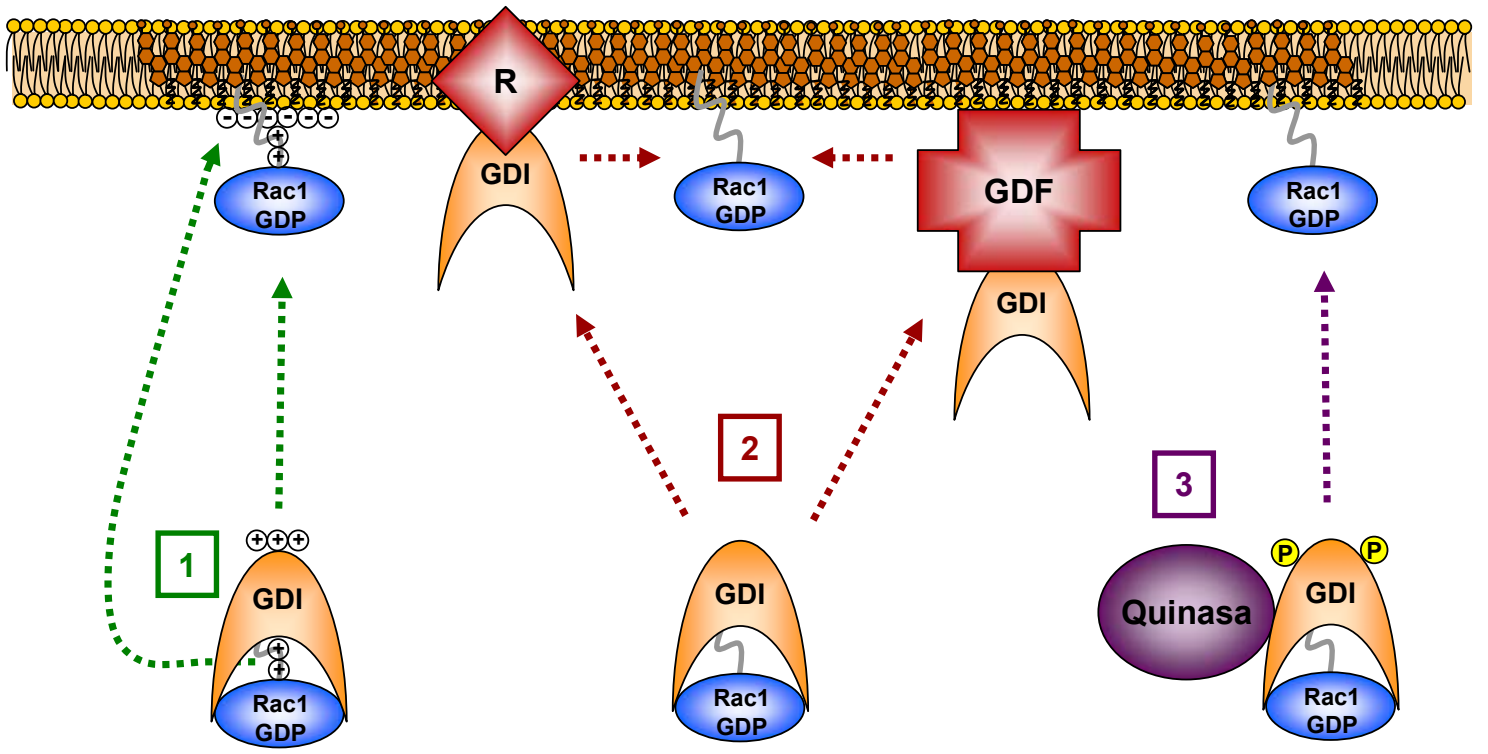

Figura 7. Modelo para la liberación de proteínas Rho/Rac a la membrana plasmática desde los complejos citosólicos RhoGDI-GTPasa. En este proceso hay múltiples mecanismos involucrados: (1) atracción electrostática entre la región polibásica de Rac1 o el extremo carboxiloterminal de RhoGDI y la cara interna de la membrana plasmática; (2) reclutamiento de los complejos RhoGDI/GTPasa a nivel local regulado por determinados receptores de la membrana plasmática $(\mathbf{R})$ o factores de desplazamiento (GDFs) y (3) desestabilización de los complejos RhoGDI/GTPasa a través de la fosforilación de RhoGDI por determinadas quinasas. La modularidad de RhoGDI puede permitir el reclutamiento del extremo carboxiterminal prenilado de Rac1 en la membrana plasmática antes de la disociación completa del complejo Rac1/RhoGDI. Adaptado de Dransart et al., 2005.

RhoGDI puede ser también fosforilado, tanto in vitro como in vivo, en dos residuos, Ser101 y Ser174, por la proteína quinasa Pak1 (DerMardirossian et al., 2004), lo que conduce a la disociación de los complejos RhoGDI con Rac1, pero no con RhoA o Cdc42. Estudios cristalográficos han mostrado que estos dos residuos de serina están posicionados próximos entre sí y con el grupo prenilo de la GTPasa (Grizot et al., 2001; Scheffzek et al., 2000). Las fuerzas repulsivas entre los grupos fosfato cargados negativamente pueden inducir cambios conformacionales en el bolsillo hidrofóbico de RhoGDI que secuestra al grupo prenilo, lo cual en combinación con las diferencias en el extremo carboxiterminal de las GTPasas confiere selectividad para la liberación de Rac1 pero no de RhoA o Cdc42.

En último lugar, y por analogía a los hallazgos con la GTPasa RhoA, la disociación de los complejos RhoGDI/GTPasa puede deberse también a interacciones de estos RhoGDls con proteínas residentes en la membrana o regiones próximas a la misma. Este grupo de proteínas ha sido definido como factores de desplazamiento del RhoGDI o GDFs (del inglés, GDIs displacement factors) (Figura 7). Varias proteínas de unión a RhoGDI han comenzado a ser caracterizadas como potenciales GDFs basándose en su habilidad, tras la sobreexpresión, para disminuir la cantidad de los complejos solubles GTPasa/RhoGDI e incrementar la cantidad 
de GTPasas en su conformación activa unidas a GTP. La primera familia de proteínas a la que se le atribuye actividad GDF ha sido la familia de proteínas ezrina/radixina/moesina (ERM). Estas proteínas están involucradas en procesos de reorganización subcortical de actina de una forma dependiente de las GTPasas Rho/Rac (Bretscher et al., 2002; Ivetic and Ridley, 2004). El dominio aminoterminal de radixina, que mimetiza su estado conformacional activo, interacciona con RhoGDI tanto in vitro como in vivo, lo que conduce a la activación de algunas proteínas Rho in vitro y a la disociación del complejo RhoA/RhoGDI y la posterior activación de RhoA in vivo (Takahashi et al., 1998). Se han descrito interacciones adicionales in vivo entre RhoGDI y otros miembros de la familia ERM como ocurre con el complejo CD44-moesina (Hirao et al., 1996) y CD43-ezrina (Allenspach et al., 2001) en la membrana de células T, que podrían llevar a cabo diferentes y complejas funciones. En los complejos CD44-moesina, la proteína ERM localiza y activa a la GTPasa RhoA en sitios específicos a través de la interacción con RhoGDI (Hirao et al., 1996). Por el contrario, el complejo CD43-ezrina puede excluir a RhoGDI de la sinapsis inmunológica y por tanto evitar la extracción de la GTPasa (probablemente Cdc42) de su sitio específico de acción una vez que ha sido liberada (Allenspach et al., 2001). La interacción entre las proteínas ERM y RhoGDI puede además ser regulada mediante procesos de fosforilación. Así, recientemente se ha demostrado que la fosforilación de ezrina por la proteína quinasa Cdk5 (del inglés, Cyclin-dependent kinase 5) provoca la liberación del complejo ezrina/RhoGDI que resulta en la inhibición de la activación de Rac1 en células senescentes (Yang and Hinds, 2006). Merlin, producto del gen supresor de tumores neurofibromatosis 2, es una proteína relacionada con el grupo de ERM por poseer dominios estructurales homólogos a ellas. Al igual que ERM, Merlin también puede unir a RhoGDI aunque si dicha interacción contribuye o no a la activación de alguna GTPasa aún no ha sido determinado (Maeda et al., 1999). Otro candidato con función GDF conocida es el receptor de neurotrofinas p75 en células neuronales. Este receptor transmembrana funciona tanto en la estimulación como en la inhibición del crecimiento de neuritas, dependiendo de si los ligandos de unión son neurotrofinas o proteínas derivadas de la mielina como MAG o NOGO. Estos procesos implican la inhibición y activación de RhoA respectivamente. El receptor p75 interacciona directamente con RhoGDI in vivo tras su activación con MAG o NOGO, y su sobreexpresión estimula la liberación de RhoA desde RhoGDI (Yamashita and Tohyama, 2003).

Sin embargo, el tráfico de la GTPasa Rac1 entre diferentes compartimentos subcelulares también puede ser llevado a cabo por mecanismos alternativos. Así, se ha demostrado la existencia de ciertas proteínas con función transportadora de Rac1 como es el caso de la proteína inactivadora de Ras dependiente de $\mathrm{Ca}^{2+}$. Esta proteína, además de su función GAP sobre miembros de la familia Ras, puede unirse en el citosol a Rac1 y mediar su transporte a la membrana de células fagocíticas participando en el ciclo de translocación/activación de esta GTPasa (Zhang et al., 2005). Por otro lado, la translocación de 
Rac1 a la membrana plasmática ha sido relacionada con procesos endocíticos. Este modelo sugiere que Rac1 se encuentra unido a la membrana de endosomas en células en reposo y que tras la estimulación del receptor se produciría la activación de Rac1, llevada a cabo por el GEF Tiam1, en estas estructuras endomembranosas. La estimulación de esta ruta endocítica dependiente de Rab5/clatrina desencadenaría al mismo tiempo el movimiento de estos endosomas desde el citosol hasta la membrana plasmática permitiendo a la GTPasa activa ponerse en contacto con la maquinaria de polimerización de actina en regiones de la membrana específicas (Palamidessi et al., 2008)

Un último nivel regulador de la estabilidad de Rac1 a la membrana plasmática se basa en la "receptividad" de la membrana plasmática para el anclaje y estabilización de la población de Rac1 unida a la membrana. Este proceso está controlado por diferentes mecanismos como por ejemplo la interacción de subespecies de lípidos específicos con el extremo carboxiloterminal de Rac1, cuya atracción electrostática, como hemos visto anteriormente, favorecería la asociación de la GTPasa con las membranas celulares (Heo et al., 2006; Yeung et al., 2008). Además, también parece ser importante en este contexto la presencia y estabilización de las balsas lipídicas en la superficie celular, fenómeno controlado por el estado de activación de integrinas. Las integrinas incrementan la afinidad de las balsas lipídicas por Rac1, lo que favorece el desplazamiento del motivo geranil-geranilo de la GTPasa desde el bolsillo hidrofóbico del RhoGDI hacia los fosfolípidos hidrofóbicos de la membrana. Tras la pérdida de adhesión al sustrato, en células adherentes, las integrinas también regulan la internalización de las balsas lipídicas, y por tanto la inactivación y localización en la membrana de Rac1, mediada por caveolina-1 y el citoesqueleto de microtúbulos (Balasubramanian et al., 2007; del Pozo et al., 2004; del Pozo et al., 2005). Estudios recientes, señalan que el reciclaje de estas balsas lipídicas internalizadas desde la membrana plasmática es importante en la correcta translocación/activación de Rac1 en la membrana para llevar a cabo procesos de extensión celular y migración dependientes de Rac1. Este reciclaje de las balsas lipídicas hasta la superficie celular es llevado a cabo por Arf6 en cooperación con el citoesqueleto de microtúbulos (Balasubramanian et al., 2007). Aparte, como se mencionó anteriormente, algunos trabajos han señalado que la correcta translocación y ensamblaje de Rac1 en la membrana plasmática requiere asimismo de la interacción física directa con otras proteínas, con una función adaptadora en este proceso, como ArhGEF7 (ten Klooster et al., 2006b).

A pesar de todos los conocimientos aportados por estos estudios, permanece aún sin esclarecer el mecanismo por el cual todos estos niveles reguladores se coordinan para asegurar la activación de las rutas dependientes de Rac1 de una manera eficiente y fisiológicamente coherente. Además, aunque la compleja red de señalización que controla la translocación y activación de Rac1 sugiere que las células probablemente utilizan varias 
oleadas de translocación y activación de Rac1 para ensamblar las respuestas biológicas de una manera óptima, aún no conocemos cómo este proceso se coordina in vivo. Finalmente, no sabemos si todos estos procesos reguladores son generales para todos los tipos celulares o si podrían mostrar algún tipo de especificidad celular. 


\section{OBJETIVOS}



1. Rastreo celómico de una genoteca de expresión de cDNA usando una línea celular reportera que expresa establemente la proteína de fusión EGFP-Rac1 (HEK293T EGFP-Rac1) con el fin de identificar moléculas translocadoras de Rac1 a la membrana plasmática

2. Caracterización del mecanismo de translocación de Rac1 inducido por los clones aislados durante el rastreo celómico 




\section{PLÁSMIDOS}

Los plásmidos que codifican para la versión silvestre de Coronina-1A fusionada a EGFP (pCoronin1 $\mathrm{A}^{\mathrm{WT}}$-EGFP) y a RFP (pCoronin1 $\mathrm{A}^{\mathrm{WT}}$-mRFP) fueron donados por el Dr. W. S. Trimble (Hospital for Sick Children, Toronto, Canadá). Las formas silvestres de las GTPasas Rac1, RhoA, Cdc42 y el mutante de deleción amino terminal de RhoGDI ( $\Delta 1-60$ RhoGDI) subclonados en el vector de expresión pCEFL-AU5 y la forma silvestre de RhoGDI clonado en pEF1-Myc fueron un obsequio del Dr. P. Crespo (Departamento de Biología Molecular, Unidad de Biomedicina de la Universidad de Cantabria-CSIC, Santander). Los vectores de expresión que codifican para la versión silvestre de RhoG (pAM3) (Prieto-Sanchez et al., 2006) y para la versión silvestre de Rac1 fusionada a EGFP (pNM32) (Caloca et al., 2004) han sido previamente descritos. El plásmido codificante para la versión etiquetada con Myc de IRSp53 fue obtenido del Dr. R. Buchsbaum (New England Medical Center, Boston, MA, EEUU). EI vector de expresión que codifica para la sonda roja fluorescente de F-actina pmRFPRuby-N1Lifeact (Riedl et al., 2008) fue obtenido del Dr. R. Wedlich-Soldner (Max Planck Institute of Biochemistry, Martinsried, Alemania). El plásmido pmCherry-Rac1 y la forma dominante negativa de la dinamina-2 etiquetada con HA (pcDNA3-HA-dinamina- ${ }^{\mathrm{K} 44 \mathrm{~A}}$ ) fueron obtenidos del Dr. M.A. del Pozo (Centro Nacional de Investigaciones Cardiovasculares, Madrid). Los vectores de expresión para la versión etiquetada con Myc de la forma silvestre de Pak1 (pCMV6M-Pak1) y ArhGEF7 (Myc-AhrGEF7) fueron un obsequio de los Drs. J. Field (University of Pennsylvania School of Medicine, PA, EEUU) y A. S. Mak (Queen's University, Kingston, Ontario, Canadá) respectivamente. El mutante de Pak1 $\triangle P R R$, carente de región central rica en prolinas (pCMV6M-Pak1 ${ }^{\mathrm{P} 191 \mathrm{G}, \mathrm{P} 192 \mathrm{~A}}$ ) se compró en Addgene (http://www.addgene.org/pgvec1). El vector de expresión bacteriano que codifica el dominio de unión a Rac1 de la proteína quinasa Pak1 (dominio CRIB) (pGEX-PBD) fue cedido por el Dr. J. Chernoff (Fox Chase Cancer Center, $P A, E E U U)$. El vector de expresión que codifica el mismo dominio de unión a Rac1 de la proteína Pak1 (Pak1 RBD) fusionado a la EGFP (pJRC45) fue generado mediante digestión del plásmido pGEX-PBD con las enzimas de restricción BamHI y EcoRI y posterior subclonación del fragmento de ADNc liberado en el vector pEGFP-C1 (Clontech) linearizado con las mismas enzimas de restricción. El plásmido que codifica para Basigina (isoforma 2 de humanos) etiquetada con HA (pBSG-HA) fue cedido por el Dr. K. Kadomatsu (Nagoya University Graduate School of Medicine, Nagoya, Japón). El plásmido de expresión que codifica WDR26 (pWDR26) fue obtenido del Dr. M. Liu (Hunan Normal University, Hunan, China). El vector de expresión que expresa la proteína de fusión TMEM8A-FLAG (pTMEM8A-FLAG) fue un regalo del Dr. Motohashi (Gifu University Graduate School of Medicine, Japón).

Para generar el vector de expresión que codifica la proteína híbrida Basigina-EGFP (pACC05) realizamos una PCR (del inglés, polymerase chain reaction) usando como ADN molde el plásmido pBSG-HA y los oligos sentido 5' CGGGATCCATG GCGGCTGCGCTGTTCGTG 3' y antisentido 5' CGGGATCCGGAAGAGTTCCTCTGGCGG 3' 
(la secuencia de restricción BamHI utilizada para el clonaje aparece subrayada), respectivamente. A continuación se clonó el producto resultante de la PCR en el vector pEGFPN3 (Clontech) en pauta de lectura con la secuencia de la proteína fluorescente verde EGFP utilizando la diana de restricción BamHI. El vector de expresión para la proteína TMEM8AEGFP (pACC19) se generó en dos pasos. En primer lugar realizamos la mutación de un codón de fin de la traducción situado tras la etiqueta FLAG del plásmido pTMEM8A-FLAG. A continuación, digerimos el plásmido resultante con EcoRI para subclonar el fragmento liberado (TMEM8A-FLAG ${ }^{\text {STOP Codon Mut }}$ ) en el vector de expresión pEGFP-N1 (Clontech) y en pauta de lectura con la EGFP utilizando la diana de restricción EcoRI. El vector de expresión que codifica la proteína EGFP-WDR26 (pACC13) se obtuvo mediante PCR usando el plásmido pWDR26 como molde y los oligos sentido 5' CGGGATCCATGCAAGAGTCAGGATGTCG 3' y antisentido 5' CGGGATCCACTATCCATG CTACTGCATTC 3' (la secuencia de restricción BamHI utilizada para el clonaje aparece subrayada), respectivamente. El producto de PCR obtenido se subclonó en el vector pEGFP-C1 (Clontech) en pauta de lectura con la EGFP usando la diana de restricción BamHI.

La generación de los mutantes puntuales que se indican en la Tabla 1 (pág. siguiente), se realizó con el kit de mutagénesis dirigida QuickChange ${ }^{T M}$ (Stratagene) de acuerdo a las instrucciones del fabricante. En la Tabla 1 se indica el nombre de la proteína mutante, el nombre del plásmido que la codifica y los oligonucleótidos (Invitrogen) sentido y antisentido portadores de la mutación introducida en cada vector de expresión.

Para la generación de los vectores retrovirales que codifican para EGFP (pACC42) y Coronina-1A-EGFP (pACC33), digerimos los vectores pEGFP-N1 (Clontech) y pCoronin1A ${ }^{W T}$ EGFP con las enzimas de restricción Xhol y Notl. El fragmento de ADNc liberado fue subclonado en el vector retroviral pLZRS-IRES-Zeo (plásmido cedido por el Dr. Arnoud Sonnenberg, The Netherlands Cancer Institute, Amsterdam, Países Bajos) linearizado con Xhol y Notl. Para la generación del vector retroviral que codifica para Coronina-1A ${ }^{R 29 D}$-EGFP (pACC59), se amplificó por PCR con oligonucleótidos específicos el fragmento de ADNc para Coronina-1A ${ }^{R 29 D}$-EGFP a partir del plásmido pACC53 y, tras digestión con Bglll y EcoRI, se subclonó en el vector retroviral pBABE-puro linearizado con Bglll y EcoRI. Todos los plásmidos utilizados en este trabajo fueron secuenciados en la Unidad de Genómica de nuestro Centro.

\section{CULTIVOS CELULARES}

La línea celular COS1 y sus derivadas fueron cultivadas en medio DMEM suplementado con $10 \%$ suero de ternera, $1 \%$ L-glutamina y $1 \%$ penicilina-estreptomicina. La línea celular HEK293T se cultivó en el mismo medio, pero sustituyendo el suero de ternera por suero bovino fetal. Ambas líneas celulares fueron mantenidas a $37^{\circ} \mathrm{C}$ en una atmósfera conteniendo un $5 \%$ 
$\mathrm{CO}_{2}$. Todos los medios y reactivos utilizados para cultivos celulares fueron comprados a Invitrogen. Cuando fue necesario las células COS1 fueron privadas de suero durante $4 \mathrm{~h}$ y, posteriormente, estimuladas o no con EGF (100 ng/ml, Millipore) durante los períodos de tiempo indicados. Cuando fue necesario, las células COS1 fueron incubadas a $37^{\circ} \mathrm{C}$ y $5 \% \mathrm{CO}_{2}$ con $10 \mathrm{mM} \mathrm{M \beta CD} \mathrm{(Sigma)} \mathrm{durante} 30 \mathrm{~min}, 2 \mu \mathrm{M}$ citocalasina D (Sigma) durante $15 \mathrm{~min}, 5 \mu \mathrm{M}$ GF109203X (Calbiochem) durante $1 \mathrm{~h}, 10 \mu \mathrm{M}$ del péptido Tat-Pak18 o de su versión inactiva TAT-Pak $^{\text {R192A }}$ (Calbiochem) durante toda la noche.

Tabla 1. Mutantes puntuales utilizados en este trabajo. Esta tabla recoge el nombre de cada proteína mutante, el nombre del plásmido de expresión que la codifica (entre paréntesis) y la secuencia de oligonucleótidos sentido y antisentido complementarios utilizados para la mutagénesis.

\begin{tabular}{|c|c|}
\hline MUTANTE & OLIGONUCLEÓTIDOS \\
\hline $\begin{array}{c}\text { Coronina-1A }{ }^{\text {R29D-EGFP }} \\
(p A C C 53)\end{array}$ & $\begin{array}{l}\text { Sentido: } \\
\text { 5' CCAGTGCTATGAAGATGTGGACGTCTCACAGACCACCTGG 3' } \\
\text { Antisentido: } \\
\text { 5' CCAGGTGGTCTGTGAGACGTCCACATCTTCATAGCACTGG 3' }\end{array}$ \\
\hline $\begin{array}{l}\text { Myc-Pak1 }{ }^{\text {T423E }} \\
\quad(\mathrm{pACC} 31)\end{array}$ & $\begin{array}{l}\text { Sentido: } \\
\text { 5' GAGCAGAGCAAACGGAGCGAGATGGTAGGAACCCCATAC 3' } \\
\text { Antisentido: } \\
\text { 5' GTATGGGGTTCCTACCAGCTCGCTCCGTTTGCTCTGCTC 3' }\end{array}$ \\
\hline $\begin{array}{l}\text { Myc-Pak1 }{ }^{\text {K299R }} \\
\quad(\text { pACC30) }\end{array}$ & $\begin{array}{l}\text { Sentido: } \\
\text { 5' GGACAGGAGGTGGCCATTAGGCAGATGAATCTTCAGCAG 3' } \\
\text { Antisentido: } \\
\text { 5' CTGCTGAAGATTCATCTGCCTAATGGCCACCTCCTGTCC 3' }\end{array}$ \\
\hline $\begin{array}{l}\text { Myc- } \\
\text { RhoGDIS101A/S174A } \\
(\mathrm{pACC} 46)\end{array}$ & $\begin{array}{l}\text { Sentido para la mutación S101A: } \\
\text { 5' GAGAGCTTCAAGAAGCAGGCCTTTGTGCTGAAGGAGGG 3' } \\
\text { Antisentido para la mutación S101A: } \\
\text { 5' CCCTCCTTCAGCACAAAGGCCTGCTTCTTGAAGCTCTC } 3 \\
\text { Sentido para la mutación S174A: } \\
\text { 5' GCCCAAGGGCATGCTGGCGCGAGGCAGCTACAACATCAAG 3' } \\
\text { Antisentido para la mutación S174A: } \\
\text { 5' CTTGATGTTGTAGCTGCCTCGCGCCAGCATGCCCTTGGGC 3' }\end{array}$ \\
\hline $\begin{array}{l}\text { AU5-Rac1 }{ }^{\text {R66E }} \\
\text { (pJRC69) }\end{array}$ & $\begin{array}{l}\text { Sentido: } \\
\text { 5' GCTGGACAAGAAGATTATGACGAATTACGCCCCCTATCCTATCC 3' } \\
\text { Antisentido: } \\
\text { 5' GGATAGGATAGGGGGCGTAATTCGTCATAATCTTCTTGTCCAGC 3' }\end{array}$ \\
\hline $\begin{array}{l}\text { AU5-Rac1 } \\
\text { (pACC17) }\end{array}$ & $\begin{array}{l}\text { Sentido: } \\
\text { 5' GGAGACGGAGCTGTAGGTAAAAATTGCCTACTGATCAGTTACAC 3' } \\
\text { Antisentido: } \\
\text { 5' GTGTAACTGATCAGTAGGCAATTTTTACCTACAGCTCCGTCTCC 3' }\end{array}$ \\
\hline
\end{tabular}

\section{GENERACIÓN DE LÍNEAS CELULARES ESTABLES}

Para generar la línea celular reportera expresando EGFP-Rac1 (Vincent \#6), transfectamos un clon de células HEK293T que expresaba de forma ectópica las proteínas anti-apoptóticas p35, CrmA y Bcl-XL con $1 \mu \mathrm{g}$ del plásmido pNM32 y 100 ng del plásmido pBABE-puro mediante la 
técnica de precipitación de fosfato cálcico (pág. 41). Pasadas $48 \mathrm{~h}$, las células fueron seleccionadas durante una semana usando puromicina $(1 \mu \mathrm{g} / \mathrm{ml}$, Sigma) y las células resistentes al antibiótico y positivas para EGFP purificadas mediante citometría de flujo. Finalmente se confirmó la expresión ectópica de la proteína EGFP-Rac1 mediante epifluorescencia directa de la EGFP y análisis por Western blot.

Utilizamos técnicas de transducción retroviral para generar las líneas celulares derivadas de células COS1 que expresan de forma estable EGFP (ACC1-1) y Coronina-1AEGFP (ACC1-2) (pág. 69). Para generar las partículas retrovirales, transfectamos células HEK293T, previamente tratadas con cloroquina $25 \mu \mathrm{M}$ (Sigma) durante $5 \mathrm{~min}$, con 2,5 $\mu \mathrm{g}$ de pMD-G, $5 \mu \mathrm{g}$ de pNGVLMLV-gag-pol y $4 \mu \mathrm{g}$ del vector retroviral apropiado (pACC42 y pACC33, respectivamente) a través de la técnica de precipitación con fosfato cálcico. Pasadas 48-72 h el medio de cultivo de cada una de las placas fue recogido y filtrado a través de filtros de $0,45 \mu \mathrm{M}$ (Millipore). Los sobrenadantes obtenidos conteniendo las partículas retrovirales fueron suplementados con polibreno ( $8 \mu \mathrm{g} / \mathrm{ml}$, Sigma) y añadidos a células COS1 ( $3 \mathrm{ml}$ por pocillo) que habían sido previamente sembradas en placas de 6 pocillos a un $40 \%$ de confluencia. Posteriormente, las placas de cultivo fueron centrifugadas a temperatura ambiente durante 45 min a $1.500 \mathrm{rpm}$ y dejadas en incubación durante toda la noche a $37^{\circ} \mathrm{C}$ y $5 \% \mathrm{CO}_{2}$. A la mañana siguiente, la mezcla retroviral fue reemplazada por medio DMEM suplementado. A las $72 \mathrm{~h}$ de la transducción, las células se pasaron a placas de cultivo de $100 \mathrm{~mm}$ y fueron seleccionadas con zeocina $(400 \mu \mathrm{g} / \mathrm{ml}$, Invitrogen) durante 7 días. Finalmente, las células resistentes al antibiótico y positivas para EGFP fueron purificadas por citometría de flujo y la expresión de las proteínas ectópicas detectada por epifluorescencia y análisis por Western blot.

Para la generación de las líneas celulares deficientes en Coronina-1A ○ ArhGEF7 utilizamos técnicas de transducción lentiviral con partículas lentivirales MISSION® (Sigma). Para la eliminación de la expresión del transcrito para CORO1A infectamos células COS1 con partículas lentivirales TRCN0000029343 (para generar la línea celular designada como ACC21) y TRCN0000029342 (para generar la línea celular designada como ACC2-2) (pág. 72). Para la eliminación de la expresión del ARNm de ArhGEF7 infectamos la línea celular ACC1-2 con partículas lentivirales TRCN0000047597 (para generar la línea celular designada como ACC1-2 Control shRNA) y TRCN0000047595 (para generar la línea celular designada como ACC1-2 ArhGEF7 shRNA) (pág. 94). Para ello, $20 \mu \mathrm{l}$ del concentrado lentiviral fueron diluidos en $2 \mathrm{ml}$ de DMEM suplementado con polibreno $(8 \mu \mathrm{g} / \mathrm{ml})$ y la mezcla fue añadida a la respectiva línea celular que había sido previamente sembrada al $40 \%$ de confluencia en placas de 6 pocillos. Seguidamente, las placas fueron centrifugadas a $1.500 \mathrm{rpm}$ durante $45 \mathrm{~min}$ a temperatura ambiente y, tras ello, las células fueron incubadas durante toda la noche a $37^{\circ} \mathrm{C}$ y $5 \% \mathrm{CO}_{2}$. A la mañana siguiente, la mezcla lentiviral fue sustituida por medio DMEM suplementado y, $48 \mathrm{~h}$ después, las células fueron transferidas a placas de $100 \mathrm{~mm}$ en diluciones de 1:10, 1:20 y 1:50 
de la placa original. Posteriormente las células fueron seleccionadas con puromicina $(1 \mu \mathrm{g} / \mathrm{ml})$ durante quince días. Se picaron clones aislados de células resistentes al antibiótico usando cilindros de clonación de $8 \times 8 \mathrm{~mm}$ (Genechoice) y $150 \mu \mathrm{l}$ de tripsina, depositándose cada uno de los clones aislados en un pocillo de placas de 24 pocillos para ser cultivadas hasta llegar a confluencia. Finalmente, los clones fueron expandidos y caracterizados para la represión de la proteína endógena mediante Western blot.

\section{SISTEMA DE ANÁLISIS DE LA GENOTECA DE ADNC}

Se partió de una librería de ADNc obtenida a partir de células T humanas y clonada en el vector de expresión mamífero pEAK (Edge Biosystems, Gaithersburg, MD, EEUU). Dicha librería fue sembrada en placas de $22 \times 22 \mathrm{~cm}$ con LB-Agar al 2\%, $50 \mu \mathrm{g} / \mathrm{ml}$ de ampicilina (Calbiochem), $10 \mu \mathrm{g} / \mathrm{ml}$ de cicloheximida (Sigma) y $5 \mu \mathrm{l}$ de Antifoam (Sigma) para evitar la formación de espuma. Las colonias bacterianas obtenidas se inocularon en placas de 384 pocillos con $80 \mu \mathrm{l}$ de medio TB (Terrific-Broth) (1,2\% triptona, 2,4\% extracto de levadura) suplementado con 50 $\mu \mathrm{g} / \mathrm{ml}$ de ampicilina, $10 \mu \mathrm{g} / \mathrm{ml}$ de cicloheximida y glicerol al $7,5 \%$ para protegerlas de la congelación. Estas placas de 384 pocillos se mantuvieron a $-70^{\circ} \mathrm{C}$ hasta el momento de su utilización. Se agruparon cada uno de los 96 clones que se generan al dividir la placa original en 4 sectores en un nuevo pocillo de un bloque de 96 pocillos con 1,5 ml de TB por punto, 50 $\mu \mathrm{g} / \mathrm{ml}$ de ampicilina y $10 \mu \mathrm{g} / \mathrm{ml}$ de cicloheximida usando el robot picador Qpixll (Genetix, Hampshire, Reino Unido). De este modo, se obtuvo un volumen suficiente de cultivo para poder extraer el ADN plasmídico utilizando el Biorobot-3000 (Qiagen). Estos grupos o pooles de 96 ADNc (grupos primarios) fueron transfectados en la línea celular reportera EGFP-Rac1 HEK293T mediante el método de precipitación de fosfato cálcico. Después de $36 \mathrm{~h}$, las células transfectadas se analizaron in vivo utilizando un microscopio de fluorescencia invertido (Axiovert 135; Carl Zeiss Microlmaging, Inc). Para aislar el clon responsable del fenotipo dentro del grupo de 96 clones que se había detectado como positivo, se descongeló la placa original de 384 pocillos y, el cuadrante a partir del cual se había obtenido el grupo de 96 clones, se reagrupó por filas y columnas. El nuevo ADN plasmídico extraído de estos subgrupos (grupos secundarios) se transfectó en la línea celular reportera EGFP-Rac1 HEK293T. De este modo, en la intersección entre las filas y columnas positivas se localizaban los genes de interés (Figura 8, pág. 55).

\section{TRANSFECCIONES TRANSITORIAS}

Método de la precipitación de fosfato cálcico. Este método se empleó para la generación de la línea celular reportera Vincent \#6 (EGFP-Rac1 HEK293T) y para la producción de partículas retrovirales en HEK293T. Para ello, 1,5 × $10^{5}$ células HEK293T fueron sembradas en placas de 
$100 \mathrm{~mm}$ de diámetro y transfectadas al día siguiente como sigue: se diluyeron los plásmidos a transfectar en un volumen final de $0,5 \mathrm{ml}$ de $\mathrm{H}_{2} \mathrm{O}$ (por placa). Las cantidades de plásmido transfectadas se indican en el apartado de "Generación de líneas celulares estables". A esta mezcla se añadieron $0,5 \mathrm{ml}$ de $0,5 \mathrm{M} \mathrm{CaCl}$. La solución anterior se añadió lentamente sobre 1 ml de tampón HNP (para $100 \mathrm{ml}: 98 \mathrm{ml}$ de $50 \mathrm{mM}$ HEPES [pH 7,1], $280 \mathrm{mM} \mathrm{NaCl}$, más $2 \mathrm{ml}$ de 70 mM tampón fosfato [pH 7,1]), burbujeando aire a través de una pipeta, y la mezcla se incubó a temperatura ambiente hasta la aparición de un precipitado blanco. Cada punto se incluyó por duplicado en un mismo experimento. Los tubos se agitaron suavemente para resuspender el precipitado, añadiéndose seguidamente a las células. Tras 20-22 h en condiciones estándar de cultivo, el medio fue aspirado y las células lavadas dos veces con DMEM conteniendo un $5 \%$ de suero de ternera. Después de este lavado, las células se mantuvieron en medio suplementado durante $24 \circ 48 \mathrm{~h}$, dependiendo de si serían utilizadas para la creación de la línea celular reportera o para la producción de partículas retrovirales, respectivamente.

Liposomas. Las células que se emplearon en experimentos transitorios de inmunofluorescencia se transfectaron usando el reactivo FuGENE 6 (Roche Molecular Biochemicals) según especifican las intrucciones del fabricante. Los ARN de interferencia usados en experimentos de inmunofluorescencia o los plásmidos utilizados en los experimentos de inmunoprecipitación y de GST Pull down fueron transfectados con Lipofectamina 2000 (Invitrogen) de acuerdo a las recomendaciones del fabricante.

\section{INMUNOFLUORESCENCIA INDIRECTA}

Se utilizaron cubreobjetos redondos de $12 \mathrm{~mm}$ de diámetro (Menzel-Glaser). Estos fueron recubiertos previamente de poli-L-lisina (Sigma) mediante incubación en una solución $1 \mu \mathrm{g} / \mathrm{ml}$ durante $30 \mathrm{~min}$ a temperatura ambiente. Los cubreobjetos se colocaron en placas de 6 pocillos. Aproximadamente 80.000 células por pocillo fueron adheridas a los cubreobjetos y transfectadas entre 18-24 h más tarde utilizando un reactivo basado en liposomas (FuGENE 6), según las instrucciones facilitadas por el fabricante. La cantidad de plásmido total transfectada fue de $1 \mu \mathrm{g}$ de plásmido por pocillo. Aproximadamente 24-36 h después de la transfección, las células fueron privadas de suero durante $4 \mathrm{~h}$, se lavaron en PBS (del inglés, phosphate buffered saline) y se fijaron en formaldehído al 3,7\% en PBS durante 20 min. A continuación, se permeabilizaron mediante incubación con $0,25 \%$ Triton X-100 en TBS-T $(25 \mathrm{mM}$ Tris- $\mathrm{HCl}$ [pH 8,0], 0,1\% de Tween-20 (Sigma) durante $10 \mathrm{~min}$ y lavaron durante $5 \mathrm{~min}$ en TBS-T. El bloqueo de los sitios inespecíficos de unión se llevó a cabo incubando las células en solución de bloqueo ( $2 \%$ albúmina de suero de ternera o BSA (del inglés, Bovine serum albumine), $0,1 \%$ azida sódica y $0,1 \%$ Triton X-100 en TBS-T) durante $30 \mathrm{~min}$. La detección de las proteínas de interés se llevó a cabo utilizando los anticuerpos primarios detallados en la Tabla 2 (pág. siguiente). Los anticuerpos secundarios anti-lgG de conejo y anti-lgG de ratón conjugados con 
Cy2 (fluorescencia verde), Сy3 (fluorescencia roja) y Сy5 (fluorescencia azul) se utilizaron en dilución 1:200, 1:800 y 1:400, respectivamente. Todos ellos fueron obtenidos de Jackson Immunoresearch. Las disoluciones de todos los anticuerpos, tanto primarios como secundarios, se prepararon en solución de bloqueo. Todos los pasos descritos en el protocolo fueron llevados a cabo a temperatura ambiente. Las células se incubaron durante $1 \mathrm{~h}$ con los anticuerpos correspondientes y después de cada incubación fueron lavadas tres veces con TBS-T durante $5 \mathrm{~min}$. Cuando se indica, el citoesqueleto de actina se tiñó incubando las células durante $20 \mathrm{~min}$ con faloidina conjugada a rodamina o a Alexa Fluor 635 (Molecular Probes, Invitrogen), preparada según las instrucciones del fabricante y diluida 1:200 en solución de bloqueo. Para detectar la presencia de balsas lipídicas, las células fueron incubadas con CTxB conjugada al fluorocromo Alexa Fluor 647 (Molecular Probes, Invitrogen) durante 2 min (0,5 $\mu \mathrm{g} / \mathrm{ml}$ ) previo a la fijación. Finalmente, las preparaciones fueron montadas sobre portaobjetos utilizando Mowiol (Calbiochem) como medio de montaje. Las células fueron analizadas mediante microscopía confocal, utilizando un microscopio Zeiss LSM510 con un objetivo de magnificación 63x. Para estimular la epifluorescencia de la EGFP o los fluorocromos Cy2 se utilizó un láser de ${ }^{18} \mathrm{Ar}$ a una longitud de onda de excitación de $488 \mathrm{~nm}$; para Cy3 y rodamina se usó un láser de ${ }^{2} \mathrm{He} /{ }^{10} \mathrm{Ne}$ a una longitud de onda de excitación de $543 \mathrm{~nm}$, y para excitar el fluorocromo Cy5 se empleó el mismo láser, pero utilizando una longitud de onda de $633 \mathrm{~nm}$. Los perfiles de distribución de fluorescencia a lo largo de las secciones celulares indicadas en cada figura, indicada con una línea blanca que atraviesa la célula seleccionada, fueron realizados con el software LSM510 de Zeiss.

Tabla 2. Anticuerpos utilizados en los ensayos de inmunofluorescencia. Esta tabla recoge el nombre de cada anticuerpo, la casa comercial donde fue adquirido y dilución utilizada en los experimentos. Los anticuerpos monoclonales hechos en ratón se indican con una ( $r$ y los policlonales hechos en conejo con una (c).

\begin{tabular}{|l|l|l|}
$\begin{array}{l}\text { Nombre del } \\
\text { anticuerpo }\end{array}$ & Casa comercial & $\begin{array}{l}\text { Dilución para } \\
\text { inmunofluorescencia }\end{array}$ \\
\hline Anti-AU5 $(r)$ & Covance & $1: 1.000$ \\
\hline Anti-AU5 (c) & Abcam & $1: 200$ \\
\hline Anti-Myc (r) & Roche & $1: 1.000$ \\
\hline Anti-Myc (c) & Upstate & $1: 400$ \\
\hline Anti-RhoGDI (c) & Santa Cruz Biotechnology & $1: 1.000$ \\
\hline Anti-Rac1 (r) & BD Transduction Laboratories & $1: 1.000$ \\
\hline Anti-ArhGEF7 (c) & Millipore & $1: 1.000$ \\
\hline Anti-HA (r) & Covance & $1: 500$ \\
\hline
\end{tabular}




\section{CUANTIFICACIÓN DE LA FLUORESCENCIA RELATIVA EN LA MEMBRANA PLASMÁTICA}

Los niveles de fluorescencia en la membrana plasmática fueron cuantificados usando la herramienta ImageJ (NIH Software).Tras ajustar los niveles threshold en cada una de las imágenes a cuantificar aplicamos la paleta edges para obtener los valores de fluorescencia total en la membrana plasmática. Los valores obtenidos en cada caso fueron normalizados en base al área medida en la membrana plasmática de cada una de las células seleccionadas para estos estudios. Finalmente, estos valores normalizados respecto al área fueron estandarizados con respecto a los valores basales considerados como control, según el experimento, y aparecen en el cuadrante inferior derecho de cada imagen analizada.

\section{DETERMINACIÓN DEL ÍNDICE DE TRANSLOCACIÓN}

El índice de translocación de Rac1, Pak1 y ArhGEF7 a la membrana plasmática fue calculado como ha sido descrito en otros trabajos (Del Pozo et al., 2002). Brevemente, las células expresando ectópicamente AU5-Rac1, Myc-Pak1 o Myc-ArhGEF7 fueron clasificadas con valores de 0 (para la ausencia total de señal de la proteína ectópica en la membrana plasmática), 1 (para una presencia débil) y 2 (para una presencia clara y masiva en la membrana celular). El índice de translocación resulta de aplicar la fórmula $(b+2 c) /(a+b+c)$, donde $a, b$ y $c$ son el número de células con puntuaciones de 0,1 y 2 , respectivamente. Los valores se representan como la media y la desviación estándar de tres experimentos independientes donde se contaron hasta 50 células escogidas al azar.

\section{MICROSCOPÍA TIRF}

Estos experimentos fueron llevados a cabo en colaboración con el grupo del Dr. M.A. del Pozo en el Centro Nacional de Investigaciones Cardivasculares, Madrid. Células sembradas en placas ópticas (Wilco) fueron transfectadas con plásmidos de expresión que codifican una sonda roja fluorescente para F-actina (pmRFPRuby-N1-Lifeact) o la versión fluorescente roja monomérica de Rac1 (pmCherry-Rac1). $36 \mathrm{~h}$ después, el medio fue reemplazado por Optimem (Invitrogen) suplementado con $10 \%$ de suero de ternera fetal. Las células fueron observadas in vivo con un objetivo de inmersión 100x y una penetrancia de $90 \mathrm{~nm}$ (apertura numérica 1,45) en un microscopio Leica DMI6000B equipado con un iluminador TIRF y un láser de iluminación acoplado a fibra óptica con dos líneas diferentes de láser (488 nm y $546 \mathrm{~nm}$ ) y filtros adecuados para fluoresceína/Alexa/GFP y rodamina/RFP. 


\section{ELECTROFORESIS EN GELES DE POLIACRILAMIDA Y WESTERN BLOT}

Los extractos proteicos se hirvieron en tampón de muestra de Laemmli durante 10 min y a continuación se resolvieron en geles de poliacrilamida al 12\%, 10\% u $8 \%$ dependiendo del peso molecular de las proteínas a separar utilizando un tampón de carrera conteniendo 0,25 M Tris, $2 \mathrm{M}$ glicina y $0,5 \%$ SDS. A continuación, las proteínas fueron transferidas a una membrana de nitrocelulosa usando el iBlot Dry Blotting System (Invitrogen) de acuerdo a las instrucciones del fabricante. Las membranas fueron bloqueadas en leche desnatada (para anticuerpos estándar) o BSA (para anticuerpos fosfo-específicos) al 5\% en TBS-T. Las membranas se mantuvieron en esta solución durante $1 \mathrm{~h}$ a temperatura ambiente. La hibridación con los anticuerpos primarios se llevó a cabo indistintamente durante $1 \mathrm{~h}$ a temperatura ambiente o durante toda la noche a $4^{\circ} \mathrm{C}$. Las diluciones utilizadas de los diferentes anticuerpos primarios se indican en la Tabla 3 (pág. siguiente). Seguidamente, las membranas se incubaron con una dilución 1:5.000 de los anticuerpos secundarios de la especificidad adecuada conjugados con peroxidasa de rábano (GE Healthcare) durante $1 \mathrm{~h}$ a temperatura ambiente. Ambos tipos de anticuerpos se utilizaron diluidos en leche al $5 \%$ en TBS-T. Después de cada incubación, la membrana se lavó 3 veces en TBS-T durante $10 \mathrm{~min}$. La detección de las proteínas se llevó a cabo por quimioluminiscencia utilizando el reactivo ECL (GE Healthcare). Cuando fue necesario realizar un stripping de las membranas para el rebloteo con nuevos anticuerpos primarios, las membranas fueron incubadas con $10 \mathrm{ml}$ de una disolución de Re-Blot Plus Strong 10X (Millipore) durante $15 \mathrm{~min}$ a temperatura ambiente en agitación. Posteriormente, fueron lavadas con TBS-T 3 veces durante $5 \mathrm{~min}$, bloqueadas de nuevo y finalmente incubadas con los anticuerpos correspondientes.

\section{FRACCIONAMIENTO SUBCELULAR}

Células procedentes de cultivos subconfluentes de las líneas celulares ACC1-1 y ACC1-2 creciendo exponencialmente en placas de $100 \mathrm{~mm}$ fueron lavadas con PBS frío y lisadas en 1 $\mathrm{ml}$ de un tampón de lisis hipotónico que contenía $20 \mathrm{mM}$ Tris- $\mathrm{HCl}[\mathrm{pH}$ 7,5], $10 \mathrm{mM} \mathrm{NaCl}, 5 \mathrm{mM}$ $\mathrm{MgCl}_{2}, 10 \mathrm{mM} \mathrm{KCl}, 1 \mathrm{mM} \mathrm{Na} \mathrm{VO}_{4}$ (Sigma), $1 \mathrm{mM}$ ditiotreitol (Roche), $10 \mathrm{mM}$ ß-glicerofosfato (Sigma) y la mezcla de inhibidores de proteasas Cømplete (Roche). Las células fueron homogeneizadas haciéndolas pasar 15 veces a través de una jeringa de $2 \mathrm{ml}$ acoplada a una aguja 20G. Los lisados se mantuvieron posteriormente en hielo durante $10 \mathrm{~min}$, tras lo cual fueron centrifugados a $14.000 \mathrm{rpm}$ durante $10 \mathrm{~min}$ a $4^{\circ} \mathrm{C}$ para eliminar las células enteras y núcleos. Los sobrenadantes obtenidos en este paso fueron transferidos a tubos de policarbonato (Beckman) y ultracentrifugados a $100.000 \mathrm{xg}$ durante $1 \mathrm{~h}$ en una ultracentrífuga refrigerada (Beckman). Tras este paso, los sobrenadantes que contenían la fracción citosólica fueron desechados y el pellet enriquecido en membranas fue lavado con el tampón de lisis hipotónico y ultracentrifugado de nuevo. Las fracciones de membrana fueron analizadas para la 
determinación de proteína total mediante el reactivo Bio-Rad Protein Assay, separadas electroforéticamente en geles de poliacrilamida y analizadas finalmente mediante Western blot. La cantidad de Rac1 presente en la fracción de membrana fue cuantificada con el software ImageJ (NIH Software) y normalizada con respecto a la cantidad de Rac1 total en el lisado celular total.

Tabla 3. Anticuerpos utilizados en los ensayos de Western blot. Esta tabla recoge el nombre de cada anticuerpo, la casa comercial donde fue adquirido y dilución utilizada en los experimentos. Los anticuerpos monoclonales hechos en ratón se indican con una (r), los policlonales hechos en conejo con una (c) y los policlonales hechos en cabra con una (ca).

\begin{tabular}{|l|l|l|}
\hline Nombre del anticuerpo & Casa comercial & Dilución para Western blot \\
\hline Anti-Rac1 $(r)$ & BD Transduction Laboratories & $1: 1.000$ \\
\hline Anti-RhoA $(c)$ & Cell Signaling & $1: 1.000$ \\
\hline Anti-CD98 $(c a)$ & Santa Cruz Biotechnology & $1: 200$ \\
\hline Anti-Erk1/2 $(c)$ & Cell Signaling & $1: 1.000$ \\
\hline Anti-fosfo-Erk1/2 (c) & Cell Signaling & $1: 1.000$ \\
\hline Anti-EGFP $(r)$ & Covance & $1: 3.000$ \\
\hline Anti-fosfo-tirosinas $(r)$ & Santa Cruz Biotechnology & $1: 1.000$ \\
\hline Anti-EGFR $(c)$ & Santa Cruz Biotechnology & $1: 1.000$ \\
\hline Anti-Coronina-1A $(r)$ & Sigma & $1: 500$ \\
\hline Anti-Myc $(r)$ & Roche & $1: 1.000$ \\
\hline Anti-RhoGDI $(c)$ & Santa Cruz Biotechnology & $1: 200$ \\
\hline Anti-ArhGEF7 $(c)$ & Millipore & $1: 1.000$ \\
\hline Anti-tubulina $(r)$ & Sigma & $1: 5.000$ \\
\hline Anti-integrina $\beta 1(r)$ & BD Transduction Laboratories & $1: 2.500$ \\
\hline
\end{tabular}

\section{PURIFICACIÓN DE LA PROTEÍNA DE FUSIÓN GST-CRIB}

Brevemente, un cultivo de bacterias DH5a transformadas con el vector de expresión pGEXPBD (que codifica el dominio CRIB de Pak1 fusionado a GST) fue crecido durante toda la noche a $37^{\circ} \mathrm{C}$ en medio de Luria-Bertani conteniendo $100 \mu \mathrm{g} / \mathrm{ml}$ de ampicilina. A la mañana siguiente, el cultivo fue diluido hasta alcanzar una densidad óptica a $600 \mathrm{~nm}$ de 0,2-0,3 y crecido de nuevo hasta una densidad óptica a $600 \mathrm{~nm}$ de 0,8. En ese momento, se indujo la expresión de las proteínas de fusión mediante la adición al cultivo de isopropil- $\beta$ tiogalactopiranósido (GE-Healthcare) a una concentración final de 0,5 mM. Transcurridas 3-4 h a $37^{\circ} \mathrm{C}$, las células fueron recogidas mediante centrifugación a $4^{\circ} \mathrm{C}$, resuspendidas en PBS frío 
con la mezcla de inhibidores de proteasas Cømplete y sometidas a sonicación. A continuación, se añadió Tritón X-100 a una concentración final del 1\%, incubándose la mezcla en hielo durante $30 \mathrm{~min}$. Los restos de membranas y núcleos procedentes de la rotura de las células fueron separados por centrifugación, y el sobrenadante se incubó con una suspensión al 50\% de una matriz de sefarosa conjugada con glutatión (GE-Healthcare) durante $2 \mathrm{~h}$ a $4^{\circ} \mathrm{C}$. La proteína GST-CRIB fue recuperada de la matriz por incubación con una solución stock de glutatión (10 mM glutatión, $50 \mathrm{mM}$ Tris- $\mathrm{HCl}[\mathrm{pH} 8,0]$ ) durante $10 \mathrm{~min}$ a temperatura ambiente, seguida de centrifugación. La proteína de fusión fue purificada a partir de los sobrenadantes utilizando columnas PD-10 (GE-Healthcare) almacenándose en una solución de glicerol al 50\% en PBS a $-80^{\circ} \mathrm{C}$ hasta su uso posterior. La concentración de proteína fue calculada mediante espectrofotometría usando el reactivo Bio-Rad Protein Assay y corroborada mediante el análisis de una muestra de la misma por electroforesis en un gel de poliacrilamida al $10 \%$, utilizando como estándares cantidades crecientes de BSA (fracción V, Sigma). Los geles se tiñeron con una solución de azul de Coomassie (0,5\% Coomassie, 10\% ácido acético, $50 \%$ metanol) y se lavaron con una solución de desteñido (10\% ácido acético, 50\% metanol) para visualizar las proteínas. Todos los reactivos utilizados para la tinción y el desteñido fueron comprados a Sigma.

\section{ENSAYOS DE PULL DOWN CON LA PROTEÍNA DE FUSIÓN GST-CRIB}

Las diferentes líneas celulares fueron transfectadas con los vectores de expresión indicados en cada figura utilizando Lipofectamina 2000. $24 \mathrm{~h}$ después las células fueron privadas de suero durante $4 \mathrm{~h}$ y estimuladas o no con EGF (100 $\mathrm{ng} / \mathrm{ml}$ ) (Millipore) durante los tiempos indicados. Seguidamente las células fueron lavadas con PBS frío y lisadas en un tampón conteniendo 20 $\mathrm{mM}$ Tris- $\mathrm{HCl}$ [pH 7,5], $150 \mathrm{mM} \mathrm{NaCl}, 5 \mathrm{mM} \mathrm{MgCl}$, 0,5\% Triton X-100, 5 mM $\beta$-glicerofosfato, 1 $\mathrm{mM}$ ditiotreitol y la mezcla de inhibidores de proteasas Cømplete. La proteína GST-CRIB fue añadida directamente a este tampón (10 $\mu \mathrm{g}$ de proteína por cada condición). Las células se incubaron con el tampón de lisis conteniendo la proteína de fusión durante 10 min en hielo y, a continuación, se centrifugaron a $14.000 \mathrm{rpm}$ durante $10 \mathrm{~min}$ a $4^{\circ} \mathrm{C}$. Una alícuota del sobrenadante se utilizó para analizar la expresión de las proteínas en los lisados totales. El resto del sobrenadante se incubó con $30 \mu \mathrm{l}$ de una suspensión al $50 \%$ de matriz de glutatiónsefarosa durante $1 \mathrm{~h} \mathrm{a} 4^{\circ} \mathrm{C}$. La matriz fue sedimentada por centrifugación a $4^{\circ} \mathrm{C}$, lavada 3 veces con tampón de lisis y hervida durante 10 min en tampón de muestra de Laemmli. Las proteínas fueron analizadas mediante electroforesis en un gel de poliacrilamida al $12 \%$, seguida de Western blot. Los niveles de Rac1-GTP fueron cuantificados con el software ImageJ (NIH Software) normalizando los valores respecto a la cantidad total de Rac1 en el lisado celular total. 


\section{EXPERIMENTOS DE COINMUNOPRECIPITACIÓN}

Células de las líneas celulares apropiadas fueron sembradas en placas de $100 \mathrm{~mm}$ a un $40 \%$ de confluencia aproximadamente. Al día siguiente fueron transfectadas con los plásmidos adecuados usando Lipofectamina 2000. Pasadas 24-36 h de la transfección las células fueron lavadas con PBS frío y lisadas en $1 \mathrm{ml}$ de tampón de lisis que contenía $20 \mathrm{mM}$ Tris- $\mathrm{HCl}[\mathrm{pH}$ 7,5], $150 \mathrm{mM} \mathrm{NaCl}, 0,5 \%$ Triton X-100, $10 \mathrm{mM} \beta$-glicerofosfato, $1 \mathrm{mM} \mathrm{Na}_{3} \mathrm{VO}_{4}$ y la mezcla de inhibidores de proteasas Cømplete. Los lisados fueron incubados en hielo durante 10 min y posteriormente centrifugados a $14.000 \mathrm{rpm}$ durante $10 \mathrm{~min}$ a $4^{\circ} \mathrm{C}$. Los sobrenadantes fueron recolectados y analizados para determinar la concentración de proteína usando el reactivo BioRad Protein Assay. Cantidades equivalentes de proteína fueron inmunoprecipitadas durante toda la noche en rotación a $4^{\circ} \mathrm{C}$ con anticuerpos policlonales anti-EGFP (Clontech) o antiRhoGDI (Santa Cruz Biotechnology). Los inmunocomplejos fueron recogidos añadiendo una matriz de Gammabind G-sefarosa (GE-Healthcare) a cada sobrenadante e incubando $1 \mathrm{~h}$ adicional a $4^{\circ} \mathrm{C}$ en rotación. Finalmente, los inmunoprecipitados fueron recogidos por centrifugación, lavados 3 veces con tampón de lisis, y analizados mediante Western blot como se indica en las figuras. Se analizaron alícuotas procedentes de los lisados celulares totales utilizados en estos estudios para comprobar la correcta expresión de todas las proteínas.

\section{ARN DE INTERFERENCIA}

Para eliminar la expresión de las proteínas Coronina-1A, integrina $\beta 1$ o CD98 endógenas, se utilizaron mezclas de ARNs de interferencia obtenidas de Dharmacon (SMARTpool siRNA Reagent, siGENOME siRNA Collection). Esta mezcla consiste en cuatro secuencias de ARNi que tienen como diana el ARN mensajero de cada una de las proteínas humanas. Para verificar la funcionalidad de estos ARNi a nivel de proteína, se transfectaron células COS1 con 200 pmoles de ARNi o bien ARN control o scramble (un oligonucleótido del mismo número y tipo de nucleótidos cuya secuencia no reconoce ningún ARNm). Esta transfección se llevó a cabo utilizando Lipofectamina 2000 (Invitrogen). Los niveles de expresión de Coronina-1A, integrina $\beta 1$ o CD98 endógena fueron analizados mediane Western blot a cada uno de los tiempos que se indican en las respectivas figuras. Para los ensayos de inmunofluorescencia, se cotransfectaron cada mezcla de siRNAs junto con los plásmidos que se indican usando Lipofectamina 2000 de acuerdo a las instrucciones del fabricante.

\section{ENSAYO DE ENDOCITOSIS DE Caveolina-1-GFP EN CÉLULAS EN SUSPENSIÓN}

Estos experimentos fueron realizados en colaboración con el grupo del Dr. M.A. del Pozo (Centro Nacional de Investigaciones Cardiovasculares, Madrid). Brevemente, células 
procedentes de una línea celular de HeLa que expresan de forma estable la proteína de fusión caveolina-1-GFP fueron transfectadas con los plásmidos de expresión que se indican en el texto usando Lipofectamina 2000 y siguiendo las indicaciones del fabricante. Tras 24-36 h, las células se desprendieron del sustrato con tripsina/EDTA y se pasaron a un tubo falcon con una solución de metilcelulosa ( $0,5 \%$ metilcelulosa, $0,2 \%$ BSA libre de lípidos y $0,5 \mathrm{mg} / \mathrm{ml}$ de inhibidor de tripsina de soja). Las células se mantuvieron en esta solución en rotación a $37^{\circ} \mathrm{C}$ durante $1 \mathrm{~h}$, posteriormente fueron centrifugadas y finalmente pasadas a un tubo eppendorf donde se fijaron durante 10 min en hielo con $4 \%$ de paraformaldehído en PBS. A continuación, las células permeabilizaron durante 5 min en PBS con $0,2 \%$ Tritón-X-100, y se bloquearon en PBS con $2 \%$ de BSA. Se incubaron con los anticuerpos anti-HA y posteriormente con un anticuerpo secundario conjugado con Alexa-594 (Jackson Inmunoresearch). Seguidamente se montaron sobre cubreobjetos y se analizaron en un microscopio de epifluorescencia (Zeiss), utilizando el objetivo de inmersión 100X. El análisis consiste en la cuantificación de células que presentan caveolina-1-GFP internalizada en un compartimento perinuclear. Las imágenes fueron tomadas con un microscopio confocal Leica SpE utilizando el objetivo de inmersión 63x.

\section{ANÁLISIS ESTADÍSTICO}

Los resultados de la fracción de Rac1 unido a membrana y de los niveles de Rac1-GTP fueron representados como la media y la desviación estándar de los valores obtenidos en tres experimentos independientes. Para realizar los correspondientes análisis estadísticos, los datos fueron analizados usando el test de $t$-Student. En los experimentos de translocación de Rac1, los valores de los índices de translocación de Rac1 representan la media y la desviación estándar de 3 conteos independientes de 50 células/conteo. Los $P$ valores $\leq 0,05$ fueron considerados como estadísticamente significativos. 




\section{CAPÍTULO 1. RASTREO CELÓMICO DE GENOTECAS DE EXPRESIÓN DE} ADNC

En esta tesis doctoral nos planteamos la identificación de nuevos mediadores de señalización implicados en la regulación de la localización subcelular de la GTPasa Rac1. Para ello, decidimos utilizar genotecas de expresión de ADNc procedentes de células T activadas para identificar y aislar aquellos clones cuya expresión fuera capaz de inducir cambios en la localización subcelular de la proteína Rac1 desde el citosol a la membrana plasmática. Esta aproximación experimental se abordó mediante técnicas celómicas, donde colecciones de ADNc se expresaron en células en cultivo y tras ello se testó su capacidad para regular las cascadas de señalización que sean de interés. Este método se basa en una propiedad que frecuentemente comparten los mediadores de transducción de señales: su capacidad para inducir la cascada de señalización en la que están implicados, simplemente al ser sobreexpresados en células susceptibles (Grimm, 2004; Kiss-Toth et al., 2004; Ting et al., 2005). Este principio general ha sido utilizado para el aislamiento de, por ejemplo, proteínas que activan las rutas de señalización de NF-KB (Matsuda et al., 2003), de la ruta de MAPK (Chanda et al., 2003) (Matsuda et al., 2003) o de reguladores de la proteólisis de la proteína amiloide (Schobel et al., 2006). Los pasos necesarios para aplicar esta aproximación experimental a nuestro rastreo celómico fueron los que siguen:

1. Generación de una línea celular reportera EGFP-Rac1 HEK293T

2. Sistema de identificación funcional y clonaje por expresión

3. Corroboración, validación y selección de los clones aislados

\subsection{Generación de una línea celular reportera EGFP-Rac1 HEK293T}

Como línea celular reportera generamos un clon estable de células HEK293T que expresaba citoplasmáticamente la versión silvestre de Rac1 fusionada al extremo C-terminal de la proteína verde fluorescente EGFP (del inglés, Enhanced green fluorescent protein) (designada como Vincent \#6). Estudios previos en nuestro laboratorio habían demostrado que la proteína quimérica EGFP-Rac1 se comporta de manera idéntica a la proteína Rac1 nativa tanto a nivel de señalización celular como de localización subcelular. El clon de células HEK293T utilizado para generar esta línea celular reportera poseía propiedades anti-apoptóticas puesto que sobreexpresaba de manera estable elementos bloqueadores de diferentes rutas de apoptosis como son $\mathrm{p} 35$, Bcl- $\mathrm{X}_{\mathrm{L}}$ y CrmA. CrmA y $\mathrm{p} 35$ son inhibidores virales de caspasas, producidos por cowpox virus y baculovirus respectivamente (Villa et al., 1997). Bcl-Xı es una proteína de la familia Bcl-2 que también actúa como inhibidor apoptótico regulando la permeabilidad mitocondrial (Green and Reed, 1998). Esta modificación se realizó puesto que se sabe que la sobreexpresión de un cierto porcentaje de genes del genoma humano puede inducir procesos de muerte celular programada. Con ello, evitamos la posibilidad de perder "hits positivos" para 
la translocación de Rac1 a la membrana plasmática que asimismo pudieran inducir procesos de muerte celular en nuestra línea celular reportera.

La línea celular reportera HEK293T EGFP-Rac1 se generó mediante la co-transfección de un vector de expresión de células de mamífero para la proteína de fusión EGFP-Rac1, que ya estaba disponible en nuestro laboratorio, junto con un vector de expresión que confería resistencia a puromicina y la subsiguiente selección con los antibióticos adecuados (pág. 39).

\subsection{Sistema de identificación funcional y clonaje por expresión}

Una vez generada la línea celular reportera que serviría como herramienta base para abordar este estudio, decidimos rastrear una genoteca de ADNc obtenida a partir de linfocitos $T$ humanos activados y clonada en el vector de expresión pEAK (Edge Biosystems). Con el fin de aumentar la capacidad del método de análisis, en lugar de transfectar clon a clon, éstos se organizaron en grupos, empleándose además sistemas robóticos que permitieron procesar una extensa colección de clones.

En primer lugar, se procedió a establecer el tamaño óptimo de los grupos de clones. Para ello, se realizaron diluciones crecientes constituidas por plásmido vacío junto con un vector que contenía la versión oncogénica del factor intercambiador de nucleótidos Vav1 ( $\Delta 1$ 189), un potente y conocido activador de la GTPasa Rac1 ya caracterizado en nuestro laboratorio (Crespo et al., 1997; Schuebel et al., 1998). De este modo se transfectaron dichas diluciones en la línea celular reportera EGFP-Rac1 HEK-293T con objeto de determinar la dilución máxima que aún permitía la detección del cambio en la localización subcelular de EGFP-Rac1 desde el citosol a la membrana plasmática. Observamos que a una dilución 1:100 del ADNc, el plásmido de expresión que codificaba la versión mutante de Vav1 aún era capaz de inducir cambios detectables en la localización subcelular de EGFP-Rac1. En base a estos resultados, se eligió un tamaño de grupo de $\mathbf{9 6}$ clones por grupo para abordar el trabajo de screening.

Para comenzar el rastreo celómico, partimos de la genoteca de ADNc que ya había sido previamente plaqueada, inoculada y organizada en grupos de 96 clones de ADNc (grupos primarios). El ADNc obtenido de cada grupo primario se transfectó por el método de precipitación con fosfato cálcico, en la línea celular reportera EGFP-Rac1 HEK293T. Pasadas $36 \mathrm{~h}$, las células transfectadas se analizaron in vivo utilizando un microscopio de fluorescencia invertido, tratando de identificar pocillos que presentaran con un cambio apreciable en la localización de la proteína de fusión EGFP-Rac1 desde el citosol a la membrana plasmática. 


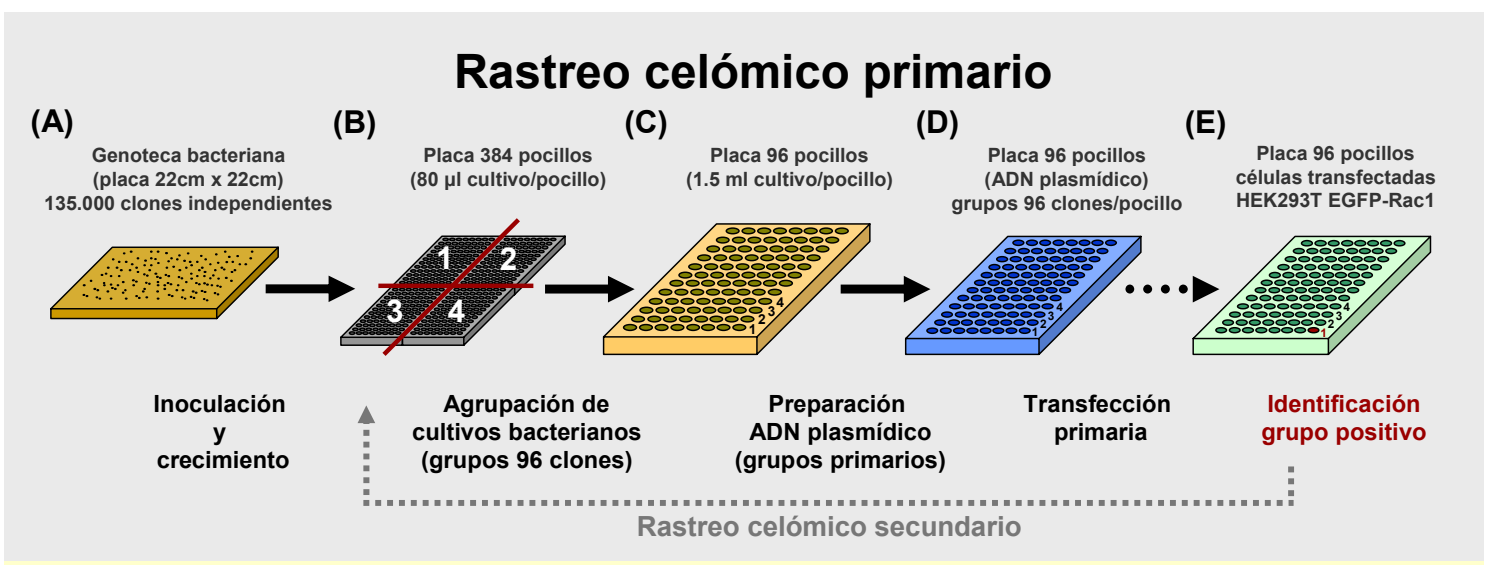

Rastreo celómico secundario

(F)

(G)

(H)

(I)

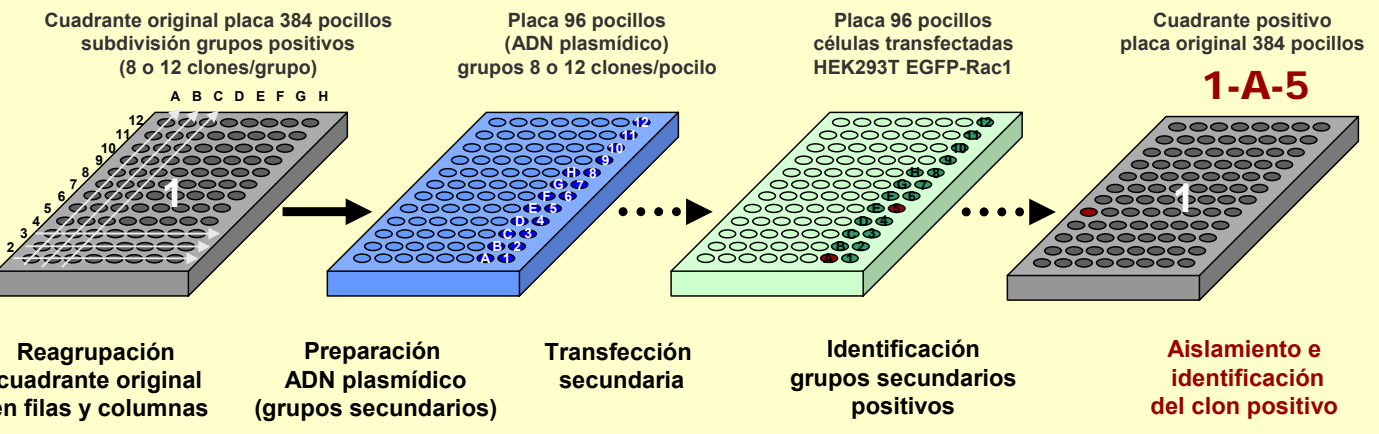

Figura 8. Esquema del clonaje por expresión realizado en este estudio. Los clones aislados de la librería de ADNc (A) fueron sembrados en placas de 384 pocillos (B). Grupos de 96 clones fueron generados a partir de cada uno de los cuatro sectores indicados en la placa (indicados con los números del 1 al 4). El ADN plasmídico obtenido de estos grupos primarios (C) se transfectó en la línea celular reportera (D) y se procedió a detectar cambios en la localización de EGFP-Rac1 36 h después (E). El aislamiento de los clones positivos se llevó a cabo subagrupando todas las filas y columnas del cuadrante original (indicado en este ejemplo con el número 1) a partir del cual se obtuvo el grupo positivo (F) y transfectando nuevamente el ADN plasmídico obtenido de estos subgrupos $(\mathbf{G}, \mathbf{H})$. Los clones positivos se localizaban en la intersección entre las filas y columnas positivas (I). Los pasos automatizados se indican con flechas de trazo contínuo, mientras que los pasos manuales con trazo punteado.

Para identificar el clon responsable de ese cambio fenotípico en la línea celular reportera y aislarlo dentro del grupo primario detectado como positivo, se descongeló de nuevo la placa original de 384 pocillos a partir de la cual se había obtenido ese grupo, y se reagrupó el cuadrante al que correspondía por filas y por columnas (grupos secundarios). De estos grupos secundarios se obtuvo de nuevo ADN plasmídico que fue nuevamente transfectado en nuestra línea celular reportera para identificar aquellos que retenían la capacidad de provocar los cambios de localización de la GTPasa Rac1. Así, el clon causante del fenotipo observado estaba representado simultáneamente en dos grupos secundarios, aquellos formados por todos los clones de la fila y de la columna en la que se encontraba localizado. La intersección entre dos grupos secundarios positivos proporcionó la posición exacta del clon en cuestión. En el caso de encontrar más de una fila o columna positivas, se estudiaron todas las 
intersecciones posibles, puesto que podía haber más de un clon positivo en el sector original (Figura 8, pág. anterior). Mediante este protocolo, analizamos hasta 135.000 clones independientes de la genoteca, aislándose un total de 60 ADNcs capaces de provocar la translocación de la proteína de fusión EGFP-Rac1 desde el citosol a la membrana plasmática. Algunas de las imágenes, correspondientes a algunos de estos clones aislados y que fueron tomadas durante el rastreo celómico en el microscopio invertido de fluorescencia se muestran en la Figura 9.
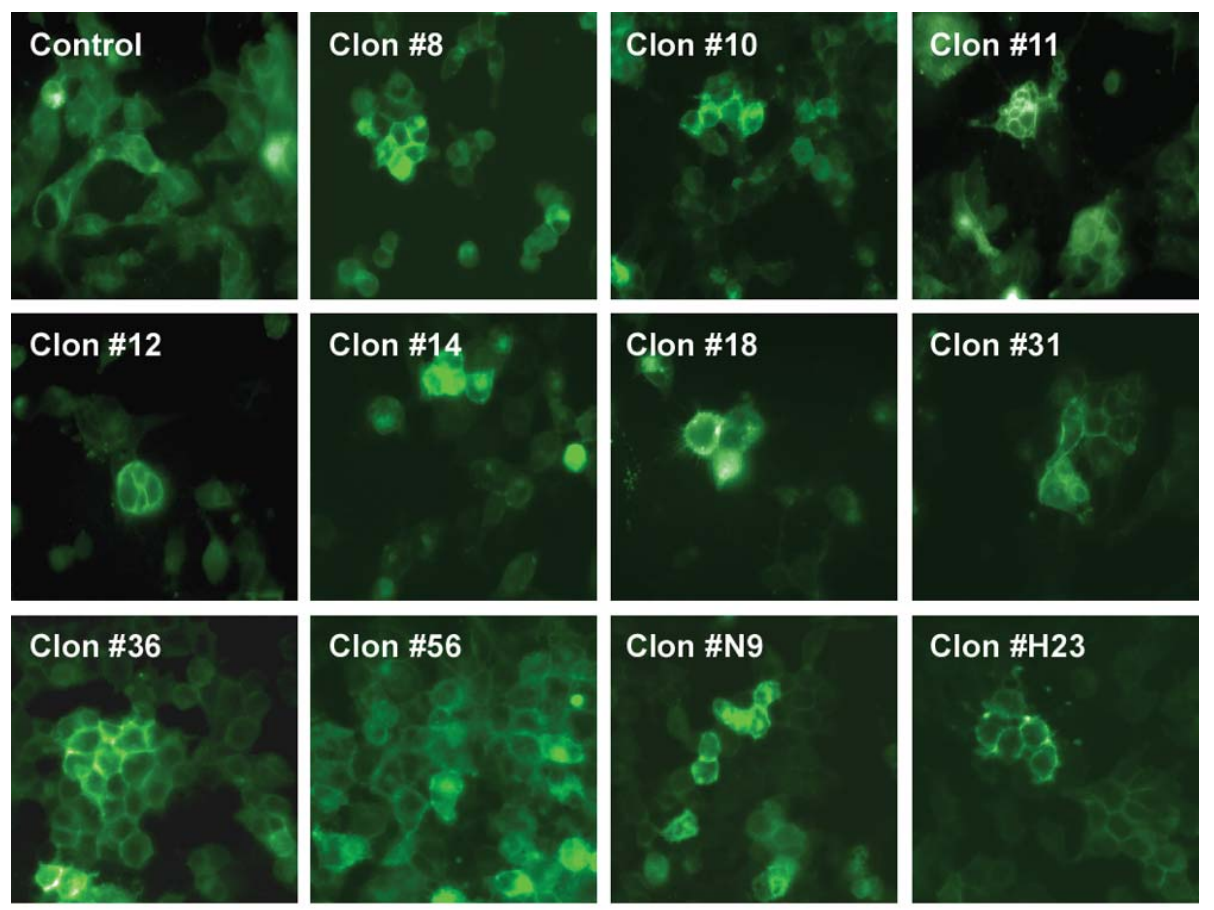

Figura 9. Aislamiento y corroboración de algunos clones aislados tras el rastreo celómico secundario. La línea celular reportera EGFP-Rac1 HEK293T fue transfectada con vector vacío (Control) y cada uno de los clones identificados tras el rastreo celómico secundario para confirmar su capacidad de inducir la translocación de Rac1 desde el citosol a la membrana. Imágenes obtenidas in vivo con un objetivo $20 \mathrm{X}$ en un microscopio de fluorescencia invertido.

\subsection{Corroboración, validación y selección de los clones aislados}

Los 60 clones de ADNc aislados durante el rastreo celómico anteriormente descrito, fueron digeridos con las enzimas de restricción Hindlll y Notl para conocer el tamaño de la región codificante clonada en cada ADNc. Estas dos enzimas de restricción estaban situadas en el sitio de clonación múltiple del vector de expresión utilizado para diseñar la genoteca flanqueando cada uno de los ADNc. Finalmente estos ADNcs fueron secuenciados con el fin de determinar qué proteínas codificaban. Una vez secuenciados, las secuencias obtenidas fueron comparadas con la base de datos del National Center for Biotechnology Information (NCBI), utilizando el algoritmo Blast. Tras este análisis comparativo, 17 de los 60 clones fueron desechados por portar secuencias no codificantes como son regiones 3' UTR de algunos 
genes (Figura 10, pág. siguiente). Los 43 ADNcs restantes alineaban con regiones codificantes del genoma humano. Con la finalidad de continuar descartando posibles falsos positivos, decidimos tener en consideración únicamente aquellos clones cuya región codificante estuviera completa o bien poseyeran un triplete señal de iniciación de traducción (ATG) interno en la misma fase de lectura de la región codificante. Así, la lista de moléculas con potencial translocador sobre Rac1 se redujo a 35 clones. Además, puesto que estábamos interesados en descubrir nuevas proteínas involucradas en el tránsito de la GTPasa Rac1 entre el citosol y la membrana plasmática, decidimos continuar el proceso de selección de sólo aquellos clones que fueran citosólicos o transmembrana, evitando ocuparnos con proteínas que pudieran estar ejerciendo este efecto de translocación de Rac1 a la membrana de un modo indirecto (Figura 10). Un análisis exhaustivo de las bases de datos del NCBI así como el procesamiento de la lista de posibles candidatos con la aplicación online Fatigo nos permitió clasificar los 35 ADNc putativos en 5 categorías independientes dependiendo de su localización subcelular mayoritaria (Figura 10). De este modo, una nueva criba en la lista de los clones aislados hasta entonces, redujo el número de candidatos interesantes a 21 (15 codificaban para proteínas citosólicas y 6 codificaban proteínas transmembrana) (Tabla 4, pág. $59)$.

El siguiente paso en nuestro estudio fue la validación de los clones seleccionados en otro sistema celular diferente al empleado durante el rastreo celómico con el fin de contrastar los resultados obtenidos inicialmente. Para ello procedimos a realizar cotransfecciones del plásmido para EGFP-Rac1 y 8 de los 21 clones seleccionados en la línea celular COS1. Esta última línea celular tiene como ventaja respecto a la línea celular reportera EGFP-Rac1 HEK293T su mayor tamaño celular, lo cual nos ayudaba a apreciar con más detalle los cambios de localización de nuestra proteína de fusión objeto de estudio. Asimismo, el análisis por microscopía confocal nos permitía tener una mayor sensibilidad para determinar si realmente dichos clones se comportaban como translocadores de la proteína de fusión quimérica EGFP-Rac1 de un modo general y conservado en diferentes líneas celulares. De los 8 clones testados en COS1, uno de ellos resultó ser un falso positivo (clon número 15). Los clones restantes que fueron analizados se confirmaron como positivos (Figura 11, pág. 60).

Como indicamos en la Introducción tanto el citoesqueleto de F-actina como ciertas proteínas relacionadas con el mismo pueden regular la activación de algunos miembros de la familia Rho/Rac, modulando la actividad de sus reguladores positivos y negativos (GEFs, GAPs y GDIs) (D'Angelo et al., 2007; Lamb et al., 2000; Post et al., 1998; Takahashi et al., 1997) o sus procesos de señalización (Rivas et al., 2004; Sotiropoulos et al., 1999; Villalba et al., 2000). Además, componentes de la membrana plasmática como integrinas y caveolina-1 controlan la correcta localización de las balsas lipídicas, las cuales constituyen los lugares de 


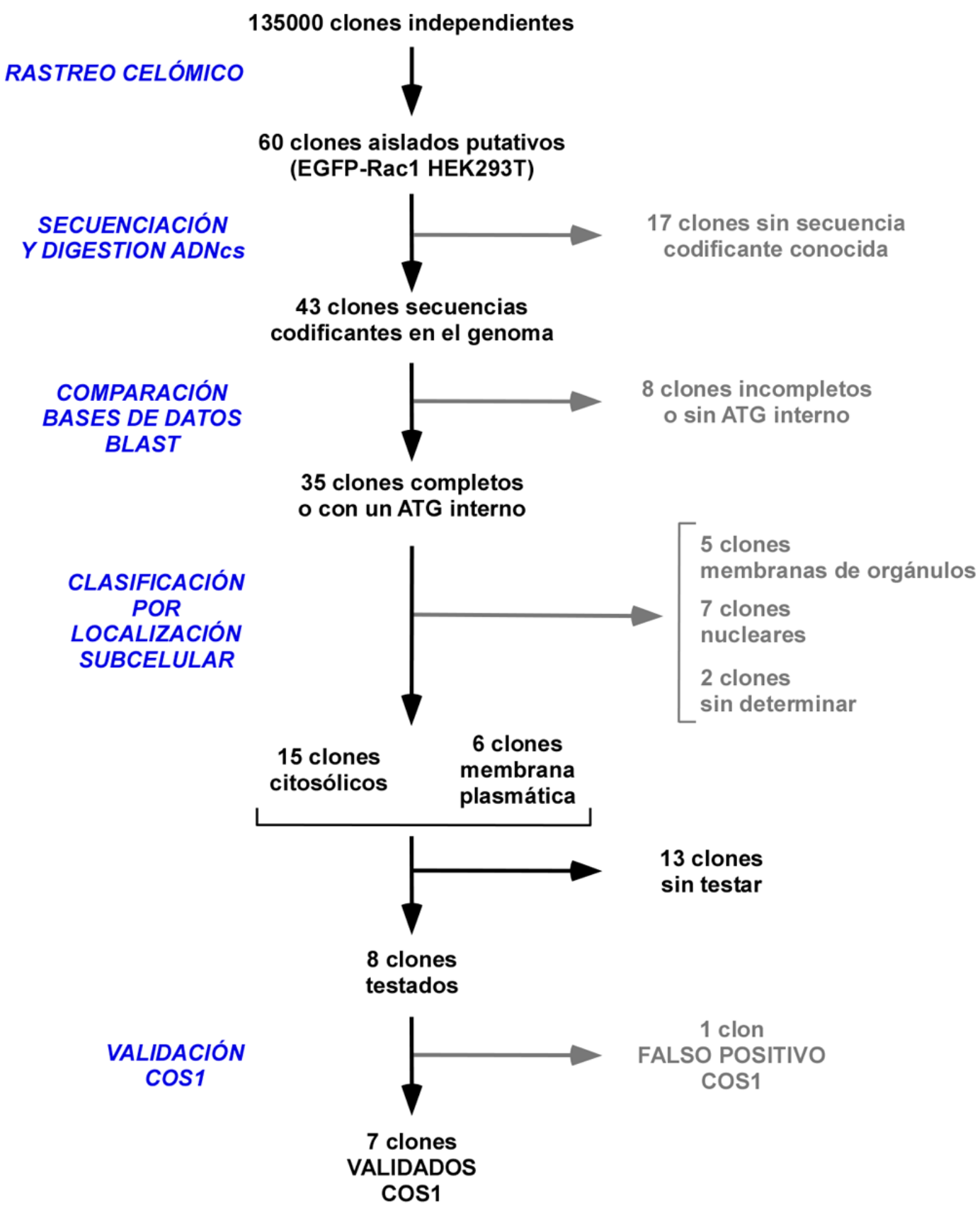

Figura 10. Esquema de la selección de los candidatos putativos aislados tras el rastreo celómico inicial. Se detalla la secuencia cronológica de los pasos seguidos para el proceso de selección y validación de los clones aislados inicialmente tras el rastreo de la genoteca de ADNc en la línea celular reportera EGFP-Rac1 HEK293T. 
Tabla 4. Localización subcelular de los clones positivos aislados en el rastreo celómico. Con la información obtenida de la base de datos del NCBI y aportada por la aplicación Fatigo, los 35 ADNcs fueron clasificados en 5 categorías dependiendo de su localización principal en el interior celular. Los clones cuya secuencia codificante está clonada completamente en la librería de ADNc se indican en negrita.

\begin{tabular}{|c|c|c|c|}
\hline $\begin{array}{l}\text { LOCALIZACIÓN } \\
\text { SUBCELULAR }\end{array}$ & $\begin{array}{l}\text { NÚMERO } \\
\text { DE CLON }\end{array}$ & $\begin{array}{l}\text { SIMBOLO } \\
\text { GENICO }\end{array}$ & $\begin{array}{l}\text { LOCUS } \\
\text { ID }\end{array}$ \\
\hline \multicolumn{4}{|l|}{ Citosol/cito esquele to } \\
\hline & Clon \#7 & CUTCICGI-32 & $\mathrm{BC} 028948$ \\
\hline & Clon \#10 & WDR26 & NM_025160 \\
\hline & Clon \#11 & NACA & NM_001113202 \\
\hline & Clon \#20 & PKM2 & $\mathrm{BC} 007952$ \\
\hline & Clon \#24 & EIF3D & $\mathrm{BC} 000469$ \\
\hline & Clon \#25 & GAPDH & $\mathrm{BC} 023632$ \\
\hline & Clon \#38 & BZW2 & $\mathrm{BC} 008453$ \\
\hline & Clon \#39 & RPS19 & $\mathrm{BC} 017386$ \\
\hline & Clon \#41 & TPT 1 & BC052333 \\
\hline & Clon \#42 & PSMA7 & AK312025 \\
\hline & Clon \#47 & RPS11 & BC100025 \\
\hline & Clon \#50 & ARHGAP4 & $\mathrm{BC} 052303$ \\
\hline & Clon \#54 & COR01A & NM_007074 \\
\hline & Clon \#56 & MAP7D3 & NM_024597 \\
\hline & Clon \#57 & RPL19 & BC095445 \\
\hline \multicolumn{4}{|l|}{ Membrana plasmática } \\
\hline & Clon \#15 & VAPB & NM_004738 \\
\hline & Clon \#35 & CD3E & NM_000733 \\
\hline & Clon \#36 & BSG & NM_001728 \\
\hline & Clon \#H23 & TMEM8 & NM_021259 \\
\hline & Clon \#N9 & EMB & NM_198449 \\
\hline & Clon \#H21 & GNAS & BC108315 \\
\hline \multicolumn{4}{|c|}{ Membrana de orgánulos } \\
\hline & Clon \#16 & $\operatorname{cox} 2$ & EU482360 \\
\hline & Clon \#30 & coX1 & EU807741 \\
\hline & Clon \#34 & MESDC2 & NM_015154 \\
\hline & Clon \#40 & ATP8 & EF657678 \\
\hline & Clon \#52 & CYTB & EF556169 \\
\hline \multicolumn{4}{|l|}{ Núcleo } \\
\hline & Clon \#2 & PARK7 & NM_001123377 \\
\hline & Clon \#5 & RBM39 & BC158172 \\
\hline & Clon \#12 & $\mathrm{CCNI}$ & NM_006835 \\
\hline & Clon \#14 & SMN2 & NM_022875 \\
\hline & Clon \#18 & CCDC59 & $\mathrm{BC} 020647$ \\
\hline & Clon \#33 & HNRPA1 & BC071945 \\
\hline & Clon \#43 & NP220 & $\mathrm{BC} 083513$ \\
\hline \multicolumn{4}{|l|}{ Sin determinar } \\
\hline & Clon \#1 & ARMCX3 & BC005194 \\
\hline & Clon \#45 & ТTC39B & BC142985 \\
\hline
\end{tabular}



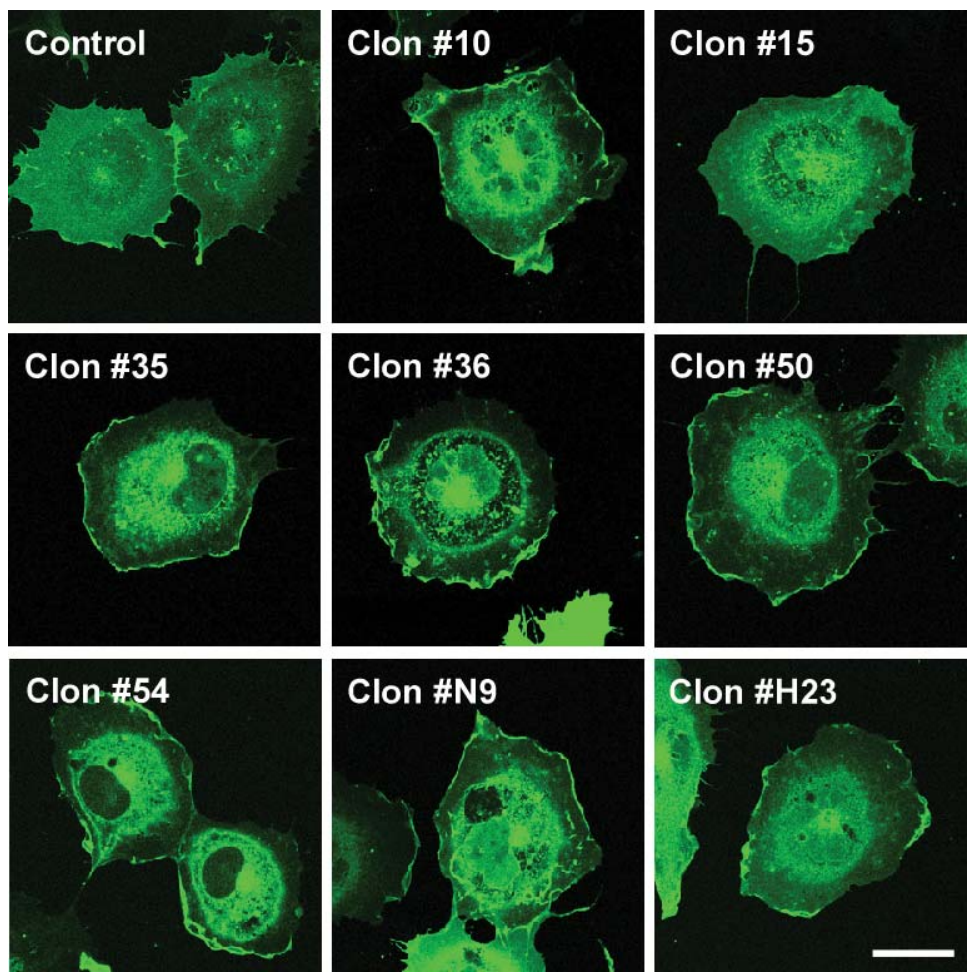

Figura 11. Validación de los clones aislados en el rastreo celómico usando la línea celular COS1. Células COS1 fueron cotransfectadas con el plásmido EGFP-Rac1 y ocho de los clones transmembrana y citosólicos seleccionados. Posteriormente, las células fueron fijadas y procesadas para ser analizadas mediante microscopía confocal. Barra de escala: $20 \mu \mathrm{m}$.

anclaje de Rac1 en la membrana donde interacciona con sus efectores (del Pozo et al., 2004; del Pozo et al., 2005; Del Pozo et al., 2002; del Pozo et al., 2000). En base a estas observaciones, decidimos centrar nuestro trabajo en la caracterización de cuatro de los translocadores validados en coS1 que pertenecen a dos categorías funcionales diferentes: dos proteínas citosólicas reguladoras del citoesqueleto de F-actina (Coronina-1A y WDR26) y dos proteínas transmembrana relacionadas con integrinas (Basigina y TMEM8A) (Figura 12, pág. siguiente).

Coronina-1A pertenece a una gran familia de proteínas, presentes desde levaduras a mamíferos, con dominios WD40 y estructura de beta hélice que controlan diferentes aspectos de la polimerización y ramificación de filamentos de F-actina (de Hostos, 1999; Rybakin and Clemen, 2005; Uetrecht and Bear, 2006). Éstos incluyen el empaquetamiento y estabilización de filamentos de F-actina (Galkin et al., 2008; Goode et al., 1999), el crecimiento y el ángulo de orientación de nuevas ramificaciones de F-actina (Cai et al., 2008), y el desensamblaje de viejos filamentos de F-actina (Cai et al., 2008; Kueh et al., 2008). Estas actividades están mediadas por la interacción de coroninas con diferentes estados de unión a nucleótidos de ATP/ADP de la actina (Gandhi et al., 2009), con el complejo polimerizador de actina Arp2/3 que controla la ramificación y crecimiento de nuevos filamentos de F-actina (Cai et al., 2005; Cai et al., 2007b; Goode et al., 1999; Humphries et al., 2002; Machesky et al., 1997; Shiow et al., 2008) y con Slingshot-1L (Cai et al., 2007b), una fosfatasa que activa al factor despolimerizador 
de F-actina denominado ADF/cofilina (Huang et al., 2006; Niwa et al., 2002). Las coroninas juegan un papel importante en procesos como migración celular, fagocitosis, manipulación del citoesqueleto de la célula huésped por patógenos intracelulares y tráfico de vesículas (de Hostos, 1999; Rybakin and Clemen, 2005; Uetrecht and Bear, 2006). En el caso concreto de Coronina-1A se ha observado que está involucrada en la migración y supervivencia de células $\mathrm{T}$ gracias a recientes estudios con modelos genéticos en ratón y a la identificación de mutaciones inactivadoras tanto en ratones como en humanos afectados por inmunodeficiencias de células T (Foger et al., 2006; Haraldsson et al., 2008; Mueller et al., 2008; Mugnier et al., 2008; Shiow et al., 2009; Shiow et al., 2008). Además, células T primarias derivadas de ratones deficientes en Coronina-1A muestran una activación ineficiente de Rac1 en respuesta a citoquinas como SDF1a (Foger et al., 2006).
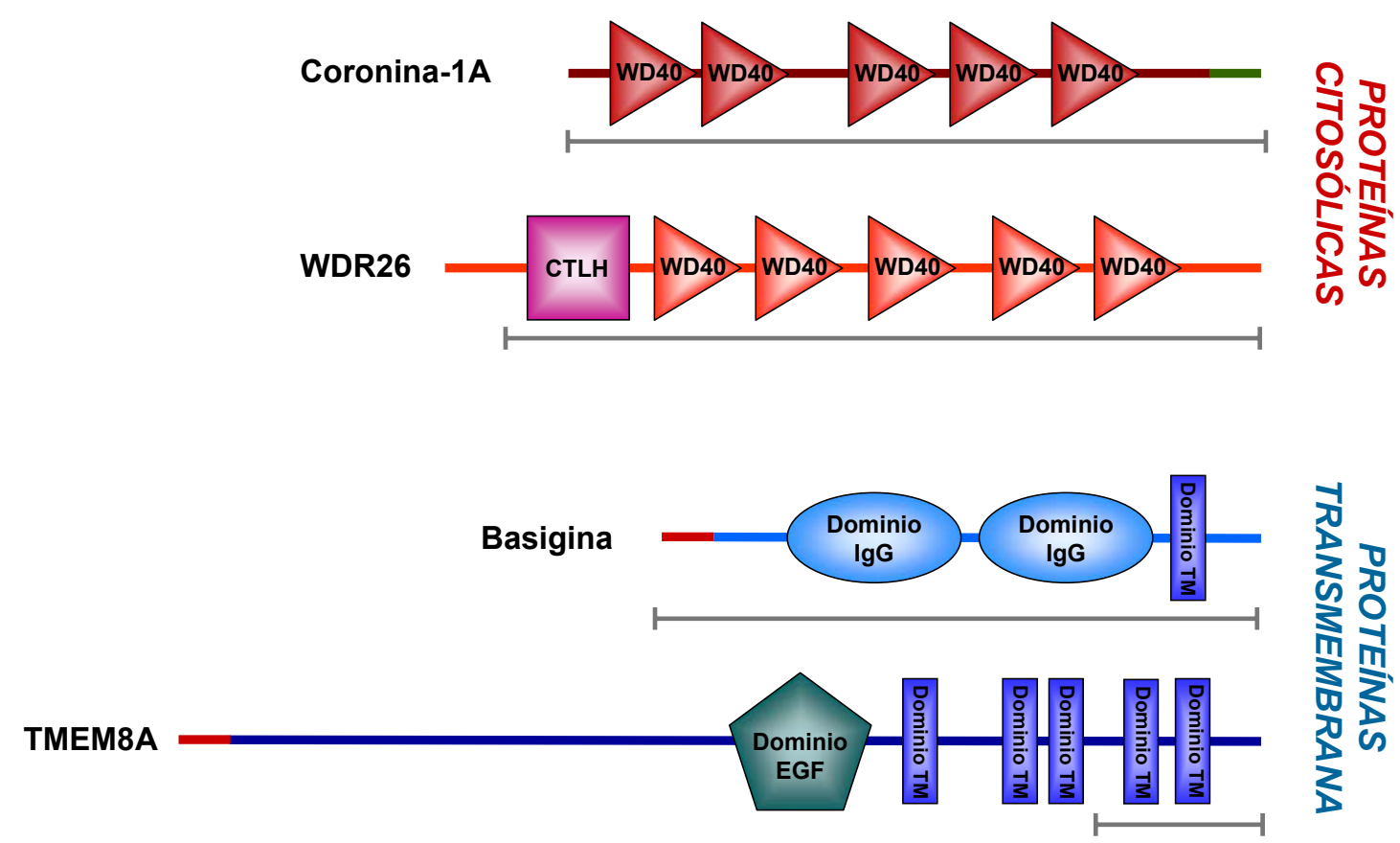

Figura 12. Estructura por dominios de las moléculas seleccionadas con capacidad translocadora de la proteína reportera EGFP-Rac1. Representación gráfica por dominios de las proteínas transmembrana y citosólicas validadas en COS1 y seleccionadas para la caracterización del mecanismo de translocación de EGFP-Rac1. TM, dominio transmembrana; Ig, dominio de tipo inmunoglobulina; EGF, dominio de tipo EGF (del inglés, epidermal growth factor). La barra roja representa el péptido señal de las proteínas transmembrana. Las barras en color gris, debajo de cada proteína, representan la región de dichas proteínas que se encuentra clonada en el interior de cada uno de los ADNc aislados de la genoteca.

La proteína WDR26, estructuralmente relacionada a Coronina-1A (Figura 12) está relacionada con procesos de estrés oxidativo y controla rutas de señalización intracelular mediadas por MAPK (Zhao et al., 2009; Zhu et al., 2004). En su extremo más aminoterminal encontramos un dominio CTLH (del inglés, $C$ terminal to LisH motif) de estructura en alfa hélice 
y función desconocida que se ha encontrado en proteínas relacionadas con la dinámica del citoesqueleto de microtúbulos (Sapir et al., 1997).

Basigina, también conocida como CD147 o Emmprin (del inglés, extracellular matrix metalloproteinase inducer), es una glicoproteína transmembrana de paso único perteneciente a la superfamilia de inmunoglobulinas (lacono et al., 2007; Muramatsu and Miyauchi, 2003; Nabeshima et al., 2006; Yan et al., 2005). Su estructura contiene un fragmento extracelular con uno o dos dominios inmunoglobulina (dependiendo de la isoforma), un fragmento transmembrana y una cola citosólica de 39 aminoácidos (Gabison et al., 2005) (Figura 12). A través de su habilidad para interaccionar con un amplio abanico de proteínas en la superficie y en el interior celular, Basigina ejerce una diversificada red de funciones dependiendo del tejido y/o del tipo celular. Con respecto al contexto molecular en el que realizamos nuestro estudio, Basigina interacciona con integrinas (Berditchevski et al., 1997; Xu and Hemler, 2005) que estabilizan en la superficie celular los lugares de anclaje de Rac1 en la membrana. Además, Basigina promueve la reorganización del citoesqueleto de actina en células embrionarias de Drosophila melanogaster a través de su acción sobre integrinas (Curtin et al., 2005). Por otra parte, ha sido demostrado que caveolina-1, proteína que media la internalización de las balsas lipídicas desde la superficie celular, interacciona y regula la localización de Basigina en la membrana plasmática (Schwab et al., 2007; Tang et al., 2004; Tang and Hemler, 2004).

Finalmente, TMEM8A (del inglés, transmembrane protein $8 A$ ) es una glicoproteína, con cinco segmentos hidrofóbicos putativos que atraviesan la membrana plasmática (Figura 12). perteneciente a una familia "atípica" dentro del grupo de proteínas transmembrana de paso múltiple, que normalmente poseen cuatro o siete dominios transmembrana (Motohashi et al., 2000). Este hallazgo sugiere que TMEM8A podría formar parte de una nueva subfamilia dentro de este grupo de proteínas de múltiple paso transmembrana. Una búsqueda pormenorizada en las bases de datos de NCBI ha mostrado que TMEM8B comparte una alta homología con TMEM8A, particularmente en su región aminoterminal y el primer dominio transmembrana. Además, el espacio entre los residuos de cisteína de la región extracelular está totalmente conservado entre ambas proteínas. Estos resultados revelan que TMEM8A y TMEM8B podrían definir una nueva subfamilia dentro de la gran superfamilia de proteínas transmembrana de paso múltiple (Motohashi et al., 2000). Se ha demostrado que alguno de los miembros de esta superfamilia puede interaccionar en la superficie celular con integrinas y modular su función (Brown et al., 1990; Wang and Frazier, 1998; Wang et al., 1999), interaccionar con proteínas citoesqueléticas del complejo ERM que regulan la actividad de moduladores positivos y negativos para miembros de la familia Rho/Rac (D'Angelo et al., 2007; Peng et al., 2007; Takahashi et al., 1998; Takahashi et al., 1997), e incluso promover procesos dependientes de la actividad de Rac1 en determinados tipos celulares (Miyashita et al., 2004). 


\section{CAPÍTULO 2. CARACTERIZACIÓN DE LA INTERACCIÓN FUNCIONAL ENTRE Coronina-1A Y Rac1}

\subsection{Papel de Coronina-1A en el mecanismo de translocación y activación de Rac1}

\subsubsection{Coronina-1A solamente transloca GTPasas de la subfamilia Rac}

Dado que la mayoría de GTPasas de la familia Rho/Rac presentan una regulación de la localización subcelular similar a Rac1, decidimos abordar en primer lugar si Coronina-1A podía también regular la translocación de otros miembros de la familia Rho/Rac. Para ello, realizamos estudios de inmunofluorescencia en células COS1 que expresaban de forma transitoria las versiones silvestres de las GTPasas Rac1, RhoG, RhoA y Cdc42, bien aisladamente o en combinación con Coronina-1A. Para facilitar estos estudios, las GTPasas y Coronina-1A fueron etiquetadas con el epitopo AU5 y la proteína verde fluorescente EGFP, respectivamente. Tras las transfecciones transitorias y la fijación de las células, el análisis del efecto de Coronina-1A sobre la localización subcelular de las GTPasas seleccionadas se realizó mediante técnicas de microscopía confocal. Para ello, se realizaron tres aproximaciones técnicas diferentes, aunque complementarias. En primer lugar, se determinó la localización subcelular de las GTPasas y Coronina-1A a través de la adquisción estándar de imágenes con el microscopio confocal utilizando la inmunofluorescencia de las GTPasas teñidas con anticuerpos contra el epitopo AU5 y la epifluorescencia de la EGFP fusionada a Coronina-1A. En segundo lugar, se registraron los perfiles de inmunofluorescencia y epifluorescencia de las anteriores proteínas en zonas concretas de las células en estudio, lo que facilitaba una imagen más cuantitativa de la translocación de estas moléculas en la membrana plasmática y el citosol. En estos estudios, una proteína citosólica presentará un perfil constante a lo largo del eje escogido para el análisis. Por el contrario, si la proteína se encuentra localizada en la membrana plasmática se detectarán picos de mayor intensidad en los lugares donde el eje atraviesa esas zonas de membrana. En tercer lugar, se cuantificaron también los niveles de intensidad de fluorescencia de cada GTPasa en las regiones correspondientes a la membrana plasmática utilizando la herramienta ImageJ (NIH Image Software). Los valores de fluorescencia absolutos obtenidos en cada caso fueron normalizados respecto a los valores obtenidos en células que expresaban cada GTPasa de forma individual, tal y como se explica en Materiales y Métodos (pág. 44).

Estos experimentos mostraron que todas las GTPasas seleccionadas para este estudio tenían una distribución citosólica cuando se expresaron en ausencia de Coronina-1A-EGFP en células COS1 (Figuras 13 y 14, págs. 64 y 65, respectivamente). Por el contrario, Coronina1A-EGFP mostraba una localización tanto citoplasmática como membranaria, encontrándose especialmente enriquecida en las ondulaciones de membrana tipo membrane ruffles que aparecían como consecuencia de la expresión ectópica de esta proteína citoesquelética 
(Figuras 13 y 14). Mientras que la coexpresión de Coronina-1A-EGFP con las GTPasas no cambio el patrón habitual de distribución subcelular de aquélla, sí se observó un enriquecimiento de las GTPasas AU5-Rac1 y AU5-RhoG en la membrana plasmática y membrane ruffles en estas condiciones (Figura 13). La microscopía confocal mostró también que estas GTPasas colocalizaban con Coronina-1A en estas estructuras celulares (Figura 13). A diferencia de estas GTPasas, estos experimentos indicaron que la coexpresión de Coronina1A-EGFP no afectaba a la distribución subcelular de las GTPasas AU5-RhoA y AU5-Cdc42

(Figura 14). Estos resultados indican que la acción de Coronina-1A está limitada a miembros de la subfamilia Rac.

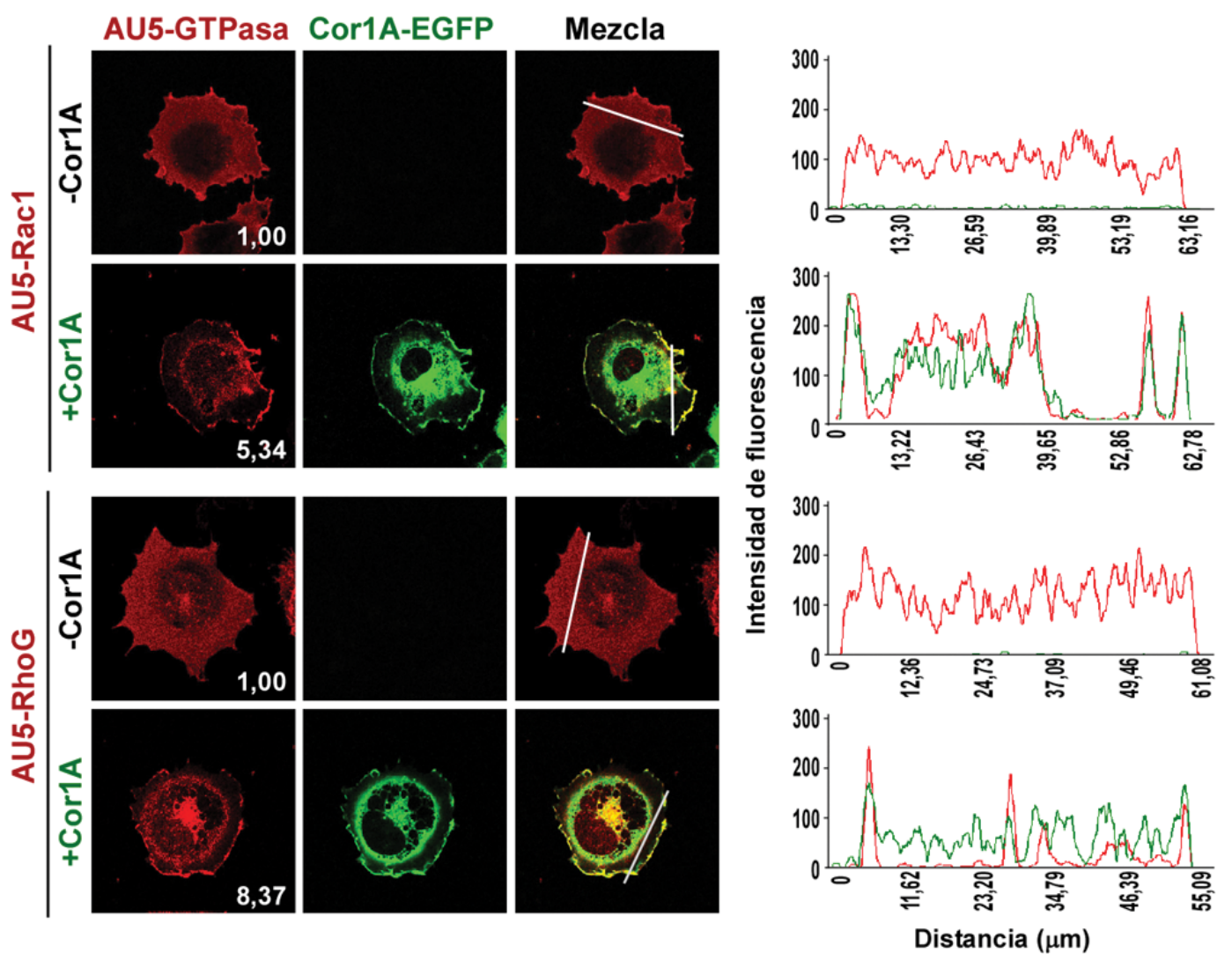

Figura 13. Coronina-1A transloca a las GTPasas Rac1 y RhoG a la membrana plasmática. Se transfectaron células COS1 con los plásmidos de expresión para las versiones silvestres etiquetadas con AU5 de las GTPasas Rac1 y RhoG de forma individual o junto con el plásmido de expresión para la proteína de fusión Coronina-1A-EGFP. Las células fueron fijadas y la expresión de las proteínas transfectadas se detectó con anticuerpos anti-AU5 seguido de anticuerpos secundarios conjugados a Cy3 (en rojo), en el caso de las GTPasas, y gracias a la epifluorescencia de la EGFP, en el caso de Coronina1A. Las preparaciones se analizaron finalmente mediante microscopía confocal. En el cuadrante inferior derecho de cada panel de las GTPasas se muestran los niveles de fluorescencia relativa medidos en la membrana de cada imagen tomada. A la derecha se muestran las gráficas de distribución de intensidad de fluorescencia a lo largo del eje trazado (indicado como una línea blanca que atraviesa la célula) en la imagen correspondiente. 

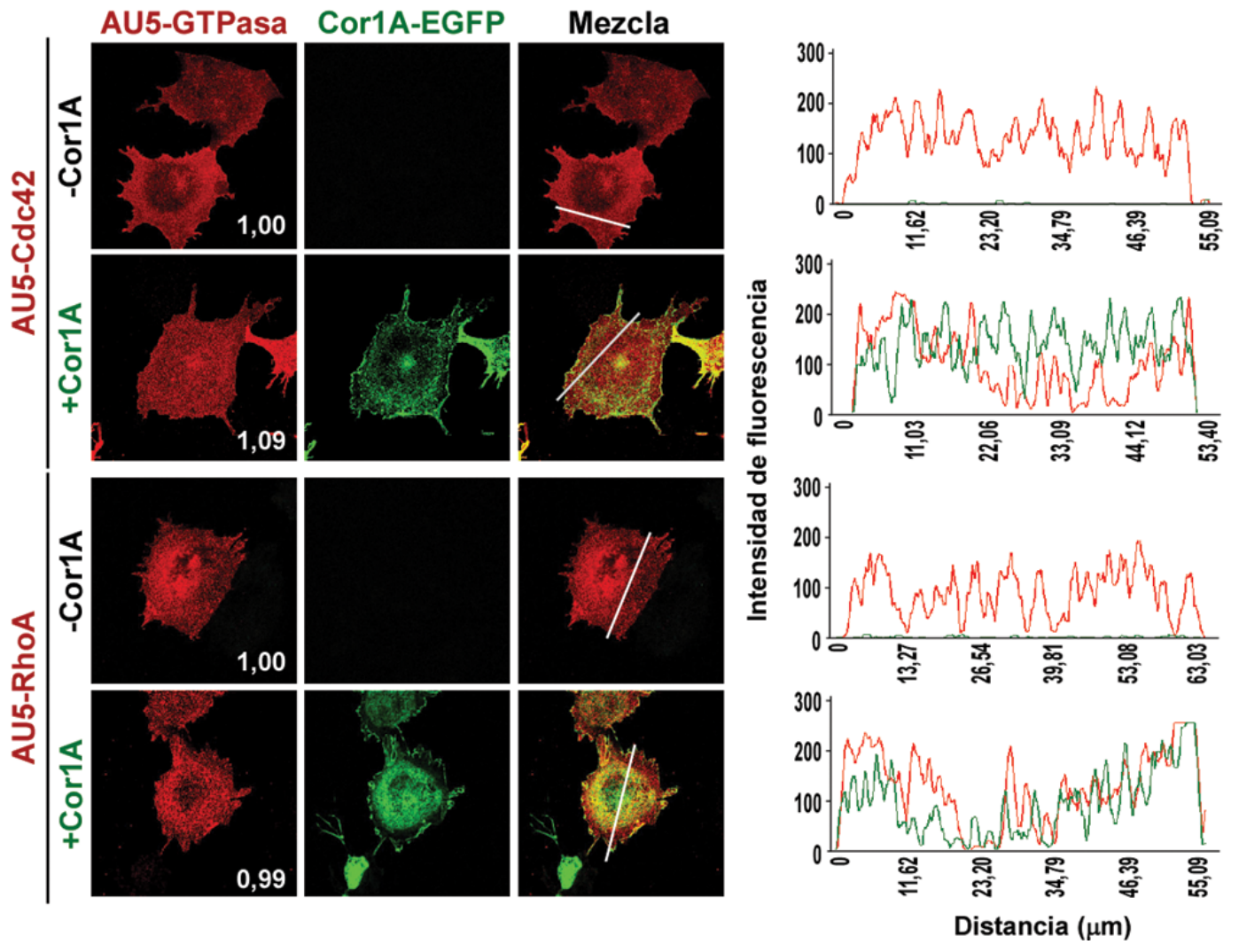

Figura 14. Coronina-1A no transloca a las GTPasas Cdc42 y RhoA a la membrana plasmática. Se transfectaron células COS1 con los plásmidos de expresión para las versiones silvestres etiquetadas con AU5 de las GTPasas Cdc42 y RhoA de forma individual o junto con el plásmido de expresión para la proteína de fusión Coronina-1A-EGFP. La expresión de las proteínas transfectadas se detectó como se indica en la Figura 13 (pág. anterior). Las preparaciones se analizaron finalmente mediante microscopía confocal. Los niveles de fluorescencia a lo largo de la membrana plasmática para cada una de las GTPasas en cada condición experimental se muestran en el cuadrante inferior derecho. A la derecha se muestran las gráficas de distribución de intensidad de fluorescencia a lo largo del eje (línea blanca que atraviesa la célula) trazado en la imagen correspondiente.

\subsubsection{Coronina-1A necesita unirse a F-actina para translocar a la GTPasa Rac1 a}

\section{la membrana plasmática}

Coronina-1A es una proteína citoesquelética que interacciona físicamente tanto con filamentos de F-actina como con el complejo Arp2/3. Con el fin de verificar si la translocación de Rac1 dependía de estas proteínas citoesqueléticas, decidimos emplear en los estudios de translocación una versión mutante de Coronina-1A en la que la arginina presente en la posición 29 se había sustituido por un residuo de ácido aspártico (de carga electrostática opuesta). Estudios previos realizados con Coronina-1B han demostrado que esta mutación elimina la capacidad de estas moléculas de interaccionar con F-actina pero no con el complejo Arp2/3 (Cai et al., 2007a). Por tanto, el uso de este mutante nos permitía investigar directamente el grado de contribución de la F-actina y Arp2/3 en el proceso de translocación de Rac1. El efecto de este mutante en la translocación de Rac1 se estudió por técnicas de microscopía confocal, 
tal como se describió en el apartado anterior de esta sección (pág. 63). Junto a ello, y con el fin de tener una imagen más cuantitativa del proceso, utilizamos una cuarta aproximación técnica basada en el cálculo del índice de translocación de Rac1 a la membrana plasmática descrito en trabajos previos (pág. 44). Estos estudios mostraron que la mutación R29D elimina la distribución membranaria de Coronina-1A así como su capacidad de inducir la translocación de Rac1 (Figura 15A).

Con el fin de averiguar si la translocación de Rac1 podría ser un evento general de múltiples reguladores citoesqueléticos, comprobamos seguidamente si la sobreexpresión de otras proteínas implicadas en la reorganización de filamentos de F-actina subcorticales afectaba a la localización subcelular de nuestra GTPasa. Para ello, decidimos comprobar si la proteína IRSp53 podía también inducir la translocación de Rac1 a la membrana plasmática. Esta proteína participa en la modificación citoesquelética en los lamelipodios inducida por Rac1, ya que favorece la interacción entre la GTPasa y WAVE (Miki et al., 2000; Teodorof et al., 2009). Pese a esta función citoesquelética, estudios por microscopía confocal demostraron que la sobreexpresión de IRSp53 no afecta la localización subcelular de la forma silvestre de Rac1 (Figura 15B).

A
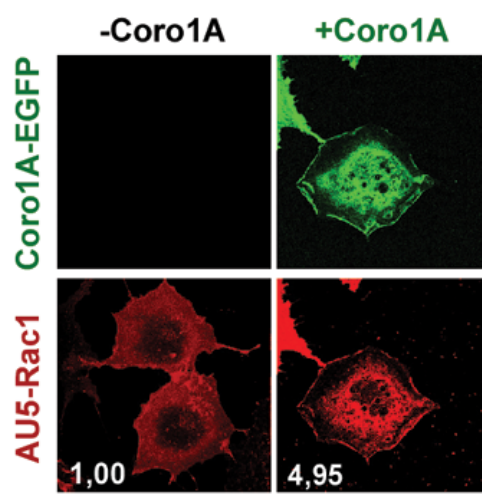

+ Coro1A ${ }^{\text {R29D }}$

$0,33 \pm 0,05$

$1,01 \pm 0,05$

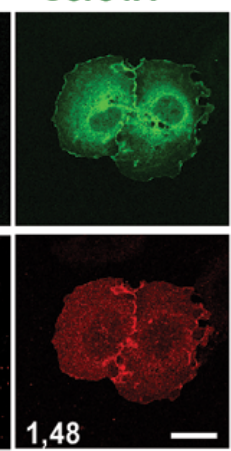

B

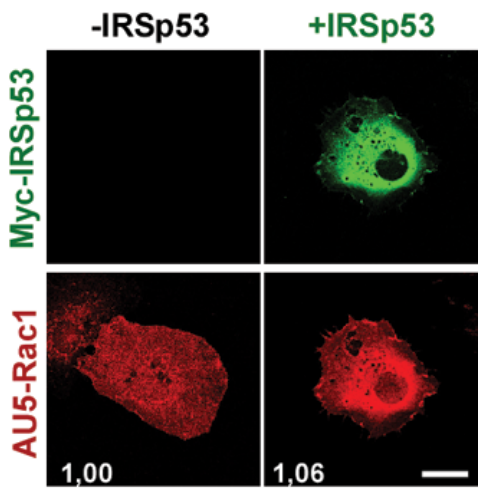

Índice de translocación de Rac1

Figura 15. Coronina-1A transloca a Rac1 a la membrana de una forma dependiente de su unión a Factina. (A) Células COS1 fueron transfectadas con plásmidos codificantes para AU5-Rac1 de forma individual o conjunta con los vectores de expresión para las proteínas de fusión Coronina-1A-EGFP y Coronina-1 $A^{R 29 D}$-EGFP. Las células se tiñeron para inmunofluorescencia como se indica en la Figura 13 (pág. 64). Los valores de fluorescencia relativa para Rac1 en la membrana plasmática se indican en el cuadrante inferior izquierdo de cada imagen. En la parte inferior del panel se muestra el índice de translocación de Rac1 representado en valores numéricos. (B) Se transfectaron células COS1 con la versión silvestre de Rac1 etiquetada con AU5 de forma individual o conjunta con el vector de expresión para IRSp53 etiquetada con el epitopo Myc. Las células se fijaron y tiñeron con anticuerpos anti-AU5 y anti-Myc seguido de anticuerpos secundarios conjugados a Cy3 (rojo) y Cy2 (verde) para la detección de la GTPasa AU5-Rac1 y la proteína Myc-IRSp53, respectivamente. Las preparaciones se analizaron mediante microscopía confocal. Los valores de fluorescencia relativa para Rac1 en la membrana plasmática se indican en el cuadrante inferior izquierdo de cada imagen. Barra de escala: $20 \mu \mathrm{m}$. 
Puesto que Coronina-1A y Rac1 parecen colocalizar en la membrana plasmática usando microscopía confocal, decidimos llevar a cabo estudios de localización subcelular utilizando microscopía TIRF para investigar la posible existencia de complejos Coronina-1A/Factina y Coronina-1A/Rac1 en la membrana basal de células COS1 vivas. Este tipo de microscopía utiliza ondas evanescentes para excitar selectivamente fluoróforos situados en una región restringida de la muestra inmediatamente adyacente a la superficie vidrio-medio acuoso (muestra). Esta onda evanescente sólo se genera cuando la luz incidente se refleja totalmente en la superficie vidrio-agua. El campo electromagnético generado por este tipo de ondas decae de manera exponencial desde la interfaz, por lo que penetra a una profundidad de sólo aproximadamente $100 \mathrm{~nm}$ en el medio de la muestra. Así, la microscopía TIRF permite una visualización selectiva de la superficie de determinadas regiones en la célula viva, como la membrana plasmática basal (que posee alrededor de $7,5 \mathrm{~nm}$ de espesor) y la región citoplasmática inmediatamente debajo de la misma. Esto permite la obtención de imágenes de alta resolución en una región subcelular muy específica en la que excitamos únicamente las proteínas fluorescentes en esa región y no en el resto de la muestra, aumentando considerablemente el cociente "señal/ruido de fondo" con respecto a otros tipos de microscopía convencionales. Utilizamos en estos experimentos la versión fluorescente de Coronina-1A (Coronina-1A-EGFP), el mutante defectivo para la unión a F-actina (Coronina-1A ${ }^{\text {R29D }}$-EGFP) y la proteína fluorescente no quimérica EGFP junto con un plásmido de expresión que codificaba para un fragmento de la proteína Abp140 (Lifeact) fusionada al extremo amino-terminal de la proteína fluorescente roja (mRFP-Rubi), la cual sirve como sonda fluorescente para visualizar filamentos de F-actina in vivo (Riedl et al., 2008). Observamos, como era de esperar, que la versión silvestre Coronina-1A-EGFP colocalizaba con la sonda roja para F-actina en las proximidades de la membrana plasmática basal. $\mathrm{Ni}$ el mutante Coronina-1 $\mathrm{A}^{\mathrm{R} 29 \mathrm{D}}$-EGFP ni la proteína no quimérica EGFP exhibieron dichas propiedades (Figura 16A, pág. siguiente). Estos datos están de acuerdo con las propiedades de Coronina-1A como proteína de unión a Factina. Para examinar la existencia de complejos Coronina-1A/Rac1, utilizamos junto con las proteínas verdes fluorescentes anteriormente indicadas la versión silvestre de Rac1 etiquetada con una proteína roja fluorescente (mCherry-Rac1). Estos experimentos nos permitieron corroborar la existencia de complejos Coronina-1A/Rac1 en las zonas próximas a la membrana plasmática únicamente cuando Coronina-1A mantenía su capacidad de unirse a F-actina (Figura 16B). Estas observaciones indican, por tanto, que Coronina-1A requiere la interacción con F-actina, pero no la del complejo Arp2/3, para inducir la translocación de Rac1. Además, demuestran que esta translocación es una característica intrínseca de Coronina-1A y no un fenómeno general ejercido por cualquier proteína que una o regule los filamentos de F-actina. 

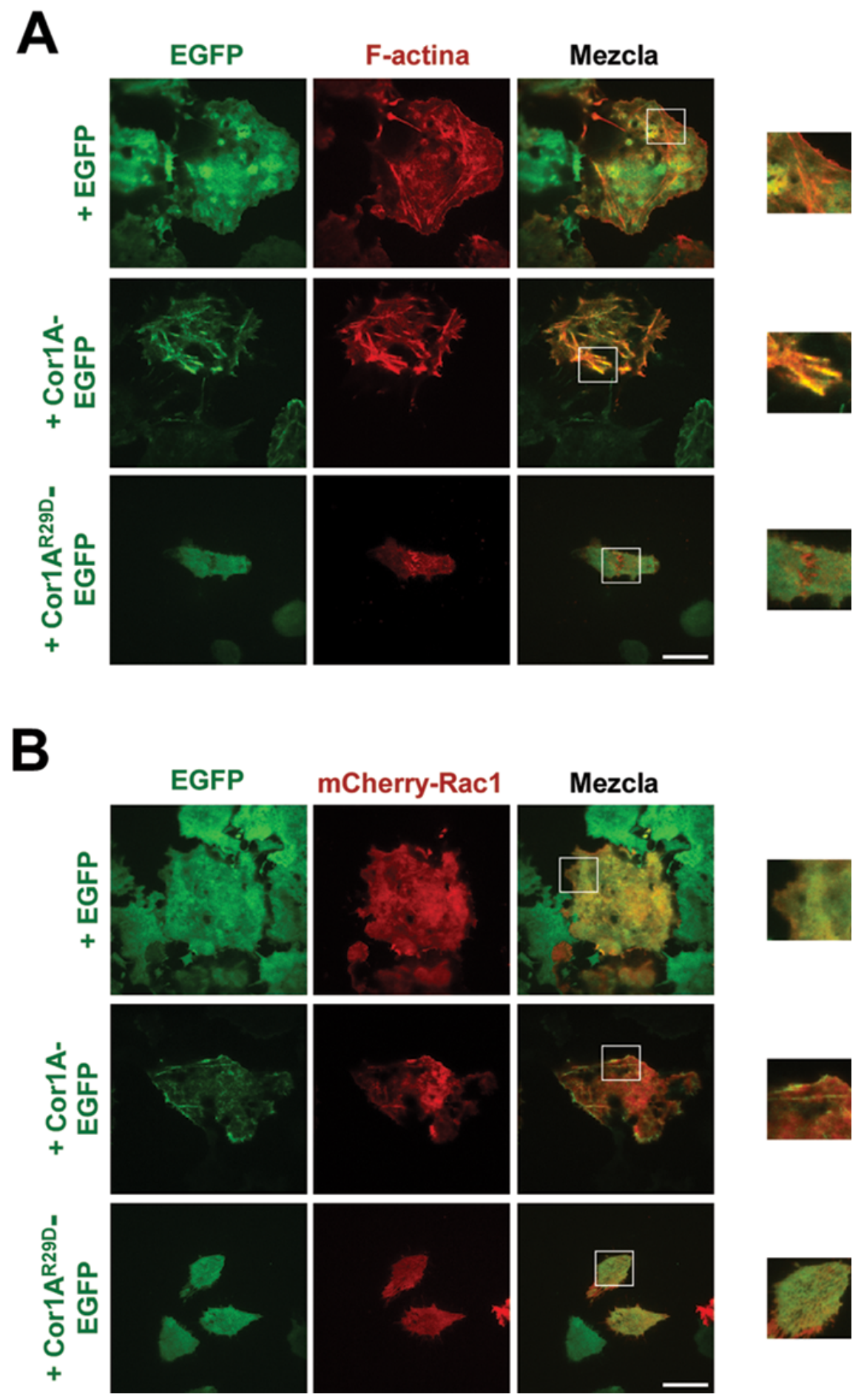

Figura 16. Colocalización in vivo de Coronina-1A/F-actina/Rac1 en la membrana plasmática basal de células COS1. Células COS1 expresando las proteínas fluorescentes verdes EGFP, Coronina-1AEGFP y Coronina-1A ${ }^{R 29 D}$-EGFP fueron transfectadas con plásmidos de expresión para Lifeact-Rubi (A) y mCherry-Rac1 (B) y analizadas mediante microscopía TIRF in vivo. Las zonas de colocalización entre las proteínas de fusión verdes y las sondas fluorescentes rojas de F-actina (A) o mCherry-Rac1 (B) se muestran en amarillo. A la derecha se representa la magnificación de las zonas indicadas y seleccionadas en cada una de las imágenes tomadas. Barra de escala: $25 \mu \mathrm{m}$. 


\subsubsection{Coronina-1A es importante para la correcta translocación y activación de} la GTPasa Rac1 in vivo

Con el fin de confirmar las observaciones anteriores mediante técnicas independientes, decidimos emplear ensayos de sobreexpresión y pérdida de función para verificar el efecto de Coronina-1A ectópica y endógena en la localización y nivel de actividad de Rac1 in vivo. Para ello, decidimos llevar a cabo en primer lugar ensayos de fraccionamiento subcelular que nos permitieran aislar la fracción de membrana del resto de contenido celular y analizar en dicha fracción los niveles de Rac1 endógeno. De esta forma, podríamos confirmar los estudios previos realizados con técnicas de inmunofluorescencia mediante una metodología diferente que, además, nos daba una lectura poblacional más que un registro de célula única como el caso de la microscopía. Para facilitar estos estudios, generamos mediante técnicas de transducción retrovirales dos líneas celulares derivadas de células COS1 que expresaban de forma estable Coronina-1A-EGFP o EGFP como control negativo. Estas dos líneas se denominaron ACC1-2 y ACC1-1, respectivamente (pág. 40). Cultivos exponenciales de estas células se sometieron a fraccionamiento subcelular por técnicas de ultracentrifugación, tras lo cual la presencia de la proteína Rac1 endógena fue determinada mediante el uso de Western blot con anticuerpos dirigidos contra esta GTPasa (pág. 45). De acuerdo con lo observado en los estudios por microscopía, estos experimentos demostraron que los niveles de Rac1 en las fracciones de membrana aisladas eran significativamente mayores en las células ACC1-2 que en las ACC1-1. Por el contrario, los niveles endógenos de la GTPasa RhoA en esas mismas fracciones de membrana no mostraron cambio alguno (Figura 17, pág. siguiente).

Seguidamente llevamos a cabo experimentos de Pull down para verificar si el aumento de la localización membranaria de Rac1 inducida por Coronina-1A iba asociada a un aumento en sus niveles de activación (pág. 47). Estos experimentos se basan en la incubación de extractos celulares con una proteína Glutatión-S-transferasa (GST) fusionada al dominio CRIB de Pak1. Esta proteína híbrida se une exclusivamente a Rac1 cuando la GTPasa está unida a GTP, por lo que es una herramienta muy útil para determinar niveles de activación de Rac1 in vivo. Para realizar estos experimentos, las células ACC1-1 y ACC1-2 fueron privadas de suero brevemente, estimuladas con EGF durante los tiempos indicados, lisadas, los extractos celulares sometidos a Pull down y posteriormente analizados mediante Western blot. Estos análisis demostraron que la sobreexpresión de Coronina- $1 \mathrm{~A}$ induce un aumento de los niveles de activación de Rac1 tanto en condiciones basales como tras la estimulación con EGF (Figura 18A,B, pág. 71). El efecto de Coronina-1A sobre la ruta de Rac1 es específico, puesto que su sobreexpresión no afectó los niveles de activación de la ruta Ras/Erk1/2 (Figura 18A, tercer panel desde arriba). 
A

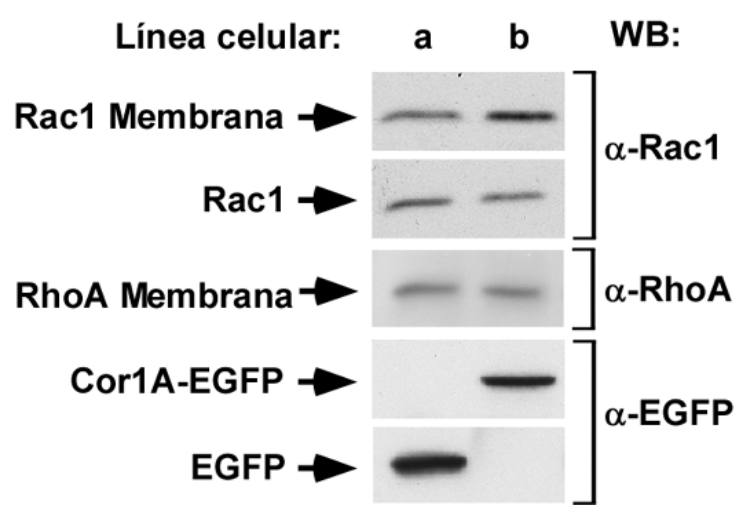

B

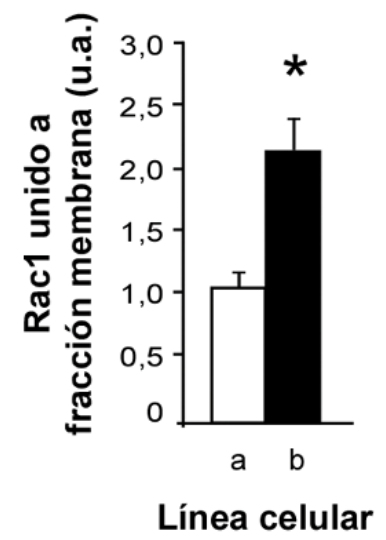

Figura 17. Coronina-1A promueve el enriquecimiento de Rac1 en la fracción de membrana. (A) Células en crecimiento exponencial procedentes de las líneas celulares ACC1-1 (a) y ACC1-2 (b) fueron sometidas a fraccionamiento subcelular mediante ultracentrifugación para aislar la fracción de membrana. Cantidades equivalentes de proteína procedentes de la fracción de membrana y de los lisados celulares totales fueron separados electroforéticamente y analizados mediante Western blot. La cantidad de Rac1 endógena unida a la membrana y en los lisados totales se detectó con anticuerpos anti-Rac1. La cantidad de RhoA endógeno unido a la membrana se detectó con anticuerpos anti-RhoA. La expresión de las proteínas fluorescentes Coronina-1A-EGFP y EGFP se detectó con anticuerpos anti-EGFP. (B) Las bandas obtenidas por Western blot con anticuerpos anti-Rac1 de las fracciones de membrana fueron cuantificadas por densitometría usando el software ImageJ. Los valores obtenidos fueron normalizados respecto a la cantidad de Rac1 en el lisado celular total. La media y la desviación estándar de los valores obtenidos en tres experimentos independientes se representan en la gráfica en unidades arbitrarias (u.a.). * $P \leq 0,05$, comparado con los valores obtenidos en las células ACC1-1 (a).

Con el fin de determinar si esta activación ocurría en la membrana plasmática o en otras regiones celulares, decidimos realizar una segunda aproximación experimental basada en la expresión de un biosensor que permite detectar la localización del GTP-Rac1 en el interior celular. Esta molécula estaba compuesta del dominio CRIB de Pak1, descrita anteriormente, unida a la EGFP. El plásmido que codificaba esta proteína fue transfectado en células COS1 bien solo o en combinación de Coronina-1A, tras lo cual las células se fijaron y analizaron por microscopía confocal. Para facilitar la detección de ambas proteínas, en estos experimentos utilizamos una versión de Coronina-1A fusionada a la RFP (del inglés, Red fluorescent protein). El biosensor EGFP-CRIB mostró una distribución citoplásmica y nuclear cuando se expresó en ausencia de Coronina-1A (Figura 18C). Sin embargo, la coexpresión de esta última proteína provocó un enriquecimiento del EGFP-CRIB en la membrana plasmática (Figura 18C). Estos resultados demuestran que la sobreexpresión de Coronina-1A promueve la movilización de la GTPasa Rac1 desde el citosol hasta la membrana y que este cambio en la localización subcelular se correlaciona con la activación de la misma en esta región subcelular. 
A

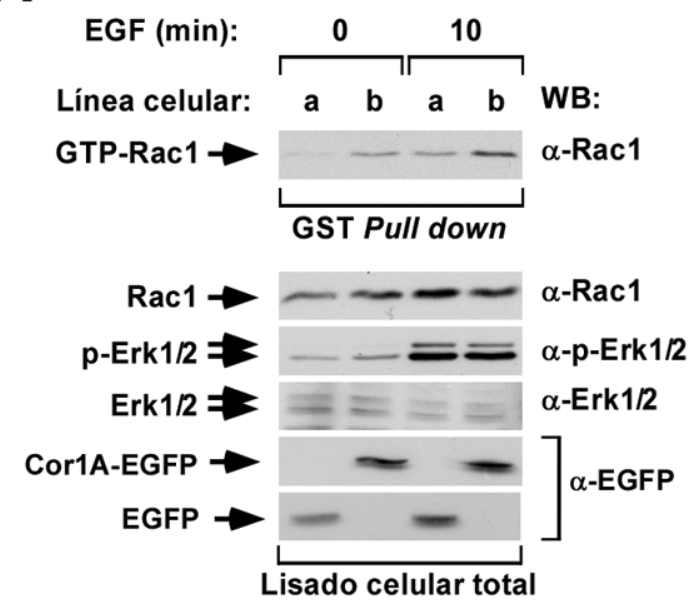

C

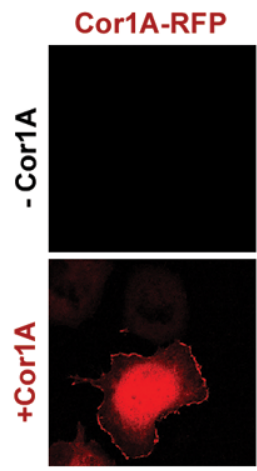

B
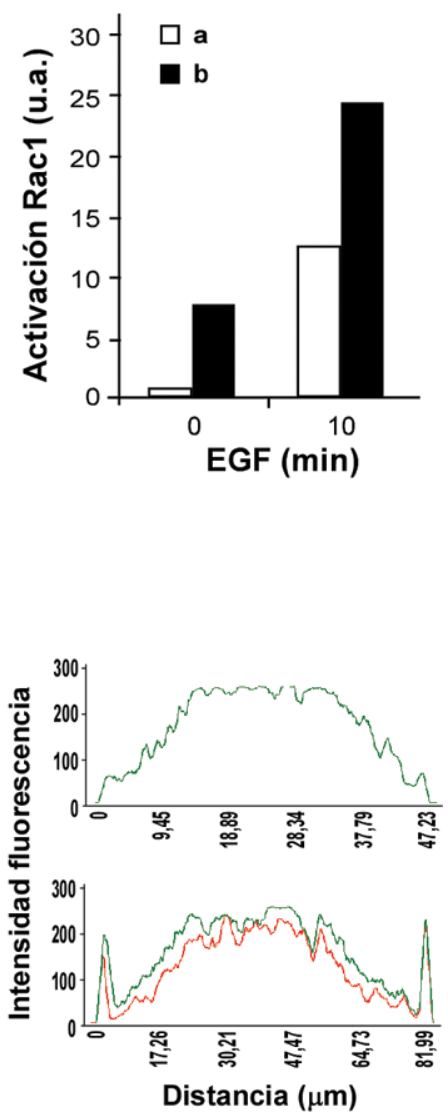

Figura 18. Coronina-1A induce la activación de Rac1 en la membrana plasmática. (A) Células procedentes de las líneas celulares ACC1-1 (a) y ACC1-2 (b) privadas de suero y posteriormente estimuladas o no con EGF fueron lisadas en presencia de la proteína recombinante GST-CRIB para realizar un ensayo de Pull down y analizar así la activación de Rac1 in vivo. Las fracciones de Pull down y alícuotas de los lisados celulares totales fueron separados electroforéticamente y la cantidad de Rac1 endogéna en cada fracción se detectó por Western blot con anticuerpos anti-Rac1. El resto de proteínas se detectaron en los lisados totales con los anticuerpos que se indican a la derecha de cada panel. (B) Las bandas detectadas con anticuerpos anti-Rac1 correspondientes a los niveles de Rac1-GTP fueron cuantificadas mediante densitometría usando el software ImageJ y normalizadas respecto a la cantidad de Rac1 en el lisado celular total. Los valores expresados en la gráfica representan los valores en unidades arbitrarias (u.a.) de un experimento representativo. (C) Se transfectaron células COS1 con el plásmido de expresión para la proteína híbrida EGFP-CRIB de forma individual o junto con el vector de expresión que codifica la proteína de fusión Coronina-1A-RFP. Las células fueron fijadas y las preparaciones se analizaron mediante microscopía confocal. Las medidas de fluorescencia relativas para EGFP-CRIB se muestran en el cuadrante inferior derecho de cada imagen. A la derecha se muestran las gráficas de distribución de intensidad de fluorescencia a lo largo del eje trazado (línea blanca que atraviesa la célula) en la imagen correspondiente.

Dado que los experimentos anteriores estaban basados en la sobreexpresión ectópica de Coronina-1A, procedimos a continuación a analizar si la presencia de Coronina-1A endógena era importante para el ciclo de translocación/activación de Rac1. Con este fin, generamos una nueva línea celular (denominada ACC2-2) en la que la expresión de Coronina$1 \mathrm{~A}$ endógena estaba inhibida tras la transducción de un lentivirus que codificaba un shRNA (del 
inglés, short hairping RNA) específico para el transcrito de esta proteína. Como control, utilizamos otra línea celular (designada como ACC2-1) que contenía un segundo shRNA dirigido contra el ARNm de Coronina-1A que había fallado en la inhibición de esta proteína. La transducción, selección, caracterización y cultivo de estos clones celulares se discute en detalle en la sección de Materiales y Métodos (pág. 40). Los niveles de expresión de Coronina-1A endógena en estas dos líneas celulares se muestra en la Figura 19A (panel inferior).

Para investigar cómo la deficiencia en esta proteína afectaba a la activación de Rac1, las células ACC2-1 y ACC2-2 privadas de suero fueron estimuladas con EGF y, tras ello, los niveles de GTP-Rac1 determinados bioquímicamente mediante nuevos ensayos de Pull down con la proteína GST-CRIB. Estos experimentos indicaron que las células deficientes en Coronina-1A inducían una activación muy deficiente de Rac1 tras la estimulación con EGF (Figura 19A, panel superior; Figura 19B). Esta deficiencia en la activación de Rac1 no se debe a un defecto general en la capacidad de señalización de las células ACC2-2, puesto que estas células y las ACC2-1 control pueden inducir niveles similares de autofosforilación del receptor del EGF (Figura 19A, tercer panel desde arriba) y de activación de la ruta Ras/Erk tras su estimulación con EGF (Figura 19A, quinto panel desde arriba).

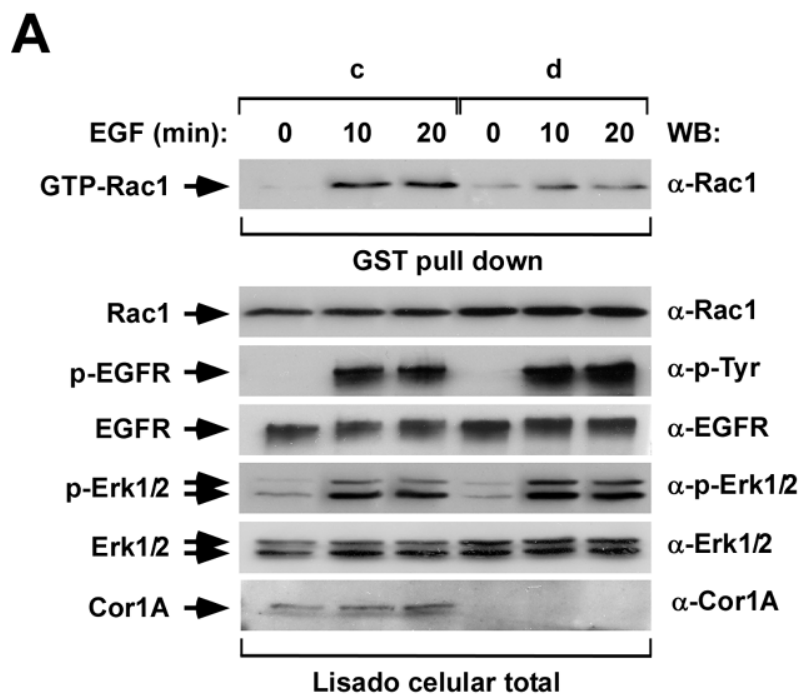

B

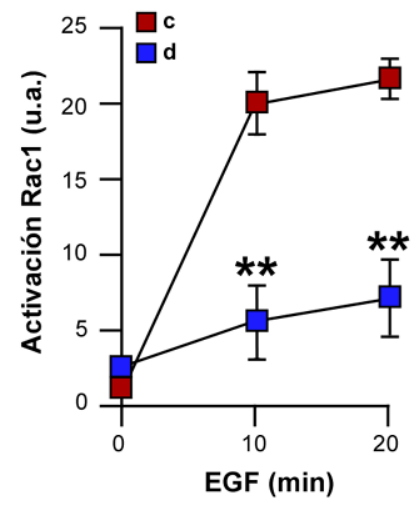

Figura 19. La inhibición de Coronina-1A endógena en células Cos1 reduce los niveles de activación de Rac1 en respuesta a EGF. (A) Las líneas celulares ACC2-1 (c) y ACC2-2 (d) se mantuvieron privadas de suero y posteriormente se estimularon con EGF durante los tiempos indicados. Las células se lisaron y se realizó un ensayo de Pull down utilizando la proteína recombinante GST-CRIB. Las fracciones de Pull down y alícuotas de los lisados celulares totales fueron separados por electroforesis y la cantidad de Rac1 endógena en cada fracción se detectó por Western blot con anticuerpos anti-Rac1. El resto de proteínas se detectaron en los lisados totales con los anticuerpos indicados a la derecha de cada panel. (B) Las bandas detectadas por Western blot con anticuerpos antiRac1 en la fracción Pull down fueron cuantificadas mediante densitometría usando el software ImageJ y normalizadas con respecto a la cantidad de Rac1 en el lisado celular total. Los valores expresados en la gráfica representan la media y la desviación estándar de tres experimentos independientes expresados en unidades arbitrarias (u.a.). ${ }^{* *}, P \leq 0,01$, comparado con los valores obtenidos en las células ACC2-1 (c) para cada uno de los tiempos analizados. 
A

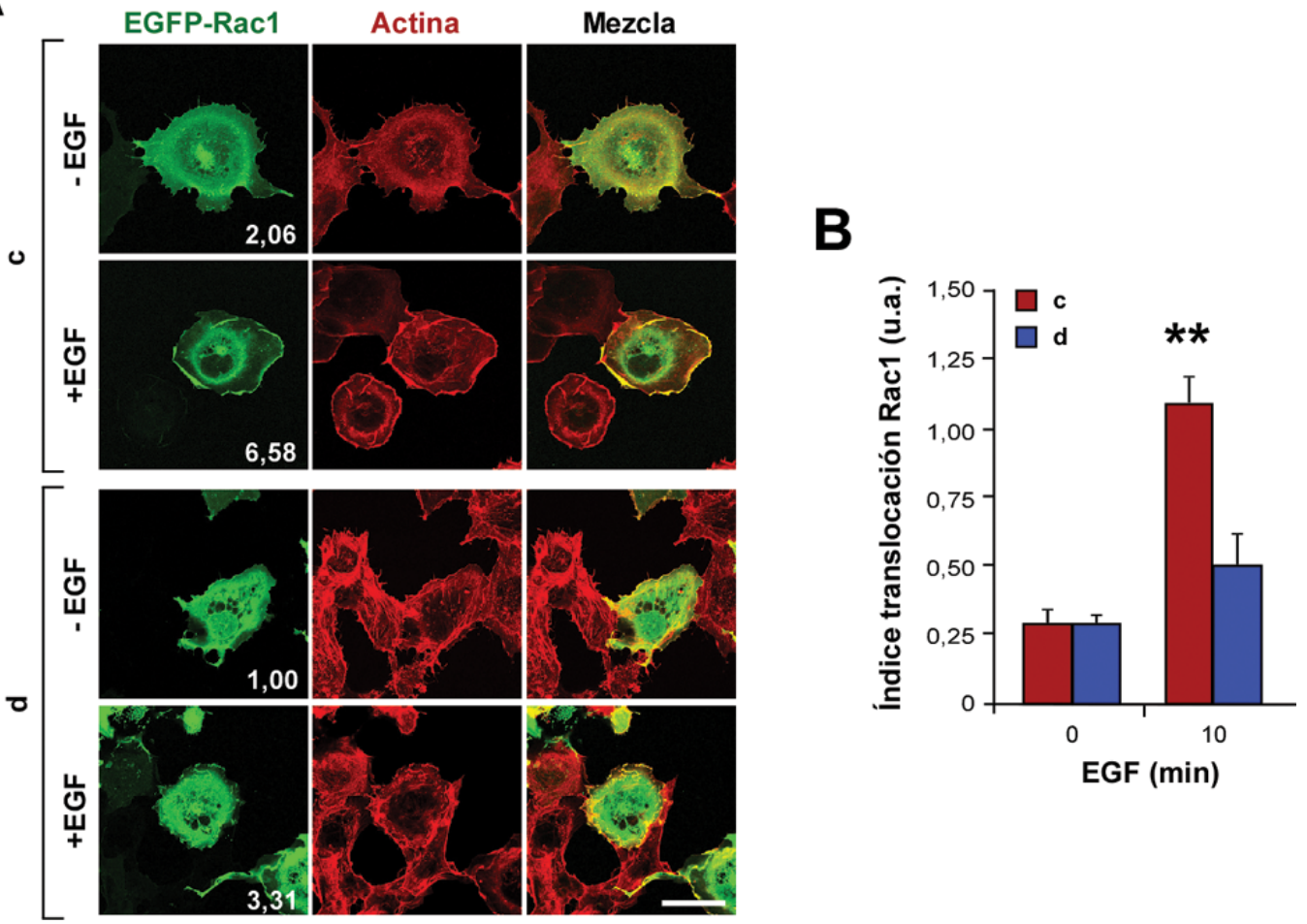

Figura 20. La ausencia de Coronina-1A endógena en células COS1 afecta a la translocación de Rac1 a la membrana en respuesta a EGF. (A) Células procedentes de las líneas ACC2-1 (c) y ACC2-2 (d) expresando de forma transitoria la proteína de fusión EGFP-Rac1 fueron privadas de suero y seguidamente estimuladas con EGF durante $10 \mathrm{~min}$. Seguidamente, las células fueron fijadas y teñidas con faloidina conjugada a rodamina. Finalmente las muestras se analizaron mediante microscopía confocal. Las medidas de fluorescencia relativas para EGFP-Rac1 se muestran en el cuadrante inferior derecho de cada imagen. Barra de escala: $20 \mu \mathrm{m}$. (B) La cuantificación de la translocación de Rac1 a la membrana plasmática se hizo según la manera descrita en Materiales y Métodos (pág. 44). **, $P \leq 0,01$, comparado a los valores obtenidos en las células ACC2-2 (d) tras 10 min de estimulación con EGF.

Para comprobar si el déficit en la activación de Rac1 en respuesta a EGF se correlacionaba con una menor translocación de Rac1 a la membrana en células deficientes en Coronina-1A, decidimos comparar la translocación de EGFP-Rac1 del citosol a la membrana plasmática durante la estimulación de las células ACC2-1 y ACC2-2 con EGF. Adicionalmente, decidimos analizar el citoesqueleto de actina mediante la tinción de las células con faloidina acoplada al fluorocromo rodamina. La faloidina nos permite detectar la presencia de filamentos de F-actina puesto que esta micotoxina se une específicamente a actina polimerizada y no a monómeros libre de G-actina (Tranter et al., 1991; Wehland et al., 1980). En ausencia de estimulación, se observó que la proteína EGFP-Rac1 tenía una distribución uniforme por todo el citosol independientemente de la línea celular estudiada (Figura 20A). Ambas líneas mostraban también una ausencia de filamentos de F-actina, lo que está en consonacia con los bajos niveles de activación de Rac1 en estas condiciones. Tras la estimulación con EGF, la comparación de ambas líneas celulares permitió descubrir que la ausencia de Coronina-1A 
conllevaba una translocación deficiente de Rac1 y, al mismo tiempo, un ensamblaje defectuoso del citoesqueleto de actina (Figura 20A,B). Tomados colectivamente, estos datos indican que Coronina-1A juega un papel importante en la translocación y activación de Rac1 durante, al menos, la respuesta de células COS1 al EGF.

\subsection{Caracterización de la ruta de señalización que media la translocación y activación de Rac1 por Coronina-1A}

\subsubsection{La translocación de Rac1 mediada por Coronina-1A es dependiente de} balsas lipídicas, citoesqueleto de actina y actividad Pak

Para profundizar en el mecanismo por el cual Coronina-1A media la translocación de Rac1 a la membrana plasmática decidimos analizar, mediante ensayos de inmunofluorescencia, el efecto de diversas drogas sobre la translocación de Rac1 inducida por la Coronina-1A. En concreto, nos centramos en inhibidores químicos que alteraban procesos que son importantes para el ciclo de activación de Rac1 en diversos tipos celulares. Éstos incluyeron metil- $\beta$-ciclodextrina ( $M \beta C D$, Sigma), un compuesto que impide la translocación de Rac1 a la membrana plasmática al extraer el colesterol de las membranas celulares y, por tanto, eliminar las balsas lipídicas presentes en la misma (del Pozo et al., 2004; Simons and Toomre, 2000); citocalasina D (CytD, Sigma), un agente desorganizador del citoesqueleto de actina que produce la dispersión de las fibras periféricas de actina y la aparición de aglomeraciones de F-actina en el citoplasma celular (Schliwa, 1982); GF109203X (Calbiochem), un inhibidor específico de múltiples isoformas de PKC (Toullec et al., 1991) que bloquea la disociación de Rac1 de su secuestrador RhoGDI inducida por PKC en vías de señalización mediadas por calcio (Price et al., 2003) y Tat-Pak18 (Calbiochem), un péptido que puede atravesar la membrana plasmática (gracias a la secuencia Tat derivada del virus de la inmunodeficiencia humana) e inhibir la actividad serín/treonín quinasa de los miembros de la familia Pak (Maruta et al., 2002; Zhao et al., 2006). Como control negativo de éste último compuesto, utilizamos un péptido mutado (Tat-Pak ${ }^{\mathrm{R} 192 \mathrm{~A}}$, Calbiochem) que, a pesar de poder atravesar la membrana plasmática, no puede inhibir a estas quinasas.

Para evaluar el efecto de estos inhibidores, células COS1 expresando transitoriamente las combinaciones de AU5-Rac1 y Coronina-1A-EGFP indicadas en las figuras correspondientes se trataron con los inhibidores anteriormente citados, de un modo previo a la fijación. Una vez fijadas, la localización subcelular de AU5-Rac1 y Coronina-1A-EGFP fue visualizada mediante microscopía confocal y cuantificada tal como se describió en el apartado previo. Junto con la tinción de anticuerpos contra el epitopo AU5, en algunos casos se realizaron tinciones con la subunidad $B$ de la toxina colérica (CTXB) conjugada al fluorocromo Alexa Fluor 647 y con faloidina conjugada a Alexa Fluor 635 para poder visualizar el estado de 
las balsas lipídicas y el citoesqueto, respectivamente. La CTXB es un buen marcador de balsas lipídicas puesto que se une al gangliósido GM1, un componente de estas estructuras de membrana (Holmgren et al., 1973). De acuerdo con lo que habíamos observado en el apartado previo, AU5-Rac1 mostró una distribución citosólica en células COS1 cuando se expresó en ausencia de Coronina-1A-EGFP (Figura 21, panel superior, pág. siguiente). La coexpresión de Coronina-1A-EGFP provocó la translocación de AU5-Rac1 a la membrana plasmática y, además, una agregación de balsas lipídicas. La microscopía confocal reveló que Rac1, Coronina-1A y las balsas lipídicas estaban presentes en las mismas regiones subcelulares (Figura 21, segundo panel desde arriba). El tratamiento con $M \beta C D$ eliminó la presencia de AU5-Rac1 en la membrana plasmática inducida por la expresión de Coronina-1A-EGFP y provocó la desorganización de las balsas lipídicas en la periferia celular (Figura 21, tercer panel desde arriba). Asimismo, el tratamiento con CytD también afectó a la translocación de AU5-Rac1 mediada por Coronina-1A-EGFP y eliminó la capacidad de esta última de provocar la aparición de los membrane ruffles típicos que habíamos observado en experimentos previos (Figura 13, pág. 64). El citoesqueleto de F-actina apareció colapsado en el interior celular formando pequeños agregados (Figura 21, panel intermedio). El tratamiento con el péptido inhibitorio Tat-Pak18 también eliminó la capacidad de Coronina-1A-EGFP para translocar a AU5-Rac1 a la membrana plasmática (Figura 21, sexto panel desde arriba). Por el contrario, ni el péptido inactivo Tat-Pak ${ }^{R 192 A} \mathrm{ni}$ el inhibidor GF109203X afectaron a la localización en membrana de AU5-Rac1 en células que expresaban Coronina-1A-EGFP (Figura 21, paneles quinto y septimo desde arriba), indicando que el efecto bloqueante del péptido Tat-Pak18 era una consecuencia directa de la inhibición de la actividad quinasa endógena y, al mismo tiempo, descartando que este paso regulatorio en la localización de AU5-Rac1 fuera dependiente de la actividad de PKC. La cuantificación del índice de translocación para Rac1 nos permitió evaluar cuantitativamente el efecto de las drogas utilizadas en estos experimentos de inmunofluorescencia. El potencial translocador de Coronina-1A-EGFP, estimado en base a este índice de translocación de Rac1, se vio bloqueado casi al 100\% tras los tratamientos con MBCD y CytD mientras que Tat-Pak18 lo redujo casi en un $80 \%$. Por contra, Tat-Pak ${ }^{R 192 A}$ y GF109203X no alteraron el valor de este parámetro con respecto a células sin tratar (Figura 22, pág.77). Como aproximación técnica diferente, y para confirmar que la translocación de Rac1 mediada por Coronina-1A era dependiente de la actividad quinasa de Pak, optamos por utilizar la expresión de una forma inactiva de Pak1 etiquetada con el epitopo Myc (Myc$P a k 1^{\mathrm{K} 299 \mathrm{R}}$ ) que, además, funciona como dominante negativo puesto que bloquea la actividad Pak endógena al inducir la formación de complejos inactivos con las quinasas Pak endógenas (Lei et al., 2000; Sells et al., 1997). Realizamos de nuevo experimentos de cotransfección transitoria con células COS1 en las que expresamos AU5-Rac1 y Coronina-1A-EGFP de forma individual o conjunta con Myc-Pak1 ${ }^{\mathrm{K} 299 \mathrm{R}}$. De acuerdo con los resultados con el péptido TatPak18, la coexpresión de este mutante dominante negativo bloqueó la translocación de Rac1 dependiente de esta proteína citoesquelética (Figura 23, pág. 77). 


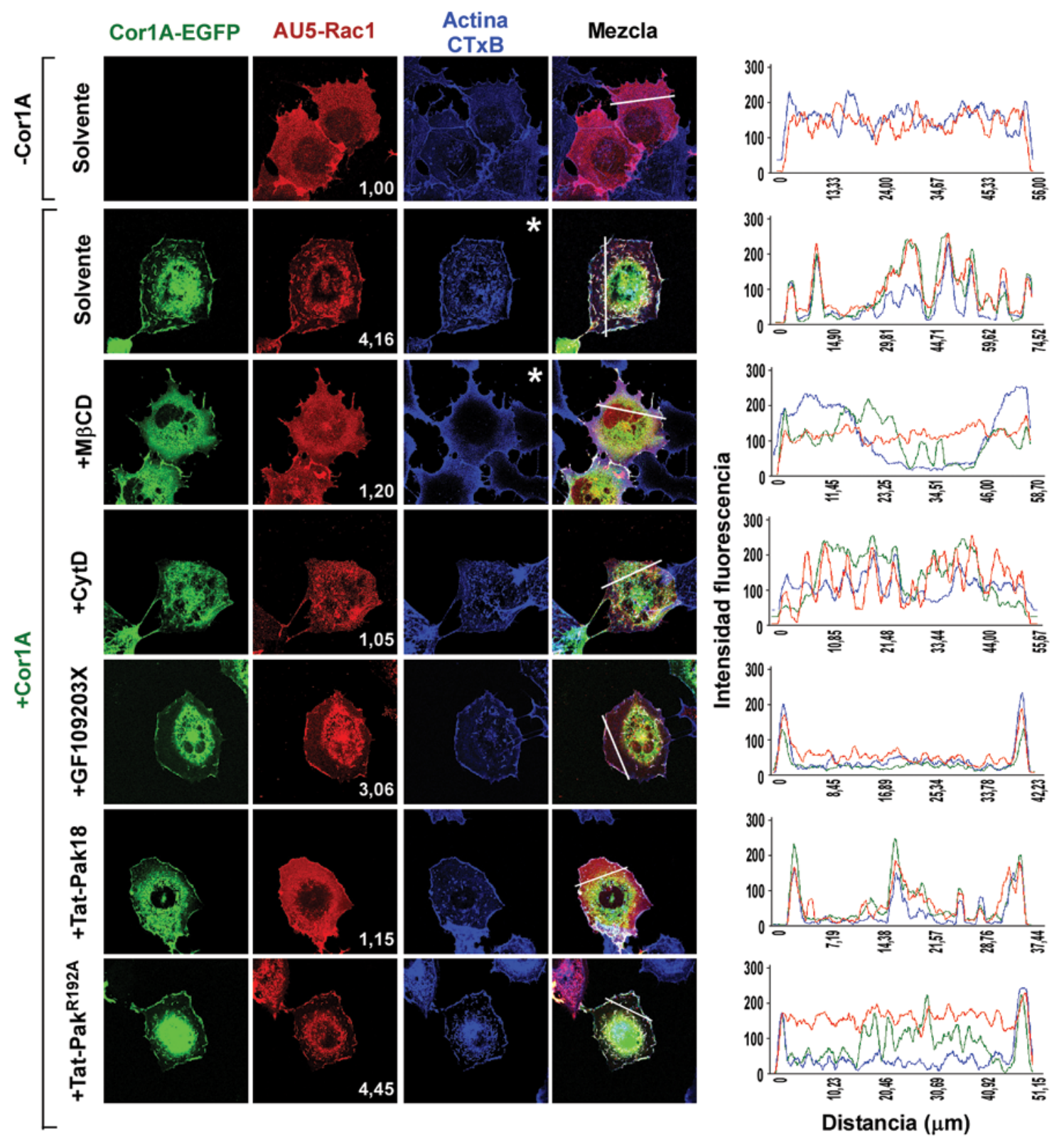

Figura 21. Efecto de los inhibidores utilizados en la translocación de Rac1 a la membrana inducida por Coronina-1A. Células COS1 expresando de forma transitoria AU5-Rac1 y Coronina-1A-EGFP, tal y como se indica en la parte superior de cada panel, fueron privadas de suero y tratadas con los inhibidores

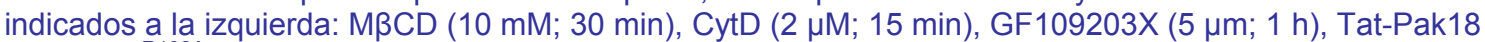
o Tat-Pak ${ }^{R 192 A}(10 \mu \mathrm{M} ; 12 \mathrm{~h})$. Posteriormente las células se fijaron y se tiñeron para inmunuflourescencia como indicamos en la Figura 13 (pág. 64). En este caso analizamos el citoesqueleto de F-actina mediante la incubación de las preparaciones con faloidina conjugada al fluorocromo Alexa Fluor 635 (en azul) y la presencia de balsas lipídicas gracias a CTxB conjugada a Alexa Fluor 647 (en azul, paneles indicados con asterisco). Los niveles de fluorescencia relativa en la membrana para la GTPasa Rac1 se indican en el cuadrante inferior derecho de cada imagen. A la derecha se muestran las gráficas de distribución de intensidad de fluorescencia a lo largo del eje trazado (línea blanca que atraviesa la célula) en la imagen correspondiente. 


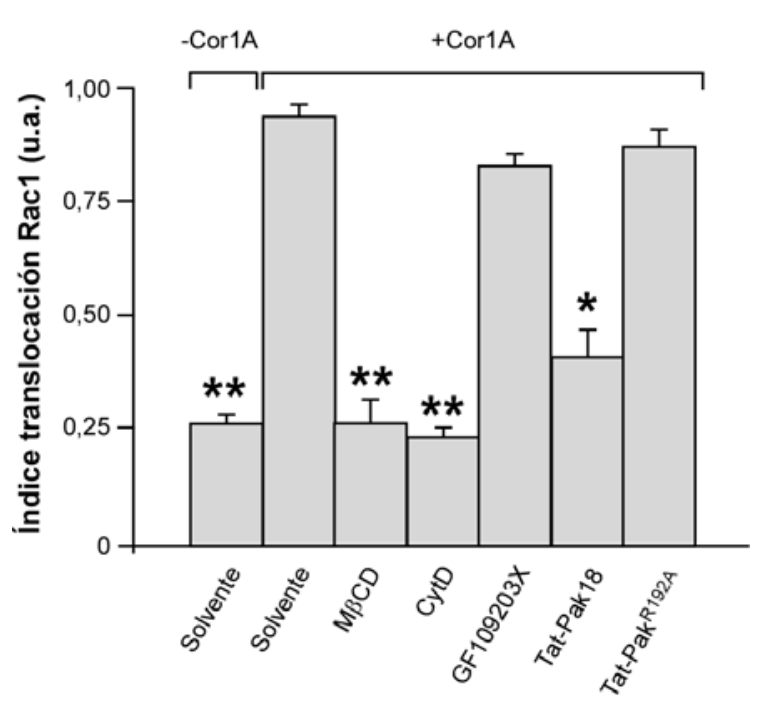

Figura 22. Índice de translocación de Rac1 mediado por Coronina-1A-EGFP en presencia de los inhibidores usados en estos experimentos. La cuantificación de la translocación a la membrana plasmática se hizo según se ha descrito previamente en Materiales y Métodos (pág. 44). **, $P \leq 0,01$; ${ }^{*}, P \leq 0,05$, comparado a los valores obtenidos con respecto al tratamiento con Solvente (+Cor1A).

Tratamiento
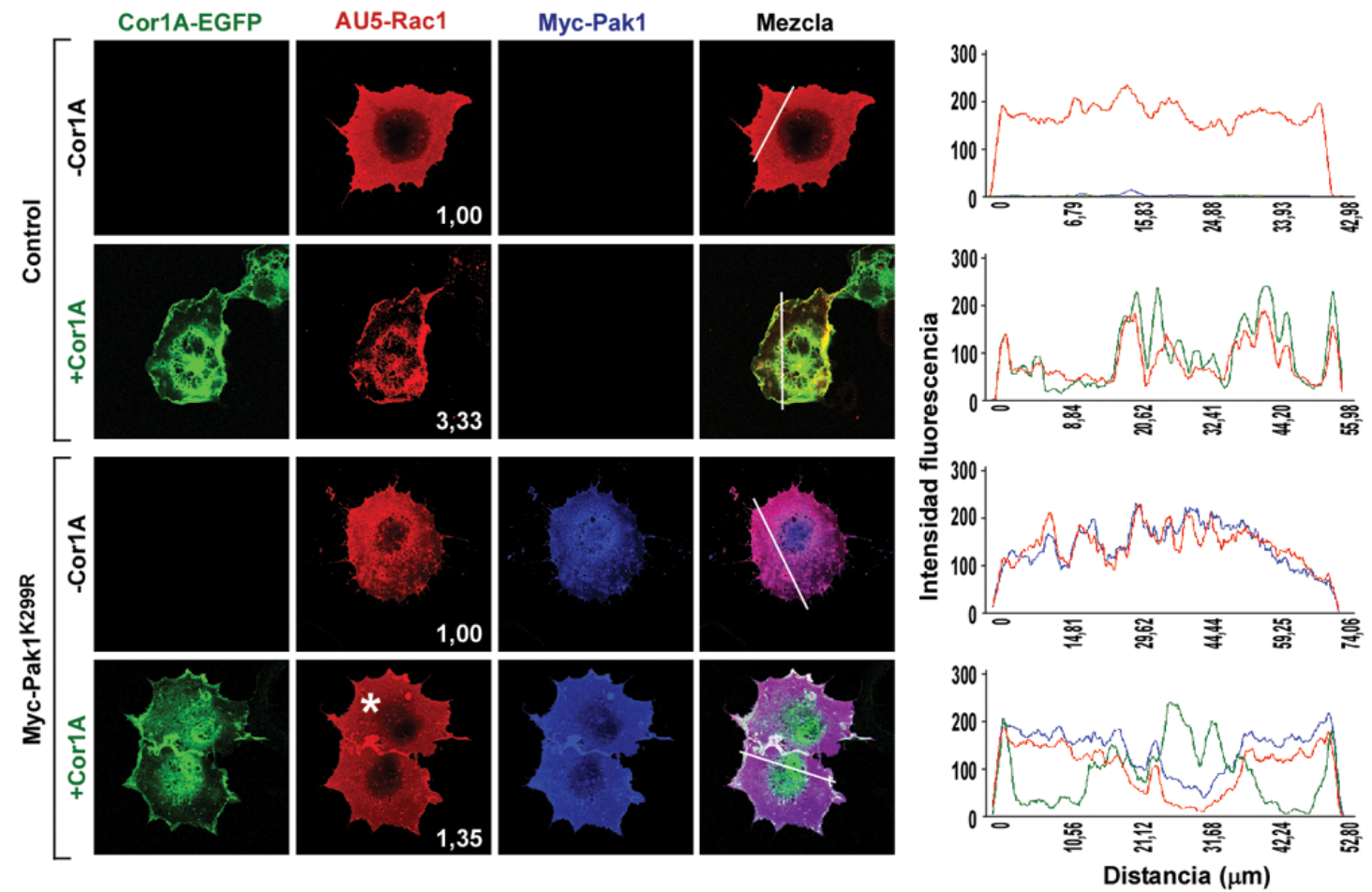

Figura 23. La translocación de Rac1 inducida por Coronina-1A está mediada por la actividad quinasa de Pak1. Células COS1 expresando de forma transitoria las proteínas ectópicas AU5-Rac1, Coronina-1A-EGFP y Myc-Pak1 ${ }^{\mathrm{K} 299 R}$, tal y como se indica en la figura, se fijaron y se tiñeron con anticuerpos anti-AU5 y anti-Myc seguido de anticuerpos secundarios conjugados a Cy3 (rojo) y Cy5 (azul), respectivamente. Finalmente las preparaciones se analizaron al microscopio confocal. Los niveles de fluorescencia relativa en la membrana para la GTPasa Rac1 se indican en el cuadrante inferior derecho de cada imagen. El asterisco indica la célula seleccionada para la cuantificación de dichos niveles de fluorescencia. A la derecha se muestran las gráficas de distribución de intensidad de fluorescencia a lo largo del eje trazado (línea blanca que atraviesa la célula) en la imagen correspondiente. 
Para situar el efecto de las drogas utilizadas anteriormente aguas arriba o debajo de Coronina-1A, analizamos en paralelo la localización subcelular de la misma en los experimentos anteriores. Los tratamientos con MBCD y CytD eliminaron la distribución membranaria de Coronina-1A hacia el citosol y agregados de F-actina citosólicos, respectivamente. Esta última localización subcelular está de acuerdo con las propiedades ya conocidas de Coronina-1A como proteína de unión a F-actina (Appleton et al., 2006; Goode et al., 1999; Oku et al., 2003) y con los resultados mostrados en esta tesis demostrando que la localización en la membrana plasmática de Coronina-1A es un proceso dependiente del citoesqueleto de F-actina. (Figura 15, pág. 66). Sin embargo, la adición de Tat-Pak18,

GF109203X o la coexpresión de la proteína Myc-Pak1 ${ }^{\mathrm{K} 299 R}$ no afectaron para nada la localización subcelular de Coronina-1A-EGFP en la membrana plasmática (Figuras 21 y 23 , págs. 76 y 77 , respectivamente). Estos resultados indican que:

1. el efecto de la eliminación de las balsas lipídicas y del citoesqueleto sobre la translocación de Rac1 inducida por Coronina-1A actúa aguas arriba de esta última proteína

2. Pak1 actúa aguas debajo de Coronina-1A en el proceso de translocación de Rac1

3. $\quad \mathrm{PKC}$ no es requerida en este proceso

\subsubsection{La translocación de Rac1 mediada por Coronina-1A requiere actividad} basal de Rac1

Dado que tanto la agregación de balsas lipídicas (Villalba et al., 2001) como las reorganizaciones subcorticales de actina en forma de membrane ruffles (Ridley et al., 1992) son dos procesos interconectados y regulados de forma conjunta por Rac1 y que, además, la integridad de las balsas lipídicas es necesaria para la señalización por esta GTPasa, seguidamente decidimos investigar si la pérdida de la localización en regiones yuxtamembrana de la proteína Coronina-1A-EGFP y Rac1 en respuesta a los tratamientos con M $\beta C D$ y CytD podría ser una consecuencia la eliminación de una vía de señalización Rac1-dependiente que, a su vez, conllevase la inactivación de la ruta de Coronina-1A. Esta posibilidad tenía alto interés a nivel funcional porque, de ser cierta, indicaría la existencia de un mecanismo de retroalimentación positivo en el que la activación de Rac1 conllevaría mayores niveles de activación de su ruta mediante el aumento de la translocación y activación de nuevas moléculas de Rac1 a través de Coronina-1A y el citoesqueleto. Para comprobar esta hipótesis, decidimos evaluar el efecto de la expresión de un dominante negativo de Rac1 (Rac1 ${ }^{\top 17 N}$ ) sobre la localización subcelular de la Coronina-1A-EGFP y su efecto sobre el citoesqueleto de actina usando una aproximación similar a la realizada con el mutante dominante negativo de Pak1 (Figura 23). En el caso de que Rac1 estuviese implicado en la activación de la ruta de Coronina-1A, esperaríamos por tanto que la coexpresión de la forma dominante negativa de Rac1 afectase a la localización celular de Coronina-1A-EGFP en la membrana plasmática de 
una manera análoga a como lo habían hecho los tratamientos con M $\beta C D$ y CytD (Figura 21, pág. 76). Como puede verse en la Figura 24, los experimentos realizados confirmaron esta hipótesis, puesto que la coexpresión de la proteína AU5-Rac1 ${ }^{\top 17 N}$ eliminó la localización en membrana de Coronina-1A-EGFP y su acción sobre el citoesqueleto. De acuerdo con la distribución citosólica de Coronina-1A-EGFP, la versión mutante de Rac1 no fue translocada a la membrana plasmática por la coexpresión de la proteína citoesquelética. Estos resultados indican que Rac1 es necesario para iniciar la señalización que da lugar a la localización membranaria de Coronina-1A y, por ende, la estimulación de la ruta que induce la translocación y activación de nuevas moléculas de Rac1.
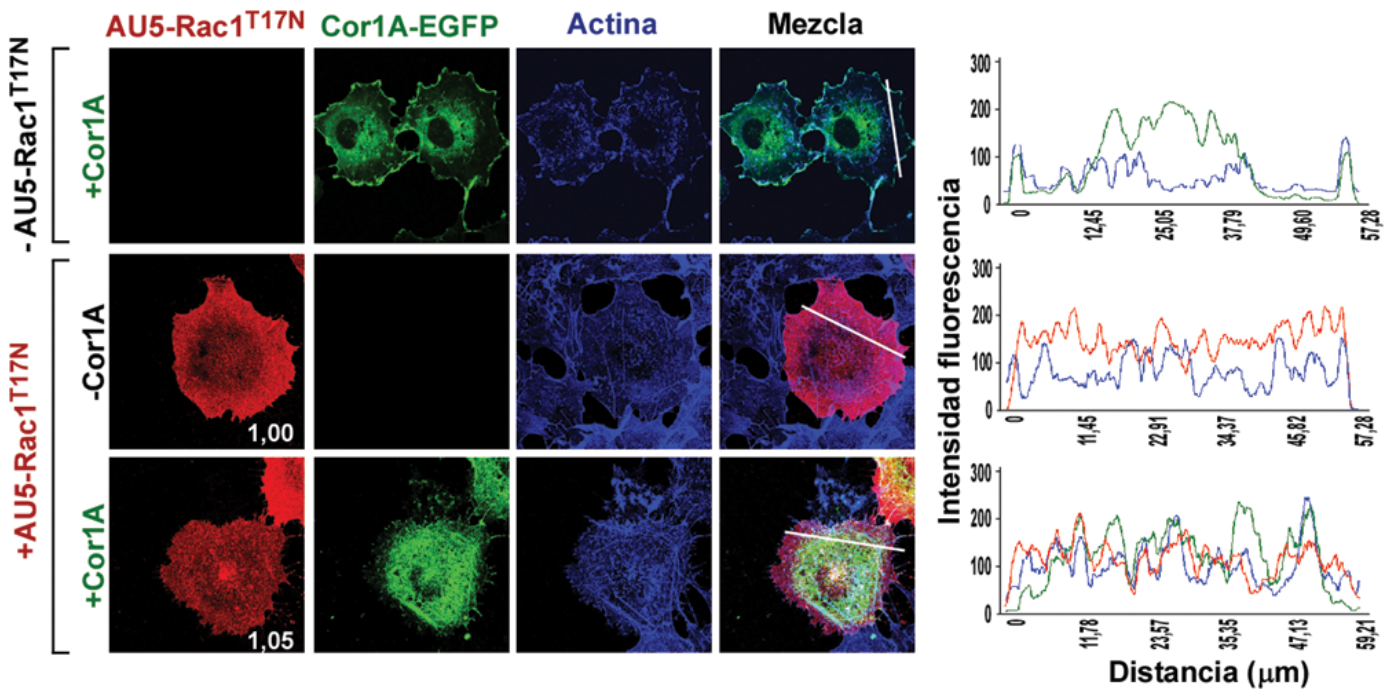

Figura 24. La localización subcelular de Coronina-1A y su capacidad de promover reorganización citoesquelética dependen de Rac1. Se transfectaron células COS1 con plásmidos de expresión para el mutante Rac1 ${ }^{\top 17 N}$ etiquetado con AU5 y Coronina-1A-EGFP tal y como se indica a la izquierda. Posteriormente las células fueron fijadas y teñidas tal y como se indica en la Figura 13 (pág. 64). En este caso analizamos el citoesqueleto de F-actina mediante la incubación de las preparaciones con faloidina conjugada al fluorocromo Alexa Fluor 635 (en azul). Finalmente las preparaciones se analizaron al microscopio confocal. Los niveles de fluorescencia relativa en la membrana para la GTPasa AU5Rac1 $1^{T 17 N}$ se indican en el borde inferior derecho de cada imagen. A la derecha se muestran las gráficas de distribución de intensidad de fluorescencia a lo largo del eje trazado (línea blanca que atraviesa la célula) en la imagen correspondiente.

\subsubsection{Papel de Pak1 en la translocación de Rac1 inducida por Coronina-1A}

Estudios recientes indican que la inhibición de la actividad quinasa de Pak1, mediante el inhibidor IPA-3, conduce a la disminución de los niveles de activación de Rac1 tanto en células normales como tumorales (Flaiz et al., 2009). En base a estos estudios y a nuestros propios resultados decidimos comprobar en primer lugar si Pak1 y Coronina-1A podrían cooperar en el proceso de activación de Rac1. Para ello, las líneas celulares ACC1-1 y ACC1-2, previamente descritas (pág. 40), fueron transfectadas con un vector de expresión que codificaba la versión silvestre de Pak1 fusionada al epitopo Myc. Posteriormente, fueron privadas de suero y estimuladas con EGF para analizar los niveles de activación de Rac1 mediante la técnica de 
Pull-down usando la proteína GST-CRIB tal y como se indicó en el apartado 2.1.3. de esta sección (pág. 69). Estos experimentos demostraron que la expresión de la versión silvestre de esta quinasa aumentaba los niveles de activación de Rac1 en células que expresaban EGFP (ACC1-1) tanto en reposo como tras su estimulación con EGF (Figura 25A, panel superior). Como se observó previamente (Figura 18, pág. 71), las células que expresaban Coronina-1AEGFP (ACC1-2) mostraban también mayores niveles de estimulación de Rac1 que las ACC1-1 tanto en quiescencia como tras la estimulación con dicho mitógeno (Figura 25A, panel superior). Sin embargo, estos experimentos demostraron también que la coexpresión de Pak1 y Coronina-1A-EGFP daba lugar a aumento mayor de los niveles de activación de Rac1 inducidos por cada una de estas proteínas cuando se expresaban de forma individual (Figura 25B). Este efecto sinérgico se circunscribió a la ruta de Rac1, puesto que la coexpresión de estas dos proteínas no resultó en mayores niveles de activación de la ruta de Ras/Erk, tal como demostraron análisis paralelos por Western blot de alícuotas de los extractos celulares utilizadas en los experimentos de Pull-down (Figura 25A, tercer panel desde arriba).

A

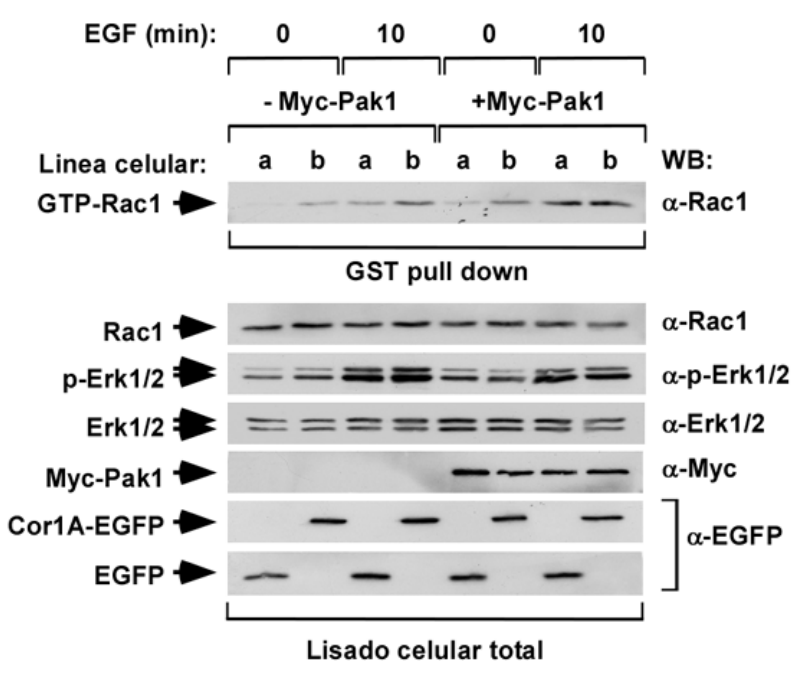

B

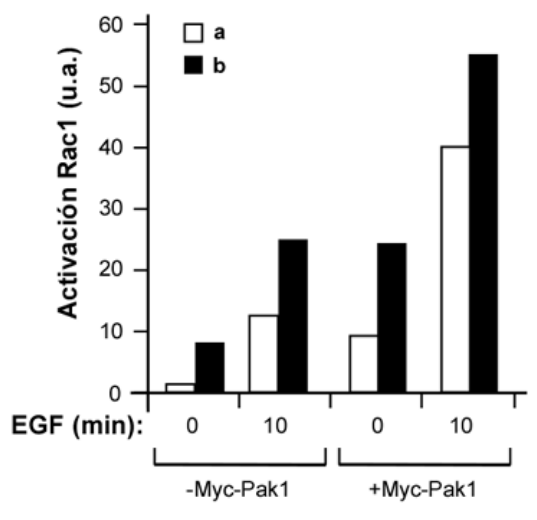

Figura 25. Cooperación funcional entre Coronina-1A y Pak1 en la activación de Rac1. (A) Células en reposo privadas de suero procedentes de las líneas celulares ACC1-1 (a) y ACC1-2 (b), que previamente habían sido transfectadas con vector vacío (-Myc-Pak1) o con un vector de expresión para la forma silvestre de Pak1 (+Myc-Pak1), fueron estimuladas con EGF. A continuación se lisaron las células y los extractos celulares se sometieron a ensayo de Pull down con la proteína GST-CRIB. Las fracciones de Pull down y alícuotas de los lisados celulares totales fueron separados electroforéticamente y la cantidad de Rac1 endogéna en cada fracción se detectó por Western blot con anticuerpos anti-Rac1. El resto de proteínas se detectaron en los lisados celulares totales utilizando los anticuerpos indicados a la derecha de cada panel. (B) El histograma de barras representa los niveles de Rac1-GTP en cada muestra normalizados con respecto a la cantidad de Rac1 total y en unidades arbitrarias (u.a.). Se representan los valores obtenidos en un experimento representativo $(n=2)$. 
Dados los resultados anteriores y previas observaciones indicando que algunas proteínas con dominios WD40 pueden interaccionar físicamente con Pak1 (Leberer et al., 2000; Xia et al., 2001), decidimos preguntarnos seguidamente si Coronina-1A y Pak1 podían interaccionar físicamente y, si así fuera, comprobar si dicha interacción era dependiente de la capacidad de Coronina-1A de unirse a F-actina. Para investigar esta posibilidad, realizamos estudios de coinmunoprecipitación en lisados celulares procedentes de células COS1 que expresaban diferentes combinaciones las proteínas ectópicas de Myc-Pak1, EGFP, Coronina1A-EGFP y Coronina-1A ${ }^{R 29 D}$-EGFP. Estos lisados fueron inmunoprecipitados con anticuerpos contra EGFP y, tras la recuperación de los inmunocomplejos, la presencia de Myc-Pak1 en dichos inmunoprecipitados fue detectada por análisis de Western blot con anticuerpos contra el epitopo Myc. Como se muestra en la Figura 26A (panel superior, pág. siguiente), estos experimentos demostraron que la proteína Myc-Pak1 coinmunoprecipitaba con Coronina-1AEGFP pero no con el mutante de Coronina-1A que no puede unirse a F-actina ni tampoco con la proteína EGFP no quimérica. La falta de co-inmunoprecipitación con estas últimas proteínas no se debió a problemas de expresión o de inmunoprecipitación, como se demostró al analizar la expresión de cada una de las proteínas transfectadas en los lisados celulares totales y en los inmunoprecipitados (Figura 26A).

De acuerdo con dicha interacción física, estudios por microscopía confocal demostraron que la coexpresión de Coronina-1A-EGFP con Myc-Pak1 en células COS1 inducía un enriquecimiento de la quinasa en la membrana plasmática (Figura 26B, paneles superior e intermedio). Sin embargo, dicha translocación no se producía si la versión silvestre de Coronina-1A se sustituía en estos experimentos por su mutante R29D (Figura 26B, panel inferior), de una manera análoga a lo que habíamos observado previamente con AU5-Rac1 (Figura 15, pág. 66). Este aumento de la translocación de Pak1 inducida por Coronina-1A se puede ver de manera más cuantitativa en la Figura 26C, donde se muestran los índices de translocación obtenidos para Pak1 en estos experimentos. Estos datos están de acuerdo con los observados mediante coinmunoprecipitación y por tanto confirman que la interacción física que observamos entre Coronina-1A y Pak1 es un proceso dependiente de la unión de Coronina-1A a F-actina y que parece tener lugar en la membrana plasmática $\mathrm{O}$ en sus proximidades. 
A
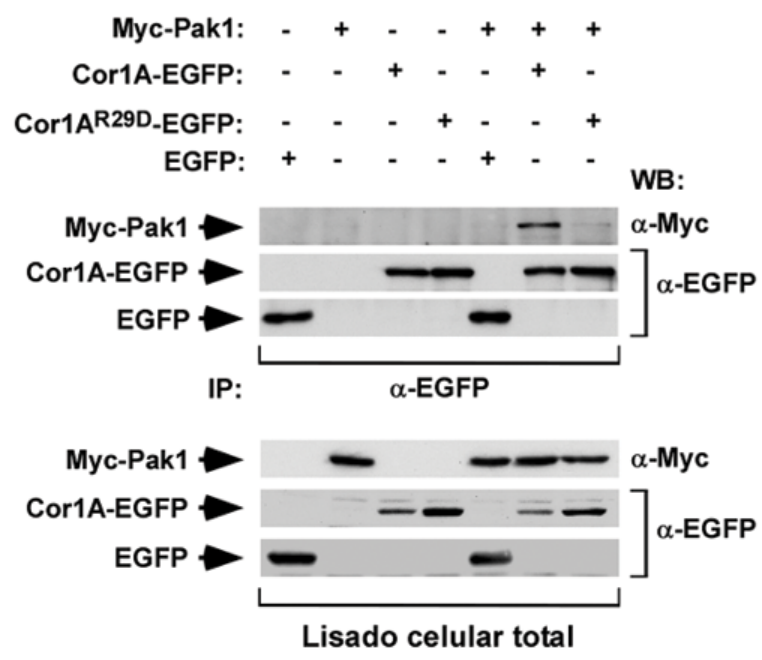

B
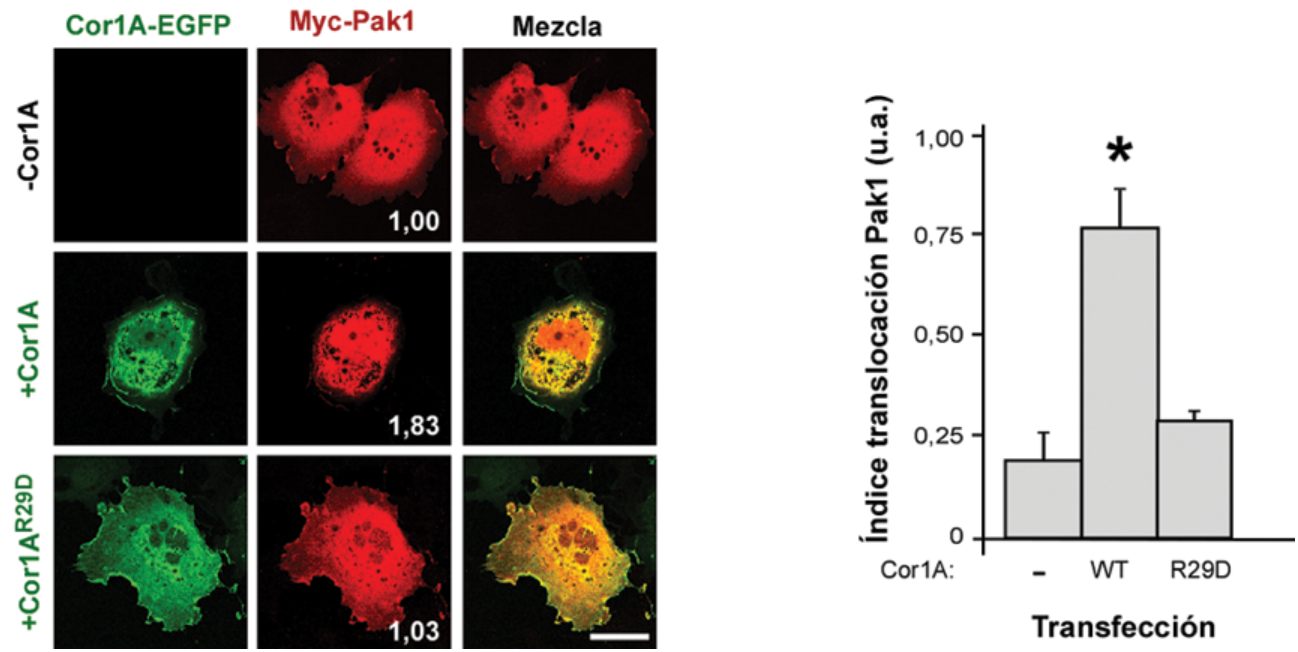

Figura 26. Coronina-1A inteacciona con Pak1 in vivo de una forma dependiente de su unión a filamentos de F-actina. (A) Células COS1 transfectadas con diferentes combinaciones de plásmidos de expresión para las proteínas indicadas fueron lisadas y los extractos celulares sometidos a inmunoprecipitación con anticuerpos anti-EGFP. Los inmunoprecipitados y alícuotas de los lisados celulares totales fueron separados electroforéticamente y analizados mediante Western blot con con anticuerpos anti-Myc y anti-EGFP, tal como se indica a la derecha de cada panel. (B) Células COS1 expresando de forma transitoria Myc-Pak1 sóla o en combinación con las proteínas fluorescentes Coronina-1A-EGFP y Coronina-1A ${ }^{\text {R29D }}$-EGFP fueron fijadas y teñidas con anticuerpos anti-Myc seguido de anticuerpos secundarios conjugados a Cy3 (rojo). Finalmente las preparaciones se analizaron por microscopía confocal. Los valores de fluorescencia relativa para Pak1 en la membrana plasmática se indican en el cuadrante inferior derecho de cada imagen. Barra de escala: $20 \mu \mathrm{m}$. (C) La cuantificación de la translocación a la membrana plasmática de Pak1 se realizó de forma idéntica al índice de translocación de Rac1 según la manera ya descrita en Materiales y Métodos (pág. 44). ${ }^{*}, P \leq 0,05$, comparado a los valores obtenidos con respecto a las células sin Coronina-1A-EGFP. 

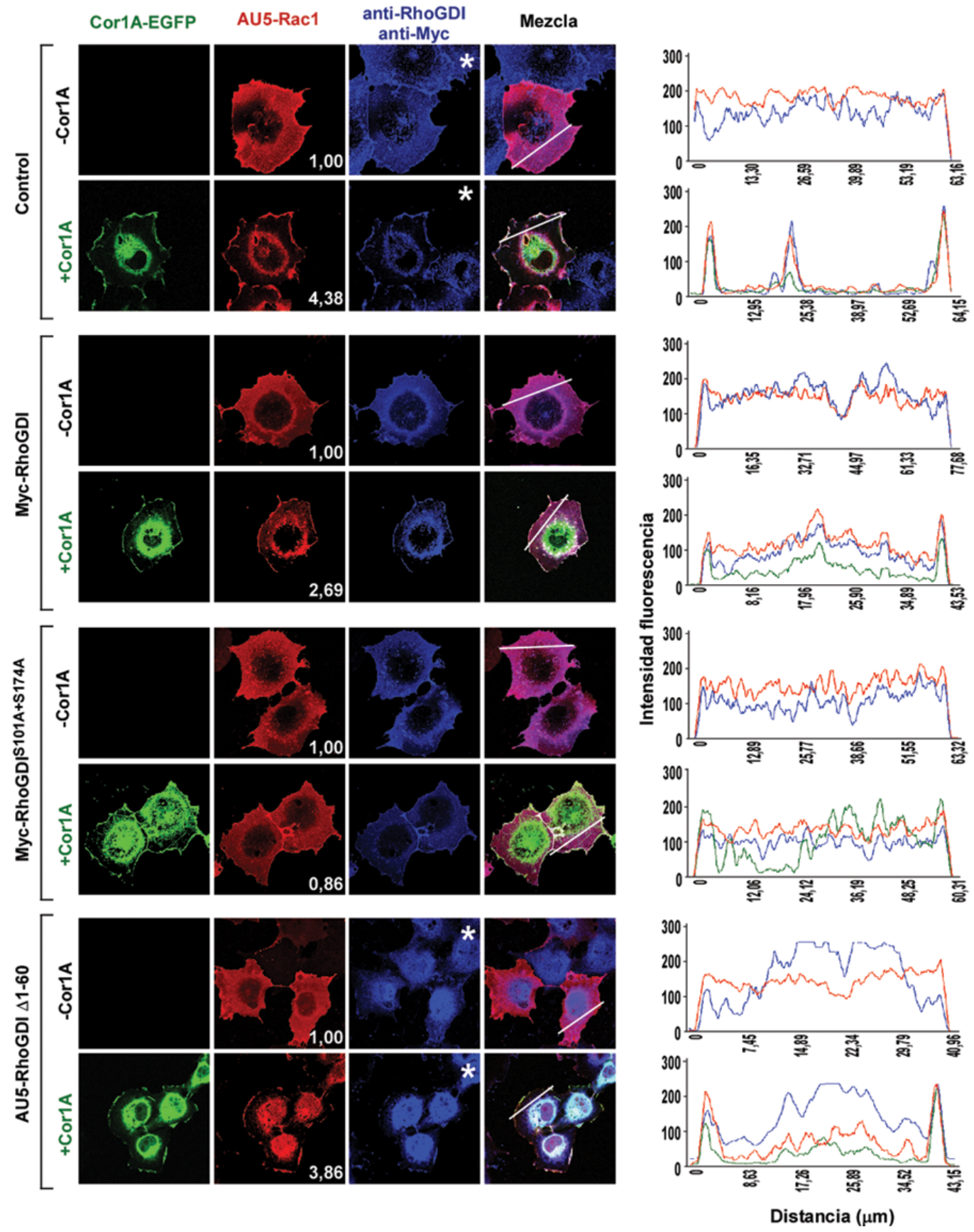

Figura 27. Efecto de Coronina-1A en la translocación de Rac1 en presencia de diferentes mutantes de RhoGDI. Células COS1 expresando transitoriamente AU5-Rac1 de forma aislada o junto con Coronina-1A-EGFP y cada uno de los mutantes de RhoGDI etiquetados con Myc o AU5 indicados a la izquierda, fueron fijadas y teñidas con anticuerpos anti-AU5 y anti-RhoGDI (paneles con asteriscos) o antiMyc (resto de paneles) seguido de anticuerpos secundarios conjugados a Cy3 (rojo) y Cy5 (azul), respectivamente. Finalmente las preparaciones fueron analizadas mediante microscopía confocal. Los niveles de fluorescencia relativa en la membrana para Rac1 se indican en el cuadrante inferior derecho de cada imagen. A la derecha se muestran las gráficas de distribución de intensidad de fluorescencia a lo largo del eje trazado (línea blanca que atraviesa la célula) en la imagen correspondiente. 


\subsubsection{Coronina-1A favorece la formación de complejos Pak1/RhoGDI in vivo}

Como vimos en la Introducción, existen diferentes mecanismos que favorecen la disociación de Rac1 de su secuestrador citosólico RhoGDI. Entre ellos encontramos la inactivación de estas proteínas inhibitorias a través de la fosforilación mediada por Pak1 de dos residuos de serina (S101 y S174) que se encuentran situados en las proximidades del bolsillo hidrofóbico de RhoGDI que interacciona con los grupos prenilo de las GTPasas (DerMardirossian et al., 2004). Para averiguar si un mecanismo similar podría estar ocurriendo en el caso de la translocación de Rac1 mediada por Coronina-1A, decidimos realizar experimentos de microscopía confocal para evaluar el efecto de diferentes versiones de RhoGDI sobre la translocación de Rac1 mediada por Coronina-1A. Para ello, AU5-Rac1 y Coronina-1A-EGFP se expresaron de manera transitoria en células COS1 en ausencia o presencia de Myc-RhoGDI o diversos mutantes de RhoGDI. Éstos incluyeron Myc-RhoGDI ${ }^{\text {S101A+S174A }}$, un mutante de RhoGDI que no puede ser fosforilado, y por tanto inhibido, por Pak1 (DerMardirossian et al., 2004) y RhoGDI ( $\Delta 1-60$ ), una forma truncada de RhoGDI que no puede interaccionar con GTPasas de la familia Rho/Rac (Gosser et al., 1997). Estos experimentos estaban basados en la asunción de que si la acción de Pak1 en la traslocación de Rac1 por Coronina-1A se debía a su acción inhibitoria sobre los RhoGDI, entonces la sobreexpresión de estas moléculas o de mutantes que no fuesen inhibidos por Pak1 permitiría contrarrestar el efecto de Pak1 y, por tanto, eliminar la traslocación de Rac1 por Coronina-1A. En cambio, dicho efecto no se produciría en el caso de usar mutantes de RhoGDI incapaces de interactuar con Rac1. Estos estudios revelaron que la coexpresión de Myc-RhoGDI (Figura 27, paneles tercero y cuarto desde arriba, pág. anterior) $y$, en un mayor grado, de Myc-RhoGDI ${ }^{\text {S101A+S174A }}$ (Figura 27, paneles quinto y sexto desde arriba) bloquearon la translocación de AU5-Rac1 inducida por Coronina-1A-EGFP. Este efecto se debía a la interacción con Rac1, puesto que la coexpresión del mutante RhoGDI ( $\Delta 1-60)$ con AU5-Rac1 y Coronina-1A no dio lugar a ningún tipo de inhibición de la translocación de la GTPasa (Figura 27, paneles inferiores). Para representar de forma cuantitativa el efecto de los RhoGDI, determinamos en paralelo el índice de translocación de Rac1 en cada una de las condiciones experimentales descritas anteriormente. Observamos de este modo que la expresión de la forma silvestre Myc-RhoGDI disminuía hasta en un $40 \%$ el índice de translocación de AU5-Rac1 inducido por Coronina-1A-EGFP mientras que la expresión de la versión mutante myc-RhoGDI ${ }^{\text {S101A+S174A }}$ bloqueaba en un $100 \%$ la translocación de AU5-Rac1 a la membrana plasmática (Figura 28, pág. siguiente). En cambio, la expresión del mutante de RhoGDI defectivo para la unión de GTPasas no alteró el índice de translocación de Rac1 obtenidos en presencia de Coronina-1A-EGFP. Curiosamente, los RhoGDls no ejercieron ningún efecto sobre la presencia de la Coronina-1A en la membrana plasmática (Figura 27, paneles cuarto y sexto desde arriba), lo que sugiere que, al igual que en el caso de la inhibición de Pak1 (Figuras 21 y 23, págs. 76 y 77, respectivamente), la acción de los RhoGDI está localizada aguas debajo de Coronina-1A. 


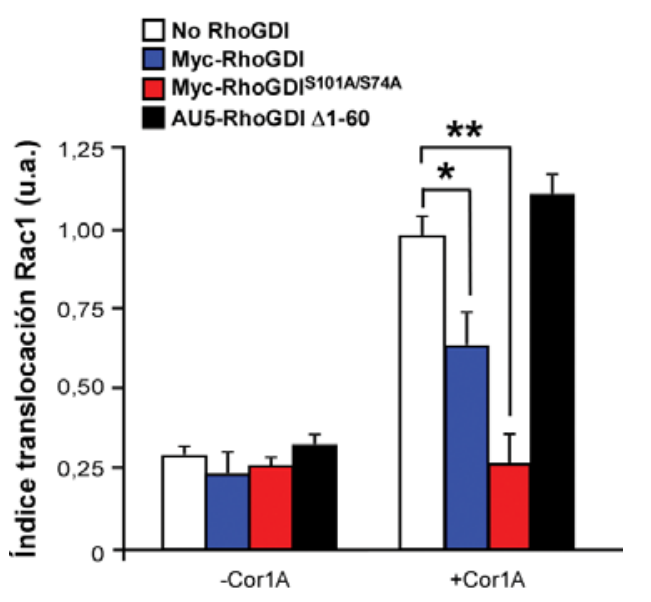

Proteina expresada
Figura 28. Cuantificación del índice de translocación de Rac1 inducido por Coronina-1A en presencia de los mutantes de RhoGDI utilizados. Se estimó el índice de translocación de Rac1 en cada una de las condiciones experimentales anteriores tal y como se indica en Materiales y Métodos (pág. 44). ${ }^{* *}, P \leq 0,01$, comparado con los valores obtenidos en células sin Myc-RhoGDI
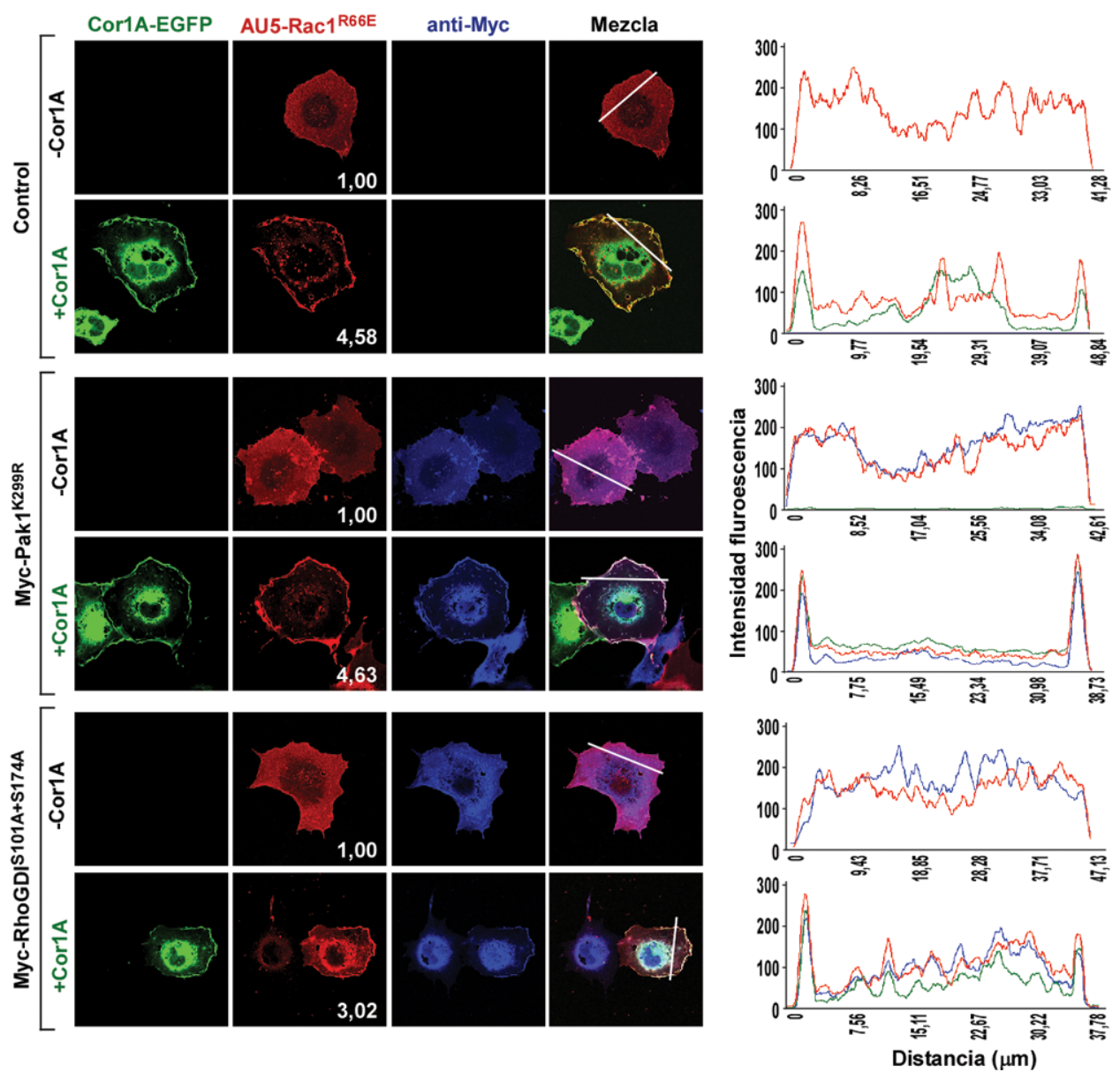

Figura 29. Efecto de Coronina-1A en la translocación de Rac1 $1^{\mathrm{R} 66 \mathrm{E}}$ en presencia de los mutantes Myc-Pak1 ${ }^{\mathrm{K} 29 \mathrm{R}}$ y Myc-RhoGDI ${ }^{\text {S101A+S174A. }}$. Células COS1 expresando transitoriamente AU5-Rac1 ${ }^{\mathrm{R} 66 \mathrm{E}} \mathrm{de}$ forma aislada o conjunta con Coronina-1A-EGFP y cada una de las proteínas etiquetadas con el epitopo Myc indicadas a la izquierda, fueron fijadas y teñidas como se indica en la Figura 23 (pág. 77). Finalmente las preparaciones se analizaron por microscopía confocal. Los niveles de fluorescencia relativa en la membrana para $\operatorname{Rac} 1^{\mathrm{R} 66 \mathrm{E}}$ se indican en el cuadrante inferior derecho de cada imagen. A la derecha se muestran las gráficas de distribución de intensidad de fluorescencia a lo largo del eje trazado (línea blanca que atraviesa la célula) en la imagen correspondiente. 
Con el fin de demostrar mediante una aproximación diferente que el efecto inhibitorio de los RhoGDI sobre la traslocación de Rac1 inducida por Coronina-1A se establecía a través de su unión directa con Rac1, decidimos comprobar el efecto que la sobreexpresión de los RhoGDI tenía sobre el mutante R66E de Rac1. Estudios previos han demostrado que esta versión mutante de Rac1 no puede interaccionar con RhoGDI (Gandhi et al., 2004; Gibson and Wilson-Delfosse, 2001). Observamos que AU5-Rac1 ${ }^{\mathrm{R} 66 \mathrm{E}}$, en contra de lo que cabría esperar por su incapacidad de ser retenido y secuestrado en el citosol mediante su unión a RhoGDI, mostraba una distribución citosólica (Figura 29, panel superior, pág. anterior). La coexpresión de Coronina-1A-EGFP con este mutante de Rac1 provocó su translocación a la membrana, donde se observó que ambas proteínas colocalizaban (Figura 29, segundo panel desde arriba). Sin embargo, la expresión de la forma dominante negativa de Pak1 o del mutante de RhoGDI insensible a inhibición por Pak1 no bloquearon la translocación de este mutante de Rac1 a la membrana mediada por Coronina-1A-EGFP (Figura 29, cuarto y sexto panel desde arriba), a diferencia de lo anteriormente observado con la forma silvestre de Rac1 (Figuras 23 y 27, págs. 77 y 83, respectivamente). La cuantificación del índice de translocación de Rac1 en estos experimentos confirmaron los resultados observados mediante microscopía confocal (Figura 30). Estos resultados apoyan la idea de que el desplazamiento de la GTPasa Rac1 desde el citosol hasta la membrana plasmática mediado por Coronina-1A es una consecuencia directa de la disociación de los complejos RhoGDI-Rac1 citosólicos dependiente de la actividad quinasa de Pak1. Sin embargo, estos resultados también ponen de manifiesto que existe un mecanismo subyacente, e independiente de RhoGDI, que colabora en la translocación de Rac1 mediada por Coronina-1A (ver Discusión, pág. 119).

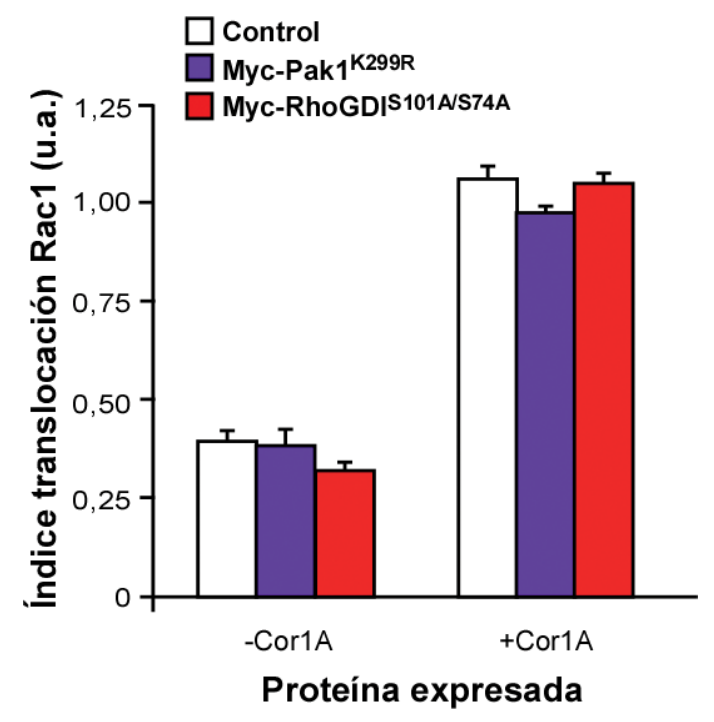

Figura 30. Cuantificación del índice de translocación de Rac1 ${ }^{\mathrm{R} 66 \mathrm{E}}$ inducido por Coronina-1A en presencia de los mutantes de Pak1 y RhoGDI utilizados. Se estimó el índice de translocación de $\operatorname{Rac} 1^{\mathrm{R} 66 \mathrm{E}}$ en cada una de las condiciones experimentales anteriores tal y como se indica en Materiales y Métodos (pág. 44). 
Para establecer el tipo de conexión funcional conexión entre Coronina-1A, Pak1 y RhoGDI, decidimos comprobar seguidamente si Coronina-1A podía interaccionar también con RhoGDI o bien si, como nuestros datos apuntaban, la expresión de Coronina-1A podría conducir a una mejor interacción entre Pak1 y RhoGDI. Con este fin, decidimos llevar a cabo nuevos experimentos de coinmunoprecipitación usando las líneas celulares ACC1-1 y ACC1-2, donde expresamos la versión silvestre de Pak1 etiquetada con el epitopo Myc para llevar la inmunoprecipitación de las proteínas EGFP ectópicas y RhoGDI endógenas. En estos inmunoprecipitados analizaríamos la presencia de complejos Pak1/RhoGDI y Pak1/Coronina1A-EGFP, respectivamente. Como habíamos comprobado previamente (Figura 26A, panel superior pág. 82), detectamos la interacción entre Myc-Pak1 y Coronina-1A-EGFP en los inmunoprecipitados de las proteínas EGFP procedentes de células que expresaban ambas proteínas ectópicas (Figura 31A, panel superior, pág. siguiente). Además, pudimos detectar la presencia de RhoGDI endógeno en los inmunoprecipitados de Coronina-1A-EGFP únicamente cuando Myc-Pak1 se coexpresaba de forma ectópica junto con Coronina-1A-EGFP (Figura 31A, segundo panel desde arriba). Como control negativo de estos experimentos, dichas coinmunoprecipitaciones no se detectaron cuando se inmunoprecipitó la proteína EGFP no quimérica. Los mismos resultados se observaron en estos estudios de coinmunoprecipitación cuando analizamos los inmunoprecipitados de las proteínas RhoGDI endógenas (Figura 31B, paneles superiores). Para comprobar que la expresión de todas las proteínas en estos experimentos era la adecuada analizamos mediante Western blot alícuotas de los extractos celulares utilizados en las inmunoprecipitaciones anteriores (Figura 31C). Estos resultados constatan que Coronina-1A promueve la formación de complejos Pak1/RhoGDI in vivo y que la interacción entre las tres proteínas está mediada por Pak1.

Para averiguar si la translocación de Rac1 a la membrana y la formación de complejos Pak1/RhoGDI inducidos por Coronina-1A eran fenómenos funcionalmente interconectados, decidimos estudiar la interacción entre Pak1, RhoGDI y Coronina-1A mediante la misma aproximación farmacológica descrita en el apartado 2.2.1. (pág. 74). Realizamos toda una batería de experimentos de inmunoprecipitación tratando las células previamente con cada uno de los inhibidores descritos en aquel apartado. De este modo encontramos que la formación del complejo Coronina-1A/Pak1/RhoGDI era bloqueada mediante el uso del péptido inhibitorio Tat-Pak18 (Figura 31D,E), M $\beta C D$ (Figura 32A, B, pág. 89) y CytD (Figura 32D,E) pero no por el péptido inactivo Tat-Pak ${ }^{R 192 A}$ o GF109203X (Figuras 31D,E y 32D,E). La falta de interacción entre las tres proteínas tras la inhibición de Pak1, balsas lipídicas o citoesqueleto de F-actina no se debía a problemas de expresión de estas proteínas como observamos mediante Western blot en los lisados celulares totales empleados en cada inmunoprecipitación (Figuras 31C,F, y 32C,F). 
A

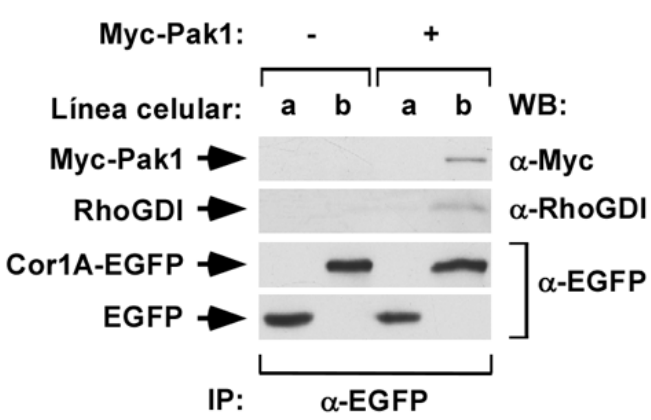

C

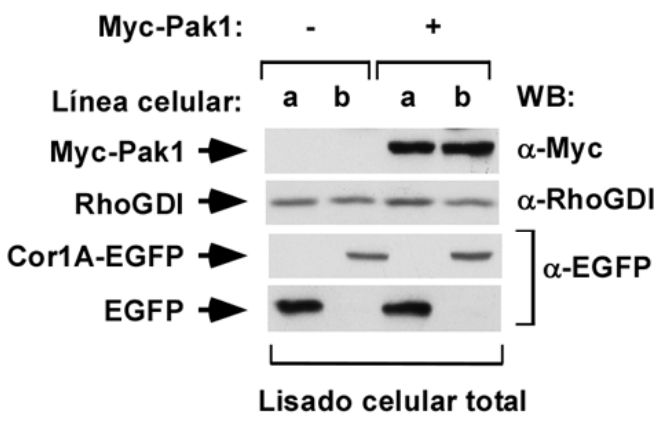

$\mathbf{E}$

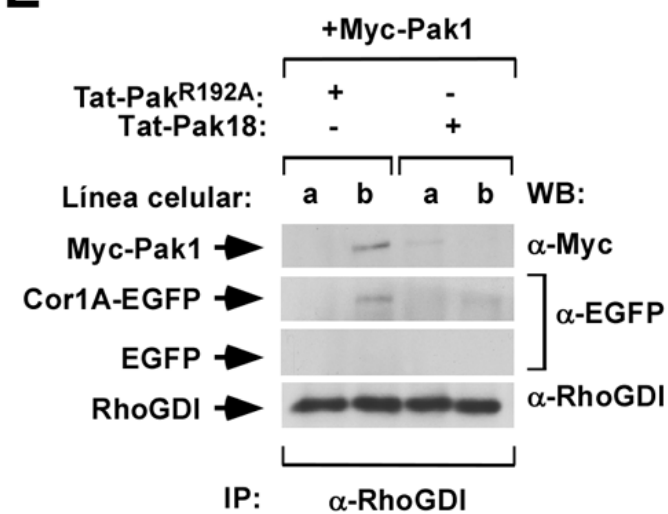

B

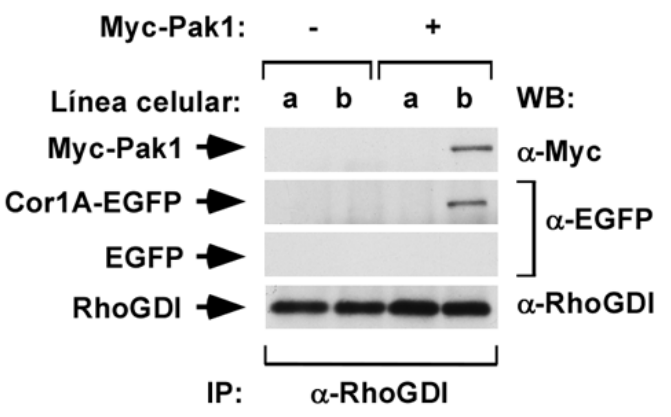

D

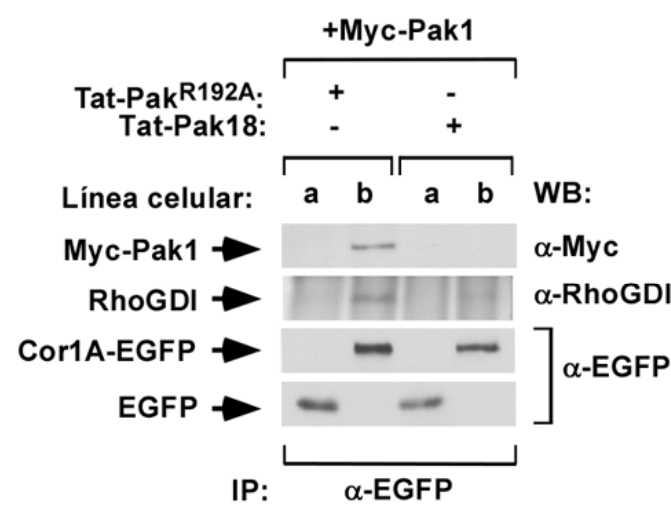

$\mathbf{F}$

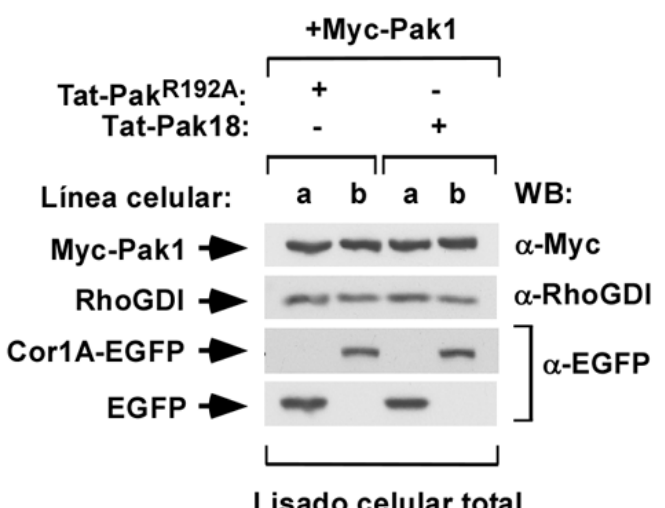

Figura 31. Coronina-1A promueve la formación de complejos Pak1/RhoGDI in vivo de una forma dependiente la actividad quinasa de Pak1. Las líneas celulares ACC1-1 (a) y ACC1-2 (b) fueron transfectadas con vector vacío (-) o con un vector de expresión para Myc-Pak1 (+) y posteriormente lisadas para llevar a cabo la inmunoprecipitación de las proteínas con etiqueta EGFP (A) o de las proteínas RhoGDI endógenas (B). Los inmunocomplejos $(\mathbf{A}, \mathbf{B})$ fueron separados electroforéticamente y analizados mediante Western blot con los anticuerpos indicados a la derecha de cada panel. Se analizaron alícuotas de los extractos celulares (C) utilizados en ambas inmunoprecipitaciones mediante Western blot con los anticuerpos indicados a la derecha de cada panel para detectar la correcta expresión de las proteínas usadas en estos experimentos. Lisados celulares obtenidos de las líneas celulares ACC1-1 (a) y ACC1-2 (b) que habían sido transfectadas previamente con un vector de expresión para Myc-Pak1 e incubadas con Tat-Pak18 o Tat-Pak ${ }^{R 192 A}$ (10 $\mu \mathrm{M}$ durante toda la noche) fueron inmunoprecipitados con anticuerpos anti-EGFP (D) o anti-RhoGDI (E). Los inmunoprecipitados (D,E) fueron separados electroforéticamente y analizados mediante Western blot con los anticuerpos indicados a la derecha de cada panel. La expresión de todas las proteínas utilizadas en este estudio fue también analizada mediante Western blot con los anticuerpos indicados a la derecha de cada panel en alícuotas de los lisados celulares totales (F). 
A

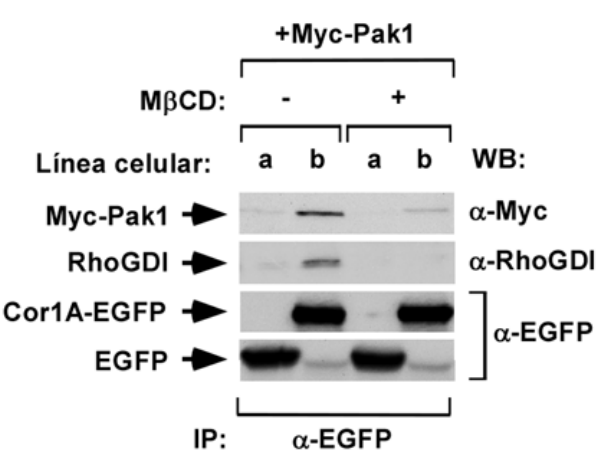

C

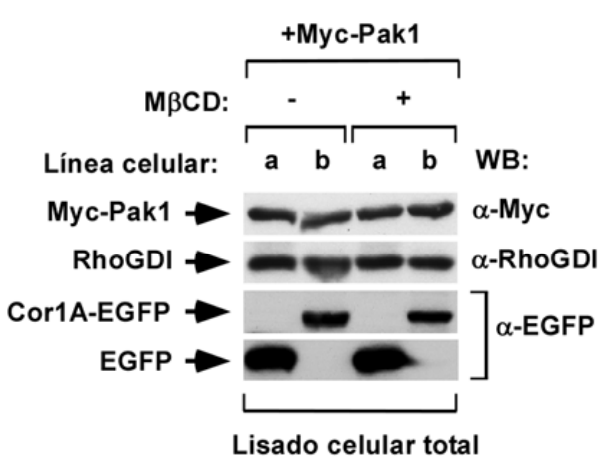

$\mathbf{E}$

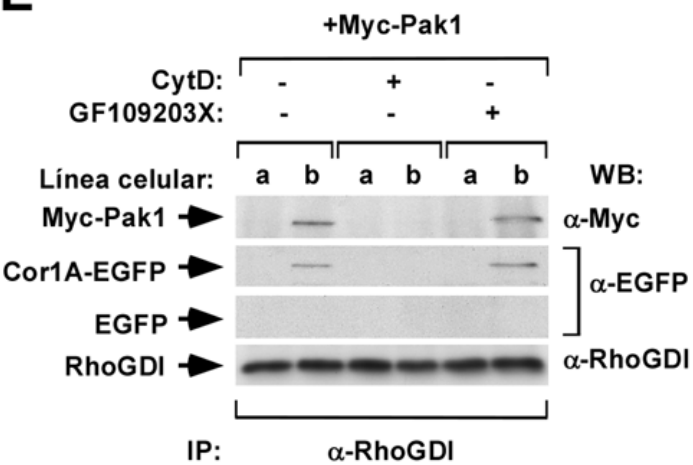

B

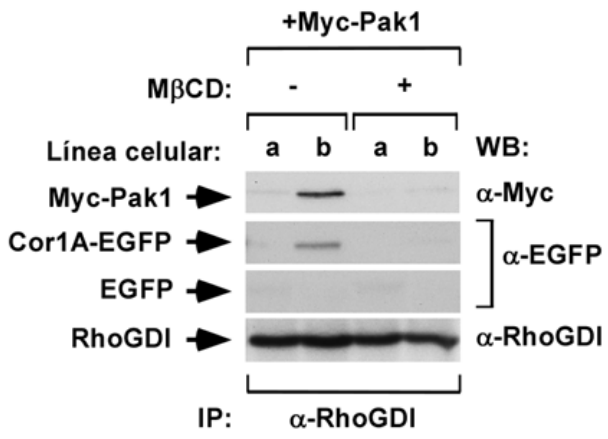

D

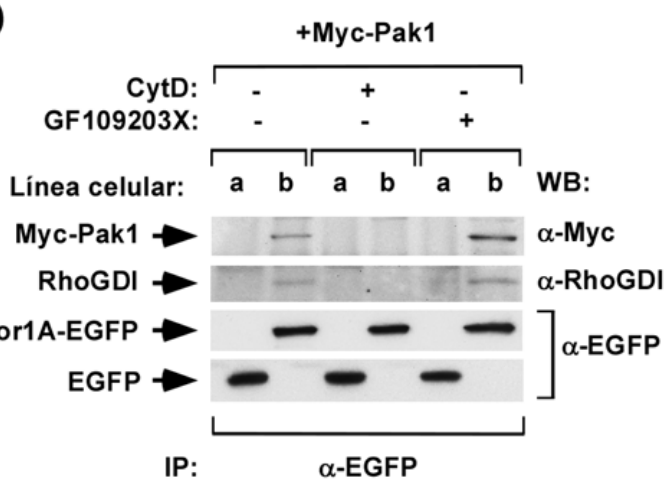

$\mathbf{F}$

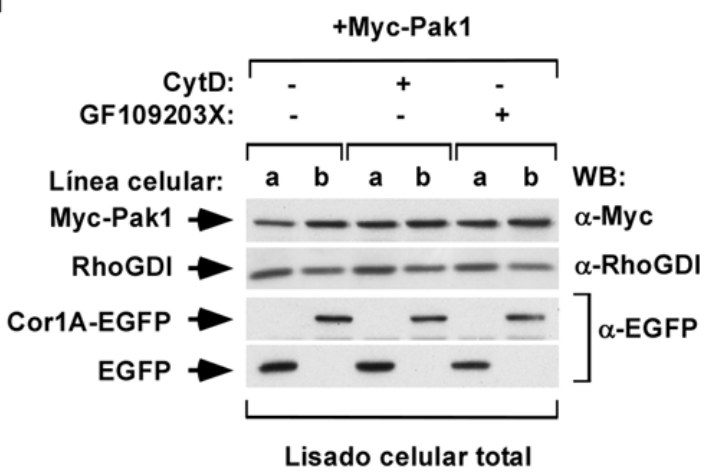

Figura 32. La formación de complejos Coronina-1A/Pak1/RhoGDI requiere la correcta funcionalidad de balsas lipídicas y del citoesqueleto de F-actina pero no actividad PKC. Las líneas celulares ACC1-1 (a) y ACC1-2 (b) expresando de forma transitoria la proteína Myc-Pak1 y tratadas o no con $\mathrm{M} \beta C D(10 \mathrm{mM} ; 1 \mathrm{~h})$ fueron lisadas para llevar a cabo la inmunoprecipitación de las proteínas EGFP (A) y RhoGDI endógenas (B). Los inmunocomplejos (A,B) fueron separados electroforéticamente y analizados mediante Western blot con los anticuerpos que se indican a la derecha de cada panel. Alícuotas de los mismos lisados utilizados para la inmunoprecipitaciones anteriores (C) fueron separadas electroforéticamente y analizadas mediante Western blot con los anticuerpos indicados a la derecha de cada panel. Lisados celulares obtenidos de las líneas celulares ACC1-1 (a) y ACC1-2 (b) que habían sido transfectadas previamente con un vector de expresión para Myc-Pak1 e incubadas con CytD (2 $\mu \mathrm{m} ; 15$ min) y GF109203X (5 $\mu \mathrm{M} ; 1 \mathrm{~h})$ fueron inmunoprecipitados con anticuerpos anti-EGFP (D) 0 anti-RhoGDI (E). Los inmunoprecipitados $(D, E)$ fueron entonces separados electroforéticamente y analizados mediante Western blot con los anticuerpos indicados a la derecha de cada panel. Alícuotas de esos mismos lisados (F) fueron igualmente resueltos por electroforesis y analizados por Western blot usando los anticuerpos indicados a la derecha de cada panel. 
A continuación, decidimos estudiar si la unión de Coronina-1A al citoesqueleto de Factina era necesaria para promover la formación de complejos Coronina-1A/Pak1/RhoGDI in vivo. Para ello, transfectamos células COS1 de forma transitoria con plásmidos de expresión para Myc-Pak1, EGFP, Coronina-1A-EGFP y Coronina-1A ${ }^{R 29 D}$-EGFP y realizamos la inmunoprecipitación de las proteínas RhoGDI endógenas. Tras analizar los inmunoprecipitados mediante Western blot encontramos, como ya habíamos observado en experimentos anteriores, que la versión silvestre de Coronina-1A-EGFP inducía la formación de complejos Coronina-1A/Pak1/RhoGDI (Figura 31B, pág. 88) mientras que el mutante Coronina1 $A^{\text {R29D }}$ EGFP fallaba en promover tal interacción (Figura 33, panel superior, pág. siguiente). Estos resultados apoyan la idea de que la interacción entre las tres proteínas no ocurre en el citosol y requiere del ensamblaje de Coronina-1A en el citoesqueleto de F-actina.

Recapitulando los datos obtenidos en nuestros experimentos de inmunofluorescencia, nos preguntamos si Coronina-1A necesitaría de una cierta actividad basal de Rac1 para promover la formación de estos complejos Coronina-1A/Pak1/RhoGDI in vivo. Así, transfectamos las líneas celulares ACC1-1 y ACC1-2 con plásmidos para Myc-Pak1, AU5-Rac1 o la forma dominante negativa AU5-Rac1 ${ }^{T 17 N}$. Encontramos que la interacción de Coronina1A/Pak1 /RhoGDI era bloqueada por la coexpresión de AU5-Rac1 ${ }^{\text {T17N }}$ (Figura 34A,B, pág. siguiente). Además, encontramos que la cantidad de Coronina-1A-EGFP en los inmunoprecipitados de las proteínas con etiqueta EGFP era considerablemente menor cuando se coexpresaba con AU5-Rac1 ${ }^{\top 17 N}$. Este déficit no se debió a una falta de expresión de Coronina-1A-EGFP puesto que las cantidades de esta proteína detectadas por Western blot en los lisados celulares totales fueron homogéneas en todos los casos (Figura 34C).

Estos resultados junto con los obtenidos en los estudios de translocación de AU5-Rac1 inducida por Coronina-1A-EGFP mediante técnicas de inmunofluorescencia, confirman que:

1. la liberación de Rac1 desde las reservas citosólicas RhoGDI/Rac1 que induce Coronina-1A a través de la actividad quinasa de Pak1 requiere de la integridad funcional tanto de balsas lipídicas como del citoesqueleto de F-actina

2. Coronina-1A precisa de una cierta actividad basal procedente de Rac1 y su ensamblaje en el citoesqueleto de F-actina para translocarse a la membrana plasmática y poder llevar a cabo su papel en la translocación de más proteínas Rac1 desde sus reservas citosólicas 


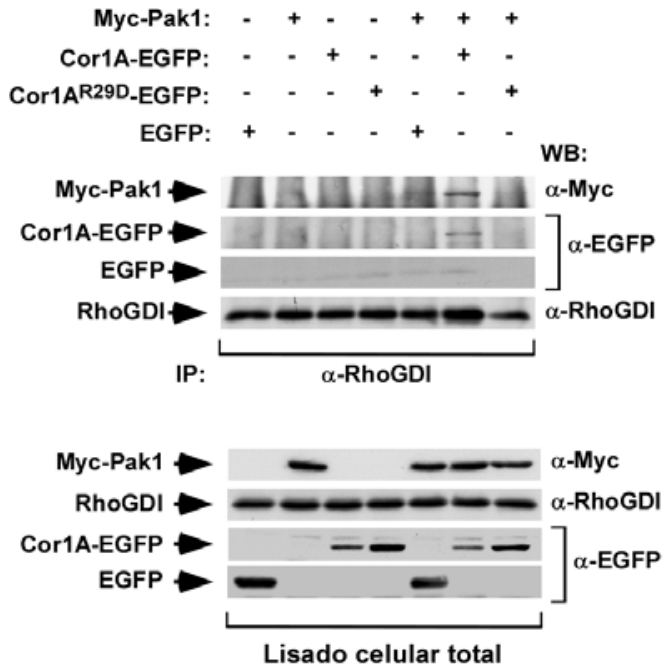

Figura 33. Coronina-1A promueve la interacción de Pak1 con RhoGDI in vivo de una forma dependiente de su unión a F-actina. Células COS1 transfectadas con diferentes combinaciones de plásmidos de expresión para las proteínas indicadas fueron lisadas y los extractos celulares sometidos a inmunoprecipitación con anticuerpos anti-RhoGDI. Alícuotas de los inmunocomplejos (cuatro paneles superiores) y de los extractos celulares (cuatro paneles inferiores) fueron separados electroforéticamente y analizados mediante Western blot con los anticuerpos que se indican a la derecha de cada panel.

A

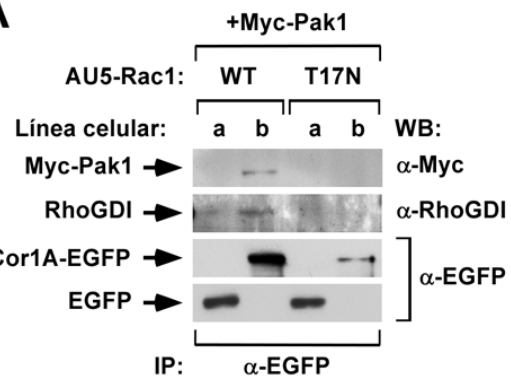

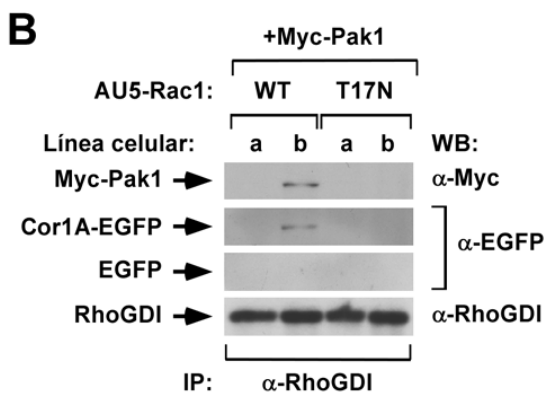

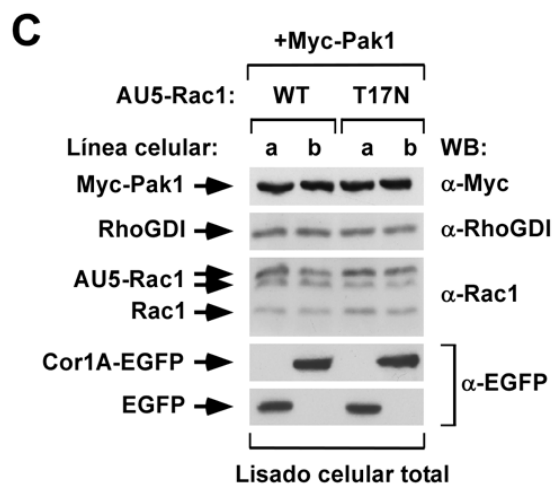

Figura 34. La formación de complejos Coronina-1A/Pak1/RhoGDI requiere actividad de Rac1. Las líneas celulares ACC1-1 (a) y ACC1-2 (b) expresando de forma transitoria las proteínas ectópicas MycPak1, AU5-Rac1 ${ }^{\mathrm{WT}}$ (WT) o AU5-Rac1 ${ }^{\mathrm{T} 17 \mathrm{~N}}$ (T17N) fueron lisadas para llevar a cabo la inmunoprecipitación de las proteínas EGFP (A) o RhoGDI endógenas (B). Los inmunocomplejos (A,B) fueron separados electroforéticamente y analizados mediante Western blot con los anticuerpos indicados a la derecha de cada panel. Alícuotas de los lisados celulares (C) empleados en estos experimentos fueron separados electroforéticamente y analizados mediante Western blot usando los anticuerpos indicados a la derecha de cada panel. 


\subsubsection{La formación de complejos Coronina-1A/Pak1/RhoGDI requiere ArhGEF7}

Con el fin de diseccionar el mecanismo molecular a través del cual Coronina-1A controlaba la formación de estos complejos Coronina-1A/Pak1/RhoGDI decidimos utilizar en nuestros experimentos de inmunoprecipitación una colección de mutantes de Pak1 etiquetados con el epitopo Myc. Éstos incluían la versión mutante inactiva en su dominio quinasa que funciona como dominante negativo (Myc-Pak1 $1^{\mathrm{K} 299 \mathrm{R}}$ ), una versión mutante constitutivamente activa (MycPak1 ${ }^{\text {T423E }}$ ) (Yu et al., 1998; Zenke et al., 1999) y un mutante en la región central rica en prolinas (Myc-Pak1 $\triangle P R R$ ) encargada de establecer interacciones con otras proteínas que contienen dominios SH3 (Bokoch, 2003). Transfectamos nuestras líneas celulares ACC1-1 y ACC1-2 con vectores de expresión para cada una de las versiones de Pak1 anteriormente descritas. Tras realizar la inmunoprecipitación de las proteínas etiquetadas con EGFP y las proteínas RhoGDI endógenas encontramos que la interacción entre Myc-Pak1 y RhoGDI era dependiente de Coronina-1A-EGFP únicamente en el caso de la versión silvestre de Pak1, ya que la forma constitutivamente activada de esta quinasa se asociaba a RhoGDI tanto en ausencia como en presencia de Coronina-1A-EGFP (Figura 35B, panel superior, pág. siguiente). Sin embargo, no encontramos asociación de Pak1 con Coronina-1A-EGFP o RhoGDI en las células que expresaban la forma inactiva de la proteína quinasa Myc-Pak $1^{\mathrm{K} 299 \mathrm{R}}$, indicando que la formación de estos complejos heteromoleculares necesita la actividad quinasa de Pak1 (Figura 35A,B, panel superior). Nuestros resultados están de acuerdo a lo ya descrito previamente en otros estudios en los que se muestra que Pak1 puede unir y fosforilar a RhoGDI únicamente en su conformación activa (DerMardirossian et al., 2004). Curiosamente, pudimos observar también que el mutante de la región central rica en prolinas (Myc-Pak1 $\triangle P R R$ ) también fue incapaz de promover la formación de estos complejos Coronina-1A/Pak1/RhoGDI, indicando que existen otros candidatos potenciales que se unen a esta zona rica en prolinas implicados en la interacción de estas tres proteínas (Figura 35A,B. panel superior). Para comprobar que la expresión de todas las proteínas era la adecuada analizamos mediante Western blot una alícuota de los lisados celulares utilizados en estos experimentos de inmunoprecipitación (Figura 35C). Estos resultados nos indican que la interacción entre Coronina-1A, Pak1 y RhoGDI necesita, además de la actividad quinasa de Pak1, de otras moléculas adicionales que interaccionan con Pak1 a través de su región central rica en prolinas.

Mientras que la formación de complejos Coronina-1A/Pak1/RhoGDI de una forma dependiente del citoesqueleto de F-actina podría explicar la translocación de Rac1 a la membrana inducida por la propia Coronina-1A, ello no justifica el aumento en los niveles de activación de Rac1 promovidas por Coronina-1A. Dado que la activación de Rac1 requiere el intercambio de GDP por GTP catalizado por GEFs (Bos et al., 2007), decidimos investigar a continuación la participación de algún GEF para Rac1 en esta ruta de señalización. El candidato más obvio para comenzar nuestros estudios era ArhGEF7 ya que este GEF posee un dominio $\mathrm{SH} 3$ que actúa como sitio de unión a la región central rica en prolinas de Pak1 
(Bokoch, 2003; Manser et al., 1998; Rosenberger and Kutsche, 2006). A favor de esta idea, habíamos observado que el mutante de Pak1 deficiente para la unión de ArhGEF7 no podía interaccionar con RhoGDI en células que expresaban Coronina-1A-EGFP (Figura 35B, panel superior).

A

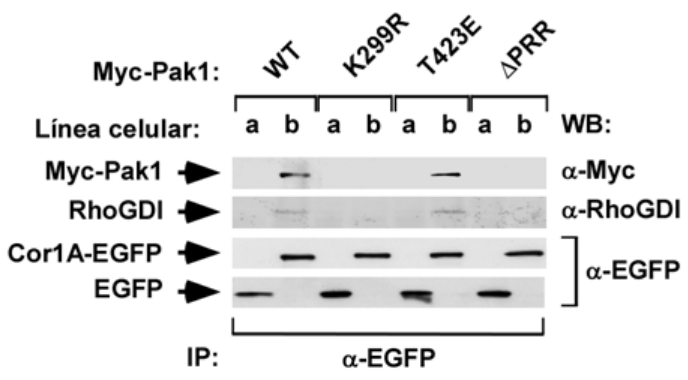

B

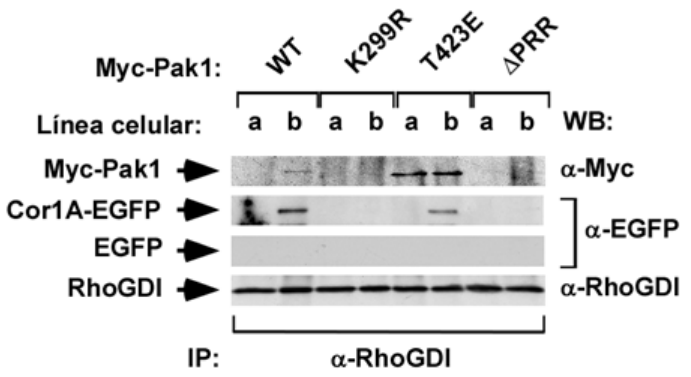

C

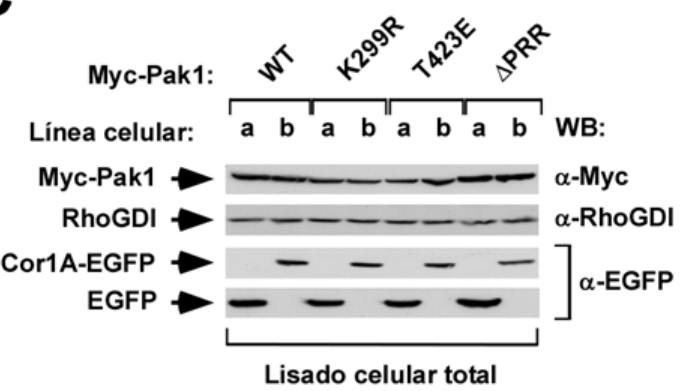

Figura 35. Interacción de Coronina-1A con diferentes mutantes de Pak1. Lisados celulares procedentes de las líneas celulares ACC1-1 (a) y ACC1-2 (b) previamente transfectadas con plásmidos de expresión para las diferentes versiones de Myc-Pak1 indicadas arriba fueron inmunoprecipitados con anticuerpos anti-EGFP (A) o anti-RhoGDI (B). Los inmunoprecipitados (A,B) y alícuotas de los lisados celulares totales (C) fueron separados electroforéticamente y analizados mediante Western blot con los anticuerpos que se indican a la derecha de cada panel.

Dadas estas premisas, quisimos investigar si Coronina-1A interaccionaba con ArhGEF7, y si así fuera, comprobar si dicha interacción dependía o no de la capacidad de Coronina-1A de unir F-actina. Para ello, realizamos estudios de coinmunoprecipitación en lisados celulares procedentes de células COS1 que expresaban diferentes combinaciones de las proteínas Myc-ArhGEF7, Coronina-1A-EGFP, Coronina-1A ${ }^{R 29 D}-E G F P$ y la proteína no quimérica EGFP. Estos lisados fueron inmunoprecipitados con anticuerpos contra EGFP y, tras la recuperación de los inmunocomplejos y los lavados correspondientes la presencia de MycArhGEF7 en dichos inmunoprecipitados fue determinada por análisis de Western blot con anticuerpos contra ArhGEF7. Como se muestra en la Figura 36A (panel superior, pág. 95), estos experimentos demostraron que la proteína Myc-ArhGEF7 coinmunoprecipitaba con Coronina-1A-EGFP y no con la proteína no quimérica EGFP. A diferencia de las asociaciones intermoleculares previas, (Figura 26A, pág. 82), esta nueva interacción no requería la 
formación de complejos Coronina-1A/F-actina, puesto que también se observaba en los experimentos de coinmunoprecipitación realizados con Coronina- $1 A^{R 29 D}$-EGFP, deficiente para la unión de filamentos de F-actina (Figura 36A, panel superior). En paralelo, se analizaron alícuotas procedentes de los lisados celulares totales mediante Western blot para comprobar la correcta expresión de todas las proteínas ectópicas utilizadas en estos experimentos (Figura 36A, paneles inferiores).

De acuerdo con dicha interacción funcional, estudios por microscopía confocal demostraron que la coexpresión de Coronina-1A-EGFP con Myc-ArhGEF7 en células COS1 inducía un enriquecimiento de este GEF en la membrana plasmática (Figura 36B, paneles superior e intermedio). Sin embargo, dicha translocación no se producía si la versión silvestre de Coronina-1A se sustituía en estos experimentos por su mutante R29D (Figura 36B, panel inferior). Este aumento de la translocación de ArhGEF7 inducido por Coronina-1A se puede apreciar de manera más cuantitativa en la Figura 36C, donde se muestran los índices de translocación obtenidos para ArhGEF7 en estos experimentos. Estos resultados demuestran que Coronina-1A puede formar complejos citosólicos estables con ArhGEF7 de una forma independiente de F-actina. Sin embargo, la translocación de ArhGEF7 a la membrana plasmática todavía requiere la asociación de Coronina-1A con filamentos de F-actina.

Dado que el mutante de Pak1 en la región central rica en prolinas (myc-Pak1 $\triangle P R R$ ) no interacciona con Coronina-1A-EGFP (Figura 35, panel superior, pág.anterior) quisimos determinar si ArhGEF7 podría tener un papel determinante en la formación de los complejos Coronina-1A/Pak1/RhoGDI. En este caso, generamos una nueva línea celular (denominada ACC1-2 ArhGEF7 shRNA) derivada de la línea celular ACC1-2, previamente descrita, donde bloqueamos parcialmente la expresión endógena de ArhGEF7 mediante transducción de partículas lentivirales que portaban secuencias shRNAs contra el transcrito de esta proteína. Como control, utilizamos otra línea celular (designada como ACC1-2 Control shRNA) que contenía un segundo shRNA dirigido contra el ARNm de ArhGEF7 que había fallado en disminuir la expresión de dicha proteína. La transducción, selección, caracterización y expansión de estos clones celulares se discute en detalle en la sección de Materiales y Métodos (pág. 40). Los niveles de expresión de ArhGEF7 endógena en ambas líneas celulares se muestran en la Figura 37C (panel inferior, pág. 96).

Llevamos a cabo la transfección transitoria en estas nuevas líneas celulares de vectores de expresión para Myc-Pak1 y la posterior inmunoprecipitación de las proteínas con etiqueta EGFP y las proteínas RhoGDI endógenas. Encontramos que la inhibición de ArhGEF7 a nivel endógeno en células que expresaban Coronina-1A-EGFP bloqueaba la interacción de Myc-Pak1 y RhoGDI con Coronina-1A-EGFP (Figura 37A, panel superior). De un modo 


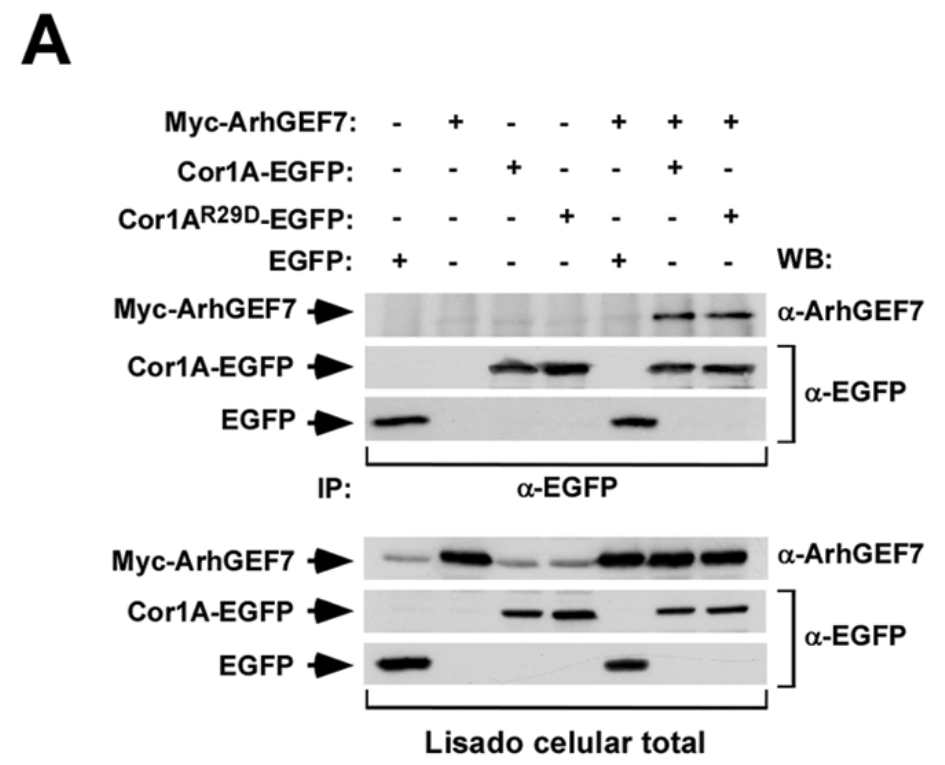

B

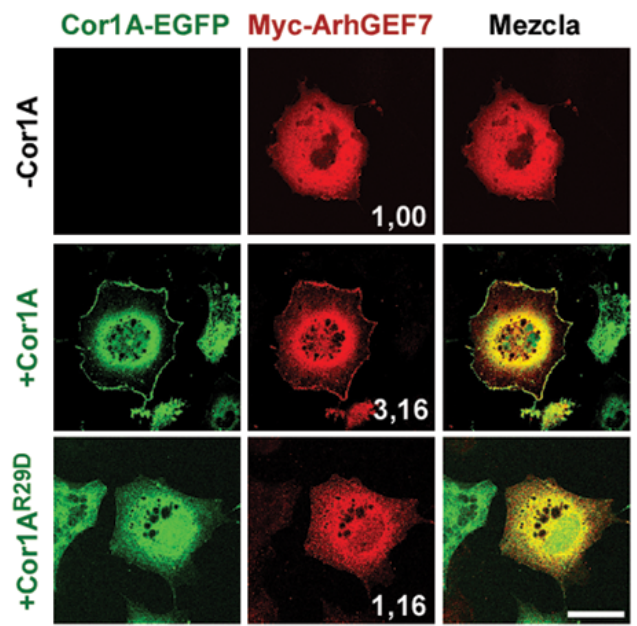

C

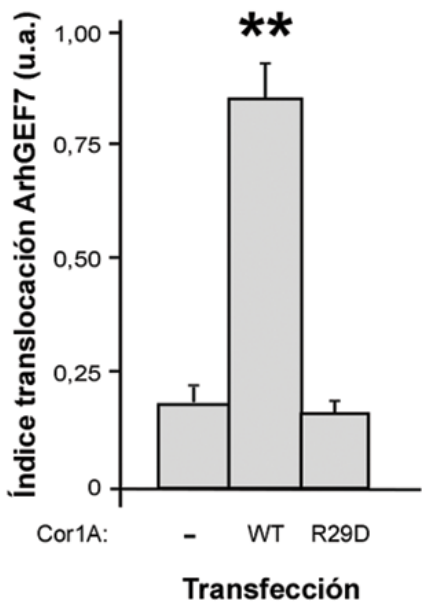

Figura 36. Coronina-1A interacciona in vivo con ArhGEF7 de una forma independiente de su unión a F-actina. (A) Células COS1 transfectadas con diferentes combinaciones de plásmidos de expresión para las proteínas indicadas fueron lisadas y los extractos celulares sometidos a inmunoprecipitación con anticuerpos anti-EGFP. Los inmunoprecipitados (tres paneles superiores) y alícuotas de los lisados celulares totales (tres paneles inferiores) fueron separados electroforéticamente y analizados mediante Western blot con con los anticuerpos que se indican a la derecha de cada panel. (B) Se transfectaron células COS1 con un vector de expresión para Myc-ArhGEF7 y para cada una de las proteínas EGFP que se indican a la izquierda. Posteriormente las células fueron fijadas y teñidas tal y como se indica en la Figura 26B (pág. 82). Finalmente las preparaciones se analizaron al microscopio confocal. Los valores de fluorescencia relativa para ArhGEF7 en la membrana plasmática se indican en el cuadrante inferior derecho de cada imagen. Barra de escala: $20 \mu \mathrm{m}$. (C) La cuantificación de la translocación a la membrana plasmática de ArhGEF7 se realizó de forma idéntica a la translocación de Rac1 según lo descrito en Materiales y Métodos (pág. 44). **, $P \leq 0,01$, comparado con los valores obtenidos en células sin Coronina-1A-EGFP. 
A

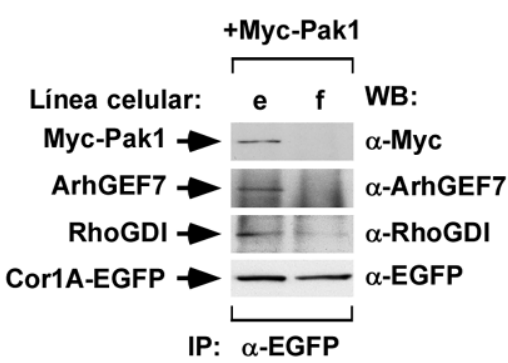

B

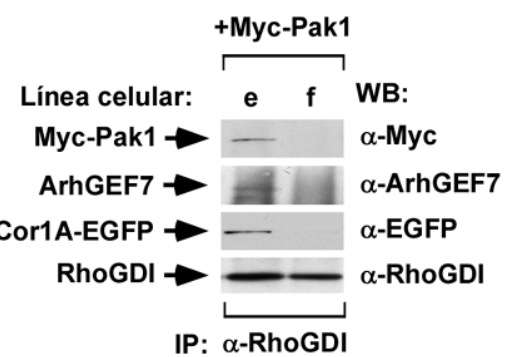

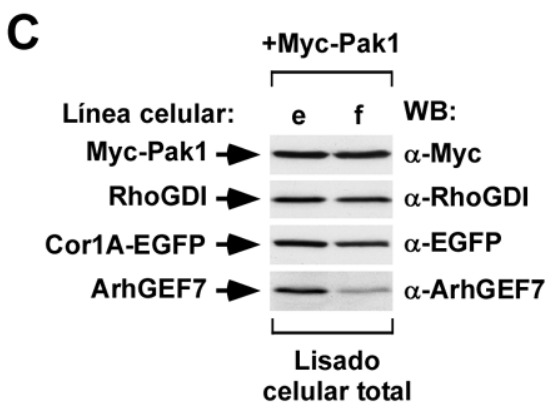

Figura 37. La formación de complejos Coronina-1A/Pak1/RhoGDI requiere ArhGEF7. Lisados procedentes de las líneas celulares ACC1-2 Control shRNA (e) y ACC1-2 ArhGEF7 shRNA (f) que expresaban de forma transitoria la proteína ectópica Myc-Pak1 fueron inmunoprecipitados con anticuerpos anti-EGFP (A) o anti-RhoGDI (B). Los inmunocomplejos (A,B) y alícuotas de los lisados celulares totales (C) fueron separados electroforéticamente y analizados mediante Western blot con los anticuerpos indicados a la derecha de cada panel.

inverso, la represión de la expresión de ArhGEF7 también condujo a la eliminación de la formación de los complejos Coronina-1A/Pak1/RhoGDI como pudimos observar en los inmunoprecipitados de las proteína RhoGDI endógenas (Fig 37B, panel superior). Estos experimentos demostraron también la presencia de ArhGEF7 endógeno en los inmunoprecipitados de Coronina-1A-EGFP, confirmando que la interacción ectópica que habíamos encontrado entre ambas proteínas también ocurría a nivel endógeno in vivo (Fig 37A, segundo panel desde arriba). Análisis por Western blot demostraron la expresión adecuada de todas las proteínas en este estudio (Figura 37C). Estos resultados indican que ArhGEF7 es esencial en la formación de complejos Coronina-1A/Pak1/RhoGDI in vivo en el interior celular.

\subsubsection{ArhGEF7 es esencial para la translocación y activación de Rac1 mediada} por Coronina-1A

Con el fin de estudiar la participación de ArhGEF7 en la activación y translocación de Rac1 dependiente de Coronina-1A, decidimos comprobar si la deficiencia de ArhGEF7 endógeno mimetizaba los efectos de la eliminación de Coronina-1A endógena en células COS1. En primer lugar, analizamos los niveles de activación de Rac1 en células en reposo y estimuladas con EGF utilizando las líneas celulares ACC1-2 ArhGEF7 shRNA y ACC1-2 Control shRNA. 
Experimentos de Pull down con la proteína GST-CRIB mostraron que tanto los niveles basales de Rac1-GTP como los desencadenados en respuesta a la estimulación con EGF en células deficientes en ArhGEF7 eran significativamente inferiores a los observados en las células control (Figura 38A,B). Sin embargo, la disminución en los niveles de expresión de ArhGEF7 no afectó a otros procesos desencadenados por la estimulación de EGF como la autofosforilación del EGFR (Figura 38A, tercer panel desde arriba) o la activación de elementos situados aguas abajo como la ruta de Ras/Erk (Figura 38A, quinto panel desde arriba).

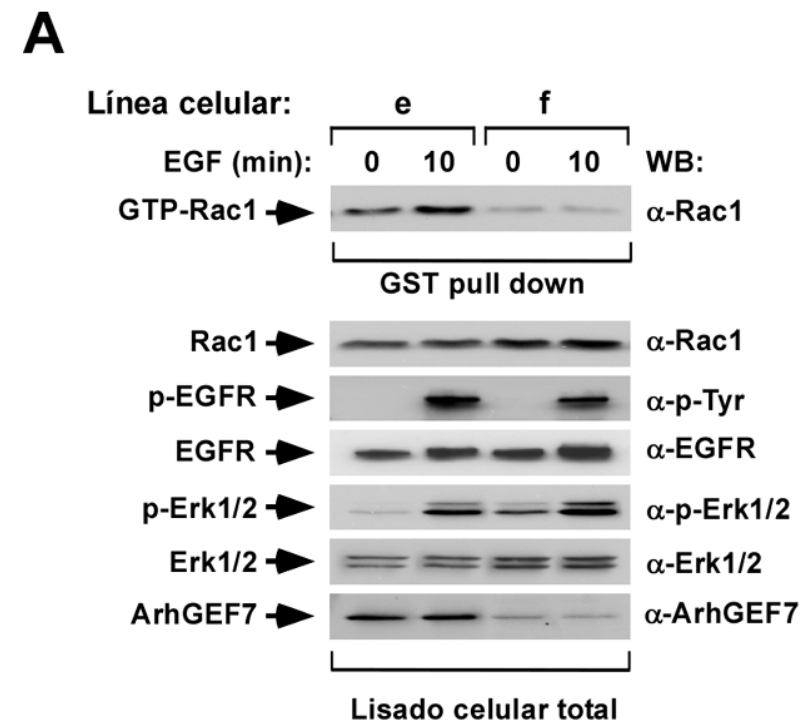

B

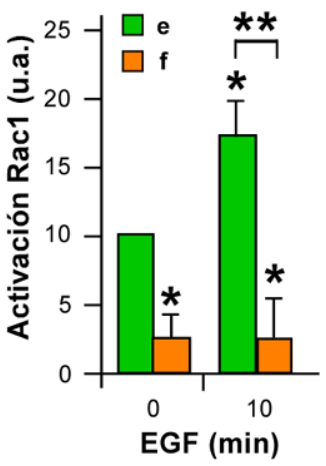

Figura 38. ArhGEF7 es esencial para la activación de Rac1 inducida por Coronina-1A durante la señalización con EGF. (A) Las líneas celulares ACC1-2 Control shRNA (e) y ACC1-2 ArhGEF7 shRNA (f) privadas de suero, fueron estimuladas con EGF y lisadas en presencia de la proteína GST-CRIB para realizar un ensayo de Pull down y analizar la activación de Rac1 in vivo. Las fracciones de Pull down y alícuotas de los lisados celulares totales fueron separados electroforéticamente y la cantidad de Rac1 endogéna en cada fracción se detectó por Western blot con anticuerpos anti-Rac1. El resto de proteínas se detectó en los lisados totales con los anticuerpos indicados a la derecha de cada panel. (B) Las bandas detectadas por Western blot con anticuerpos anti-Rac1 en la fracción Pull down fueron densitometradas usando el software ImageJ y normalizadas con respecto a la cantidad de Rac1 en el lisado celular total. Los valores expresados en la gráfica representan la media y la desviación estándar de tres experimentos independientes en unidades arbitrarias (u.a.). ${ }^{*}, P \leq 0,05$. ${ }^{* *}, P \leq 0,01$, comparado a los valores obtenidos con respecto al control sin estimular o entre las condiciones experimentales indicadas por los corchetes.

Finalmente, quisimos averiguar si la translocación de Rac1 a la membrana plasmática inducida por Coronina-1A-EGFP se veía también afectada por la carencia de ArhGEF7 endógeno en estas células. Para ello, transfectamos las líneas celulares ACC1-2 Control shRNA y ACC1-2 ArhGEF7 shRNA con plásmidos de expresión para AU5-Rac1 y realizamos experimentos de inmunofluorescencia mediante microscopía confocal. Observamos que la inhibición de la expresión de ArhGEF7 eliminó la capacidad de Coronina-1A-EGFP de translocar a AU5-Rac1 a la membrana plasmática (Figura 39A,B, pág. siguiente). Sin embargo, 
la localización subcelular de nuestra proteína quimera fluorescente no se vio afectada por la disminución de los niveles endógenos de ArhGEF7, tal como ocurría cuando se coexpresaba el dominante negativo AU5-Rac1 ${ }^{T 17 N}$ (Figura 24, pág. 79). Este resultado sugiere que la localización yuxtamembranaria de Coronina-1A-EGFP depende de otros GEFs específicos para Rac1. En conjunto, nuestros resultados apuntan a un modelo funcional en el cual una pequeña población de Rac1 activada, o cualquier otra GTPasa íntimamente relacionada, activaría el mecanismo que, a través de la formación de complejos constituidos por Coronina-1A, ArhGEF7, Pak1 y RhoGDI/Rac1, contribuye al reclutamiento y activación posterior de más proteínas Rac1 en la membrana plasmática.

A

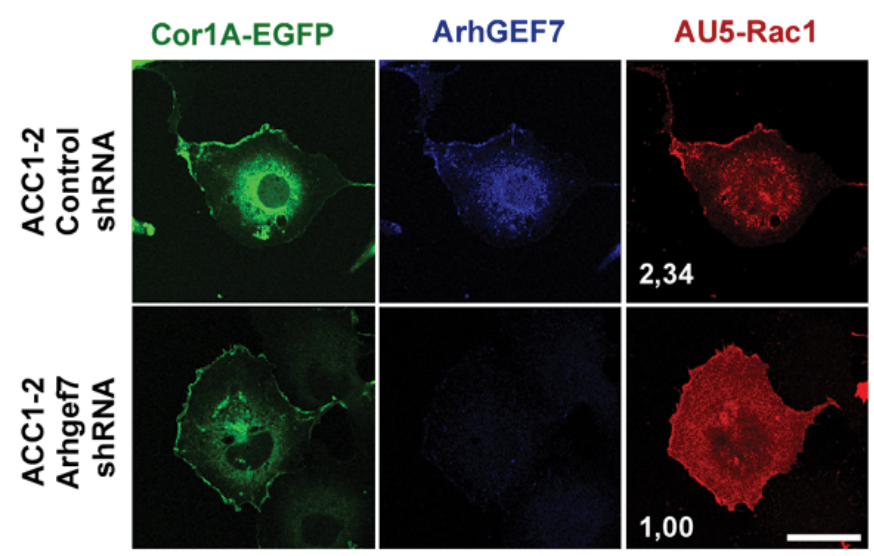

B

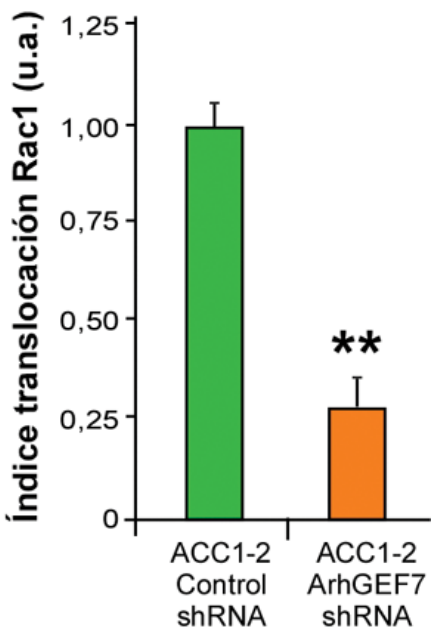

Línea celular

Figura 39. ArhGEF7 es importante para la translocación de Rac1, pero no de Coronina-1A, a la membrana. (A) Se transfectaron las líneas celulares ACC1-2 Control shRNA y ACC1-2 ArhGEF7 shRNA con un vector de expresión para AU5-Rac1. Posteriormente las células fueron fijadas y teñidas con anticuerpos anti-AU5 y anti-ArhGEF7 seguido de anticuerpos secundarios conjugados a Cy3 (rojo) y Cy5 (azul), respectivamente. Finalmente las muestras se analizaron mediante microscopía confocal. Los valores de fluorescencia relativa para Rac1 en la membrana plasmática se indican en el cuadrante inferior izquierdo de cada imagen. Barra de escala: $20 \mu \mathrm{m}$. (B) El índice de translocación de Rac1 en estos experimentos se calculó de la manera descrita en Materiales y Métodos (pág. 44). ${ }^{* *}, P \leq 0,01$, comparado a los valores obtenidos en células ACC1-2 Control shRNA. 


\section{CAPITULO 3. MECANISMOS DE REGULACIÓN DE LA TRANSLOCACIÓN DE Rac1 INDUCIDA POR OTROS CLONES AISLADOS EN EL RASTREO CELÓMICO}

\subsection{Especificidad de las proteínas translocadoras en la regulación de la localización subcelular de las GTPasas de la familia Rho/Rac}

A continuación quisimos averiguar si el mecanismo de translocación de Rac1 mediado por Coronina-1A era un mecanismo conservado entre las proteínas transmembrana (Basigina $y$ TMEM8A) y citosólicas (WDR26) aisladas en nuestro rastreo celómico. Comenzamos analizando el comportamiento de estas proteínas en la regulación de la localización subcelular de otros miembros de la familia Rho/Rac mediante técnicas de microscopía confocal. Como en el caso de Coronina-1A (Capítulo 2, pág. 63), utilizamos versiones silvestres de las GTPasas Rac1, RhoG, RhoA y Cdc42 etiquetadas con AU5 y cada uno de los translocadores fusionados a la EGFP para llevar a cabo estos estudios. La localización yuxtamembranaria de cada uno de nuestros translocadores cuando se expresaron en células cos1 provocó la aparición de pequeñas ondulaciones tipo membrane ruffles a lo largo de la membrana plasmática (Figura 40, pág. 100). Además, como se había observado en el caso de Coronina-1A-EGFP (Figura 13, pág. 64), la coexpresión de Basigina-EGFP, TMEM8A-EGFP o EGFP-WDR26 con las GTPasas AU5-Rac1 y AU5-RhoG provocó la translocación de estas últimas desde el citosol hasta las zonas de la membrana plasmática donde nuestras proteínas verdes fluorescentes estaban presentes (Figura 40). Sin embargo, a diferencia de Coronina-1A-EGFP y EGFPWDR26, pudimos apreciar que Basigina-EGFP y TMEM8A-EGFP también promovieron un enriquecimiento de AU5-Cdc42 en la membrana plasmática (Figura 41, pág. 101). Finalmente, ninguno de los translocadores afectó a la distribución citosólica de AU5-RhoA (Figura 41). Estos resultados indican que las proteínas con repeticiones WD40 (Coronina-1A y WDR26) poseen un efecto similar sobre las GTPasas Rac1 y RhoG, mientras que las proteínas transmembrana (Basigina y TMEM8A) poseen un espectro de acción más amplio al controlar también la localización subcelular de Cdc42.

\subsection{El efecto de las proteínas translocadoras sobre Rac1 depende de la correcta funcionalidad de las balsas lipídicas y del citoesqueleto de F- actina}

Con la intención de seguir desgranando las rutas moleculares por las cuales estos dos grupos de proteínas parecían estar ejerciendo su acción reguladora sobre Rac1, decidimos analizar la necesidad de balsas lipídicas y del citoesqueleto de F-actina, tal como hicimos previamente en el caso de Coronina-1A-EGFP. Para ello, realizamos de nuevo experimentos de 
inmunofluorescencia en células COS1 que expresaban AU5-Rac1 junto con cada uno de nuestros translocadores fusionados a EGFP. En esta ocasión, tratamos a las células con M $\beta C D$ y CytD, previamente a la fijación de las mismas, para observar el efecto de dichas drogas en el contexto de la translocación de Rac1 inducido por nuestras proteínas. Para monitorizar el efecto de dichas drogas decidimos teñir las balsas lipídicas y el citoesqueleto de actina usando CTxB conjugada al fluorocromo Alexa Fluor 647 y faloidina conjugada a Alexa Fluor 635 respectivamente, como ya indicamos en el Capítulo 2 (págs. 73 y 74).

A

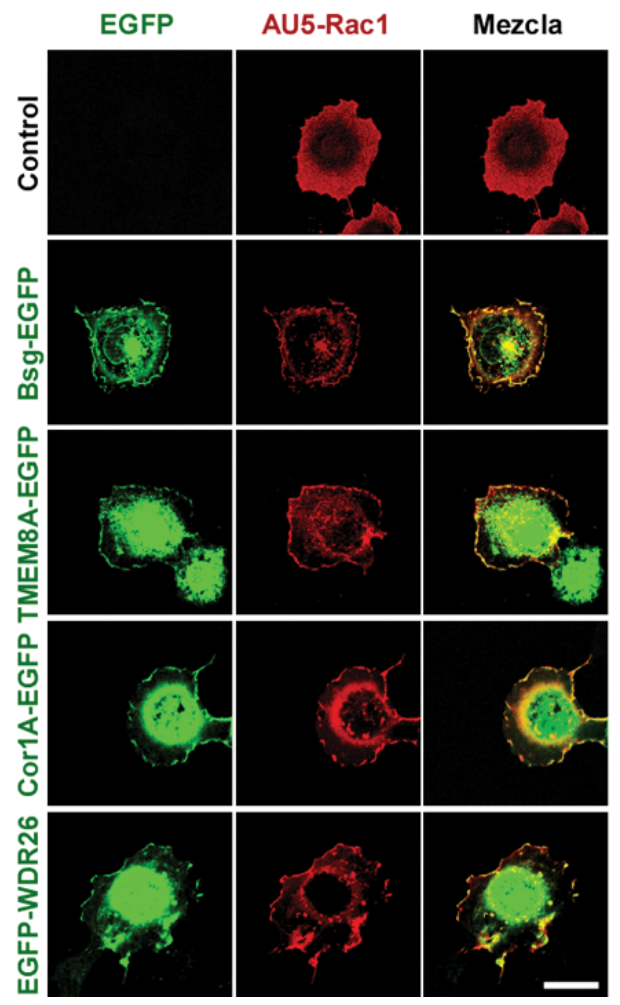

B

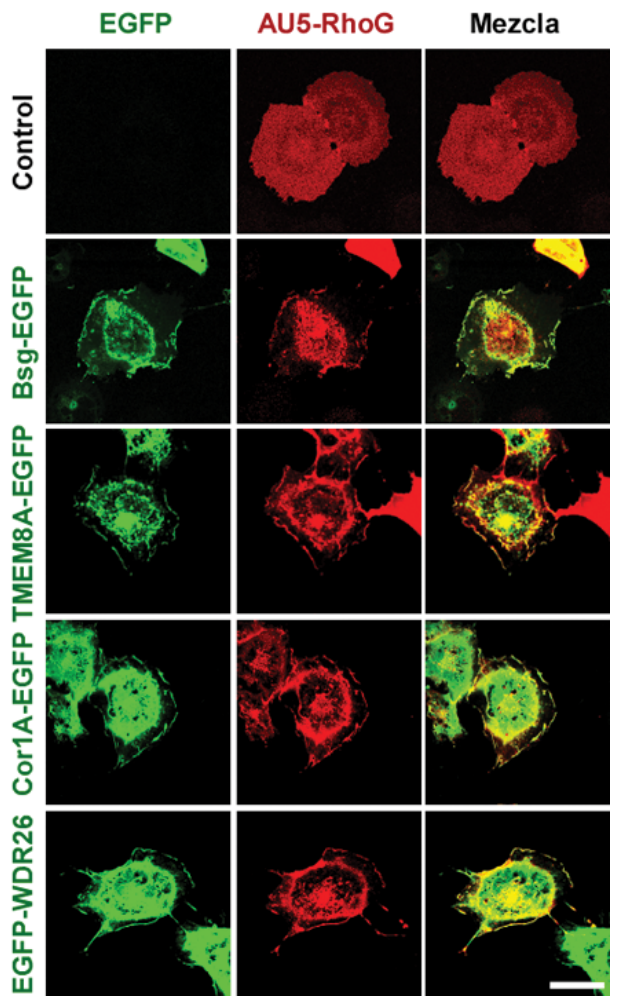

Figura 40. Efecto de los translocadores aislados en el rastreo celómico en la regulación de la localización subcelular de las GTPasas Rac1 y RhoG. Se transfectaron células COS1 con los plásmidos para las versiones silvestres etiquetadas con AU5 de las GTPasas Rac1 y RhoG de forma individual o junto con plásmidos para cada una de las proteínas translocadoras fusionadas a EGFP que se indican a la izquierda de cada panel. Las células fueron fijadas y la expresión de las proteínas transfectadas se detectó como se indica en la Figura 13 (pág. 64). Las preparaciones se analizaron finalmente mediante microscopía confocal. Barra de escala: $20 \mu \mathrm{m}$.

Estos experimentos indicaron que todas las proteínas translocadoras provocaban la agregación de balsas lipídicas en aquellas zonas de la membrana plasmática donde estaban presentes (Figura 42, tercera columna desde la izquierda, pág. 102) y promovían el anclaje de AU5-Rac1 a estas regiones de la membrana en células sin estimular ni tratadas con ninguna droga (Figura 42, segunda columna desde la izquierda). El tratamiento con M $\beta C D$ provocó la 
desaparición de balsas lipídicas de la superficie celular, tal como se aprecia en la dispersión de la tinción de CTxB tras dicho tratamiento (Figura 42, sexta columna desde la izquierda), y bloqueó la translocación de AU5-Rac1 a la membrana plasmática (Figura 42, quinta columna desde la izquierda). Asimismo, esta droga afectó a la propia localización de todas nuestras proteínas translocadoras las cuales sufrieron una deslocalización parcial de áreas yuxtamembrana con respecto a las células sin tratar (Figura 42, primera y cuarta columnas desde la izquierda).

De forma paralela, observamos que la expresión de estos translocadores iba acompañada de la acumulación de F-actina en aquellas regiones periféricas próximas a la membrana plasmática (Figura 43, tercera columna desde la izquierda, pág. 103) donde translocadores y AU5-Rac1 estaban presentes (Figura 43, primera y segunda columna desde la izquierda). El tratamiento con CytD condujo a la inhibición de la translocación de la GTPasa a

A

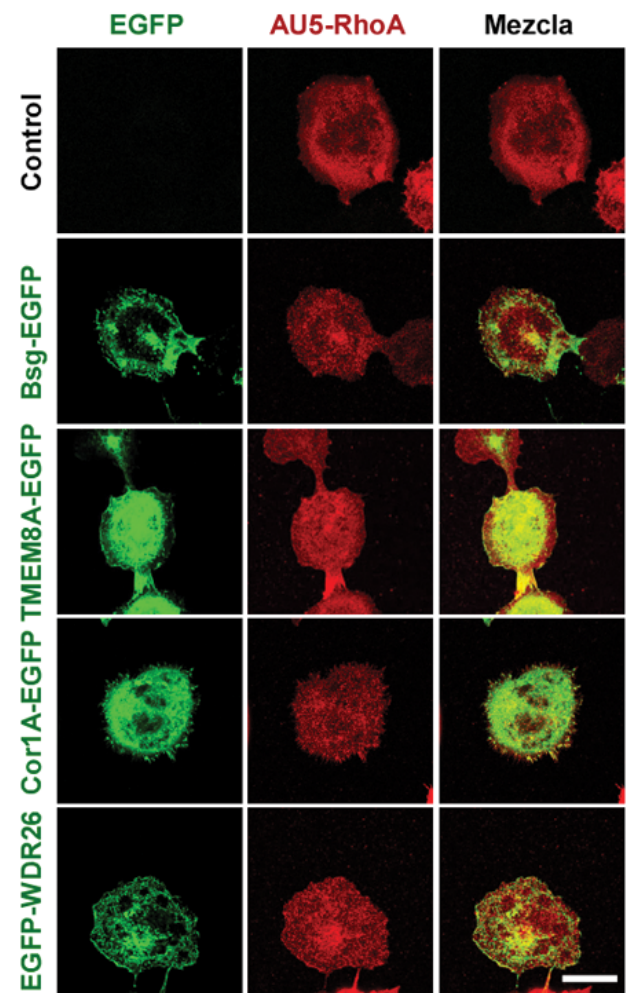

B

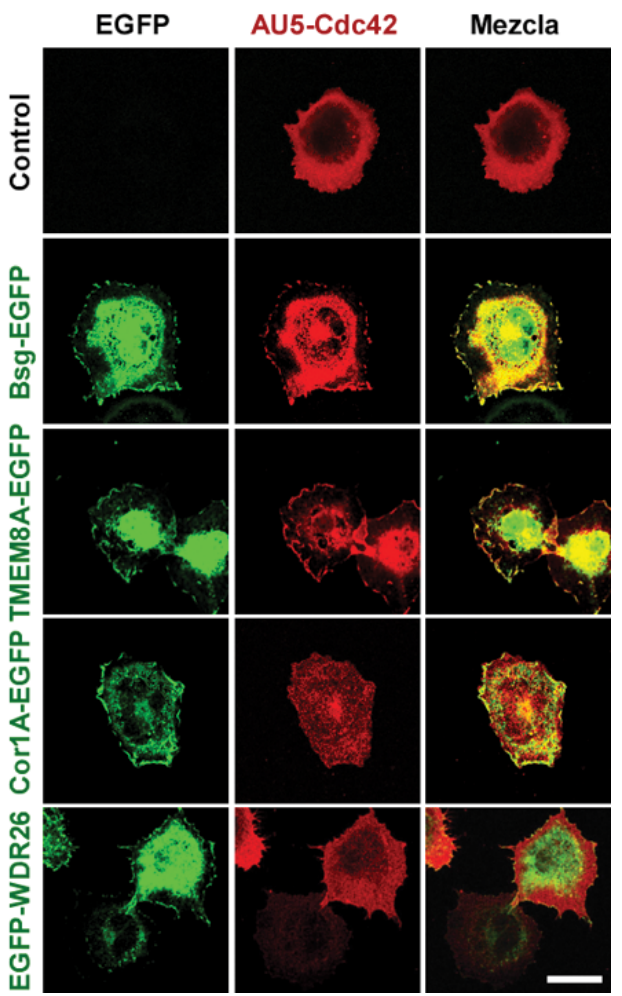

Figura 41. Efecto de los translocadores aislados en el rastreo celómico en la regulación de la localización subcelular de las GTPasas RhoA y Cdc42. Se transfectaron células COS1 con los plásmidos para las versiones silvestres etiquetadas con AU5 de las GTPasas RhoA y Cdc42 de forma individual o junto con plásmidos para cada una de las proteínas translocadoras fusionadas a EGFP que se indican a la izquierda de cada panel. Las células fueron fijadas y la expresión de las proteínas transfectadas se detectó como se indica en la Figura 13 (pág. 64). Las preparaciones se analizaron finalmente mediante microscopía confocal. Barra de escala: $20 \mu \mathrm{m}$. 

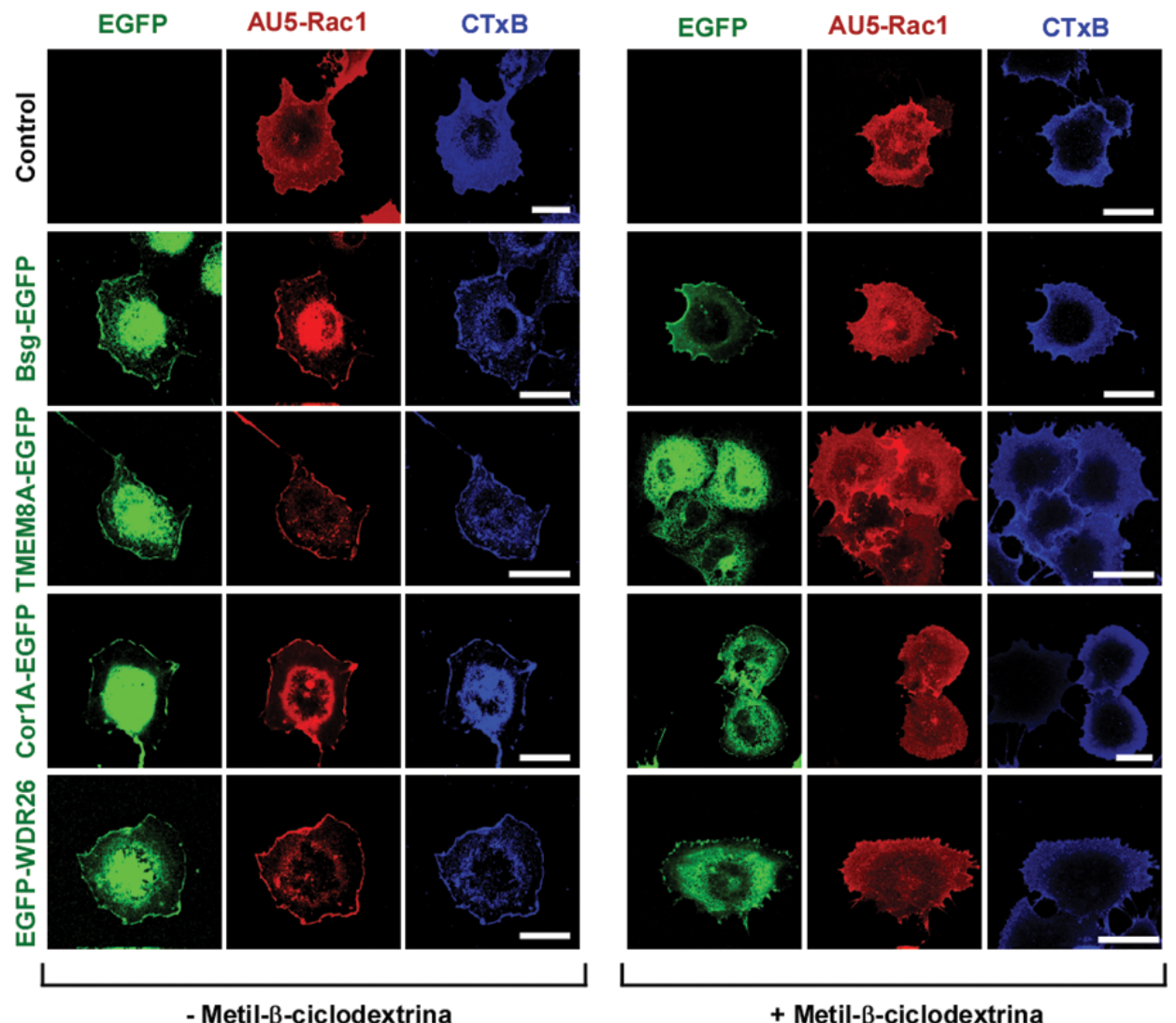

+ Metil- $\beta$-ciclodextrina

Figura 42. La translocación de Rac1 mediada por nuestras proteínas translocadoras requiere balsas lipídicas funcionales. Células COS1 expresando de forma transitoria la versión silvestre de AU5Rac1 sola o en combinación con cada uno de las proteínas translocadoras fusionadas a EGFP que se indican a la izquierda de cada panel fueron tratadas o no con $\mathrm{M} \beta C D$ (10 mM, $30 \mathrm{~min}$ ). Posteriormente las células fueron fijadas y teñidas tal y como se indica en la Figura 13 (pág. 64). Ademas fueron incubadas con CTxB conjugada al fluorocromo Alexa Fluor 647 para la visualización de las balsas lipídicas. Finalmente las muestras se analizaron por microscopía confocal. Barra de escala: $20 \mu \mathrm{m}$.

la membrana plasmática en todos los casos (Figura 43, quinta columna desde la izquierda) así como la desaparición de las ondulaciones de membrana o membrane ruffles, ricos en F-actina, que iban asociadas a la expresión de nuestras proteínas translocadoras previo al tratamiento con esta droga (Figura 43, sexta columna desde la izquierda). Como ocurrió en el caso de $M \beta C D$, el tratamiento con CytD afectó a la propia localización subcelular de todos y cada uno de los translocadores analizados. Basigina-EGFP y TMEM8A-EGFP aumentaron su localización intracelular en regiones perinucleares y asociadas a estructuras membranosas internas en detrimento de la acumulación que previamente habíamos detectado en zonas yuxtamembrana de células COS1 sin tratar. Aparecieron aglomeraciones intracelulares de Factina, como consecuencia del efecto de CytD, donde Coronina-1A-EGFP y EGFP-WDR26 parecían colocalizar, de acuerdo a las propiedades de Coronina-1A como proteína de unión a F-actina y sugiriendo, a su vez, que WDR26 pudiera tener un comportamiento similar en cuanto a esta propiedad de unión al citoesqueleto (Figura 43, cuarta columna desde la izquierda). De 
estos resultados se desprende que tanto balsas lipídicas como el citoesqueleto de F-actina son elementos esenciales en el mecanismo por el cual estas proteínas promueven el desplazamiento de la GTPasa Rac1 desde el citosol hasta la membrana plasmática. La propia localización intrínseca tanto de proteínas transmembrana como de las citosólicas precisan de balsas lipídicas y un citoesqueleto de F-actina funcionales.

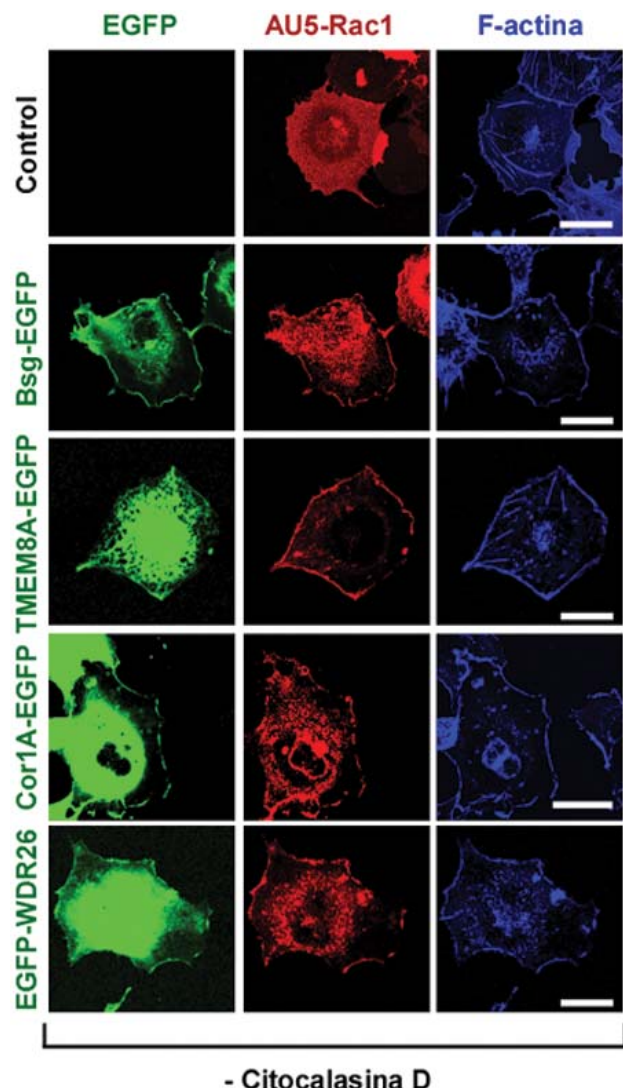

- Citocalasina D

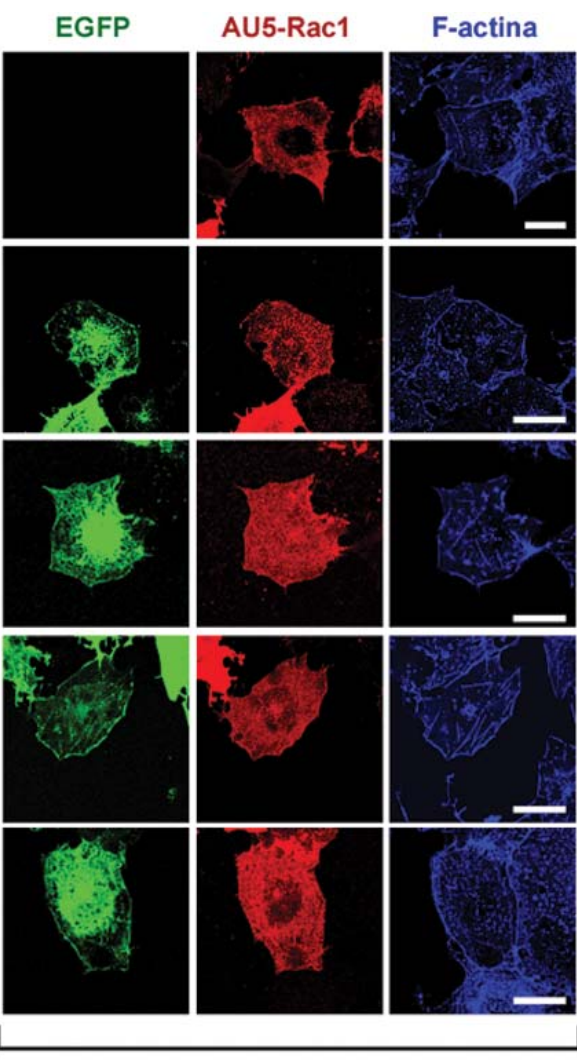

+ Citocalasina D

Figura 43. La translocación de Rac1 mediada por nuestras proteínas translocadoras depende del citoesqueleto de F-actina. Células COS1 expresando de forma transitoria la versión silvestre de AU5Rac1 sola o en combinación con cada uno de las proteínas translocadoras fusionadas a EGFP que se indican a la izquierda de cada panel fueron tratadas o no con CytD ( $2 \mu \mathrm{M}, 15 \mathrm{~min})$. Posteriormente las células fueron fijadas y teñidas tal y como se indica en la Figura 13 (pág. 64). Además fueron incubadas con faloidina conjugada al fluorocromo Alexa Fluor 635 para revelar el citoesqueleto de F-actina. Finalmente las muestras se analizaron por microscopía confocal. Barra de escala: $20 \mu \mathrm{m}$.

\subsection{Dependencia diferencial de Rac1 de las proteínas translocadoras}

Dado que Coronina-1A necesitaba de cierta actividad basal de Rac1 para promover la translocación de más moléculas de Rac1 a la membrana (Figura 24, pág. 79), quisimos verificar si esta dependencia era un fenómeno general aplicable al resto de proteínas translocadoras. Para ello llevamos a cabo experimentos de inmunofluorescencia en los que coexpresamos cada una de nuestras proteínas translocadoras fusionadas a EGFP y la forma dominante negativa AU5-Rac1 ${ }^{\top 17 N}$ en células COS1. 

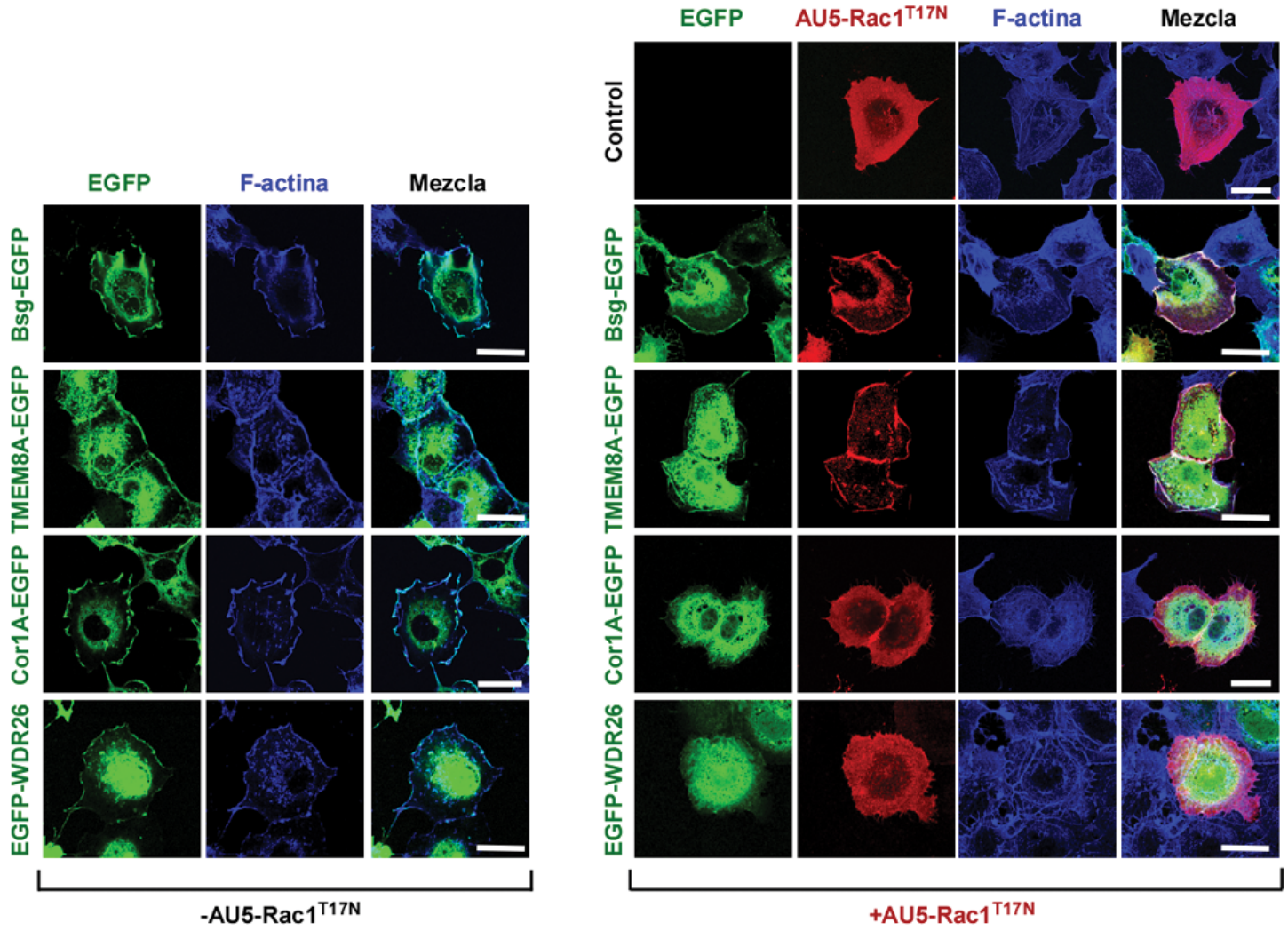

Figura 44. Efecto del mutante dominante negativo Rac1 ${ }^{\mathrm{T} 17 \mathrm{~N}}$ en la localización subcelular y reorganización citoesquelética de las proteínas translocadoras. Células COS1 expresando de forma transitoria cada una de las proteínas translocadoras fusionadas a EGFP de forma aislada o junto con AU5- Rac1 ${ }^{T 17 N}$ fueron fijadas y teñidas como se indica en la Figura 24 (pág. 79). Las preparaciones se analizaron al microscopio confocal. Barra de escala: $20 \mu \mathrm{m}$.

De un modo parecido a como ocurría en el caso de Coronina-1A-EGFP, encontramos que la proteína EGFP-WDR26, tras la coexpresión con AU5-Rac1 ${ }^{\top 17 N}$, también sufría una deslocalización de las regiones yuxtamembrana hacia el citoplasma (Figura 44, cuarta columna desde la izquierda). Además las ondulaciones de membrana tipo ruffles inducidos por EGFPWDR26 también se vieron inhibidos por la coexpresión de la forma inactiva de la GTPasa Rac1 (Figura 44, sexta columna desde la izquierda). Por el contrario, la coexpresión de ese mutante de Rac1 no afectó a la localización subcelular de Basigina-EGFP o TMEM8A-EGFP, que continuaban asociadas a la membrana plasmática (Figura 44, cuarta columna desde la izquierda). Además, estos experimentos indicaron que estas dos proteínas translocadoras, a diferencia de Coronina-1A-EGFP y EGFP-WDR26, eran capaces de inducir la translocación de la GTPasa inactiva AU5-Rac1 ${ }^{\text {T17N }}$ a la membrana plasmática (Figura 44, quinta columna desde la izquierda). Asimismo, observamos una clara acumulación de F-actina subcortical que ambas proteínas transmembrana provocaban cuando se expresaron de forma aislada o conjunta con AU5-Rac1 ${ }^{\text {T17N }}$ (Figura 44, sexta columna desde la izquierda). Tomados conjuntamente, estos resultados nos sugieren que el mecanismo de translocación de Rac1 inducido por estas proteínas está mediado por rutas de señalización diferentes. Mientras que las proteínas con repeticiones WD40 precisan de actividad basal de Rac1 para poder translocarse a regiones 
periféricas de membrana, promover la acumulación de Rac1 en la membrana plasmática e inducir la reorganización subcortical del citoesqueleto de actina, las proteínas transmembrana son independientes de la actividad de Rac1 en todos estos procesos.

\subsection{WDR26, pero no Basigina y TMEM8A, requiere de actividad quinasa} de Pak1 para promover la translocación de Rac1 a la membrana

Seguidamente decidimos llevar a cabo una aproximación farmacológica para seguir profundizando en el mecanismo molecular en el que funcionaban nuestras proteínas translocadoras regulando el tráfico de Rac1 desde el citosol a la membrana. Células COS1 transfectadas con plásmidos para la versión silvestre de AU5-Rac1 de forma aislada o conjunta con cada una de nuestras proteínas translocadoras fusionadas a EGFP fueron incubadas con DMSO (tratamiento indicado como Solvente), GF109203X, Tat-Pak ${ }^{\text {R192A }}$ y Tat-Pak18 para ser posteriormente fijadas y analizadas mediante microscopía confocal como indicamos en el Capítulo 2 (pág. 74). En esta ocasión, analizamos el efecto de estas drogas comparando los índices de translocación de Rac1 para cada proteína tras cada tratamiento. Encontramos que los tratamientos con Tat-Pak ${ }^{\text {R192A }}$ o GF109203X no afectaron al índice de translocación de Rac1 para ninguna de nuestras proteínas translocadoras cuando se compararon con respecto al tratamiento control con DMSO (Figura 45A, pág. siguiente). El tratamiento con Tat-Pak18 inhibió la capacidad translocadora de EGFP-WDR26 sobre AU5-Rac1 (Figura 45A), como habíamos observado previamente en el caso de Coronina-1A-EGFP. Sin embargo, en el caso de Basigina-EGFP y TMEM8A-EGFP, el índice de translocación de AU5-Rac1 tras la inhibición de la actividad quinasa de Pak1 con el péptido Tat-Pak18 no varió significativamente con respecto a los valores obtenidos en el tratamiento con DMSO (Figura 45A).

Para corroborar estos resultados mediante otra aproximación experimental, decidimos repetir estos experimentos de inmunofluorescencia en presencia de la forma dominante negativa de Pak1. Transfectamos células COS1 con vectores de expresión para la versión silvestre AU5-Rac1 y cada una de nuestras proteínas translocadoras fusionadas a EGFP en ausencia o presencia de un vector de expresión para Myc-Pak $1^{\mathrm{K} 299 \mathrm{R}}$. La expresión de MycPak $1^{\text {K299R }}$ en células que expresaban EGFP-WDR26 bloqueó la translocación de AU5-Rac1 a la membrana plasmática (Figura 45A; B, cuarta columna desde la izquierda), en consonancia con lo observado previamente en el caso de Coronina-1A-EGFP (Figura 23, pág. 77). No obstante, y como también habíamos observado con Coronina-1A-EGFP, la forma inactiva de la quinasa Pak1 no afectó a la localización subcelular en regiones yuxtamembrana de EGFPWDR26 (Figura 45B, tercera columna desde la izquierda). La expresión de este mutante dominante negativo de Pak1 en células que expresaban Basigina-EGFP y TMEM8A-EGFP 


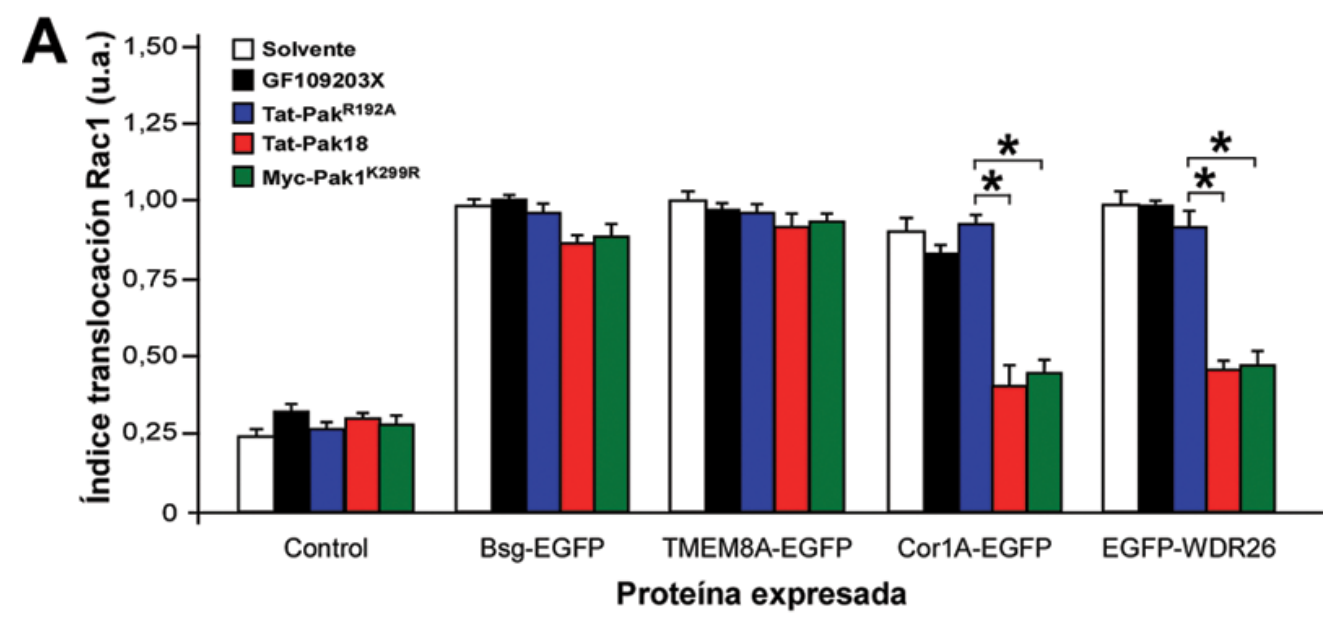

B
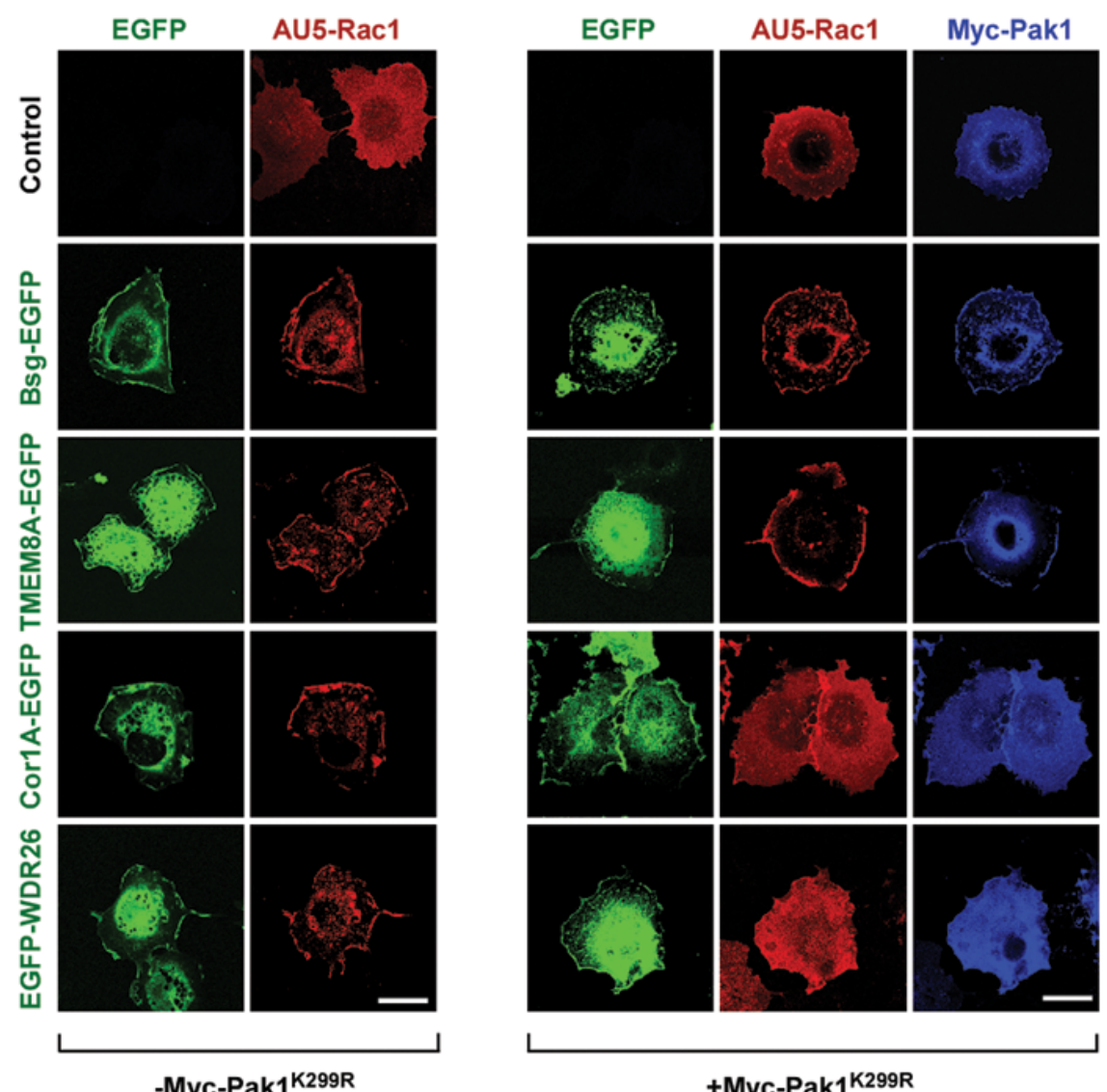

Figura 45. La translocación de Rac1 mediada por Coronina-1A y WDR26, pero no por Basigina y TMEM8A, precisa la participación de Pak1. (A) Células COS1 expresando de forma transitoria AU5Rac1 de forma aislada o junto con nuestras proteínas translocadoras fusionadas a EGFP, fueron tratadas con DMSO (Solvente), GF109203X, Tat-Pak1 ${ }^{\mathrm{R} 192 \mathrm{~A}}$ o Tat-Pak18, fijadas y teñidas tal y como se indica en la Figura 21 (pág. 76). El índice de translocación de Rac1 para cada proteína tras estos tratamientos se estimó como se detalla en Materiales y Métodos, pág. 44. * $P \leq 0,05$, comparado a los valores obtenidos con el tratamiento con Tat-Pak1 ${ }^{\mathrm{R} 192 \mathrm{~A}}$. (B) Células COS1 expresando transitoriamente AU5-Rac1 y las proteínas translocadoras fusionadas a EGFP, indicadas a la izquierda de cada panel, de forma aislada (izquierda) o con Myc-Pak1 $1^{\mathrm{K} 299 \mathrm{R}}$ (derecha), fueron fijadas y teñidas como se indica en la Figura 23 (pág. 77) Finalmente las preparaciones se analizaron por microscopía confocal. Barra de escala: $20 \mu \mathrm{m}$ 
tampoco afectó la translocación de AU5-Rac1 a la membrana plasmática (Figura 45A;B, cuarta columna desde la izquierda) ni a la localización subcelular de estas proteínas transmembrana (Figura 45B, tercera columna desde la izquierda). Tomados colectivamente, estos resultados sugieren que estas cuatro proteínas translocadoras de Rac1 funcionan en dos rutas aparentemente diferentes. Así, Coronina-1A y WDR26 necesitan de cierta actividad basal de Rac1 y de Pak1 para promover la acumulación de más proteínas Rac1 en la membrana, mientras que Basigina y TMEM8A funcionan de una forma totalmente independiente de aquellas dos moléculas. Las cuatro proteínas translocadoras poseen un mecanismo de acción totalmente independiente de la actividad de PKC en este contexto de la regulación de la translocación de Rac1.

\subsection{La translocación de Rac1 inducida por las proteínas transmembrana y}

\section{las citoesqueléticas está mediada por dos rutas funcionales independientes}

Decidimos investigar a continuación si podría existir alguna relación funcional entre estas cuatro proteínas translocadoras y/o entre las dos diferentes rutas en las que están funcionando. Comenzamos analizando si la translocación de Rac1 inducida por WDR26 y Basigina era dependiente de Coronina-1A, eliminando la expresión endógena de esta última en células COS1 mediante ARNs de interferencia cortos (siRNAs, del inglés, small interfering RNAs) contra el ARNm de Coronina-1A. Como control, empleamos siRNAs de secuencia aleatoria. En primer lugar comprobamos la eficiencia de los siRNAs, que a las $72 \mathrm{~h}$ consiguieron la mayor inhibición de expresión de Coronina-1A a nivel de proteína (Figura 46A, pág. siguiente). Células COS1 transfectadas con plásmidos de expresión para AU5-Rac1, Basigina-EGFP y EGFP-WDR26 junto con estos siRNAs fueron fijadas tras $72 \mathrm{~h}$, procesadas y analizadas al microscopio confocal. Observamos que la inhibición de Coronina-1A endógena no afectó a la capacidad de Basigina-EGFP para translocar a AU5-Rac1 a la membrana ni a su capacidad inducir la formación de membrane ruffles enriquecidos en F-actina (Figura 46B,C). Por el contrario, la inhibición de Coronina-1A si afectó a la localización de AU5-Rac1 en la membrana plasmática promovida por EGFP-WDR26, sin que ello eliminara la localización de esta proteína en regiones yuxtamembrana o la acumulación de F-actina en las mismas (Figura 46B,C).

A continuación investigamos el papel de alguna de nuestras proteínas transmembrana en la translocación de Rac1 inducida por Coronina-1A o WDR26 usando una estrategia similar. La carencia de anticuerpos específicos que nos permitieran analizar la represión endógena de alguna de estas dos proteínas de membrana nos llevó a diseñar una aproximación experimental diferente a la anteriormente usada. Recientemente ha sido descrito que Basigina 
A

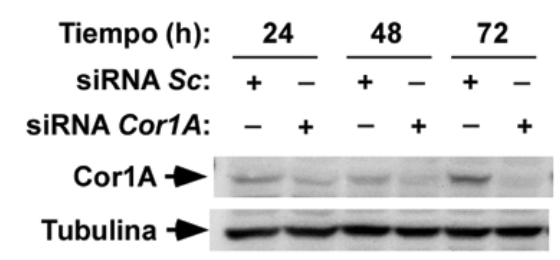

WB:

$\alpha-$-Cor1A

$\alpha$-Tubulina

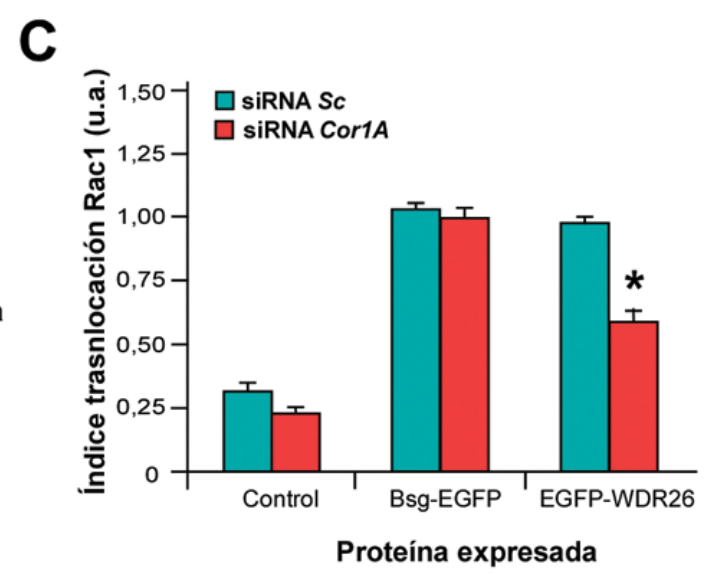

B
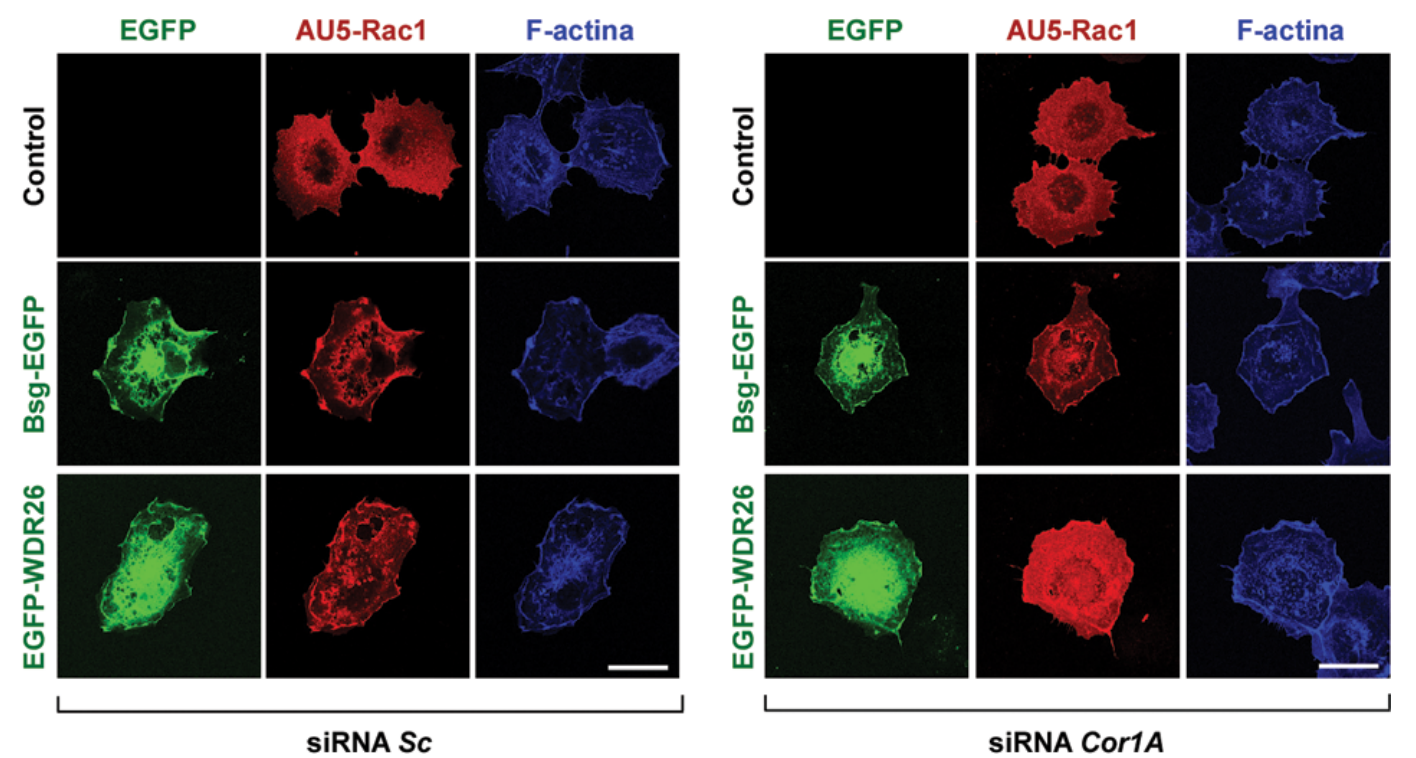

Figura 46. Coronina-1A es importante para la translocación de Rac1 mediada por WDR26 pero no por Basigina. (A) Células COS1 fueron transfectadas de forma transitoria con siRNAs de secuencia aleatoria (siRNA Sc) o contra Coronina-1A (siRNA Cor1A). Posteriormente las células fueron lisadas a los tiempos indicados y la expresión de Coronina-1A endógena se detectó mediante Western blot con anticuerpos anti-Coronina-1A. Como control de carga se analizaron los mismos lisados celulares con anticuerpos anti-tubulina. (B) Células COS1 fueron transfectadas de forma transitoria con plásmidos para AU5-Rac1, Basigina-EGFP y EGFP-WDR26 junto con los siRNAs Sc (izquierda) o siRNAs Cor1A (derecha). Las células fueron fijadas a las $72 \mathrm{~h}$ y teñidas con anticuerpos anti-AU5 seguido de anticuerpos secundarios conjugados a Cy3 (rojo). La presencia del citoesqueleto de F-actina se reveló con faloidina conjugada al fluorocromo Alexa Fluor 635 (azul). Finalmente las preparaciones se analizaron al microscopio confocal. Barra de escala: $20 \mu \mathrm{m}$. (C) El índice de translocación de Rac1 en cada una de las condiciones experimentales anteriores se estimó como se detalla en Materiales y Métodos, pág. 44. *, $P$ $\leq$ 0,05 comparado con los valores obtenidos en células que expresan EGFP-WDR26 (siRNA Sc).

forma parte de un macrocomplejo molecular en la superficie celular junto con otras proteínas de adhesión como son integrinas $\beta 1$ o CD98 (Xu and Hemler, 2005). Por esta razón, decidimos primero investigar el papel de integrinas $\beta 1$ y de la proteína de adhesión CD98 en la translocación de Rac1 mediado por Basigina. La transfección en células COS1 de siRNAs contra contra integrinas $\beta 1$ y CD98 mostró una disminución específica de los niveles de expresión endógena de ambas proteínas tras 48 h de transfección (Figura 47A, pág. 109). A 
continuación, transfectamos células COS1 con plásmidos para AU5-Rac1 y Basigina-EGFP con diferentes combinaciones de siRNAs contra las integrinas $\beta 1$, CD98 o de secuencia aleatoria. Mientras que la eliminación de integrinas $\beta 1$ no afectó a la translocación de Rac1 provocada por la expresión de Basigina-EGFP (Figura 47B,C), la represión de CD98 provocó la inhibición casi total de la translocación de Rac1 mediada por Basigina-EGFP (Figura 47B,C). Estos resultados nos indican que CD98, y no otras proteínas como la subunidad $\beta 1$ de las integrinas, resulta esencial para la translocación de Rac1 mediada por Basigina.

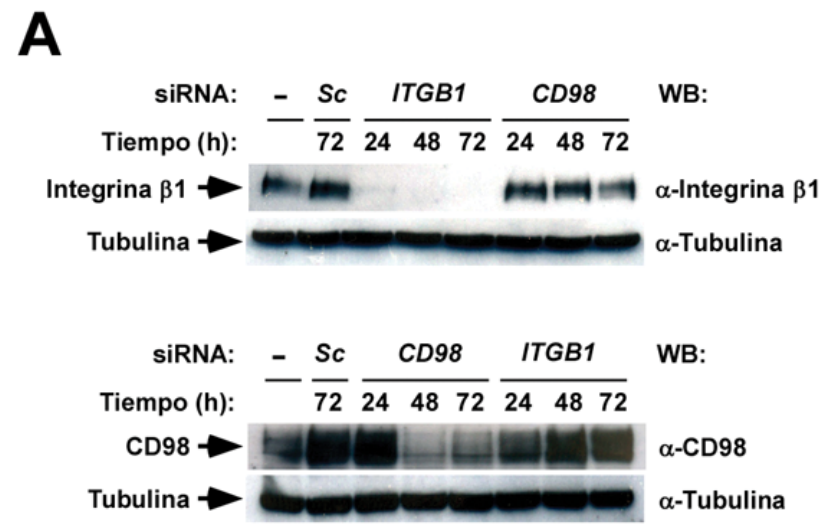

B
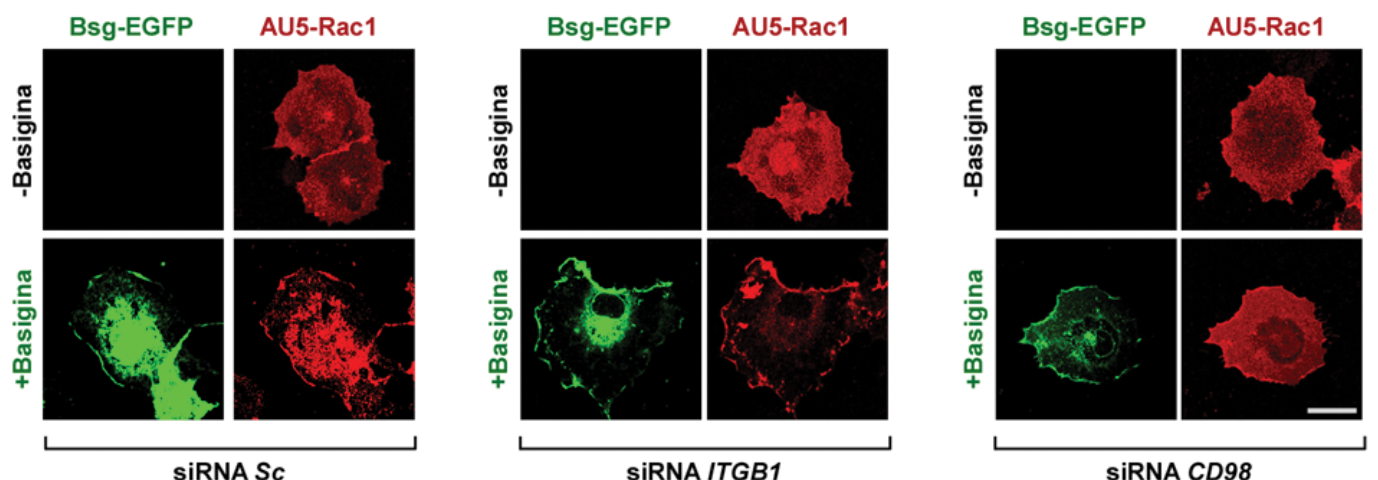

Figura 47. CD98, pero no las integrinas $\beta 1$, es importante para la translocación de Rac1 mediada por Basigina. (A) Células COS1 fueron transfectadas de forma transitoria con siRNAs de secuencia aleatoria (siRNA Sc), siRNAs contra integrinas $\beta 1$ (siRNA ITGB1) o CD98 (siRNA CD98). Posteriormente las células fueron lisadas a los tiempos indicados y la expresión endógena de CD98 o integrinas $\beta 1$ detectada mediante Western blot con anticuerpos anti-CD98 o anti-integrina $\beta 1$. Como control de carga se analizaron los mismos lisados celulares con anticuerpos anti-tubulina. (B) Células COS1 fueron transfectadas de forma transitoria con plásmidos para AU5-Rac1 y Basgina-EGFP junto con los siRNAs de secuencia aleatoria (izquierda), siRNAs contra integrinas $\beta 1$ (centro) o siRNAs contra CD98 (derecha). Las células fueron fijadas a las $48 \mathrm{~h}$ y teñidas con anticuerpos anti-AU5 seguido de anticuerpos secundarios conjugados a Cy3 (rojo). Finalmente las preparaciones se analizaron al microscopio confocal. Barra de escala: $20 \mu \mathrm{m}$. (C) El índice de translocación de Rac1 en cada una de las condiciones experimentales anteriores se estimó como se detalla en Materiales y Métodos, pág $44 .{ }^{*}, P \leq 0,05$ comparado a los valores obtenidos en células que expresan Basigina (siRNA Sc). 


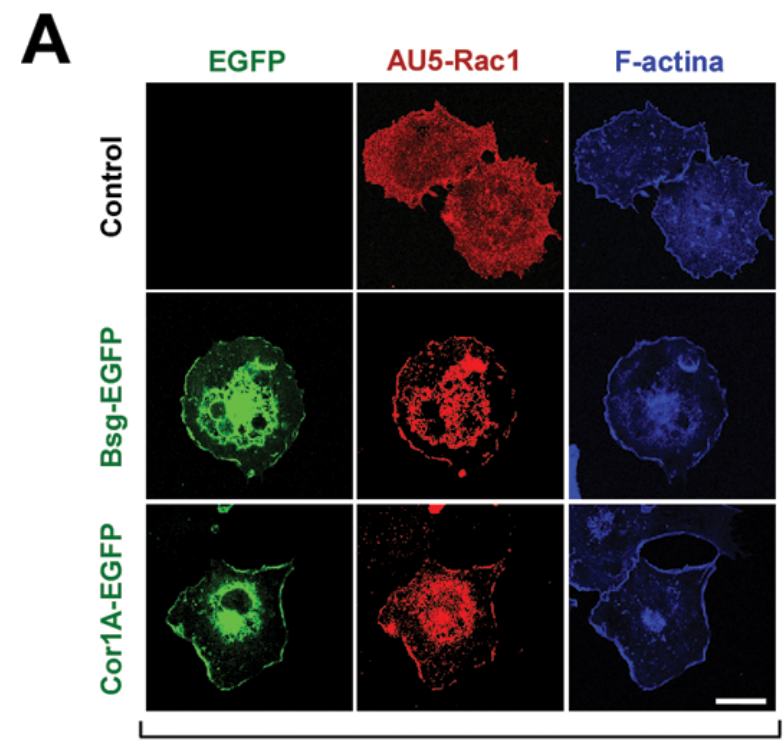

SIRNA Sc

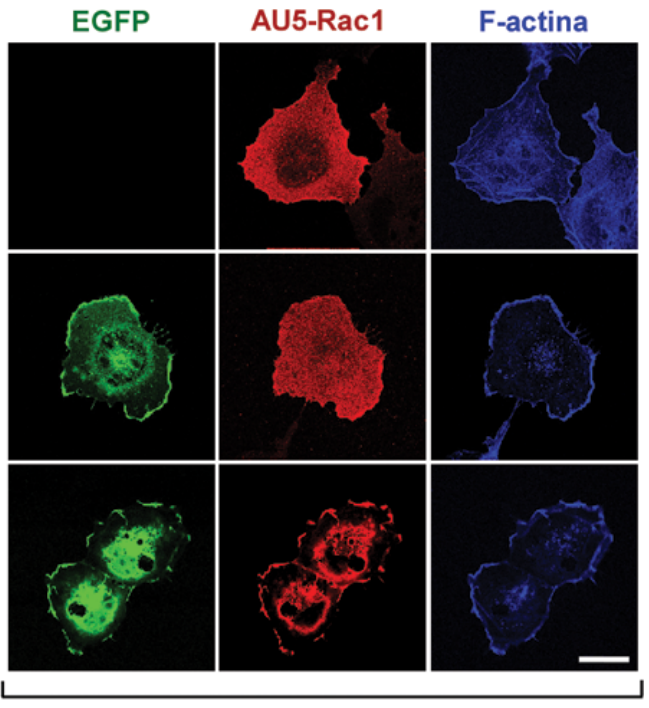

SiRNA CD98

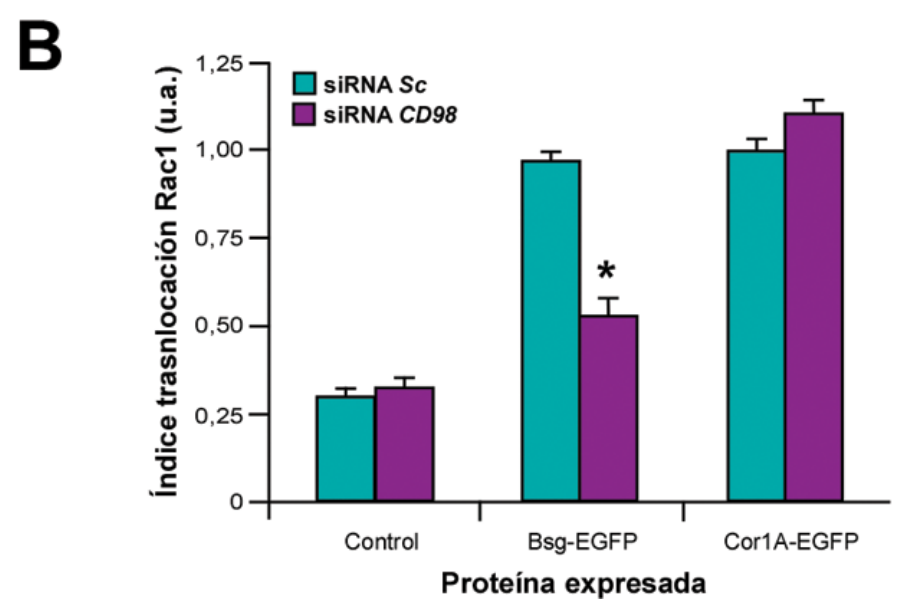

Figura 48. CD98 es importante para la translocación de Rac1 mediada por Basigina pero no por Coronina-1A. (A) Células COS1 fueron transfectadas de forma transitoria con plásmidos para AU5-Rac1 y las proteínas translocadoras fusionadas a EGFP que se indican a la izquierda de cada panel junto con siRNAs contra CD98 (derecha) o de secuencia aleatoria (izquierda). Las células fueron fijadas a las $48 \mathrm{~h}$ y teñidas con anticuerpos anti-AU5 seguido de anticuerpos secundarios conjugados a Cy3 (rojo). La presencia del citoesqueleto de F-actina se reveló con faloidina conjugada al fluorocromo Alexa Fluor 635 (azul). Finalmente las preparaciones se analizaron al microscopio confocal. Barra de escala: $20 \mu \mathrm{m}$. (B) El índice de translocación de Rac1 en cada una de las condiciones experimentales anteriores se estimó como se detalla en Materiales y Métodos, pág. 44. *, $P \leq 0,05$ comparado con respecto a los valores obtenidos en células que expresan Bsg-EGFP (siRNA Sc).

Dado el papel de CD98 en la translocación de Rac1 mediado por Basigina, seguidamente estudiamos el papel de estos complejos Basigina/CD98 en la translocación de Rac1 mediada por Coronina-1A. Para ello, transfectamos de nuevo de forma transitoria células COS1 con plásmidos para AU5-Rac1, Basigina-EGFP y Coronina1A-EGFP junto con siRNAs contra CD98 o siRNAs control. Como ya habíamos observado previamente, la eliminación de la 
expresión de CD98 resultó bloquear la translocación de AU5-Rac1 mediada por Basigina-EGFP (Figura 48A, pág. anterior). Sin embargo, CD98 no afectó a la translocación de AU5-Rac1 mediada por Coronina-1A-EGFP (Figura 48A,B). De este conjunto de experimentos concluimos, por tanto, que estos dos grupos de proteínas (Basigina/TMEM8A y Coronina1A/WDR26) definen dos rutas reguladoras de la localización subcelular de Rac1 que son independientes entre sí. En cambio, los resultados indican que sí existe cierta interrelación funcional entre Coronina-1A y WDR26.

\subsection{La translocación de Rac1 mediada por Basigina es consecuencia de la estabilización de balsas lipídicas en la superficie celular}

Dado que todas las proteínas translocadoras utilizadas en nuestros estudios promovieron la agregación de balsas lipídicas cuando fueron expresadas ectópicamente (Figura 42, pág. 102), quisimos investigar si la translocación de Rac1 a la membrana plasmática inducida por nuestros translocadores podría ser consecuencia de su efecto sobre la estabilización de balsas lipídicas en la superficie celular. Esta hipótesis se basa en estudios previos en los que se describe un papel fundamental de integrinas en la estabilización de balsas lipídicas en la superficie celular que son necesarias para la disociación de los complejos Rac1/RhoGDI y la estabilidad de Rac1 en la membrana plasmática (del Pozo et al., 2004; Del Pozo et al., 2002; del Pozo et al., 2000). Para abordar esta posibilidad, llevamos a cabo experimentos en los que analizamos la tasa de internalización de estas balsas lipídicas en células en suspensión mediante el uso de un biosensor (Cav1-GFP) que contiene una proteína residente en balsas lipídicas (caveolina-1) fusionada en su extremo carboxilo terminal a GFP. Se ha descrito que la puesta en suspensión de células adherentes induce la inhibición de la señalización por integrinas y la subsecuente internalización de las balsas lipídicas (del Pozo et al., 2004), lo que nos permitiría evaluar si alguna de nuestras proteínas translocadoras podría estabilizar la presencia de balsas lipídicas en la periferia celular. Utilizamos en estos experimentos una línea celular derivada de células HeLa que expresa de forma estable Cav1-GFP (pág. 48). Las células fueron transfectadas de forma transitoria con plásmido vacío o con vectores de expresión para la proteína Basigina etiquetada con el epitopo HA y Coronina-1A-RFP. Como control positivo de estos experimentos, utilizamos la versión mutante K44A de la proteína dinamina 2 etiquetada con HA, la cual funciona como un dominante negativo que inhibe la internalización de balsas lipídicas (del Pozo et al., 2005). Tras la expresión ectópica de cada una de las proteínas indicadas, las células fueron tripsinizadas y mantenidas en suspensión para posteriormente ser fijadas y analizadas al microscopio confocal. En células transfectadas con plásmido vacío, encontramos que Cav1-GFP se encontraba mayoritariamente localizada en un compartimento perinuclear, lo que indicaba que las balsas lipídicas habían sido 


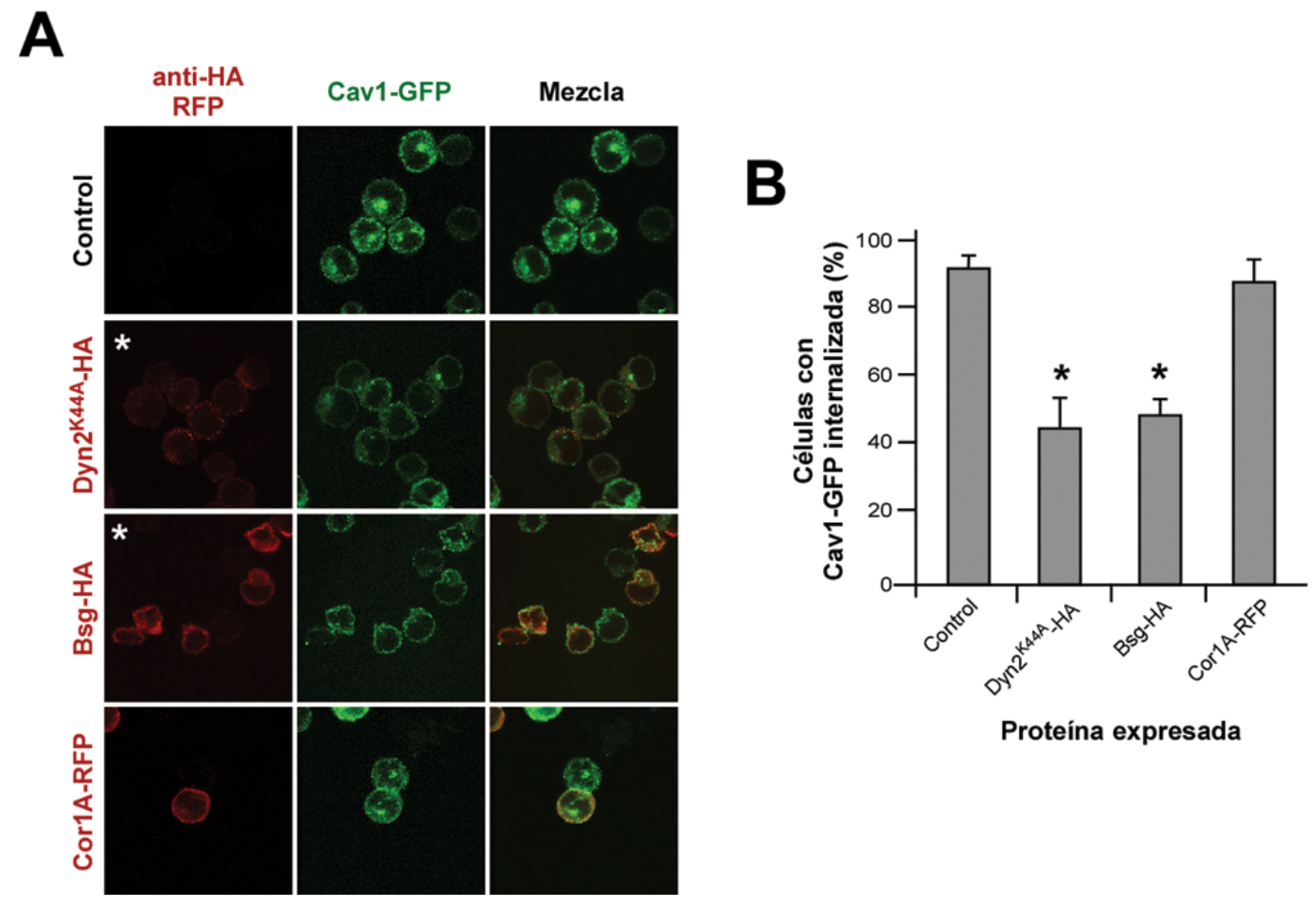

Figura 49. Basigina, pero no Coronina-1A, promueve la estabilización de balsas lipídicas en la superficie celular. (A) Células HeLa expresando de forma estable Cav1-GFP fueron transfectadas de forma transiente con plásmidos de expresión para las proteínas indicadas a la izquierda de cada panel. Posteriormente, las células fueron tripsinizadas y puestas en suspensión durante $1 \mathrm{~h}$ para ser finalmente fijadas y teñidas con anticuerpos anti-HA (paneles indicados con asterisco) seguido de anticuerpos secundarios conjugados a Alexa594. Finalmente las preparaciones se analizaron mediante microscopía confocal. (B) La tasa de internalización de Cav1-GFP se estimó como se indica en Materiales y Métodos (pág. 48). * $P \leq 0,05$ comparado con los valores obtenidos en células transfectadas con vector vacío (indicado como Control).

internalizadas hasta dicho compartimento (Figura 49A, paneles fila superior). La expresión ectópica de Coronina-1A-RFP no afectó a la internalización de Cav1-GFP, observándose la acumulación perinuclear de este biosensor propia de células control transfectadas con vector vacío (Figura 49A, paneles fila inferior). En cambio, la expresión de Basigina-HA iba asociada a un retraso en la internalización de Cav1-GFP puesto que las células que expresaban ambas proteínas no mostraban acumulación perinuclear de la sonda biológica (Figura 49A, paneles tercera fila desde arriba). Para cuantificar el efecto de nuestras proteínas en este proceso a nivel poblacional, decidimos analizar la cantidad de células que mostraban acumulación de Cav1-GFP en aquel compartimento perinuclear en cada una de las condiciones experimentales. La estimación de este parámetro confirmó que Basigina-HA inhibía la internalización de balsas lipídicas casi un 50\% mientras que Coronina1A-RFP no inducía efecto alguno (Figura 49B). Estos resultados vuelven a apoyar nuestras observaciones previas indicando que nuestras proteínas translocadoras (Basigina/TMEM8A y Coronina-1A/WDR26) 
controlan la regulación de la localización subcelular de Rac1 a través de dos rutas de señalización independientes entre sí.

Resumimos pues que las proteínas Coronina-1A y WDR26 controlan la regulación de la localización subcelular de Rac1 y RhoG a través de un mecanismo que requiere balsas lipídicas y un citoesqueleto de F-actina funcionales junto con la actividad quinasa de Pak1 y actividad basal procedente de la propia GTPasa Rac1. Por otro lado, las proteínas transmembrana Basigina y TMEM8A regulan la localización subcelular de Rac1, RhoG y Cdc42 a través de una ruta dependiente de balsas lipídicas y del citoesqueleto de F-actina e independiente de todos los demás elementos analizados en este trabajo (Tabla 5).

Tabla 5. Resumen de los efectos en la translocación de miembros de la familia Rho/Rac por cada una de las proteínas identificadas en esta tesis. Esta tabla recoge los resultados obtenidos en cada una de las condiciones experimentales en las que se testó la capacidad de translocación de miembros de la familia Rho/Rac a la membrana por nuestras proteínas translocadoras.

\begin{tabular}{|c|c|c|c|c|c|c|c|c|c|}
\cline { 2 - 10 } \multicolumn{1}{c|}{} & \multicolumn{3}{c|}{ Translocación a la membrana } & \multicolumn{5}{c|}{ Translocación de Rac1 a la membrana } \\
\hline Proteina & Rac1 & RhoG & Cdc42 & RhoA & MBCD & CytD & GF109203X & TAT-Pak18 & Rac1T17N \\
\hline Coronina-1A & + & + & - & - & - & - & + & - & - \\
\hline WDR26 & + & + & - & - & - & - & + & - & - \\
\hline Basigina & + & + & + & - & - & - & + & + & + \\
\hline TMEM8A & + & + & + & - & - & - & + & + & + \\
\hline
\end{tabular}





\section{DISCUSIÓN}



Nuestro objetivo principal en esta tesis doctoral era abordar una búsqueda genómica para identificar, de la forma más amplia posible, nuevas proteínas implicadas en el mecanismo de translocación de la GTPasa Rac1 a la membrana plasmática. Para ello, aprovechamos una propiedad que comparten la mayoría de mediadores de transducción de señales: su capacidad para activar la cascada de señalización que hay por debajo de ellos al ser sobreexpresados en células susceptibles. Para abordar el trabajo, y de acuerdo con este sistema de lectura, se eligió un método de screening por ganancia de función basado en el clonaje por expresión. Dicho método se basó en la sobreexpresión del ADNc procedente de una genoteca en una línea celular reportera HEK-293T que expresa de forma estable la versión silvestre de Rac1 fusionada a la EGFP. Gracias a esta biosonda fluorescente pudimos identificar y aislar aquellos clones cuya sobreexpresión promovía el tráfico de EGFP-Rac1 desde el citosol a la membrana plasmática de nuestra línea reportera.

En este trabajo se describe el análisis de alrededor de 135.000 clones de una genoteca de ADNc humana. Para llevar a cabo dicho análisis, realizamos un rastreo celómico de esa genoteca que dio como resultado la identificación de $\mathbf{2 1}$ clones con capacidad de inducir un cambio en la localización subcelular de Rac1. Puesto que estábamos interesados en descubrir nuevas proteínas directamente implicadas en el movimiento de Rac1 entre estos dos compartimentos subcelulares, decidimos centrar nuestro trabajo en cuatro de estas proteínas: dos citosólicas (Coronina-1A y WDR26) y dos transmembrana (Basigina y TMEM8A).

La identificación de Coronina-1A tras nuestro rastreo celómico nos sugirió que esta proteína, per se o de un modo concertado con el citoesqueleto de F-actina, podría estar regulando de forma activa la localización en membrana de la GTPasa Rac1. La investigación de esta hipótesis nos llevó a descubrir un nuevo ciclo de retroalimentación positiva mediado por Coronina-1A y el citoesqueleto de F-actina que contribuye a la amplificación de la fracción de Rac1 activa y unido a la membrana durante procesos de señalización celular

(Figura 50, pág. 119). De acuerdo con este modelo, hemos observado que la inhibición a nivel genético o químico de elementos de señalización que participan en esta ruta provoca un déficit considerable del índice de translocación y activación de Rac1 durante la señalización mediada por EGF. Esta nueva ruta también contribuye a generar respuestas biológicas coherentes, ya que hemos observado que dicha ruta posee una especificidad hacia determinadas GTPasas, como Rac1 y RhoG, que promueven ondulaciones en la membrana plasmática y conducen la formación de lamelipodios (Gauthier-Rouviere et al., 1998). Sin embargo, no puede desencadenar la translocación de otros miembros de la familia Rho/Rac que están involucrados en la generación de cambios citoesqueléticos diferentes, como es el caso de RhoA y Cdc42. Así, a diferencia de otros procesos de activación de Rac1 basados en el uso de interacciones proteína-proteína o de segundos mensajeros, la célula desencadenaría en este caso todo un 
proceso biológico para favorecer la adecuada activación y localización de Rac1 en la membrana plasmática.

Para llevar a cabo la translocación a la membrana y la activación en la misma de Rac1, Coronina-1A actúa a través de proteínas directamente relacionadas con el ciclo de activación de esta GTPasa como son ArhGEF7, Pak1 y RhoGDI (Figura 50). La utilización de versiones mutantes e inhibidores para algunas de esas proteínas nos ha permitido establecer la posición jerárquica relativa que cada una de estas proteínas ocupan en el complejo. Así, la observación de que ArhGEF7 puede interaccionar con el mutante Coronina$1 A^{R 29 D}$-EGFP en el citosol indica que este complejo constituye la piedra angular sobre la que se ensamblará el "complejo translocador de Rac1". Además, este resultado apunta a su vez que el complejo Coronina-1A/ArhGEF7 está preformado en una reserva citosólica funcionalmente inerte en ausencia de condiciones permisivas de polimerización/ramificación de F-actina (Figura 50). Por el contrario, la falta de interacción de Pak1 y RhoGDI con Coronina-1A ${ }^{\text {R29D }}$. EGFP indica que esas dos proteínas se ensamblan en el complejo cuando la pareja Coronina1A/ArhGEF7 se asocia a estructuras ricas en F-actina. La formación del "complejo translocador" de Rac1 también requiere ArhGEF7, ya que Pak1 y RhoGDI no se asocian a Coronina-1A en células deficientes en ArhGEF7. Pak1 parece estar en un estado activo en dicho complejo, tal y como se infiere de nuestros resultados que muestran que Coronina- $1 \mathrm{~A}$ puede interaccionar con la versión silvestre y con el mutante constitutivamente activado Pak1 ${ }^{\text {T423E }}$ pero no con la forma catalíticamente inactiva Pak1 ${ }^{\mathrm{K} 299 \mathrm{R}}$ (Figura 50).

También demostramos que RhoGDI puede unirse al complejo Coronina-1A/ArhGEF7 solamente cuando Pak1 está presente en su estado cataliticamente activo, sugiriendo que el complejo RhoGDI/Rac1 es el último componente en ser reclutado al "complejo translocador" de Rac1 (Figura 50). Además, nuestros resultados apoyan los datos obtenidos por Bockoch y colegas donde muestran que RhoGDI interacciona preferentemente con la versión activa de Pak1 mientras que la interacción con la versión silvestre o la catalíticamente inactiva de la quinasa es débil o nula, respectivamente (DerMardirossian et al., 2004). Pese a estos resultados, nuestros datos no pueden excluir la posibilidad de que de este "complejo translocador" posea elementos adicionales a los descritos en este trabajo. De hecho, una serie de experimentos proteómicos y de señalización han revelado previamente que Coronina-1A, ArhGEF7, Pak1 y RhoGDI pueden interaccionar con otras proteínas (indicadas como "X", ver Figura 50). Será interesante llevar a cabo estudios proteómicos para identificar nuevos candidatos que formen parte de este complejo en su reserva citosólica o en la localizada en regiones ricas en F-actina. 


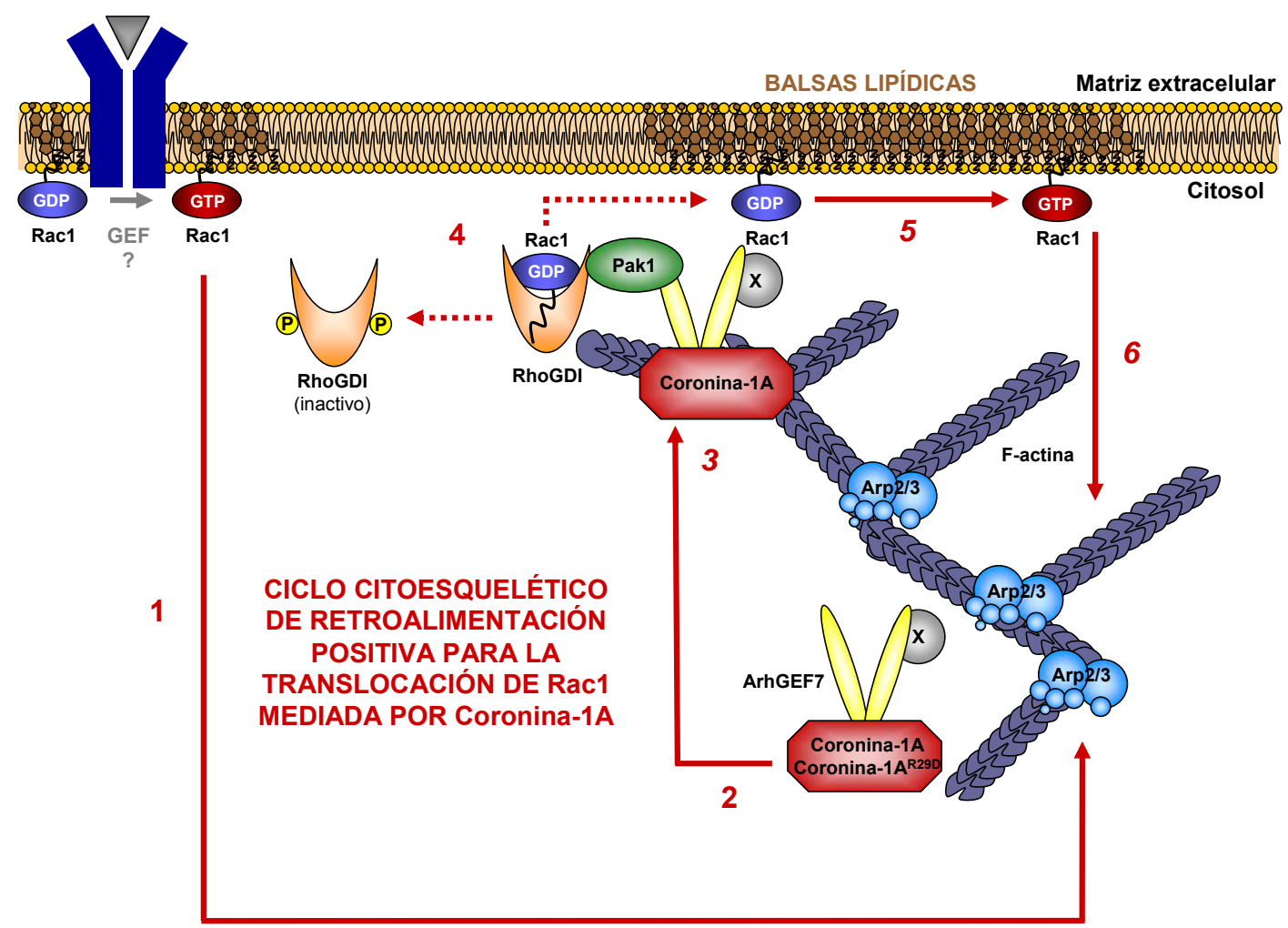

Figura 50. Modelo funcional del mecanismo de translocación de Rac1 mediado por Coronina-1A. La reorganización del citoesqueleto de F-actina (1) inducida por la activación de Rac1 (u otra GTPasa relacionada) conduciría a la translocación del complejo Coronina-1A/ArhGEF7 hacia la F-actina yuxtamembranaria (2). Una vez localizada allí, se ensamblaría el complejo citoesquelético translocador para Rac1 constituido por Coronina-1A/ArhGEF7/Pak1 (3) que actuaría sobre los complejos RhoGDI/Rac1 citosólicos promoviendo su disociación y la posterior translocación de Rac1 a la membrana (4). Una vez en la membrana esta fracción de Rac1 libre de RhoGDI sería susceptible de activación por parte de ArhGEF7 (o de proteínas adicionales en el complejo, indicadas como $\mathbf{X}$ ) próximo a la membrana plasmática mediante su unión a Coronina-1A (5). La activación de esta población de Rac1 translocada por Coronina-1A conduciría a la reorganización del citoesqueleto de F-actina volviendo a iniciar este ciclo de retroalimentación positiva (6).

Nuestro trabajo indica que la translocación/activación de Rac1 inducida por Coronina-1A está mediada por dos mecanismos solapantes. Por un lado, nuestras evidencias experimentales sugieren que el "complejo translocador" de Rac1puede inducir la liberación de Rac1 de su secuestrador RhoGDI de una forma dependiente de Pak1. Así, hemos observado que la translocación de Rac1 inducida por Coronina-1A es totalmente bloqueada por la coexpresión de un mutante de RhoGDI que no puede ser inhibido por Pak1, de la versión dominante negativa de Pak1, o por el tratamiento con el péptido inhibidor contra esa misma quinasa. Interesantemente, hemos observado que Pak1 necesita a Coronina-1A y ArhGEF7 para interaccionar con RhoGDI cuando está presente en su versión silvestre, cuya activación es susceptible de regulación. Sin embargo, la versión constitutivamente activa de Pak1 puede unir eficientemente a RhoGDI de una forma independiente de Coronina- 
1A/ArhGEF7, indicando que el mecanismo por el cual Pak1 inhibe a las moléculas de RhoGDI es altamente dependiente de la señalización global desencadenada por la ruta Rac1/Pak1. Por otro lado, nuestro hallazgo sobre la capacidad de Coronina-1A de translocar al mutante Rac1 ${ }^{R 66 E}$, un mutante que no se une a RhoGDI, sugiere la existencia de un segundo mecanismo implicado en este proceso que es dependiente de F-actina pero independiente de RhoGDI. Esta segunda ruta debe ser mecanísticamente distinta a la mencionada anteriormente porque no puede ser inhibida tras bloquear la actividad de Pak1. Aunque los resultados obtenidos con el mutante Rac1 ${ }^{\text {R66E }}$ no son probablemente fisiológicos dado los bajos niveles de proteínas Rac1 libres de RhoGDI en el citosol (Chuang et al., 1993; DerMardirossian and Bokoch, 2005; Michaelson et al., 2001), resultan interesantes porque revelan una nueva ruta que puede aumentar aún más el anclaje a la membrana de Rac1 tras su liberación de los complejos citosólicos con RhoGDI a través del "complejo translocador" constituido por Coronina-1A/ArhGEF7/Pak1. Aunque este mecanismo alternativo de translocación de Rac1 permanece aún sin caracterizar, suponemos que podría estar mediado por la generación de condiciones "permisivas" en la membrana plasmática de una forma dependiente del citoesqueleto de F-actina como es la agregación de balsas lipídicas (del Pozo et al., 2004; del Pozo et al., 2005). De acuerdo con esta hipótesis, ha sido demostrado que la integridad del citoesqueleto de actina y la agregación/estabilidad de las balsas lipídicas son procesos interconectados. De acuerdo con esta posibilidad, hemos observado que la sobreexpresión de Coronina-1A induce la agregación de balsas lipídicas en la membrana plasmática (este trabajo) y que la agregación de las mismas a través de CTxB o el mutante dominante negativo Dyn2 $2^{\mathrm{K} 44 \mathrm{~A}}$ (del Pozo et al., 2005), promueven la translocación del mutante Rac1 ${ }^{\mathrm{R} 66 \mathrm{E}}$ a la membrana (datos no mostrados). También son posibles otras opciones funcionales no mutuamente excluyentes entre sí para explicar este segundo mecanismo. Por ejemplo, se ha demostrado que fosfolipasa $D$, una proteína señalizadora que está presente tanto en estructuras ricas en F-actina como en balsas lipídicas, puede favorecer la asociación de Rac1 con las membranas a través de la generación de ácido araquidónico (Chae et al., 2008). Independientemente de la naturaleza de la ruta involucrada, es importante resaltar que este segundo mecanismo inducido por Coronina$1 \mathrm{~A}$ está sujeto a la interacción entre Pak1 y RhoGDI en condiciones fisiológicas, porque la translocación de la versión silvestre de Rac1, a diferencia del mutante Rac1 $1^{\mathrm{R} 6 \mathrm{E}}$, es totalmente dependiente de la actividad quinasa de Pak1.

Creemos que la dependencia del citoesqueleto de F-actina para la translocación de Rac1 mediada por el complejo Coronina-1A/ArhGEF7/Pak1/RhoGDI es clave para la regulación de esta nueva ruta. Así, la necesidad de unión al citoesqueleto indica que este "complejo translocador" de Rac1 está probablemente involucrado en la generación de oleadas secundarias de translocación y activación de la GTPasa más que como un elemento iniciador de la activación de Rac1 que tiene lugar tras la recepción de un estímulo extracelular. Esta idea está reforzada por nuestros resultados que muestran que la localización en membrana de 
Coronina-1A, su asociación con Pak1 y RhoGDI y su capacidad para translocar Rac1 son bloqueadas tras la coexpresión de un mutante dominante negativo de Rac1. Además, la necesidad de filamentos de F-actina preformados para desencadenar este proceso está también demostrada por la observación de que el mutante Coronina- $1 \mathrm{~A}^{\mathrm{R} 29 \mathrm{D}}$ no puede translocar a Rac1 a la membrana a pesar de interaccionar de forma estable con ArhGEF7. La eliminación de la translocación de Rac1 tras la inhibición del citoesqueleto de F-actina con el tratamiento de CytD también apoya esta idea. Por tanto, y de acuerdo con el modelo funcional propuesto, la célula tendrá que desencadenar la activación de Rac1 o RhoG para encender el mecanismo de transmisión de la señal situado aguas abajo y mediado por Coronina-1A. De un modo alternativo, esta ruta puede ser puesta en marcha por la inducción de polimerización de Factina a través de otros mecanismos como la acción de algunos Rho/Rac GEFs de forma independiente de GTPasa (Schiller et al., 2005). Independientemente del estímulo que induzca la polimerización de F-actina inicial necesaria para activar esta nueva ruta, nuestros datos indican que esas señales no están bajo control de ArhGEF7, ya que la inhibición de su expresión no afecta a la localización de Coronina-1A en el citoesqueleto de las zonas yuxtamembranarias.

Nuestras observaciones apuntan a que la proteína citoesquelética Coronina-1A es un elemento central en la relación funcional entre el citoesqueleto y Rac1. Un trabajo reciente ha demostrado que los miembros de la familia de las coroninas siguen un proceso cíclico entre el citosol y el citoesqueleto de actina. En áreas de polimerización de nuevos filamentos de Factina, estas proteínas se mueven desde el citosol hasta los puntos de ramificación recientemente formados del citoesqueleto de F-actina, donde liberan y reemplazan al complejo Arp2/3 de una forma dependiente del citoesqueleto (Cai et al., 2008). Esta actividad asegura la presencia de complejos Arp2/3 libres para posteriores procesos de ramificación de los filamentos de F-actina en regiones próximas y, además, induce flexibilidad a la malla citoesquelética a través de la modificación del ángulo de ramificación de la F-actina (Cai et al., 2008). En filamentos de F-actina viejos, sin embargo, los miembro de la familia de coroninas promueven el desensamblaje de F-actina a través de la activación de proteínas despolimerizadoras como cofilina (Cai et al., 2007b; Gandhi et al., 2009). Estas dos funciones aparentemente antagónicas están coordinadas por el tipo de nucleótido unido a la actina (ADP o ATP) y, probablemente, por señales situadas aguas arriba que alteran el estado funcional del complejo Arp2/3, cofilina y de la propia coronina. Debido a esta interconexión con las áreas donde tiene lugar una reorganización activa del citoesqueleto de F-actina, los miembros de la familia de las coroninas se encuentran asociadas principalmente a regiones yuxtamembrana del citoesqueleto. Todos estos rasgos funcionales convierten a estas proteínas en plataformas moleculares idóneas para asociar oleadas en serie de polimerización de F-actina en el frente de avance y en las ondulaciones de membrana con los ciclos de translocación y activación de Rac1. De este modo, se consigue excluir dicha activación de las regiones citoesqueléticas que 
están alejadas de la membrana plasmática y a la vez apagar la señalización mediada por Rac1 cuando el ciclo de polimerización de F-actina ha cesado.

Interesantemente, encontramos que el complejo Arp2/3 unido a F-actina representa un punto regulador crítico de las rutas dependientes de las proteínas Rho/Rac durante procesos de polimerización de F-actina. Por ejemplo, se demostrado que cortactina, una proteína que une F-actina y Arp2/3 (Daly, 2004; Weed and Parsons, 2001) también puede asociarse a FGD1, un GEF específico para Cdc42 (Hou et al., 2003; Kim et al., 2004). Esta interacción resulta en la activación recíproca de estas dos proteínas. Asimismo, N-WASP, una proteína que conecta la activación de Cdc42 con la polimerización de F-actina mediada por Arp2/3, puede interaccionar con Itsn1, otro GEF específico para Cdc42 (Hussain et al., 2001). Esta asociación participa en la activación mediada por N-WASP de Itsn1 que, a su vez, promueve la activación de N-WASP a través del intercambio GDP/GTP que induce sobre Cdc42. No se conocen con detalle los mecanismos a través de los cuales cortactina y N-WASP median la translocación y activación de Cdc42 in vivo. Sin embargo, estas dos proteínas deben usar rutas de señalización diferentes a Coronina-1A, ya que Pak1 no afecta a la estabilidad de los complejos RhoGDI/Ccd42 (DerMardirossian et al., 2004). El uso de diferentes estrategias para activar diferentes GTPasas en el contexto de las sucesivas rondas de polimerización de Factina es desde nuestro punto de vista esencial para asegurar el ensamblaje de respuestas citoesqueléticas coherentes. Gracias a esta estrecha regulación se permite la segregación espacio-temporal de la activación de Cdc42 y Rac1 necesarias para la generación paulatina y ordenada de diferentes estructuras celulares basadas en F-actina. Por ejemplo, la utilización de GEFs para Cdc42 por parte de las proteínas activadoras/estabilizadoras del complejo Arp2/3 tales como cortactina o N-WASP asegurará que Cdc42 sea reclutado en primer lugar a los puntos de ramificación de F-actina donde se encuentra Arp2/3 mientras que, al mismo tiempo, sentará las bases para el posterior reclutamiento de otras proteínas como Coronina-1A a estas estructuras. El posterior reemplazamiento de Arp2/3 por Coronina-1A en esos puntos de ramificación (Cai et al., 2008) apagará la activación de Cdc42 mientras que favorecerá el reclutamiento de nuevas proteínas Rac1. Este mecanismo gradual podría ser de interés, por ejemplo, para la generación secuencial de filopodios y lamelipodios en el frente de avance de células en migración, dos procesos que están bajo la regulación de Cdc42 y Rac1, respectivamente (Etienne-Manneville and Hall, 2002; Nobes and Hall, 1995). En este contexto funcional, es interesante mecionar un estudio publicado recientemente que muestra que células deficientes en cortactina poseen una baja actividad basal de Cdc42 y una activación deficiente de Rac1 tras su estimulación por el factor de crecimiento derivado de plaquetas (Lai et al., 2009). Sería interesante investigar si ese fenotipo está asociado al mecanismo de reclutamiento secuencial establecido a nivel del citoesqueleto de actina tal y como el que se describe en esta tesis. Ha sido también demostrado que el complejo Arp2/3 puede unirse a Tiam1, un GEF específico para Rac1 (Ten Klooster et al., 2006a). Este fenómeno podría 
resultar en la eficiente localización de dicho GEF en el citoesqueleto de actina para activar a la GTPasa Rac1, lo que, a su vez, podría desencadenar la activación de forma coordinada, junto con los filamentos de F-actina, de más proteínas Rac1. Sin embargo, este mecanismo no es probablemente operativo en células COS1 porque hemos observado que la inhibición de la expresión de ArhGEF7 bloquea de una forma altamente efectiva la translocación de Rac1 en nuestro modelo experimental. Sin embargo, no podemos excluir la posibilidad de que Tiam1 esté encargado de promover la ráfaga de activación inicial de Rac1 que se necesita para la estimulación de la ruta de translocación dependiente de Coronina-1A situada aguas abajo.

Aunque hemos centrado este trabajo en la caracterización del mecanismo de translocación por el cual Coronina-1A promueve la translocación de Rac1, es bastante probable que este mismo mecanismo pueda ser llevado a cabo por otros miembros cercanos de la familia de las coroninas como es Coronina-1B. Además, nuestro rastreo celómico resultó en la identificación de WDR26, otra proteína de la familia de proteínas con repeticiones WD40, que parece mediar funciones similares a Coronina-1A en este proceso biológico. Así, nuestras observaciones experimentales indican que WDR26 regula el movimiento entre citosolmembrana tanto de Rac1 como de RhoG. A su vez, esta proteína de estructura similar a Coronina-1A, requiere la presencia de balsas lipídicas en la membrana, un citoesqueleto de $\mathrm{F}$ actina funcional, de la actividad quinasa de Pak1 y de cierta actividad basal de Rac1 para promover el anclaje de más proteínas Rac1 en la membrana plasmática (Figura 51, pág. siguiente; Tabla 5, pág. 113). La idea de que Coronina-1A y WDR26 funcionan a través de la misma ruta se ve reforzada por nuestros resultados donde la inhibición de la expresión endógena de Coronina-1A afecta a la capacidad de WDR26 de translocar Rac1 a la membrana. No obstante, es importante destacar que el incremento de la fracción de Rac1 localizada en la membrana plasmática se puede conseguir mediante rutas alternativas a las descritas en este trabajo. Por ejemplo, además de los diferentes mecanismos descritos en la Introducción de este trabajo, nuestro rastreo celómico también ha identificado un grupo de proteínas transmembrana, Basigina y TMEM8A, que favorece la localización en membrana de Rac1 a través de un mecanismo diferente al descrito para Coronina-1A. A diferencia del caso de las proteínas con repeticiones WD40 anteriores, estas proteínas transmembrana regulan la localización subcelular de Rac1, RhoG e incluso de otro miembro de la familia Rho/Rac más distante como es Cdc42. Para llevar a cabo dicha función, Basigina y TMEM8A precisan de balsas lipídicas y del citoesqueleto de F-actina pero muestran un comportamiento totalmente independiente de la actividad quinasa de Pak1 o de la actividad de Rac1 (Figura 51, Tabla 5). Nuestros resultados experimentales en los estudios de la internalización de balsas lipídicas, donde se muestra que Basigina, y no Coronina-1A, produce un retraso en este proceso de internalización, sugieren además que nuestras proteínas transmembrana podrían estar favoreciendo la translocación de Rac1 a través de la estabilización en la superficie celular de estas balsas lipídicas. Esta hipótesis tendrá que ser analizada con profundidad en el futuro 
para confirmar la participación de nuestras proteínas transmembrana en la regulación de la internalización de balsas lipídicas; proceso que, al igual que Basigina y TMEM8A, está relacionado con receptores de adhesión como son las integrinas. En conclusión, los datos recogidos en este trabajo demuestran la existencia de diferentes rutas para mediar la translocación de la GTPasa Rac1 a la membrana. Así, la identificación de Coronina-1A en el rastreo celómico descrito ha permitido revelar la existencia un ciclo de retroalimentación positiva en la translocación de Rac1 a la membrana basado en el citoesqueleto de F-actina, Coronina-1A, ArhGEF7, Pak1 y RhoGDI. Esta misma ruta podría ser compartida por WDR26, otro miembro de la familia de proteínas WD40 aislado en el rastreo celómico inicial. Por otra parte, las proteínas transmembrana Basigina y TMEM8A funcionan en una ruta funcionalmente diferente a la anteriormente descrita. Estas proteínas podrían estar incrementando la población de proteínas Rac1 unidas a la membrana plasmática a través de la estabilización de las balsas lipídicas en la superficie celular de una forma independiente de Rac1/Pak1 (Figura 51).

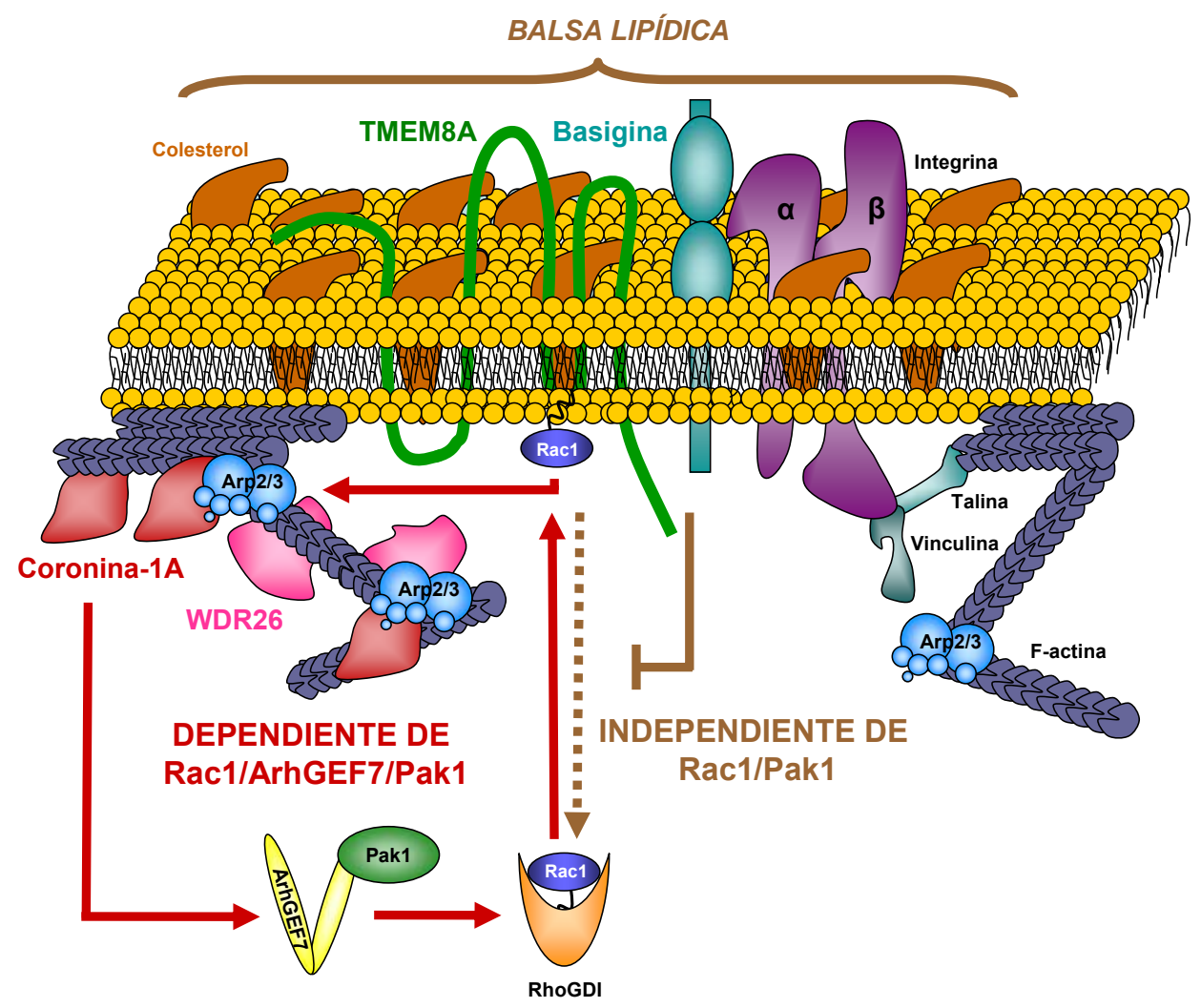

Figura 51. Modelo funcional del mecanismo de translocación de Rac1 mediada por los dos grupos de proteínas aisladas en el rastreo celómico. Mientras las proteínas Coronina-1A y WDR26 inducen la acumulación de proteínas Rac1 unidas a la membrana plasmática a través de una ruta de señalización que requiere el concurso de Rac1, ArhGEF7 y Pak1 para promover la disociación de los complejos RhoGDI/Rac1 citosólicos (indicado con línea roja), Basigina y TMEM8A podrían estar mediando su efecto en la regulación de la localización subcelular de Rac1 a través de la inhibición de la internalización de las balsas lipídicas de una forma independiente de Rac1 y Pak1 (indicado con linea marrón). 


\section{CONCLUSIONES}



1. Un rastreo celómico nos ha permitido aislar 21 candidatos potenciales con capacidad de regular la translocación de Rac1 desde el citosol a la membrana plasmática.

2. La caracterización de 4 de estas proteínas (Coronina-1A, WDR26, Basigina y TMEM8A) nos ha permitido identificar dos rutas independientes, pero solapantes entre ellas, que contribuyen a la acumulación de proteínas Rac1 en la membrana plasmática.

3. La translocación de Rac1 mediada por la proteína citoesquelética Coronina-1A requiere el concurso de elementos celulares (balsas lipídicas y citoesqueleto de F-actina) así como de proteínas señalizadoras de la ruta de Rac1 (ArhGEF7, Pak1 y RhoGDI).

4. Estos descubrimientos sugieren la existencia de un ciclo de retroalimentación positiva para la disociación de los complejos citosólicos RhoGDI/Rac1 a través de quinasas de la familia Pak y la posterior translocación/activación de la GTPasa en zonas yuxtamembranarias del citoesqueleto de F-actina.

5. La proteína WDR26, estructuralmente relacionada con Coronina-1A, parece estar involucrada en este circuito citoesquelético dependiente de Coronina1A/ArhGEF7/Pak1/RhoGDI.

6. Basigina, y probablemente TMEM8A, promueve la agregación y estabilización de balsas lipídicas en la superficie celular que podría estar contribuyendo a la translocación/acumulación de Rac1 en la membrana plasmática. A diferencia de lo observado con Coronina-1A y WDR26, este mecanismo mediado por Basigina y TMEM8A es totalmente independiente de Coronina-1A y Pak1, pero necesita balsas lipídicas y un citoesqueleto de actina funcionales. 

BIBLIOGRAFÍA 

Abo, A., Pick, E., Hall, A., Totty, N., Teahan, C. G., and Segal, A. W. (1991). Activation of the NADPH oxidase involves the small GTP-binding protein p21rac1. Nature 353, 668-670.

Abou-Kheir, W., Isaac, B., Yamaguchi, H., and Cox, D. (2008). Membrane targeting of WAVE2 is not sufficient for WAVE2-dependent actin polymerization: a role for IRSp53 in mediating the interaction between Rac and WAVE2. J Cell Sci 121, 379-390.

Abramovici, H., Mojtabaie, P., Parks, R. J., Zhong, X. P., Koretzky, G. A., Topham, M. K., and Gee, S. H. (2009). Diacylglycerol kinase zeta regulates actin cytoskeleton reorganization through dissociation of Rac1 from RhoGDI. Mol Biol Cell 20, 2049-2059.

Aghazadeh, B., Zhu, K., Kubiseski, T. J., Liu, G. A., Pawson, T., Zheng, Y., and Rosen, M. K. (1998). Structure and mutagenesis of the Dbl homology domain. Nat Struct Biol 5, 10981107.

Allen, K. M., Gleeson, J. G., Bagrodia, S., Partington, M. W., MacMillan, J. C., Cerione, R. A., Mulley, J. C., and Walsh, C. A. (1998a). PAK3 mutation in nonsyndromic X-linked mental retardation. Nat Genet 20, 25-30.

Allen, W. E., Zicha, D., Ridley, A. J., and Jones, G. E. (1998b). A role for Cdc42 in macrophage chemotaxis. J Cell Biol 141, 1147-1157.

Allenspach, E. J., Cullinan, P., Tong, J., Tang, Q., Tesciuba, A. G., Cannon, J. L., Takahashi, S. M., Morgan, R., Burkhardt, J. K., and Sperling, A. I. (2001). ERM-dependent movement of CD43 defines a novel protein complex distal to the immunological synapse. Immunity 15, 739-750.

Appledorn, D. M., Dao, K. H., O'Reilly, S., Maher, V. M., and McCormick, J. J. Rac1 and Cdc42 are regulators of HRasV12-transformation and angiogenic factors in human fibroblasts. BMC Cancer 10, 13.

Appleton, B. A., Wu, P., and Wiesmann, C. (2006). The crystal structure of murine coronin-1: a regulator of actin cytoskeletal dynamics in lymphocytes. Structure 14, 87-96.

Arlinghaus, R. B. (2002). Bcr: a negative regulator of the Bcr-Abl oncoprotein in leukemia. Oncogene 21, 8560-8567. 
Aspenstrom, P., Fransson, A., and Saras, J. (2004). Rho GTPases have diverse effects on the organization of the actin filament system. Biochem $\mathrm{J} 377,327-337$.

Bagrodia, S., Bailey, D., Lenard, Z., Hart, M., Guan, J. L., Premont, R. T., Taylor, S. J., and Cerione, R. A. (1999). A tyrosine-phosphorylated protein that binds to an important regulatory region on the cool family of p21-activated kinase-binding proteins. J Biol Chem 274, 2239322400.

Bagrodia, S., Taylor, S. J., Jordon, K. A., Van Aelst, L., and Cerione, R. A. (1998). A novel regulator of p21-activated kinases. J Biol Chem 273, 23633-23636.

Bailly, M., Wyckoff, J., Bouzahzah, B., Hammerman, R., Sylvestre, V., Cammer, M., Pestell, R., and Segall, J. E. (2000). Epidermal growth factor receptor distribution during chemotactic responses. Mol Biol Cell 11, 3873-3883.

Balasubramanian, N., Scott, D. W., Castle, J. D., Casanova, J. E., and Schwartz, M. A. (2007). Arf6 and microtubules in adhesion-dependent trafficking of lipid rafts. Nat Cell Biol 9, 1381-1391.

Barros, P., Jordan, P., and Matos, P. (2009). Rac1 signaling modulates BCL-6-mediated repression of gene transcription. Mol Cell Biol 29, 4156-4166.

Bashour, A. M., Fullerton, A. T., Hart, M. J., and Bloom, G. S. (1997). IQGAP1, a Rac- and Cdc42-binding protein, directly binds and cross-links microfilaments. J Cell Biol 137, 1555-1566.

Benvenuti, F., Hugues, S., Walmsley, M., Ruf, S., Fetler, L., Popoff, M., Tybulewicz, V. L., and Amigorena, S. (2004). Requirement of Rac1 and Rac2 expression by mature dendritic cells for T cell priming. Science 305, 1150-1153.

Berditchevski, F., Chang, S., Bodorova, J., and Hemler, M. E. (1997). Generation of monoclonal antibodies to integrin-associated proteins. Evidence that alpha3beta1 complexes with EMMPRIN/basigin/OX47/M6. J Biol Chem 272, 29174-29180.

Billuart, P., Bienvenu, T., Ronce, N., des Portes, V., Vinet, M. C., Zemni, R., Carrie, A., Beldjord, C., Kahn, A., Moraine, C., and Chelly, J. (1998). Oligophrenin 1 encodes a rho-GAP protein involved in X-linked mental retardation. Pathol Biol (Paris) 46, 678. 
Boettner, B., and Van Aelst, L. (2002). The role of Rho GTPases in disease development. Gene 286, 155-174.

Bokoch, G. M. (2003). Biology of the p21-activated kinases. Annu Rev Biochem 72, 743-781.

Bokoch, G. M., and Diebold, B. A. (2002). Current molecular models for NADPH oxidase regulation by Rac GTPase. Blood 100, 2692-2696.

Bokoch, G. M., and Knaus, U. G. (2003). NADPH oxidases: not just for leukocytes anymore! Trends Biochem Sci 28, 502-508.

Bolis, A., Corbetta, S., Cioce, A., and de Curtis, I. (2003). Differential distribution of Rac1 and Rac3 GTPases in the developing mouse brain: implications for a role of Rac3 in Purkinje cell differentiation. Eur J Neurosci 18, 2417-2424.

Bos, J. L., Rehmann, H., and Wittinghofer, A. (2007). GEFs and GAPs: critical elements in the control of small $\mathrm{G}$ proteins. Cell 129, 865-877.

Bretscher, A., Edwards, K., and Fehon, R. G. (2002). ERM proteins and merlin: integrators at the cell cortex. Nat Rev Mol Cell Biol 3, 586-599.

Brown, E., Hooper, L., Ho, T., and Gresham, H. (1990). Integrin-associated protein: a 50-kD plasma membrane antigen physically and functionally associated with integrins. J Cell Biol 111, 2785-2794.

Brunet, N., Morin, A., and Olofsson, B. (2002). RhoGDI-3 regulates RhoG and targets this protein to the Golgi complex through its unique N-terminal domain. Traffic 3, 342-357.

Bustelo, X. R., Sauzeau, V., and Berenjeno, I. M. (2007). GTP-binding proteins of the Rho/Rac family: regulation, effectors and functions in vivo. Bioessays 29, 356-370.

Cai, L., Holoweckyj, N., Schaller, M. D., and Bear, J. E. (2005). Phosphorylation of coronin 1B by protein kinase C regulates interaction with Arp2/3 and cell motility. J Biol Chem 280, 3191331923.

Cai, L., Makhov, A. M., and Bear, J. E. (2007a). F-actin binding is essential for coronin 1B function in vivo. J Cell Sci 120, 1779-1790. 
Cai, L., Makhov, A. M., Schafer, D. A., and Bear, J. E. (2008). Coronin 1B antagonizes cortactin and remodels Arp2/3-containing actin branches in lamellipodia. Cell 134, 828-842.

Cai, L., Marshall, T. W., Uetrecht, A. C., Schafer, D. A., and Bear, J. E. (2007b). Coronin 1B coordinates Arp2/3 complex and cofilin activities at the leading edge. Cell 128, 915-929.

Caloca, M. J., Fernandez, N., Lewin, N. E., Ching, D., Modali, R., Blumberg, P. M., and Kazanietz, M. G. (1997). Beta2-chimaerin is a high affinity receptor for the phorbol ester tumor promoters. J Biol Chem 272, 26488-26496.

Caloca, M. J., Garcia-Bermejo, M. L., Blumberg, P. M., Lewin, N. E., Kremmer, E., Mischak, H., Wang, S., Nacro, K., Bienfait, B., Marquez, V. E., and Kazanietz, M. G. (1999). beta2chimaerin is a novel target for diacylglycerol: binding properties and changes in subcellular localization mediated by ligand binding to its C1 domain. Proc Natl Acad Sci U S A 96, 1185411859.

Caloca, M. J., Wang, H., Delemos, A., Wang, S., and Kazanietz, M. G. (2001). Phorbol esters and related analogs regulate the subcellular localization of beta 2-chimaerin, a non-protein kinase C phorbol ester receptor. J Biol Chem 276, 18303-18312.

Caloca, M. J., Zugaza, J. L., Vicente-Manzanares, M., Sanchez-Madrid, F., and Bustelo, X. R. (2004). F-actin-dependent translocation of the Rap1 GDP/GTP exchange factor RasGRP2. J Biol Chem 279, 20435-20446.

Cancelas, J. A., Lee, A. W., Prabhakar, R., Stringer, K. F., Zheng, Y., and Williams, D. A. (2005). Rac GTPases differentially integrate signals regulating hematopoietic stem cell localization. Nat Med 11, 886-891.

Caron, E., and Hall, A. (1998). Identification of two distinct mechanisms of phagocytosis controlled by different Rho GTPases. Science 282, 1717-1721.

Condliffe, A. M., Webb, L. M., Ferguson, G. J., Davidson, K., Turner, M., Vigorito, E., Manifava, M., Chilvers, E. R., Stephens, L. R., and Hawkins, P. T. (2006). RhoG regulates the neutrophil NADPH oxidase. J Immunol 176, 5314-5320.

Corbetta, S., Gualdoni, S., Albertinazzi, C., Paris, S., Croci, L., Consalez, G. G., and de Curtis, I. (2005). Generation and characterization of Rac3 knockout mice. Mol Cell Biol 25, 5763-5776. 
Coso, O. A., Chiariello, M., Yu, J. C., Teramoto, H., Crespo, P., Xu, N., Miki, T., and Gutkind, J. S. (1995). The small GTP-binding proteins Rac1 and Cdc42 regulate the activity of the JNK/SAPK signaling pathway. Cell 81, 1137-1146.

Cox, D., Chang, P., Zhang, Q., Reddy, P. G., Bokoch, G. M., and Greenberg, S. (1997). Requirements for both Rac1 and Cdc42 in membrane ruffling and phagocytosis in leukocytes. $J$ Exp Med 186, 1487-1494.

Crespo, P., Schuebel, K. E., Ostrom, A. A., Gutkind, J. S., and Bustelo, X. R. (1997). Phosphotyrosine-dependent activation of Rac-1 GDP/GTP exchange by the vav protooncogene product. Nature 385, 169-172.

Criss, A. K., Ahlgren, D. M., Jou, T. S., McCormick, B. A., and Casanova, J. E. (2001). The GTPase Rac1 selectively regulates Salmonella invasion at the apical plasma membrane of polarized epithelial cells. J Cell Sci 114, 1331-1341.

Croker, B. A., Tarlinton, D. M., Cluse, L. A., Tuxen, A. J., Light, A., Yang, F. C., Williams, D. A., and Roberts, A. W. (2002). The Rac2 guanosine triphosphatase regulates B lymphocyte antigen receptor responses and chemotaxis and is required for establishment of B-1a and marginal zone B lymphocytes. J Immunol 168, 3376-3386.

Curtin, K. D., Meinertzhagen, I. A., and Wyman, R. J. (2005). Basigin (EMMPRIN/CD147) interacts with integrin to affect cellular architecture. J Cell Sci 118, 2649-2660.

Chae, Y. C., Kim, J. H., Kim, K. L., Kim, H. W., Lee, H. Y., Heo, W. D., Meyer, T., Suh, P. G., and Ryu, S. H. (2008). Phospholipase D activity regulates integrin-mediated cell spreading and migration by inducing GTP-Rac translocation to the plasma membrane. Mol Biol Cell 19, 31113123.

Chahdi, A., and Sorokin, A. (2008). Protein kinase A-dependent phosphorylation modulates beta1Pix guanine nucleotide exchange factor activity through 14-3-3beta binding. Mol Cell Biol 28, 1679-1687.

Chan, A. Y., Bailly, M., Zebda, N., Segall, J. E., and Condeelis, J. S. (2000). Role of cofilin in epidermal growth factor-stimulated actin polymerization and lamellipod protrusion. J Cell Biol 148, 531-542. 
Chanda, S. K., White, S., Orth, A. P., Reisdorph, R., Miraglia, L., Thomas, R. S., DeJesus, P., Mason, D. E., Huang, Q., Vega, R., et al. (2003). Genome-scale functional profiling of the mammalian AP-1 signaling pathway. Proc Natl Acad Sci U S A 100, 12153-12158.

Chang, H. Y., and Ready, D. F. (2000). Rescue of photoreceptor degeneration in rhodopsinnull Drosophila mutants by activated Rac1. Science 290, 1978-1980.

Cherfils, J., and Chardin, P. (1999). GEFs: structural basis for their activation of small GTPbinding proteins. Trends Biochem Sci 24, 306-311.

Chrostek, A., Wu, X., Quondamatteo, F., Hu, R., Sanecka, A., Niemann, C., Langbein, L., Haase, I., and Brakebusch, C. (2006). Rac1 is crucial for hair follicle integrity but is not essential for maintenance of the epidermis. Mol Cell Biol 26, 6957-6970.

Chuang, T. H., Bohl, B. P., and Bokoch, G. M. (1993). Biologically active lipids are regulators of Rac.GDI complexation. J Biol Chem 268, 26206-26211.

D'Angelo, R., Aresta, S., Blangy, A., Del Maestro, L., Louvard, D., and Arpin, M. (2007). Interaction of ezrin with the novel guanine nucleotide exchange factor PLEKHG6 promotes RhoG-dependent apical cytoskeleton rearrangements in epithelial cells. Mol Biol Cell 18, 47804793.

D'Souza-Schorey, C., Boshans, R. L., McDonough, M., Stahl, P. D., and Van Aelst, L. (1997). A role for POR1, a Rac1-interacting protein, in ARF6-mediated cytoskeletal rearrangements. Embo J 16, 5445-5454.

Daly, R. J. (2004). Cortactin signalling and dynamic actin networks. Biochem J 382, 13-25.

Dallery, E., Galiegue-Zouitina, S., Collyn-d'Hooghe, M., Quief, S., Denis, C., Hildebrand, M. P., Lantoine, D., Deweindt, C., Tilly, H., Bastard, C., and et al. (1995). TTF, a gene encoding a novel small $G$ protein, fuses to the lymphoma-associated LAZ3 gene by $t(3 ; 4)$ chromosomal translocation. Oncogene 10, 2171-2178.

Daniels, R. H., Hall, P. S., and Bokoch, G. M. (1998). Membrane targeting of p21-activated kinase 1 (PAK1) induces neurite outgrowth from PC12 cells. Embo J 17, 754-764. 
Das, B., Shu, X., Day, G. J., Han, J., Krishna, U. M., Falck, J. R., and Broek, D. (2000). Control of intramolecular interactions between the pleckstrin homology and Dbl homology domains of Vav and Sos1 regulates Rac binding. J Biol Chem 275, 15074-15081.

de Hostos, E. L. (1999). The coronin family of actin-associated proteins. Trends Cell Biol 9, 345-350.

Deacon, N. J., Tsykin, A., Solomon, A., Smith, K., Ludford-Menting, M., Hooker, D. J., McPhee, D. A., Greenway, A. L., Ellett, A., Chatfield, C., et al. (1995). Genomic structure of an attenuated quasi species of HIV-1 from a blood transfusion donor and recipients. Science 270, 988-991.

del Pozo, M. A., Alderson, N. B., Kiosses, W. B., Chiang, H. H., Anderson, R. G., and Schwartz, M. A. (2004). Integrins regulate Rac targeting by internalization of membrane domains. Science 303, 839-842.

del Pozo, M. A., Balasubramanian, N., Alderson, N. B., Kiosses, W. B., Grande-Garcia, A., Anderson, R. G., and Schwartz, M. A. (2005). Phospho-caveolin-1 mediates integrin-regulated membrane domain internalization. Nat Cell Biol 7, 901-908.

Del Pozo, M. A., Kiosses, W. B., Alderson, N. B., Meller, N., Hahn, K. M., and Schwartz, M. A. (2002). Integrins regulate GTP-Rac localized effector interactions through dissociation of Rho-GDI. Nat Cell Biol 4, 232-239.

del Pozo, M. A., Price, L. S., Alderson, N. B., Ren, X. D., and Schwartz, M. A. (2000). Adhesion to the extracellular matrix regulates the coupling of the small GTPase Rac to its effector PAK. Embo J 19, 2008-2014.

DerMardirossian, C., and Bokoch, G. M. (2005). GDls: central regulatory molecules in Rho GTPase activation. Trends Cell Biol 15, 356-363.

DerMardirossian, C., Rocklin, G., Seo, J. Y., and Bokoch, G. M. (2006). Phosphorylation of RhoGDI by Src regulates Rho GTPase binding and cytosol-membrane cycling. Mol Biol Cell 17, 4760-4768.

DerMardirossian, C., Schnelzer, A., and Bokoch, G. M. (2004). Phosphorylation of RhoGDI by Pak1 mediates dissociation of Rac GTPase. Mol Cell 15, 117-127. 
Dharmawardhane, S., and Bokoch, G. M. (1997). Rho GTPases and leukocyte cytoskeletal regulation. Curr Opin Hematol 4, 12-18.

Dharmawardhane, S., Sanders, L. C., Martin, S. S., Daniels, R. H., and Bokoch, G. M. (1997). Localization of p21-activated kinase 1 (PAK1) to pinocytic vesicles and cortical actin structures in stimulated cells. J Cell Biol 138, 1265-1278.

Dharmawardhane, S., Schurmann, A., Sells, M. A., Chernoff, J., Schmid, S. L., and Bokoch, G. M. (2000). Regulation of macropinocytosis by p21-activated kinase-1. Mol Biol Cell 11, 3341-3352.

Didsbury, J., Weber, R. F., Bokoch, G. M., Evans, T., and Snyderman, R. (1989). rac, a novel ras-related family of proteins that are botulinum toxin substrates. J Biol Chem 264, 1637816382.

Diekmann, D., Nobes, C. D., Burbelo, P. D., Abo, A., and Hall, A. (1995). Rac GTPase interacts with GAPs and target proteins through multiple effector sites. Embo J 14, 5297-5305.

Ellis, S., and Mellor, H. (2000). The novel Rho-family GTPase rif regulates coordinated actinbased membrane rearrangements. Curr Biol 10, 1387-1390.

Engers, R., Zwaka, T. P., Gohr, L., Weber, A., Gerharz, C. D., and Gabbert, H. E. (2000). Tiam1 mutations in human renal-cell carcinomas. Int J Cancer 88, 369-376.

Erickson, J. W., Cerione, R. A., and Hart, M. J. (1997). Identification of an actin cytoskeletal complex that includes IQGAP and the Cdc42 GTPase. J Biol Chem 272, 24443-24447.

Etienne-Manneville, S., and Hall, A. (2002). Rho GTPases in cell biology. Nature 420, 629635.

Eva, A., and Aaronson, S. A. (1985). Isolation of a new human oncogene from a diffuse B-cell lymphoma. Nature 316, 273-275.

Fackler, O. T., Lu, X., Frost, J. A., Geyer, M., Jiang, B., Luo, W., Abo, A., Alberts, A. S., and Peterlin, B. M. (2000). p21-activated kinase 1 plays a critical role in cellular activation by Nef. Mol Cell Biol 20, 2619-2627. 
Faure, J., Vignais, P. V., and Dagher, M. C. (1999). Phosphoinositide-dependent activation of Rho A involves partial opening of the RhoA/Rho-GDI complex. Eur J Biochem 262, 879-889.

Feig, L. A. (1999). Tools of the trade: use of dominant-inhibitory mutants of Ras-family GTPases. Nat Cell Biol 1, E25-27.

Filippi, M. D., Harris, C. E., Meller, J., Gu, Y., Zheng, Y., and Williams, D. A. (2004). Localization of Rac2 via the $C$ terminus and aspartic acid 150 specifies superoxide generation, actin polarity and chemotaxis in neutrophils. Nat Immunol 5, 744-751.

Flaiz, C., Chernoff, J., Ammoun, S., Peterson, J. R., and Hanemann, C. O. (2009). PAK kinase regulates Rac GTPase and is a potential target in human schwannomas. Exp Neurol 218, 137-144.

Fleming, I. N., Gray, A., and Downes, C. P. (2000). Regulation of the Rac1-specific exchange factor Tiam1 involves both phosphoinositide 3-kinase-dependent and -independent components. Biochem J 351, 173-182.

Foger, N., Rangell, L., Danilenko, D. M., and Chan, A. C. (2006). Requirement for coronin 1 in T lymphocyte trafficking and cellular homeostasis. Science 313, 839-842.

Fransson, A., Ruusala, A., and Aspenstrom, P. (2003). Atypical Rho GTPases have roles in mitochondrial homeostasis and apoptosis. J Biol Chem 278, 6495-6502.

Friebel, A., Ilchmann, H., Aepfelbacher, M., Ehrbar, K., Machleidt, W., and Hardt, W. D. (2001). SopE and SopE2 from Salmonella typhimurium activate different sets of RhoGTPases of the host cell. J Biol Chem 276, 34035-34040.

Fukata, M., Watanabe, T., Noritake, J., Nakagawa, M., Yamaga, M., Kuroda, S., Matsuura, Y., Iwamatsu, A., Perez, F., and Kaibuchi, K. (2002). Rac1 and Cdc42 capture microtubules through IQGAP1 and CLIP-170. Cell 109, 873-885.

Gabison, E. E., Hoang-Xuan, T., Mauviel, A., and Menashi, S. (2005). EMMPRIN/CD147, an MMP modulator in cancer, development and tissue repair. Biochimie 87, 361-368.

Galkin, V. E., Orlova, A., Brieher, W., Kueh, H. Y., Mitchison, T. J., and Egelman, E. H. (2008). Coronin-1A stabilizes F-actin by bridging adjacent actin protomers and stapling opposite strands of the actin filament. $J$ Mol Biol 376, 607-613. 
Gandhi, M., Achard, V., Blanchoin, L., and Goode, B. L. (2009). Coronin switches roles in actin disassembly depending on the nucleotide state of actin. Mol Cell 34, 364-374.

Gandhi, P. N., Gibson, R. M., Tong, X., Miyoshi, J., Takai, Y., Konieczkowski, M., Sedor, J. R., and Wilson-Delfosse, A. L. (2004). An activating mutant of Rac1 that fails to interact with Rho GDP-dissociation inhibitor stimulates membrane ruffling in mammalian cells. Biochem $\mathrm{J}$ 378, 409-419.

Gao, Y., Xing, J., Streuli, M., Leto, T. L., and Zheng, Y. (2001). Trp(56) of rac1 specifies interaction with a subset of guanine nucleotide exchange factors. J Biol Chem 276, 4753047541.

Garrett, M. D., Self, A. J., van Oers, C., and Hall, A. (1989). Identification of distinct cytoplasmic targets for ras/R-ras and rho regulatory proteins. J Biol Chem 264, 10-13.

Gauthier-Rouviere, C., Vignal, E., Meriane, M., Roux, P., Montcourier, P., and Fort, P. (1998). RhoG GTPase controls a pathway that independently activates Rac1 and Cdc42Hs. Mol Biol Cell 9, 1379-1394.

Gibson, R. M., and Wilson-Delfosse, A. L. (2001). RhoGDI-binding-defective mutant of Cdc42Hs targets to membranes and activates filopodia formation but does not cycle with the cytosol of mammalian cells. Biochem J 359, 285-294.

Glogauer, M., Marchal, C. C., Zhu, F., Worku, A., Clausen, B. E., Foerster, I., Marks, P., Downey, G. P., Dinauer, M., and Kwiatkowski, D. J. (2003). Rac1 deletion in mouse neutrophils has selective effects on neutrophil functions. J Immunol 170, 5652-5657.

Gomez, M., Tybulewicz, V., and Cantrell, D. A. (2000). Control of pre-T cell proliferation and differentiation by the GTPase Rac-I. Nat Immunol 1, 348-352.

Goode, B. L., Wong, J. J., Butty, A. C., Peter, M., McCormack, A. L., Yates, J. R., Drubin, D. G., and Barnes, G. (1999). Coronin promotes the rapid assembly and cross-linking of actin filaments and may link the actin and microtubule cytoskeletons in yeast. J Cell Biol 144, 83-98.

Gosser, Y. Q., Nomanbhoy, T. K., Aghazadeh, B., Manor, D., Combs, C., Cerione, R. A., and Rosen, M. K. (1997). C-terminal binding domain of Rho GDP-dissociation inhibitor directs N-terminal inhibitory peptide to GTPases. Nature 387, 814-819. 
Green, D. R., and Reed, J. C. (1998). Mitochondria and apoptosis. Science 281, 1309-1312.

Gregg, D., Rauscher, F. M., and Goldschmidt-Clermont, P. J. (2003). Rac regulates cardiovascular superoxide through diverse molecular interactions: more than a binary GTP switch. Am J Physiol Cell Physiol 285, C723-734.

Grimm, S. (2004). The art and design of genetic screens: mammalian culture cells. Nat Rev Genet 5, 179-189.

Grizot, S., Faure, J., Fieschi, F., Vignais, P. V., Dagher, M. C., and Pebay-Peyroula, E. (2001). Crystal structure of the Rac1-RhoGDI complex involved in nadph oxidase activation. Biochemistry 40, 10007-10013.

Gu, Y., Filippi, M. D., Cancelas, J. A., Siefring, J. E., Williams, E. P., Jasti, A. C., Harris, C. E., Lee, A. W., Prabhakar, R., Atkinson, S. J., et al. (2003). Hematopoietic cell regulation by Rac1 and Rac2 guanosine triphosphatases. Science 302, 445-449.

Hakeda-Suzuki, S., Ng, J., Tzu, J., Dietzl, G., Sun, Y., Harms, M., Nardine, T., Luo, L., and Dickson, B. J. (2002). Rac function and regulation during Drosophila development. Nature 416, 438-442.

Haraldsson, M. K., Louis-Dit-Sully, C. A., Lawson, B. R., Sternik, G., Santiago-Raber, M. L., Gascoigne, N. R., Theofilopoulos, A. N., and Kono, D. H. (2008). The lupus-related Lmb3 locus contains a disease-suppressing Coronin-1A gene mutation. Immunity 28, 40-51.

Hart, M. J., Callow, M. G., Souza, B., and Polakis, P. (1996). IQGAP1, a calmodulin-binding protein with a rasGAP-related domain, is a potential effector for cdc42Hs. Embo J 15, 2997 3005.

Hartwig, J. H., Bokoch, G. M., Carpenter, C. L., Janmey, P. A., Taylor, L. A., Toker, A., and Stossel, T. P. (1995). Thrombin receptor ligation and activated Rac uncap actin filament barbed ends through phosphoinositide synthesis in permeabilized human platelets. Cell 82, 643-653.

Heo, W. D., Inoue, T., Park, W. S., Kim, M. L., Park, B. O., Wandless, T. J., and Meyer, T. (2006). $\mathrm{PI}(3,4,5) \mathrm{P} 3$ and $\mathrm{PI}(4,5) \mathrm{P} 2$ lipids target proteins with polybasic clusters to the plasma membrane. Science 314, 1458-1461. 
Hirao, M., Sato, N., Kondo, T., Yonemura, S., Monden, M., Sasaki, T., Takai, Y., Tsukita, S., and Tsukita, S. (1996). Regulation mechanism of ERM (ezrin/radixin/moesin) protein/plasma membrane association: possible involvement of phosphatidylinositol turnover and Rhodependent signaling pathway. J Cell Biol 135, 37-51.

Ho, Y. D., Joyal, J. L., Li, Z., and Sacks, D. B. (1999). IQGAP1 integrates Ca2+/calmodulin and Cdc42 signaling. J Biol Chem 274, 464-470.

Hoffman, G. R., Nassar, N., and Cerione, R. A. (2000). Structure of the Rho family GTPbinding protein Cdc42 in complex with the multifunctional regulator RhoGDI. Cell 100, 345-356.

Holmgren, J., Lonnroth, I., and Svennerholm, L. (1973). Tissue receptor for cholera exotoxin: postulated structure from studies with GM1 ganglioside and related glycolipids. Infect Immun $\mathbf{8}$, 208-214.

Hou, P., Estrada, L., Kinley, A. W., Parsons, J. T., Vojtek, A. B., and Gorski, J. L. (2003). Fgd1, the Cdc42 GEF responsible for Faciogenital Dysplasia, directly interacts with cortactin and mAbp1 to modulate cell shape. Hum Mol Genet 12, 1981-1993.

Huang, T. Y., DerMardirossian, C., and Bokoch, G. M. (2006). Cofilin phosphatases and regulation of actin dynamics. Curr Opin Cell Biol 18, 26-31.

Humphries, C. L., Balcer, H. I., D'Agostino, J. L., Winsor, B., Drubin, D. G., Barnes, G., Andrews, B. J., and Goode, B. L. (2002). Direct regulation of Arp2/3 complex activity and function by the actin binding protein coronin. J Cell Biol 159, 993-1004.

Hussain, N. K., Jenna, S., Glogauer, M., Quinn, C. C., Wasiak, S., Guipponi, M., Antonarakis, S. E., Kay, B. K., Stossel, T. P., Lamarche-Vane, N., and McPherson, P. S. (2001). Endocytic protein intersectin-I regulates actin assembly via Cdc42 and N-WASP. Nat Cell Biol 3, 927-932.

lacono, K. T., Brown, A. L., Greene, M. I., and Saouaf, S. J. (2007). CD147 immunoglobulin superfamily receptor function and role in pathology. Exp Mol Pathol 83, 283-295.

Innocenti, M., Frittoli, E., Ponzanelli, I., Falck, J. R., Brachmann, S. M., Di Fiore, P. P., and Scita, G. (2003). Phosphoinositide 3-kinase activates Rac by entering in a complex with Eps8, Abi1, and Sos-1. J Cell Biol 160, 17-23. 
Innocenti, M., Zucconi, A., Disanza, A., Frittoli, E., Areces, L. B., Steffen, A., Stradal, T. E., Di Fiore, P. P., Carlier, M. F., and Scita, G. (2004). Abi1 is essential for the formation and activation of a WAVE2 signalling complex. Nat Cell Biol 6, 319-327.

Ivetic, A., and Ridley, A. J. (2004). Ezrin/radixin/moesin proteins and Rho GTPase signalling in leucocytes. Immunology 112, 165-176.

Jadeski, L., Mataraza, J. M., Jeong, H. W., Li, Z., and Sacks, D. B. (2008). IQGAP1 stimulates proliferation and enhances tumorigenesis of human breast epithelial cells. $\mathrm{J}$ Biol Chem 283, 1008-1017.

Jaffe, A. B., and Hall, A. (2002). Rho GTPases in transformation and metastasis. Adv Cancer Res 84, 57-80.

Janardhan, A., Swigut, T., Hill, B., Myers, M. P., and Skowronski, J. (2004). HIV-1 Nef binds the DOCK2-ELMO1 complex to activate rac and inhibit lymphocyte chemotaxis. PLoS Biol 2 , E6.

Jordan, P., Brazao, R., Boavida, M. G., Gespach, C., and Chastre, E. (1999). Cloning of a novel human Rac1b splice variant with increased expression in colorectal tumors. Oncogene 18, 6835-6839.

Joyce, D., Bouzahzah, B., Fu, M., Albanese, C., D'Amico, M., Steer, J., Klein, J. U., Lee, R. J., Segall, J. E., Westwick, J. K., et al. (1999). Integration of Rac-dependent regulation of cyclin D1 transcription through a nuclear factor-kappaB-dependent pathway. J Biol Chem 274, 25245-25249.

Kaminuma, O., Deckert, M., Elly, C., Liu, Y. C., and Altman, A. (2001). Vav-Rac1-mediated activation of the c-Jun N-terminal kinase/c-Jun/AP-1 pathway plays a major role in stimulation of the distal NFAT site in the interleukin-2 gene promoter. Mol Cell Biol 21, 3126-3136.

Katzav, S., Martin-Zanca, D., and Barbacid, M. (1989). vav, a novel human oncogene derived from a locus ubiquitously expressed in hematopoietic cells. Embo J 8, 2283-2290.

Kazanietz, M. G. (2000). Eyes wide shut: protein kinase C isozymes are not the only receptors for the phorbol ester tumor promoters. Mol Carcinog 28, 5-11. 
Keely, P. J., Westwick, J. K., Whitehead, I. P., Der, C. J., and Parise, L. V. (1997). Cdc42 and Rac1 induce integrin-mediated cell motility and invasiveness through $\mathrm{PI}(3) \mathrm{K}$. Nature 390, 632-636.

Kharas, M. G., and Fruman, D. A. (2005). ABL oncogenes and phosphoinositide 3-kinase: mechanism of activation and downstream effectors. Cancer Res 65, 2047-2053.

Kim, C., and Dinauer, M. C. (2001). Rac2 is an essential regulator of neutrophil nicotinamide adenine dinucleotide phosphate oxidase activation in response to specific signaling pathways. $J$ Immunol 166, 1223-1232.

Kim, K., Hou, P., Gorski, J. L., and Cooper, J. A. (2004). Effect of Fgd1 on cortactin in Arp2/3 complex-mediated actin assembly. Biochemistry 43, 2422-2427.

Kiosses, W. B., Shattil, S. J., Pampori, N., and Schwartz, M. A. (2001). Rac recruits highaffinity integrin alphavbeta3 to lamellipodia in endothelial cell migration. Nat Cell Biol 3, 316320.

Kirchhoff, F., Greenough, T. C., Brettler, D. B., Sullivan, J. L., and Desrosiers, R. C. (1995). Brief report: absence of intact nef sequences in a long-term survivor with nonprogressive HIV-1 infection. N Engl J Med 332, 228-232.

Kiss-Toth, E., Qwarnstrom, E. E., and Dower, S. K. (2004). Hunting for genes by functional screens. Cytokine Growth Factor Rev 15, 97-102.

Kitamura, Y., Kitamura, T., Sakaue, H., Maeda, T., Ueno, H., Nishio, S., Ohno, S., Osada, S., Sakaue, M., Ogawa, W., and Kasuga, M. (1997). Interaction of Nck-associated protein 1 with activated GTP-binding protein Rac. Biochem J 322 ( Pt 3), 873-878.

Knaus, U. G., Heyworth, P. G., Evans, T., Curnutte, J. T., and Bokoch, G. M. (1991). Regulation of phagocyte oxygen radical production by the GTP-binding protein Rac 2. Science 254, 1512-1515.

Koh, C. G., Manser, E., Zhao, Z. S., Ng, C. P., and Lim, L. (2001). Beta1PIX, the PAKinteracting exchange factor, requires localization via a coiled-coil region to promote microvilluslike structures and membrane ruffles. J Cell Sci 114, 4239-4251. 
Kourlas, P. J., Strout, M. P., Becknell, B., Veronese, M. L., Croce, C. M., Theil, K. S., Krahe, R., Ruutu, T., Knuutila, S., Bloomfield, C. D., and Caligiuri, M. A. (2000). Identification of a gene at 11q23 encoding a guanine nucleotide exchange factor: evidence for its fusion with MLL in acute myeloid leukemia. Proc Natl Acad Sci U S A 97, 2145-2150.

Krautkramer, E., Giese, S. I., Gasteier, J. E., Muranyi, W., and Fackler, O. T. (2004). Human immunodeficiency virus type 1 Nef activates p21-activated kinase via recruitment into lipid rafts. J Virol 78, 4085-4097.

Kraynov, V. S., Chamberlain, C., Bokoch, G. M., Schwartz, M. A., Slabaugh, S., and Hahn, K. M. (2000). Localized Rac activation dynamics visualized in living cells. Science 290, 333-337.

Kreck, M. L., Uhlinger, D. J., Tyagi, S. R., Inge, K. L., and Lambeth, J. D. (1994). Participation of the small molecular weight GTP-binding protein Rac1 in cell-free activation and assembly of the respiratory burst oxidase. Inhibition by a carboxyl-terminal Rac peptide. J Biol Chem 269, 4161-4168.

Kubori, T., and Galan, J. E. (2003). Temporal regulation of salmonella virulence effector function by proteasome-dependent protein degradation. Cell 115, 333-342.

Kueh, H. Y., Charras, G. T., Mitchison, T. J., and Brieher, W. M. (2008). Actin disassembly by cofilin, coronin, and Aip1 occurs in bursts and is inhibited by barbed-end cappers. J Cell Biol 182, 341-353.

Kumar, R., Gururaj, A. E., and Barnes, C. J. (2006). p21-activated kinases in cancer. Nat Rev Cancer 6, 459-471.

Kunimoto, K., Nojima, H., Yamazaki, Y., Yoshikawa, T., Okanoue, T., and Tsukita, S. (2009). Involvement of IQGAP3, a regulator of Ras/ERK-related cascade, in hepatocyte proliferation in mouse liver regeneration and development. J Cell Physiol 220, 621-631.

Kuroda, S., Fukata, M., Kobayashi, K., Nakafuku, M., Nomura, N., Iwamatsu, A., and Kaibuchi, K. (1996). Identification of IQGAP as a putative target for the small GTPases, Cdc42 and Rac1. J Biol Chem 271, 23363-23367.

Kuroda, S., Fukata, M., Nakagawa, M., Fujii, K., Nakamura, T., Ookubo, T., Izawa, I., Nagase, T., Nomura, N., Tani, H., et al. (1998). Role of IQGAP1, a target of the small 
GTPases Cdc42 and Rac1, in regulation of E-cadherin- mediated cell-cell adhesion. Science 281, 832-835.

Kutsche, K., Yntema, H., Brandt, A., Jantke, I., Nothwang, H. G., Orth, U., Boavida, M. G., David, D., Chelly, J., Fryns, J. P., et al. (2000). Mutations in ARHGEF6, encoding a guanine nucleotide exchange factor for Rho GTPases, in patients with X-linked mental retardation. Nat Genet 26, 247-250.

Lai, F. P., Szczodrak, M., Oelkers, J. M., Ladwein, M., Acconcia, F., Benesch, S., Auinger, S., Faix, J., Small, J. V., Polo, S., et al. (2009). Cortactin promotes migration and plateletderived growth factor-induced actin reorganization by signaling to Rho-GTPases. Mol Biol Cell 20, 3209-3223.

Lamaze, C., Chuang, T. H., Terlecky, L. J., Bokoch, G. M., and Schmid, S. L. (1996). Regulation of receptor-mediated endocytosis by Rho and Rac. Nature 382, 177-179.

Lamb, R. F., Roy, C., Diefenbach, T. J., Vinters, H. V., Johnson, M. W., Jay, D. G., and Hall, A. (2000). The TSC1 tumour suppressor hamartin regulates cell adhesion through ERM proteins and the GTPase Rho. Nat Cell Biol 2, 281-287.

Lanning, C. C., Daddona, J. L., Ruiz-Velasco, R., Shafer, S. H., and Williams, C. L. (2004). The Rac1 C-terminal polybasic region regulates the nuclear localization and protein degradation of Rac1. J Biol Chem 279, 44197-44210.

Lassegue, B., and Clempus, R. E. (2003). Vascular NAD(P)H oxidases: specific features, expression, and regulation. Am J Physiol Regul Integr Comp Physiol 285, R277-297.

Leberer, E., Dignard, D., Thomas, D. Y., and Leeuw, T. (2000). A conserved Gbeta binding (GBB) sequence motif in Ste20p/PAK family protein kinases. Biol Chem 381, 427-431.

Lee, S. H., Eom, M., Lee, S. J., Kim, S., Park, H. J., and Park, D. (2001). BetaPix-enhanced p38 activation by Cdc42/Rac/PAK/MKK3/6-mediated pathway. Implication in the regulation of membrane ruffling. J Biol Chem 276, 25066-25072.

Lei, M., Lu, W., Meng, W., Parrini, M. C., Eck, M. J., Mayer, B. J., and Harrison, S. C. (2000). Structure of PAK1 in an autoinhibited conformation reveals a multistage activation switch. Cell 102, 387-397. 
Lemmon, M. A., Ferguson, K. M., and Schlessinger, J. (1996). PH domains: diverse sequences with a common fold recruit signaling molecules to the cell surface. Cell 85, 621-624.

Lerm, M., Schmidt, G., and Aktories, K. (2000). Bacterial protein toxins targeting rho GTPases. FEMS Microbiol Lett 188, 1-6.

Li, B., Yu, H., Zheng, W., Voll, R., Na, S., Roberts, A. W., Williams, D. A., Davis, R. J., Ghosh, S., and Flavell, R. A. (2000). Role of the guanosine triphosphatase Rac2 in T helper 1 cell differentiation. Science 288, 2219-2222.

Li, R., Zhang, B., and Zheng, Y. (1997). Structural determinants required for the interaction between Rho GTPase and the GTPase-activating domain of p190. J Biol Chem 272, 3283032835 .

Li, R., and Zheng, Y. (1997). Residues of the Rho family GTPases Rho and Cdc42 that specify sensitivity to Dbl-like guanine nucleotide exchange factors. J Biol Chem 272, 4671-4679.

Li, S., Yamauchi, A., Marchal, C. C., Molitoris, J. K., Quilliam, L. A., and Dinauer, M. C. (2002a). Chemoattractant-stimulated Rac activation in wild-type and Rac2-deficient murine neutrophils: preferential activation of Rac2 and Rac2 gene dosage effect on neutrophil functions. J Immunol 169, 5043-5051.

Li, X., Bu, X., Lu, B., Avraham, H., Flavell, R. A., and Lim, B. (2002b). The hematopoiesisspecific GTP-binding protein RhoH is GTPase deficient and modulates activities of other Rho GTPases by an inhibitory function. Mol Cell Biol 22, 1158-1171.

Li, Z., Kim, S. H., Higgins, J. M., Brenner, M. B., and Sacks, D. B. (1999). IQGAP1 and calmodulin modulate E-cadherin function. J Biol Chem 274, 37885-37892.

Lin, R., Bagrodia, S., Cerione, R., and Manor, D. (1997). A novel Cdc42Hs mutant induces cellular transformation. Curr Biol 7, 794-797.

Lu, W., Katz, S., Gupta, R., and Mayer, B. J. (1997). Activation of Pak by membrane localization mediated by an SH3 domain from the adaptor protein Nck. Curr Biol 7, 85-94.

Luo, L. (2000). Rho GTPases in neuronal morphogenesis. Nat Rev Neurosci 1, 173-180. 
Luo, L., Liao, Y. J., Jan, L. Y., and Jan, Y. N. (1994). Distinct morphogenetic functions of similar small GTPases: Drosophila Drac1 is involved in axonal outgrowth and myoblast fusion. Genes Dev 8, 1787-1802.

Machesky, L. M., and Insall, R. H. (1998). Scar1 and the related Wiskott-Aldrich syndrome protein, WASP, regulate the actin cytoskeleton through the Arp2/3 complex. Curr Biol 8, 13471356.

Machesky, L. M., Mullins, R. D., Higgs, H. N., Kaiser, D. A., Blanchoin, L., May, R. C., Hall, M. E., and Pollard, T. D. (1999). Scar, a WASp-related protein, activates nucleation of actin filaments by the Arp2/3 complex. Proc Natl Acad Sci U S A 96, 3739-3744.

Machesky, L. M., Reeves, E., Wientjes, F., Mattheyse, F. J., Grogan, A., Totty, N. F., Burlingame, A. L., Hsuan, J. J., and Segal, A. W. (1997). Mammalian actin-related protein 2/3 complex localizes to regions of lamellipodial protrusion and is composed of evolutionarily conserved proteins. Biochem J 328 ( Pt 1), 105-112.

Maeda, M., Matsui, T., Imamura, M., Tsukita, S., and Tsukita, S. (1999). Expression level, subcellular distribution and rho-GDI binding affinity of merlin in comparison with Ezrin/Radixin/Moesin proteins. Oncogene 18, 4788-4797.

Manser, E., Loo, T. H., Koh, C. G., Zhao, Z. S., Chen, X. Q., Tan, L., Tan, I., Leung, T., and Lim, L. (1998). PAK kinases are directly coupled to the PIX family of nucleotide exchange factors. Mol Cell 1, 183-192.

Maruta, H., He, H., and Nheu, T. (2002). Interfering with Ras signaling using membranepermeable peptides or drugs. Methods Mol Biol 189, 75-85.

Massol, P., Montcourrier, P., Guillemot, J. C., and Chavrier, P. (1998). Fc receptor-mediated phagocytosis requires CDC42 and Rac1. Embo J 17, 6219-6229.

Mateer, S. C., McDaniel, A. E., Nicolas, V., Habermacher, G. M., Lin, M. J., Cromer, D. A., King, M. E., and Bloom, G. S. (2002). The mechanism for regulation of the F-actin binding activity of IQGAP1 by calcium/calmodulin. J Biol Chem 277, 12324-12333.

Matos, P., Collard, J. G., and Jordan, P. (2003). Tumor-related alternatively spliced Rac1b is not regulated by Rho-GDP dissociation inhibitors and exhibits selective downstream signaling. $J$ Biol Chem 278, 50442-50448. 
Matsuda, A., Suzuki, Y., Honda, G., Muramatsu, S., Matsuzaki, O., Nagano, Y., Doi, T., Shimotohno, K., Harada, T., Nishida, E., et al. (2003). Large-scale identification and characterization of human genes that activate NF-kappaB and MAPK signaling pathways. Oncogene 22, 3307-3318.

Matsuda, C., Kameyama, K., Suzuki, A., Mishima, W., Yamaji, S., Okamoto, H., Nishino, I., and Hayashi, Y. K. (2008). Affixin activates Rac1 via betaPIX in C2C12 myoblast. FEBS Lett 582, 1189-1196.

May, R. C., Caron, E., Hall, A., and Machesky, L. M. (2000). Involvement of the Arp $2 / 3$ complex in phagocytosis mediated by FcgammaR or CR3. Nat Cell Biol 2, 246-248.

McCarty, O. J., Larson, M. K., Auger, J. M., Kalia, N., Atkinson, B. T., Pearce, A. C., Ruf, S., Henderson, R. B., Tybulewicz, V. L., Machesky, L. M., and Watson, S. P. (2005). Rac1 is essential for platelet lamellipodia formation and aggregate stability under flow. J Biol Chem 280, 39474-39484.

Mehta, D., Rahman, A., and Malik, A. B. (2001). Protein kinase C-alpha signals rho-guanine nucleotide dissociation inhibitor phosphorylation and rho activation and regulates the endothelial cell barrier function. J Biol Chem 276, 22614-22620.

Menna, P. L., Skilton, G., Leskow, F. C., Alonso, D. F., Gomez, D. E., and Kazanietz, M. G. (2003). Inhibition of aggressiveness of metastatic mouse mammary carcinoma cells by the beta2-chimaerin GAP domain. Cancer Res 63, 2284-2291.

Mettouchi, A., Klein, S., Guo, W., Lopez-Lago, M., Lemichez, E., Westwick, J. K., and Giancotti, F. G. (2001). Integrin-specific activation of Rac controls progression through the G(1) phase of the cell cycle. Mol Cell 8, 115-127.

Michaelson, D., Silletti, J., Murphy, G., D'Eustachio, P., Rush, M., and Philips, M. R. (2001). Differential localization of Rho GTPases in live cells: regulation by hypervariable regions and RhoGDI binding. J Cell Biol 152, 111-126.

Miki, H., Suetsugu, S., and Takenawa, T. (1998). WAVE, a novel WASP-family protein involved in actin reorganization induced by Rac. Embo J 17, 6932-6941. 
Miki, H., Yamaguchi, H., Suetsugu, S., and Takenawa, T. (2000). IRSp53 is an essential intermediate between Rac and WAVE in the regulation of membrane ruffling. Nature 408, $732-$ 735 .

Minden, A., Lin, A., Claret, F. X., Abo, A., and Karin, M. (1995). Selective activation of the JNK signaling cascade and c-Jun transcriptional activity by the small GTPases Rac and Cdc42Hs. Cell 81, 1147-1157.

Miyashita, M., Ohnishi, H., Okazawa, H., Tomonaga, H., Hayashi, A., Fujimoto, T. T., Furuya, N., and Matozaki, T. (2004). Promotion of neurite and filopodium formation by CD47: roles of integrins, Rac, and Cdc42. Mol Biol Cell 15, 3950-3963.

Mizuno, T., Kaibuchi, K., Yamamoto, T., Kawamura, M., Sakoda, T., Fujioka, H., Matsuura, Y., and Takai, Y. (1991). A stimulatory GDP/GTP exchange protein for smg p21 is active on the post-translationally processed form of c-Ki-ras p21 and rhoA p21. Proc Natl Acad Sci U S A 88, 6442-6446.

Moon, S. Y., and Zheng, Y. (2003). Rho GTPase-activating proteins in cell regulation. Trends Cell Biol 13, 13-22.

Motohashi, T., Miyoshi, S., Osawa, M., Eyre, H. J., Sutherland, G. R., Matsuda, Y., Nakamura, Y., Shibuya, A., Iwama, A., and Nakauchi, H. (2000). Molecular cloning and chromosomal mapping of a novel five-span transmembrane protein gene, M83. Biochem Biophys Res Commun 276, 244-250.

Mueller, P., Massner, J., Jayachandran, R., Combaluzier, B., Albrecht, I., Gatfield, J., Blum, C., Ceredig, R., Rodewald, H. R., Rolink, A. G., and Pieters, J. (2008). Regulation of T cell survival through coronin-1-mediated generation of inositol-1,4,5-trisphosphate and calcium mobilization after T cell receptor triggering. Nat Immunol 9, 424-431.

Mugnier, B., Nal, B., Verthuy, C., Boyer, C., Lam, D., Chasson, L., Nieoullon, V., Chazal, G., Guo, X. J., He, H. T., et al. (2008). Coronin-1A links cytoskeleton dynamics to TCR alpha beta-induced cell signaling. PLoS One 3, e3467.

Muramatsu, T., and Miyauchi, T. (2003). Basigin (CD147): a multifunctional transmembrane protein involved in reproduction, neural function, inflammation and tumor invasion. Histol Histopathol 18, 981-987. 
Murga, C., Zohar, M., Teramoto, H., and Gutkind, J. S. (2002). Rac1 and RhoG promote cell survival by the activation of PI3K and Akt, independently of their ability to stimulate JNK and NFkappaB. Oncogene 21, 207-216.

Murphy, C., Saffrich, R., Grummt, M., Gournier, H., Rybin, V., Rubino, M., Auvinen, P., Lutcke, A., Parton, R. G., and Zerial, M. (1996). Endosome dynamics regulated by a Rho protein. Nature 384, 427-432.

Nabeshima, K., Iwasaki, H., Koga, K., Hojo, H., Suzumiya, J., and Kikuchi, M. (2006). Emmprin (basigin/CD147): matrix metalloproteinase modulator and multifunctional cell recognition molecule that plays a critical role in cancer progression. Pathol Int 56, 359-367.

Nakaya, M., Kitano, M., Matsuda, M., and Nagata, S. (2008). Spatiotemporal activation of Rac1 for engulfment of apoptotic cells. Proc Natl Acad Sci U S A 105, 9198-9203.

Ng, J., Nardine, T., Harms, M., Tzu, J., Goldstein, A., Sun, Y., Dietzl, G., Dickson, B. J., and Luo, L. (2002). Rac GTPases control axon growth, guidance and branching. Nature 416, 442447.

Nimnual, A. S., Yatsula, B. A., and Bar-Sagi, D. (1998). Coupling of Ras and Rac guanosine triphosphatases through the Ras exchanger Sos. Science 279, 560-563.

Niwa, R., Nagata-Ohashi, K., Takeichi, M., Mizuno, K., and Uemura, T. (2002). Control of actin reorganization by Slingshot, a family of phosphatases that dephosphorylate ADF/cofilin. Cell 108, 233-246.

Nobes, C. D., and Hall, A. (1995). Rho, rac, and cdc42 GTPases regulate the assembly of multimolecular focal complexes associated with actin stress fibers, lamellipodia, and filopodia. Cell 81, 53-62.

Nobes, C. D., and Hall, A. (1999). Rho GTPases control polarity, protrusion, and adhesion during cell movement. J Cell Biol 144, 1235-1244.

Nojima, H., Adachi, M., Matsui, T., Okawa, K., Tsukita, S., and Tsukita, S. (2008). IQGAP3 regulates cell proliferation through the Ras/ERK signalling cascade. Nat Cell Biol 10, 971-978. 
Oku, T., Itoh, S., Okano, M., Suzuki, A., Suzuki, K., Nakajin, S., Tsuji, T., Nauseef, W. M., and Toyoshima, S. (2003). Two regions responsible for the actin binding of p57, a mammalian coronin family actin-binding protein. Biol Pharm Bull 26, 409-416.

Olofsson, B. (1999). Rho guanine dissociation inhibitors: pivotal molecules in cellular signalling. Cell Signal 11, 545-554.

Ozdinler, P. H., and Erzurumlu, R. S. (2001). Regulation of neurotrophin-induced axonal responses via Rho GTPases. J Comp Neurol 438, 377-387.

Palamidessi, A., Frittoli, E., Garre, M., Faretta, M., Mione, M., Testa, I., Diaspro, A., Lanzetti, L., Scita, G., and Di Fiore, P. P. (2008). Endocytic trafficking of Rac is required for the spatial restriction of signaling in cell migration. Cell 134, 135-147.

Paterson, H. F., Self, A. J., Garrett, M. D., Just, I., Aktories, K., and Hall, A. (1990). Microinjection of recombinant p21rho induces rapid changes in cell morphology. J Cell Biol 111, 1001-1007.

Peng, S., Fan, S., Li, X., Wang, L., Liu, H., Zhou, M., Wang, L., Shen, S., and Li, G. (2007). The expression of ezrin in NPC and its interaction with NGX6, a novel candidate suppressor. Cancer Sci 98, 341-349.

Pestonjamasp, K. N., Forster, C., Sun, C., Gardiner, E. M., Bohl, B., Weiner, O., Bokoch, G. M., and Glogauer, M. (2006). Rac1 links leading edge and uropod events through Rho and myosin activation during chemotaxis. Blood 108, 2814-2820.

Pop, M., Aktories, K., and Schmidt, G. (2004). Isotype-specific degradation of Rac activated by the cytotoxic necrotizing factor 1. J Biol Chem 279, 35840-35848.

Post, P. L., Bokoch, G. M., and Mooseker, M. S. (1998). Human myosin-IXb is a mechanochemically active motor and a GAP for rho. J Cell Sci 111 (Pt 7), 941-950.

Preudhomme, C., Roumier, C., Hildebrand, M. P., Dallery-Prudhomme, E., Lantoine, D., Lai, J. L., Daudignon, A., Adenis, C., Bauters, F., Fenaux, P., et al. (2000). Nonrandom 4p13 rearrangements of the RhoH/TTF gene, encoding a GTP-binding protein, in non-Hodgkin's lymphoma and multiple myeloma. Oncogene 19, 2023-2032. 
Price, L. S., Langeslag, M., ten Klooster, J. P., Hordijk, P. L., Jalink, K., and Collard, J. G. (2003). Calcium signaling regulates translocation and activation of Rac. J Biol Chem 278 , 39413-39421.

Prieto-Sanchez, R. M., Berenjeno, I. M., and Bustelo, X. R. (2006). Involvement of the Rho/Rac family member RhoG in caveolar endocytosis. Oncogene 25, 2961-2973.

Puceat, M., Travo, P., Quinn, M. T., and Fort, P. (2003). A dual role of the GTPase Rac in cardiac differentiation of stem cells. Mol Biol Cell 14, 2781-2792.

Qualmann, B., and Mellor, H. (2003). Regulation of endocytic traffic by Rho GTPases. Biochem J 371, 233-241.

Ridley, A. J., and Hall, A. (1992). The small GTP-binding protein rho regulates the assembly of focal adhesions and actin stress fibers in response to growth factors. Cell 70, 389-399.

Ridley, A. J., Paterson, H. F., Johnston, C. L., Diekmann, D., and Hall, A. (1992). The small GTP-binding protein rac regulates growth factor-induced membrane ruffling. Cell 70, 401-410.

Riedl, J., Crevenna, A. H., Kessenbrock, K., Yu, J. H., Neukirchen, D., Bista, M., Bradke, F., Jenne, D., Holak, T. A., Werb, Z., et al. (2008). Lifeact: a versatile marker to visualize Factin. Nat Methods 5, 605-607.

Rivas, F. V., O'Keefe, J. P., Alegre, M. L., and Gajewski, T. F. (2004). Actin cytoskeleton regulates calcium dynamics and NFAT nuclear duration. Mol Cell Biol 24, 1628-1639.

Rivero, F., Dislich, H., Glockner, G., and Noegel, A. A. (2001). The Dictyostelium discoideum family of Rho-related proteins. Nucleic Acids Res 29, 1068-1079.

Roberts, A. W., Kim, C., Zhen, L., Lowe, J. B., Kapur, R., Petryniak, B., Spaetti, A., Pollock, J. D., Borneo, J. B., Bradford, G. B., et al. (1999). Deficiency of the hematopoietic cell-specific Rho family GTPase Rac2 is characterized by abnormalities in neutrophil function and host defense. Immunity 10, 183-196.

Rosenberger, G., and Kutsche, K. (2006). AlphaPIX and betaPIX and their role in focal adhesion formation. Eur J Cell Biol 85, 265-274. 
Rossman, K. L., Der, C. J., and Sondek, J. (2005). GEF means go: turning on RHO GTPases with guanine nucleotide-exchange factors. Nat Rev Mol Cell Biol 6, 167-180.

Rybakin, V., and Clemen, C. S. (2005). Coronin proteins as multifunctional regulators of the cytoskeleton and membrane trafficking. Bioessays 27, 625-632.

Sahai, E., and Marshall, C. J. (2002). RHO-GTPases and cancer. Nat Rev Cancer 2, 133-142.

Sandrock, K., Bielek, H., Schradi, K., Schmidt, G., and Klugbauer, N. The nuclear import of the small GTPase Rac1 is mediated by the direct interaction with karyopherin alpha2. Traffic 11, 198-209.

Sapir, T., Elbaum, M., and Reiner, O. (1997). Reduction of microtubule catastrophe events by LIS1, platelet-activating factor acetylhydrolase subunit. Embo J 16, 6977-6984.

Scheffzek, K., Stephan, I., Jensen, O. N., Illenberger, D., and Gierschik, P. (2000). The RacRhoGDI complex and the structural basis for the regulation of Rho proteins by RhoGDI. Nat Struct Biol 7, 122-126.

Schiller, M. R., Blangy, A., Huang, J., Mains, R. E., and Eipper, B. A. (2005). Induction of lamellipodia by Kalirin does not require its guanine nucleotide exchange factor activity. Exp Cell Res 307, 402-417.

Schliwa, M. (1982). Action of cytochalasin D on cytoskeletal networks. J Cell Biol 92, 79-91.

Schmidt, A., and Hall, A. (2002). Guanine nucleotide exchange factors for Rho GTPases: turning on the switch. Genes Dev 16, 1587-1609.

Schmidt, V. A., Scudder, L., Devoe, C. E., Bernards, A., Cupit, L. D., and Bahou, W. F. (2003). IQGAP2 functions as a GTP-dependent effector protein in thrombin-induced platelet cytoskeletal reorganization. Blood 101, 3021-3028.

Schnelzer, A., Prechtel, D., Knaus, U., Dehne, K., Gerhard, M., Graeff, H., Harbeck, N., Schmitt, M., and Lengyel, E. (2000). Rac1 in human breast cancer: overexpression, mutation analysis, and characterization of a new isoform, Rac1b. Oncogene 19, 3013-3020.

Schobel, S., Neumann, S., Seed, B., and Lichtenthaler, S. F. (2006). Expression cloning screen for modifiers of amyloid precursor protein shedding. Int J Dev Neurosci 24, 141-148. 
Schuebel, K. E., Movilla, N., Rosa, J. L., and Bustelo, X. R. (1998). Phosphorylationdependent and constitutive activation of Rho proteins by wild-type and oncogenic Vav-2. Embo J 17, 6608-6621.

Schwab, W., Harada, H., Goetz, W., Nowicki, M., Witt, M., Kasper, M., and Barth, K. (2007). Immunocytochemical and biochemical detection of EMMPRIN in the rat tooth germ: differentiation-dependent co-expression with MMPs and co-localization with caveolin-1 in membrane rafts of dental epithelial cells. Histochem Cell Biol 128, 195-203.

Sehr, P., Joseph, G., Genth, H., Just, I., Pick, E., and Aktories, K. (1998). Glucosylation and ADP ribosylation of rho proteins: effects on nucleotide binding, GTPase activity, and effector coupling. Biochemistry 37, 5296-5304.

Sells, M. A., Knaus, U. G., Bagrodia, S., Ambrose, D. M., Bokoch, G. M., and Chernoff, J. (1997). Human p21-activated kinase (Pak1) regulates actin organization in mammalian cells. Curr Biol 7, 202-210.

Settleman, J. (2001). Rac ' $n$ Rho: the music that shapes a developing embryo. Dev Cell 1, 321331.

Shin, E. Y., Lee, C. S., Cho, T. G., Kim, Y. G., Song, S., Juhnn, Y. S., Park, S. C., Manser, E., and Kim, E. G. (2006). betaPak-interacting exchange factor-mediated Rac1 activation requires smgGDS guanine nucleotide exchange factor in basic fibroblast growth factor-induced neurite outgrowth. J Biol Chem 281, 35954-35964.

Shin, E. Y., Woo, K. N., Lee, C. S., Koo, S. H., Kim, Y. G., Kim, W. J., Bae, C. D., Chang, S. I., and Kim, E. G. (2004). Basic fibroblast growth factor stimulates activation of Rac1 through a p85 betaPIX phosphorylation-dependent pathway. J Biol Chem 279, 1994-2004.

Shinohara, M., Terada, Y., Iwamatsu, A., Shinohara, A., Mochizuki, N., Higuchi, M., Gotoh, Y., Ihara, S., Nagata, S., Itoh, H., et al. (2002). SWAP-70 is a guanine-nucleotide-exchange factor that mediates signalling of membrane ruffling. Nature 416, 759-763.

Shiow, L. R., Paris, K., Akana, M. C., Cyster, J. G., Sorensen, R. U., and Puck, J. M. (2009). Severe combined immunodeficiency (SCID) and attention deficit hyperactivity disorder (ADHD) associated with a Coronin-1A mutation and a chromosome 16p11.2 deletion. Clin Immunol 131, 24-30. 
Shiow, L. R., Roadcap, D. W., Paris, K., Watson, S. R., Grigorova, I. L., Lebet, T., An, J., Xu, Y., Jenne, C. N., Foger, N., et al. (2008). The actin regulator coronin $1 \mathrm{~A}$ is mutant in a thymic egress-deficient mouse strain and in a patient with severe combined immunodeficiency. Nat Immunol 9, 1307-1315.

Simons, K., and Toomre, D. (2000). Lipid rafts and signal transduction. Nat Rev Mol Cell Biol 1, 31-39.

Sotiropoulos, A., Gineitis, D., Copeland, J., and Treisman, R. (1999). Signal-regulated activation of serum response factor is mediated by changes in actin dynamics. Cell 98, 159-169.

Stanyon, C. A., and Bernard, O. (1999). LIM-kinase1. Int J Biochem Cell Biol 31, 389-394.

Stebbins, C. E., and Galan, J. E. (2001). Structural mimicry in bacterial virulence. Nature $\mathbf{4 1 2}$, 701-705.

Steffen, A., Rottner, K., Ehinger, J., Innocenti, M., Scita, G., Wehland, J., and Stradal, T. E. (2004). Sra-1 and Nap1 link Rac to actin assembly driving lamellipodia formation. Embo J 23, 749-759.

Sugihara, K., Nakatsuji, N., Nakamura, K., Nakao, K., Hashimoto, R., Otani, H., Sakagami, H., Kondo, H., Nozawa, S., Aiba, A., and Katsuki, M. (1998). Rac1 is required for the formation of three germ layers during gastrulation. Oncogene 17, 3427-3433.

Sun, C. X., Downey, G. P., Zhu, F., Koh, A. L., Thang, H., and Glogauer, M. (2004). Rac1 is the small GTPase responsible for regulating the neutrophil chemotaxis compass. Blood 104, 3758-3765.

Symons, M., and Rusk, N. (2003). Control of vesicular trafficking by Rho GTPases. Curr Biol 13, R409-418.

Symons, M., and Settleman, J. (2000). Rho family GTPases: more than simple switches. Trends Cell Biol 10, 415-419.

Takahashi, K., Sasaki, T., Mammoto, A., Hotta, I., Takaishi, K., Imamura, H., Nakano, K., Kodama, A., and Takai, Y. (1998). Interaction of radixin with Rho small G protein GDP/GTP exchange protein Dbl. Oncogene 16, 3279-3284. 
Takahashi, K., Sasaki, T., Mammoto, A., Takaishi, K., Kameyama, T., Tsukita, S., and Takai, Y. (1997). Direct interaction of the Rho GDP dissociation inhibitor with ezrin/radixin/moesin initiates the activation of the Rho small G protein. J Biol Chem 272, 2337123375.

Tang, W., Chang, S. B., and Hemler, M. E. (2004). Links between CD147 function, glycosylation, and caveolin-1. Mol Biol Cell 15, 4043-4050.

Tang, W., and Hemler, M. E. (2004). Caveolin-1 regulates matrix metalloproteinases-1 induction and CD147/EMMPRIN cell surface clustering. J Biol Chem 279, 11112-11118.

Ten Klooster, J. P., Evers, E. E., Janssen, L., Machesky, L. M., Michiels, F., Hordijk, P., and Collard, J. G. (2006a). Interaction between Tiam1 and the Arp2/3 complex links activation of Rac to actin polymerization. Biochem J 397, 39-45.

ten Klooster, J. P., Jaffer, Z. M., Chernoff, J., and Hordijk, P. L. (2006b). Targeting and activation of Rac1 are mediated by the exchange factor beta-Pix. J Cell Biol 172, 759-769.

Teodorof, C., Bae, J. I., Kim, S. M., Oh, H. J., Kang, Y. S., Choi, J., Chun, J. S., and Song, W. K. (2009). SPIN90-IRSp53 complex participates in Rac-induced membrane ruffling. Exp Cell Res 315, 2410-2419.

Teramoto, H., Coso, O. A., Miyata, H., Igishi, T., Miki, T., and Gutkind, J. S. (1996). Signaling from the small GTP-binding proteins Rac1 and Cdc42 to the c-Jun N-terminal kinase/stress-activated protein kinase pathway. A role for mixed lineage kinase 3/proteintyrosine kinase 1, a novel member of the mixed lineage kinase family. J Biol Chem 271, 2722527228.

Teramoto, H., Malek, R. L., Behbahani, B., Castellone, M. D., Lee, N. H., and Gutkind, J. S. (2003). Identification of H-Ras, RhoA, Rac1 and Cdc42 responsive genes. Oncogene 22, 26892697.

Thurnherr, T., Benninger, Y., Wu, X., Chrostek, A., Krause, S. M., Nave, K. A., Franklin, R. J., Brakebusch, C., Suter, U., and Relvas, J. B. (2006). Cdc42 and Rac1 signaling are both required for and act synergistically in the correct formation of myelin sheaths in the CNS. $J$ Neurosci 26, 10110-10119. 
Ting, A., Lichtenthaler, S., Xavier, R., Na, S. Y., Rabizadeh, S., Holmes, T., and Seed, B. (2005). Large-scale screens for cDNAs with in vivo activity. Novartis Found Symp 267, 219-229; discussion 229-230.

Tolias, K., and Carpenter, C. L. (2000). In vitro interaction of phosphoinositide-4-phosphate 5kinases with Rac. Methods Enzymol 325, 190-200.

Tolias, K. F., Couvillon, A. D., Cantley, L. C., and Carpenter, C. L. (1998). Characterization of a Rac1- and RhoGDI-associated lipid kinase signaling complex. Mol Cell Biol 18, 762-770.

Tolias, K. F., Hartwig, J. H., Ishihara, H., Shibasaki, Y., Cantley, L. C., and Carpenter, C. L. (2000). Type lalpha phosphatidylinositol-4-phosphate 5-kinase mediates Rac-dependent actin assembly. Curr Biol 10, 153-156.

Toullec, D., Pianetti, P., Coste, H., Bellevergue, P., Grand-Perret, T., Ajakane, M., Baudet, V., Boissin, P., Boursier, E., Loriolle, F., and et al. (1991). The bisindolylmaleimide GF 109203X is a potent and selective inhibitor of protein kinase C. J Biol Chem 266, 15771-15781.

Tranter, M. P., Sugrue, S. P., and Schwartz, M. A. (1991). Binding of actin to liver cell membranes: the state of membrane-bound actin. J Cell Biol 112, 891-901.

Turner, M., and Billadeau, D. D. (2002). VAV proteins as signal integrators for multi-subunit immune-recognition receptors. Nat Rev Immunol 2, 476-486.

Uetrecht, A. C., and Bear, J. E. (2006). Coronins: the return of the crown. Trends Cell Biol 16, 421-426.

Ueyama, T., Eto, M., Kami, K., Tatsuno, T., Kobayashi, T., Shirai, Y., Lennartz, M. R., Takeya, R., Sumimoto, H., and Saito, N. (2005). Isoform-specific membrane targeting mechanism of Rac during Fc gamma R-mediated phagocytosis: positive charge-dependent and independent targeting mechanism of Rac to the phagosome. J Immunol 175, 2381-2390.

Ugolev, Y., Berdichevsky, Y., Weinbaum, C., and Pick, E. (2008). Dissociation of Rac1(GDP).RhoGDI complexes by the cooperative action of anionic liposomes containing phosphatidylinositol 3,4,5-trisphosphate, Rac guanine nucleotide exchange factor, and GTP. J Biol Chem 283, 22257-22271. 
Ugolev, Y., Molshanski-Mor, S., Weinbaum, C., and Pick, E. (2006). Liposomes comprising anionic but not neutral phospholipids cause dissociation of Rac(1 or 2) x RhoGDI complexes and support amphiphile-independent NADPH oxidase activation by such complexes. $\mathrm{J}$ Biol Chem 281, 19204-19219.

Valencia, A., Chardin, P., Wittinghofer, A., and Sander, C. (1991). The ras protein family: evolutionary tree and role of conserved amino acids. Biochemistry 30, 4637-4648.

Van Aelst, L., and D'Souza-Schorey, C. (1997). Rho GTPases and signaling networks. Genes Dev 11, 2295-2322.

Van Aelst, L., Joneson, T., and Bar-Sagi, D. (1996). Identification of a novel Rac1-interacting protein involved in membrane ruffling. Embo J 15, 3778-3786.

Vetter, I. R., and Wittinghofer, A. (2001). The guanine nucleotide-binding switch in three dimensions. Science 294, 1299-1304.

Vigorito, E., Bell, S., Hebeis, B. J., Reynolds, H., McAdam, S., Emson, P. C., McKenzie, A., and Turner, M. (2004). Immunological function in mice lacking the Rac-related GTPase RhoG. Mol Cell Biol 24, 719-729.

Vigorito, E., Billadeu, D. D., Savoy, D., McAdam, S., Doody, G., Fort, P., and Turner, M. (2003). RhoG regulates gene expression and the actin cytoskeleton in lymphocytes. Oncogene 22, 330-342.

Villa, P., Kaufmann, S. H., and Earnshaw, W. C. (1997). Caspases and caspase inhibitors. Trends Biochem Sci 22, 388-393.

Villalba, M., Bi, K., Rodriguez, F., Tanaka, Y., Schoenberger, S., and Altman, A. (2001). Vav1/Rac-dependent actin cytoskeleton reorganization is required for lipid raft clustering in $T$ cells. J Cell Biol 155, 331-338.

Villalba, M., Coudronniere, N., Deckert, M., Teixeiro, E., Mas, P., and Altman, A. (2000). A novel functional interaction between Vav and PKCtheta is required for TCR-induced $T$ cell activation. Immunity 12, 151-160.

Vincent, S., Jeanteur, P., and Fort, P. (1992). Growth-regulated expression of rhoG, a new member of the ras homolog gene family. Mol Cell Biol 12, 3138-3148. 
Wang, S., Watanabe, T., Noritake, J., Fukata, M., Yoshimura, T., Itoh, N., Harada, T., Nakagawa, M., Matsuura, Y., Arimura, N., and Kaibuchi, K. (2007). IQGAP3, a novel effector of Rac1 and Cdc42, regulates neurite outgrowth. J Cell Sci 120, 567-577.

Wang, X. Q., and Frazier, W. A. (1998). The thrombospondin receptor CD47 (IAP) modulates and associates with alpha2 beta1 integrin in vascular smooth muscle cells. Mol Biol Cell 9, 865874.

Wang, X. Q., Lindberg, F. P., and Frazier, W. A. (1999). Integrin-associated protein stimulates alpha2beta1-dependent chemotaxis via Gi-mediated inhibition of adenylate cyclase and extracellular-regulated kinases. J Cell Biol 147, 389-400.

Webb, B. A., Eves, R., Crawley, S. W., Zhou, S., Cote, G. P., and Mak, A. S. (2005). PAK1 induces podosome formation in A7r5 vascular smooth muscle cells in a PAK-interacting exchange factor-dependent manner. Am J Physiol Cell Physiol 289, C898-907.

Weed, S. A., and Parsons, J. T. (2001). Cortactin: coupling membrane dynamics to cortical actin assembly. Oncogene 20, 6418-6434.

Wehland, J., Osborn, M., and Weber, K. (1980). Phalloidin associates with microfilaments after microinjection into tissue culture cells. Eur J Cell Biol 21, 188-194.

Welch, H. C., Coadwell, W. J., Ellson, C. D., Ferguson, G. J., Andrews, S. R., ErdjumentBromage, H., Tempst, P., Hawkins, P. T., and Stephens, L. R. (2002). P-Rex1, a Ptdlns $(3,4,5) \mathrm{P} 3-$ and Gbetagamma-regulated guanine-nucleotide exchange factor for Rac. Cell $108,809-821$.

Wells, C. M., Walmsley, M., Ooi, S., Tybulewicz, V., and Ridley, A. J. (2004). Rac1-deficient macrophages exhibit defects in cell spreading and membrane ruffling but not migration. $J$ Cell Sci 117, 1259-1268.

Wennerberg, K., and Der, C. J. (2004). Rho-family GTPases: it's not only Rac and Rho (and I like it). J Cell Sci 117, 1301-1312.

Werner, E. (2004). GTPases and reactive oxygen species: switches for killing and signaling. J Cell Sci 117, 143-153. 
Williams, D. A., Tao, W., Yang, F., Kim, C., Gu, Y., Mansfield, P., Levine, J. E., Petryniak, B., Derrow, C. W., Harris, C., et al. (2000). Dominant negative mutation of the hematopoieticspecific Rho GTPase, Rac2, is associated with a human phagocyte immunodeficiency. Blood 96, 1646-1654.

Xia, C., Ma, W., Stafford, L. J., Marcus, S., Xiong, W. C., and Liu, M. (2001). Regulation of the p21-activated kinase (PAK) by a human Gbeta -like WD-repeat protein, hPIP1. Proc Natl Acad Sci U S A 98, 6174-6179.

Xu, D., and Hemler, M. E. (2005). Metabolic activation-related CD147-CD98 complex. Mol Cell Proteomics 4, 1061-1071.

Yamashita, T., and Tohyama, M. (2003). The p75 receptor acts as a displacement factor that releases Rho from Rho-GDI. Nat Neurosci 6, 461-467.

Yamauchi, A., Kim, C., Li, S., Marchal, C. C., Towe, J., Atkinson, S. J., and Dinauer, M. C. (2004). Rac2-deficient murine macrophages have selective defects in superoxide production and phagocytosis of opsonized particles. J Immunol 173, 5971-5979.

Yan, L., Zucker, S., and Toole, B. P. (2005). Roles of the multifunctional glycoprotein, emmprin (basigin; CD147), in tumour progression. Thromb Haemost 93, 199-204.

Yang, C., and Kazanietz, M. G. (2003). Divergence and complexities in DAG signaling: looking beyond PKC. Trends Pharmacol Sci 24, 602-608.

Yang, H. S., and Hinds, P. W. (2006). Phosphorylation of ezrin by cyclin-dependent kinase 5 induces the release of Rho GDP dissociation inhibitor to inhibit Rac1 activity in senescent cells. Cancer Res 66, 2708-2715.

Yeung, T., Gilbert, G. E., Shi, J., Silvius, J., Kapus, A., and Grinstein, S. (2008). Membrane phosphatidylserine regulates surface charge and protein localization. Science 319, 210-213.

Yoshii, S., Tanaka, M., Otsuki, Y., Wang, D. Y., Guo, R. J., Zhu, Y., Takeda, R., Hanai, H., Kaneko, E., and Sugimura, H. (1999). alphaPIX nucleotide exchange factor is activated by interaction with phosphatidylinositol 3-kinase. Oncogene 18, 5680-5690.

Yu, H., Leitenberg, D., Li, B., and Flavell, R. A. (2001). Deficiency of small GTPase Rac2 affects T cell activation. J Exp Med 194, 915-926. 
Yu, J. S., Chen, W. J., Ni, M. H., Chan, W. H., and Yang, S. D. (1998). Identification of the regulatory autophosphorylation site of autophosphorylation-dependent protein kinase (autokinase). Evidence that auto-kinase belongs to a member of the p21-activated kinase family. Biochem J 334 ( Pt 1), 121-131.

Yuan, S., Miller, D. W., Barnett, G. H., Hahn, J. F., and Williams, B. R. (1995). Identification and characterization of human beta 2-chimaerin: association with malignant transformation in astrocytoma. Cancer Res 55, 3456-3461.

Zalcman, G., Closson, V., Camonis, J., Honore, N., Rousseau-Merck, M. F., Tavitian, A., and Olofsson, B. (1996). RhoGDI-3 is a new GDP dissociation inhibitor (GDI). Identification of a non-cytosolic GDI protein interacting with the small GTP-binding proteins RhoB and RhoG. $J$ Biol Chem 271, 30366-30374.

Zebda, N., Bernard, O., Bailly, M., Welti, S., Lawrence, D. S., and Condeelis, J. S. (2000). Phosphorylation of ADF/cofilin abolishes EGF-induced actin nucleation at the leading edge and subsequent lamellipod extension. J Cell Biol 151, 1119-1128.

Zenke, F. T., King, C. C., Bohl, B. P., and Bokoch, G. M. (1999). Identification of a central phosphorylation site in p21-activated kinase regulating autoinhibition and kinase activity. J Biol Chem 274, 32565-32573.

Zhang, B., Zhang, Y., Wang, Z., and Zheng, Y. (2000). The role of Mg2+ cofactor in the guanine nucleotide exchange and GTP hydrolysis reactions of Rho family GTP-binding proteins. J Biol Chem 275, 25299-25307.

Zhang, J., Guo, J., Dzhagalov, I., and He, Y. W. (2005). An essential function for the calciumpromoted Ras inactivator in Fcgamma receptor-mediated phagocytosis. Nat Immunol 6, 911919.

Zhao, J., Liu, Y., Wei, X., Yuan, C., Yuan, X., and Xiao, X. (2009). A novel WD-40 repeat protein WDR26 suppresses H2O2-induced cell death in neural cells. Neurosci Lett 460, 66-71.

Zhao, L., Ma, Q. L., Calon, F., Harris-White, M. E., Yang, F., Lim, G. P., Morihara, T., Ubeda, O. J., Ambegaokar, S., Hansen, J. E., et al. (2006). Role of p21-activated kinase pathway defects in the cognitive deficits of Alzheimer disease. Nat Neurosci 9, 234-242. 
Zhu, Y., Wang, Y., Xia, C., Li, D., Li, Y., Zeng, W., Yuan, W., Liu, H., Zhu, C., Wu, X., and Liu, M. (2004). WDR26: a novel Gbeta-like protein, suppresses MAPK signaling pathway. J Cell Biochem 93, 579-587. 




\section{ÍNDICE DE FIGURAS}

Figura 1. Estructura terciaria de las GTPasas de la superfamilia Ras $\quad 4$

Figura 2. La familia de proteínas Rho/Rac $\quad 5$

Figura 3. Efectores implicados en las reorganizaciones del citoesqueleto de actina inducidas Rac1

Figura 4. Participación de la ruta Rac1/Cdc42/Paks en las reorganizaciones del citoesqueleto..

Figura 5. Mecanismo de activación/desactivación de las GTPasas Rho/Rac

Figura 6. Estructura por dominios de las principales familias de proteínas GEF para Rac1

Figura 7. Modelo para la liberación de proteínas Rho/Rac a la membrana plasmática desde los complejos citosólicos RhoGDI-GTPasa

Figura 8. Esquema del clonaje por expresión realizado en este estudio

Figura 9. Aislamiento y corroboración de algunos clones aislados tras el rastreo celómico secundario

Figura 10. Esquema de la selección de los candidatos putativos aislados tras el rastreo celómico inicial

Figura 11. Validación de los clones aislados en el rastreo celómico usando la línea celular $\cos 1$

Figura 12. Estructura por dominios de las moléculas seleccionadas con capacidad translocadora de la proteína reportera EGFP-Rac1

Figura 13. Coronina-1A transloca a las GTPasas Rac1 y RhoG a la membrana plasmática.. 64

Figura 14. Coronina-1A no transloca a las GTPasas Cdc42 y RhoA a la membrana plasmática.

Figura 15. Coronina-1A transloca a Rac1 a la membrana de una forma dependiente de su unión a F-actina

Figura 16. Colocalización in vivo de Coronina-1A/F-actina/Rac1 en la membrana plasmática basal de células COS1

Figura 17. Coronina-1A promueve el enriquecimiento de Rac1 en la fracción de membrana. 70

Figura 18. Coronina-1A induce la activación de Rac1 en la membrana plasmática

Figura 19. La inhibición de Coronina-1A endógena en células COS1 reduce los niveles de activación de Rac1 en respuesta a EGF

Figura 20. La ausencia de Coronina-1A endógena en células COS1 afecta a la translocación de Rac1 a la membrana en respuesta a EGF

Figura 21. Efecto de los inhibidores utilizados en la translocación de Rac1 a la membrana inducida por Coronina-1A 
Figura 22. Índice de translocación de Rac1 mediado por Coronina-1A-EGFP en presencia de los inhibidores usados en estos experimentos

Figura 23. La translocación de Rac1 inducida por Coronina-1A está mediada por la actividad quinasa de Pak1

Figura 24. La localización subcelular de Coronina-1A y su capacidad de promover reorganización citoesquelética dependen de Rac1

Figura 25. Cooperación funcional entre Coronina-1A y Pak1 en la activación de Rac1

Figura 26. Coronina-1A inteacciona con Pak1 in vivo de una forma dependiente de su unión a filamentos de F-actina

Figura 27. Efecto de Coronina-1A en la translocación de Rac1 en presencia de diferentes mutantes de RhoGDI

Figura 28. Cuantificación del índice de translocación de Rac1 inducido por Coronina-1A en presencia de los mutantes de RhoGDI utilizados

Figura 29. Efecto de Coronina-1A en la translocación de Rac1 $1^{\mathrm{R} 66 \mathrm{E}}$ en presencia de los mutantes Myc-Pak1 ${ }^{\text {K299R }}$ y Myc-RhoGDI ${ }^{\text {S101A+S174A }} \mathbf{8 5}$

Figura 30. Cuantificación del índice de translocación de Rac1 ${ }^{\mathrm{R} 66 \mathrm{E}}$ inducido por Coronina-1A en presencia de los mutantes de Pak1 y RhoGDI utilizados

Figura 31. Coronina-1A promueve la formación de complejos Pak1/RhoGDI in vivo de una forma dependiente la actividad quinasa de Pak1

Figura 32. La formación de complejos Coronina1A/Pak1/RhoGDI requiere la correcta funcionalidad de balsas lipídicas y del citoesqueleto de F-actina pero no actividad PKC

Figura 33. Coronina-1A promueve la interacción de Pak1 con RhoGDI in vivo de una forma dependiente de su unión a F-actina

Figura 34. La formación de complejos Coronina1A/Pak1/RhoGDI requiere actividad de Rac1 91

Figura 35. Interacción de Coronina-1A con diferentes mutantes de Pak1

Figura 36. Coronina-1A interacciona in vivo con ArhGEF7 de una forma independiente de su unión a F-actina

Figura 37. La formación de complejos Coronina-1A/Pak1/RhoGDI requiere ArhGEF7

Figura 38. ArhGEF7 es esencial para la activación de Rac1 inducida por Coronina-1A durante la señalización con EGF

Figura 39. ArhGEF7 es importante para la translocación de Rac1, pero no de Coronina-1A, a la membrana

Figura 40. Efecto de los translocadores aislados en el rastreo celómico en la regulación de la localización subcelular de las GTPasas Rac1 y RhoG

Figura 41. Efecto de los translocadores aislados en el rastreo celómico en la regulación de la localización subcelular de las GTPasas RhoA y Cdc42

Figura 42. La translocación de Rac1 mediada por nuestras proteínas translocadoras requiere balsas lipídicas funcionales 
Figura 43. La translocación de Rac1 mediada por nuestras proteínas translocadoras depende del citoesqueleto de F-actina

Figura 44. Efecto del mutante dominante negativo Rac1 $1^{T 17 N}$ en la localización subcelular y reorganización citoesquelética de las proteínas translocadoras

Figura 45. La translocación de Rac1 mediada por Coronina-1A y WDR26, pero no por Basigina y TMEM8A, precisa la participación de Pak1

Figura 46. Coronina-1A es importante para la translocación de Rac1 mediada por WDR26 pero no por Basigina

Figura 47. CD98, pero no las integrinas $\beta 1$, es importante para la translocación de Rac1 mediada por Basigina

Figura 48. CD98 es importante para la translocación de Rac1 mediada por Basigina pero no por Coronina-1A

Figura 49. Basigina, pero no Coronina-1A, promueve la estabilización de balsas lipídicas en la superficie celular

Figura 50. Modelo funcional del mecanismo de translocación de Rac1 mediado por Coronina$1 \mathrm{~A}$

Figura 51. Modelo funcional del mecanismo de translocación de Rac1 mediada por los dos grupos de proteínas aisladas en el rastreo celómico 



\section{ÍNDICE DE TABLAS}

Tabla 1. Mutantes puntuales utilizados en este trabajo

Tabla 2. Anticuerpos utilizados en los ensayos de inmunofluorescencia

Tabla 3. Anticuerpos utilizados en los ensayos de Western blot

46

Tabla 4. Localización subcelular de los clones positivos aislados en el rastreo celómico

Tabla 5. Resumen de los efectos en la translocación de miembros de la familia Rho/Rac por cada una de las proteínas translocadoras identificadas en esta tesis 



\section{AGRADECIMIENTOS}



En último lugar, pero no por ello menos importante, me gustaría expresar algunos pensamientos de gratitud hacia todas aquellas personas, que de un modo $u$ otro, han participado en "esta aventura".

Gracias Xosé, por haberme dado la oportunidad de trabajar en un laboratorio con unas condiciones técnicas inmejorables. Gracias por ayudar a mi formación científica, pipeta o puntero en mano. Gracias por haberme hecho ver que, lo que yo creía como "propias limitaciones personales", no son más que "límites virtuales" fácilmente superables con una dosis extra de autoconfianza, dedicación, esfuerzo y horas y horas y horas y más horas comiéndome el tarro (Nota mental: con menos presión, creo que también hubiera sido posible. Recuerda que somos "becarios"; que se parece a "funcionarios" pero creo que no es exactamente lo mismo... Aun así, gracias).

Gracias a todas las personas que han aportado su ayuda técnica durante la realización de este trabajo, comenzando con aquellos que colaboraron en la fase inicial (Felipe Pimentel, Vincent Sauzeau y la Unidad de Genómica del CIC), durante (Antonio Santos, Fernando, Angel Alonso, Angel Prieto y Lorena, todos ellos chicos "confocaleros") y al final del mismo en los experimentos de microscopía TIRF y ensayos de endocitosis de balsas lipídicas (Olivia Muriel, Miguel Angel del Pozo).

Gracias Mercedes, por intentar hacerme entender tras los seminarios el concepto de "crítica constructiva". Al final lo he pillado, pero dado mi carácter, creo que tendré que seguir trabajando en ello.

MIL GRACIAS a mis "mamás del laboratorio" Maite y Mariajo. Gracias Maite, porque tu calidad técnica es únicamente superable por tu calidad humana. Gracias por tu cariño, por tu apoyo, por tu inestimable ayuda (personal y profesional), por tus mimos y tus reprimendas. Gracias "cuquita" por enseñarme a ver que "yo también sé dónde tengo mi mano derecha". Gracias a ti también Mariajo, por ser más que una compañera de trabajo, por tus consejos, por tu paciencia, por intentar que yo la tuviera (ahí has estado casi casi casi a punto de conseguirlo), por todos los momentos gratos dentro y fuera del laboratorio (ah! y gracias por la COS!!). Gracias a las dos por haberme hecho sentir especial. Para mí, sois y sereis, siempre las mejores.

Gracias antiguos compañeros "Bustelo's" (Sergio, Inma, Jorge, Josiño, Celia, y un largo etcétera...). Me llevo lo mejor que he podido absorber de cada uno de vosotros. Gracias por todos los momentos de risas, de tonterías, de bromas, de discusión, de debate, de complicidad y de compañerismo que han hecho sin duda que estos largos "casi seis años" hayan sido mucho más llevaderos en Salamanca. 
Gracias también a los actuales "habitantes del laboratorio 2" (no hace falta que os enumere no? Estais todos ahí?? Si, yo creo que sí, ... :P). Gracias a todos/as por vuestra paciencia para conmigo durante esta última etapa (sé que no ha sido fácil), por vuestro ánimo, por tenderme una mano cuando la cuesta se hacía más dura. De vosotros también he aprendido todo lo que he podido (que no ha sido poco, trust me).

Gracias Alicia, amiga y compañera de "claros y oscuros". Gracias por ser cómo eres, por haberme sabido querer tal y como yo soy, por TODOS esos consejos (que tengo guardados en un cajón), por darle una nota de color a cada uno de mis días grises, por cada cigarro, por cada kebab, por cada vino, por cada copa ... Gracias simplemente por haber "salido en la peli". ;)

Gracias en general a toda la gente del CIC con la que me he topado en este tiempo (becarios, no becarios, gente de mantenimiento, informática, cocina, limpieza, conserjería, administración, etc.). Gracias por hacer que los pasillos del Centro hayan sido algo menos "estériles" y algo más "humanos".

Gracias a todos y cada uno de mis AMIGOS ("no científicos") por ayudarme a mantener la perspectiva, fuera del laboratorio, sobre la importancia y relevancia de los "problemas" dentro del laboratorio. Gracias por haberme escuchado (incluso por haber intentado entenderme) en cada momento crítico del camino... Nos vemos en los bares, no? ;)

Gracias "ma marmotte", por "estar sin estar", por tu paciencia, por tu tranquilidad, por la paz que me transmites, por cada sonrisa... gracias por haberte cruzado en mi camino, por haberlo caminado hasta ahora conmigo y por querer seguir caminándolo a mi lado... Merci beaucoup!!!

Gracias a mis "tatas". Gracias Ana por tu apoyo, por tu ánimo, por ser "ejemplo", unas veces, y "espejo", otras tantas (incluso gracias por todas esas veces en que no nos entendíamos el uno al otro y hemos tenido que hacer el esfuerzo de "acercar posturas" :P). Gracias a mi hermanita del alma Mari (Ana, no te pongas celosa!!!). Gracias por tu cariño, por hacer el papel de "mamá" secundaria (hasta los veintitantos años que ya tengo,...ejem, ejem) y por esas croquetas tan buenísimas que como cada vez que puedo!!!. Gracias a las dos, en serio, por haberme hecho sentir durante todos estos años "el niño";)

Y GRACIAS a ti "viejo", simplemente por todo lo que he podido aprender de ti en estos años. No hay palabras de gratitud suficientes para expresar lo mucho que te agradezco todo el esfuerzo, voluntad, sacrificio, optimismo, paciencia, perseverancia y empeño que has puesto a todo aquello que has afrontado en la vida (incluido el tener un hijo como yo, :P). No sabes realmente cuán orgulloso me siento de MI PADRE. Eres un fenómeno!!! 
